Prepared in cooperation with the Rhode Island Water Resources Board

\title{
Hydrologic Drought Decision Support System (HyDroDSS)
}

Open-File Report 2014-1003 



\section{Hydrologic Drought Decision Support System (HyDroDSS)}

By Gregory E. Granato

Prepared in cooperation with the Rhode Island Water Resources Board

Open-File Report 2014-1003 


\title{
U.S. Department of the Interior SALLY JEWELL, Secretary
}

\section{U.S. Geological Survey Suzette M. Kimball, Acting Director}

\author{
U.S. Geological Survey, Reston, Virginia: 2014
}

For more information on the USGS - the Federal source for science about the Earth, its natural and living resources, natural hazards, and the environment, visit http://www.usgs.gov or call 1-888-ASK-USGS.

For an overview of USGS information products, including maps, imagery, and publications, visit http://www.usgs.gov/pubprod

To order this and other USGS information products, visit http://store.usgs.gov

Any use of trade, firm, or product names is for descriptive purposes only and does not imply endorsement by the U.S. Government.

Although this information product, for the most part, is in the public domain, it also may contain copyrighted materials as noted in the text. Permission to reproduce copyrighted items must be secured from the copyright owner.

Suggested citation:

Granato, G.E., 2014, Hydrologic Drought Decision Support System (HyDroDSS): U.S. Geological Survey Open-File Report 2014-1003, 91 p., with CD-ROM, http://dx.doi.org/10.3133/ofr20141003. 


\section{Acknowledgments}

The author thanks Carl Carlson, David Bjerklie, Mary Ashman, and Kevin Breen of the U.S. Geological Survey (USGS) and Kathleen Crawley of the Rhode Island Water Resources Board for providing thoughtful and thorough technical and editorial reviews of this report, the HyDroDSS program, and accompanying digital media. Richard Vogel of Tufts University identified the position analysis approaches developed by Hirsch (1981b) as a potential method for drought-projection analyses and provided information on use of the probability-plot correlation coefficient method for evaluating the distribution of the random numbers generated by the HyDroDSS. Robert Hirsch of the USGS provided information on the application of position analysis, and Gary Tasker of the USGS provided background information on the use of bootstrap methods in the application of position analysis (Tasker and Dunne, 1997). 



\section{Contents}

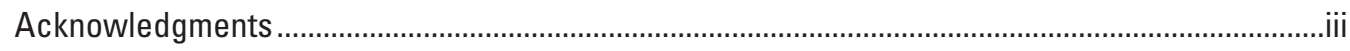

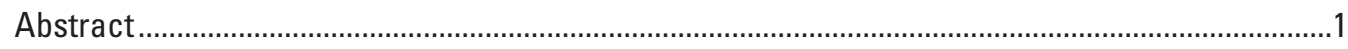

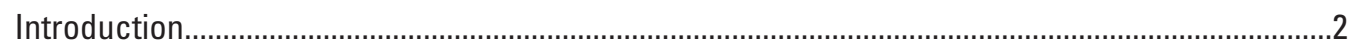

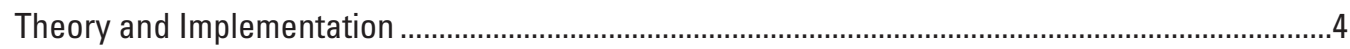

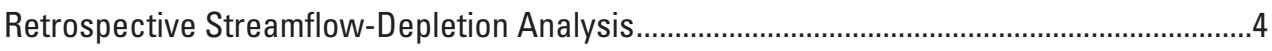

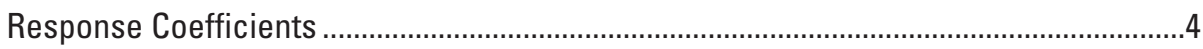

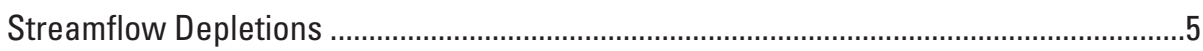

Calculating Estimated Unaltered Streamflow .................................................................

Interpreting Results of the Retrospective Streamflow-Depletion Analysis....................12

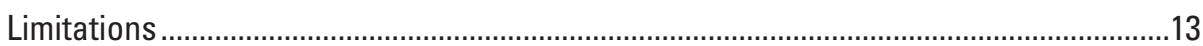

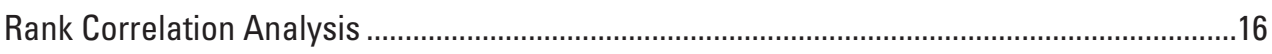

Calculating Rank Correlations and Confidence Intervals ..............................................17

Interpreting Results of the Rank Correlation Analysis .....................................................20

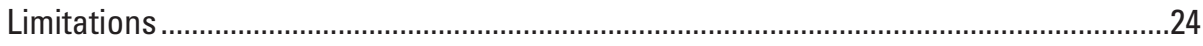

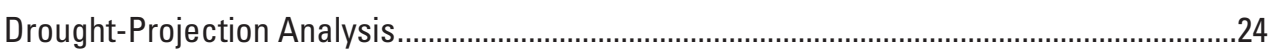

Calculating the Initial Streamflow for the Drought-Projection Analysis .........................25

Calculating Future Streamflows for the Drought-Projection Analysis ............................27

Interpreting Results of the Drought-Projection Analysis ..................................................32

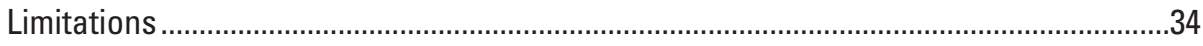

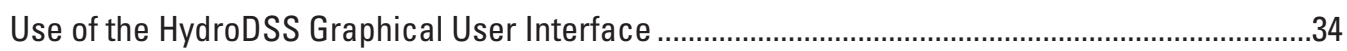

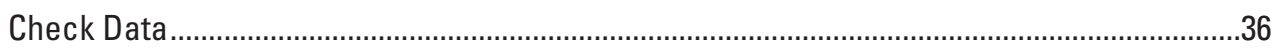

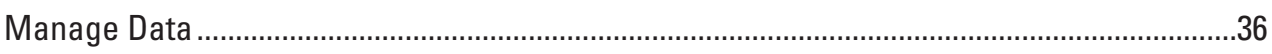

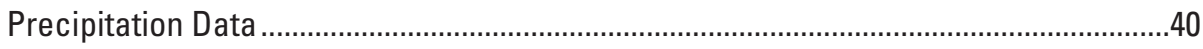

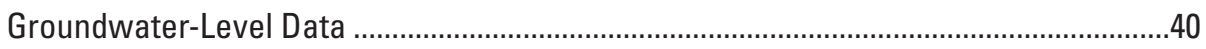

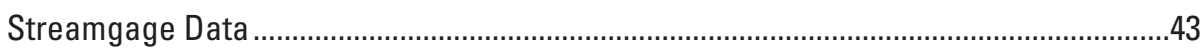

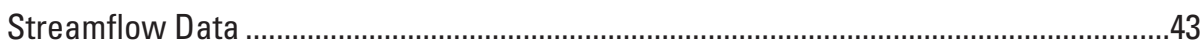

Stream Site of Interest...........................................................................................

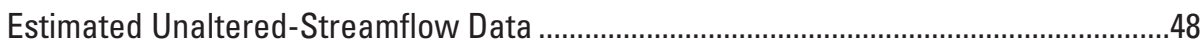

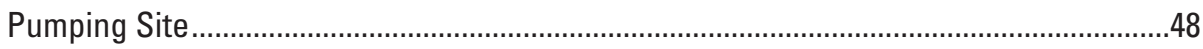

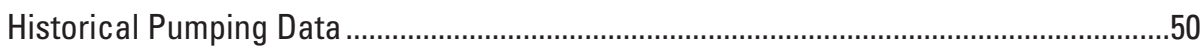

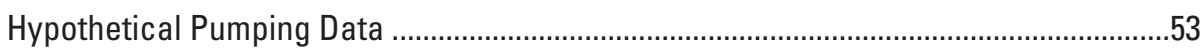

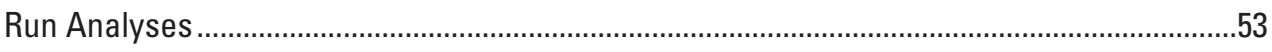

Retrospective Streamflow-Depletion Analysis..........................................................56

Rank Correlation Analysis ..........................................................................................56

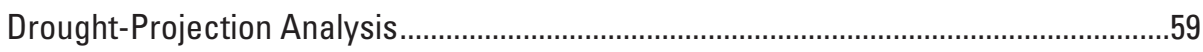

Case Study—Streamgage 01117000 Hunt River near East Greenwich, Rhode Island.....................66

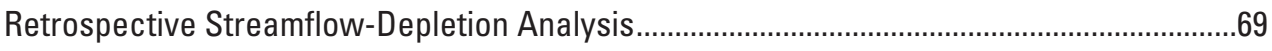

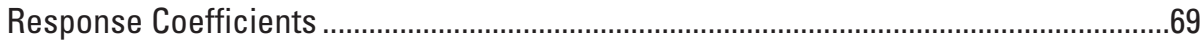

Streamflow Depletions and Estimated Unaltered Streamflow ........................................69

Conjunctive-Management Models ...................................................................................72

Interpreting Results of the Retrospective Streamflow-Depletion Analysis.....................77

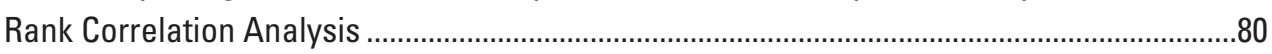

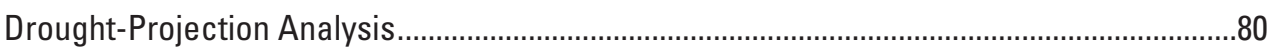

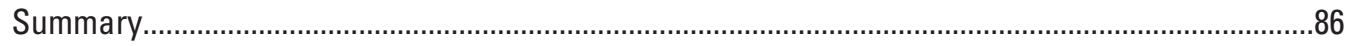

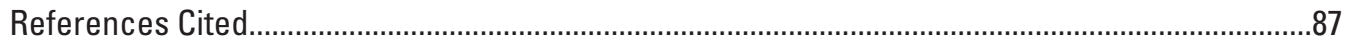




\section{Figures}

1. Graph showing selected examples of simulated response coefficients for three hypothetical wells at different distances from tributaries to the streamflowconstraint site PAWCD on the Pawcatuck River, which is below the confluence with the Beaver River in southwestern Rhode Island...

2. Graph showing examples of simulated monthly pumping and depletions from three hypothetical wells at different distances from tributaries to the streamflowconstraint site PAWCD on the Pawcatuck River in southwestern Rhode Island .8

3. Graph showing examples of simulated sums of monthly pumping and depletion from three hypothetical wells at different distances from tributaries to the streamflowconstraint site PAWCD on the Pawcatuck River in southwestern Rhode Island

4. Flow-duration curves showing the percentage of time estimated unaltered daily mean streamflow and streamflow with hypothetical depletions was equaled or exceeded at USGS streamgage 01117000 on the Hunt River in central Rhode Island (1942-2009).

5. Time series graph showing estimated unaltered streamflow and streamflow with hypothetical depletions at USGS streamgage 01117000 on the Hunt River in central Rhode Island (1960-1999)

6. Graphs showing the results of a Monte Carlo analysis to demonstrate scatter of paired uniform random-number samples around a one-to-one relation for eight different values of the correlation coefficient.....

7. Graphs showing rank correlation coefficients and confidence intervals for the months of March through the following February during the period 1942-2009 between $A$, precipitation and groundwater levels, $B$, precipitation and monthly minimum streamflow, and $C$, groundwater levels and monthly minimum streamflow.

8. Graphs showing serial rank correlation coefficient values and confidence intervals for monthly minimum streamflows at USGS streamgage 01118000 the Wood River at Hope Valley, Rhode Island, $A$, for March with values from April through the following February, $B$, for April with values from May through the following March, and $C$, for May with values from June through the following April during the period 1942-2009

9. Graphs showing example application of the percentile transfer method using groundwater measurements from USGS monitoring well RI-EXW 6 to estimate monthly minimum streamflows at USGS streamgage 01118000 the Wood River at Hope Valley, Rhode Island, for June 1957, 1991, and 1998.

10. Conceptual schematic diagram for the drought-projection analysis using Monte Carlo methods .

11. Graphs showing 251 random-number traces generated by the HyDroDSS droughtprojection analysis module with an initial position of 0.705 and a 90 -day precipitation forecast of $A$, normal conditions, $B$, below-normal (dry) conditions, and $C$, abovenormal (wet) conditions and an initial position of 0.358 with a forecast of $D$, normal conditions, $E$, below-normal conditions, and $F$, above-normal conditions

12. Graph showing flow-duration curves for June, July, August, and September that are based on sample statistics from four drought-projection analyses that were run for June through November showing the effects of the starting position and precipitation forecast on potential low-flow excursions.

13. Graph showing flow-duration curve outputs for August from a June-throughNovember drought-projection analyses with and without streamflow depletions..........35

14. "Main Menu" form for the hydrologic drought decision-support system . 36 
15. "Output Information" form with the results of the check-data analysis showing $A$, the initial view with text selected for copying and $B$, the large-text selection for reading on the screen.

16. Common dialog form for saving the data inventory file from the check-data analysis.

17. "Select the Data Management Option" form showing the "Data Management Menu" with $A$, "Precipitation Data" and $B$, "Groundwater Level Data" selected..

18. "Enter Precipitation Data" form showing $A$, the last value entered in the database for station 374266, $B$, the highlighted field showing missing data for November 2010, $C$, the grey-colored and locked fields for future values (as of June 2014), and $D$, the weather-station data page.

19. "Enter Groundwater Data" form showing the menu "Groundwater Well Data" with the "Water Levels" tab with $A$, the last value entered in the database for Well RI-CHW 18, B, the highlighted field showing missing data for November 2013, and $C$, the grey-colored and locked fields for future values (as of February 2014), and $D$, the "Well Information" tab with the monitoring-well name, town, National Water Information Service (NWIS) Web address, U.S. Geological Survey (USGS) well number and (empty) comment box.

20. "Enter USGS Streamgage Information" form showing the USGS Streamgage form with $A$, the "Gage Information" tab and $B$, the "Index Gage Information" tab.

21. The "Read Streamflow Data" form showing the "USGS Streamflow Data (Measured)" form $A$, the initial view for a station without data in the HyDroDSS, $B$, the initial view for a station with data in the HyDroDSS, $C$, a view for a station with data that has been read from a file but not imported to the streamflow table, and $D$, a view for a station with data that has been read from a file and imported to the streamflow table

22. Common dialog form for reading the mean daily streamflow data file for an index gage

23. Results of the query "qryViewlmportedStreamTable01" showing mean daily streamflow values imported for streamgage 01117000 for the period August 24, 1940 through April 26, 2010.

24. "Decision Support System Site of Interest" data-management form ..............................49

25. "Estimated Unaltered Streamflow Data" input form ........................................................49

26. The "Pumping (Withdrawal or Discharge) Site Data" form showing $A$, the "Sites" information tab and $B$, the "Response Coefficients" data tab.....

27. The "Historical Pumping (Withdrawal or Discharge) Data" form with $A$, the "Withdrawals/Discharges" tab and B, the "Site Information" tab.

28. The "Hypothetical Pumping (Withdrawal or Discharge) Plan" form with $A$, the "Pumping Plan" tab, and $B$, the "Monthly Pumping Rates" tab, and $C$, the "Add/ Remove A Site" tab

29. "Data Analysis Menu" with the $A$, "Retrospective Streamflow Depletion," $B$, "Rank Correlation," and C, "Drought Projection" options selected

30. "Retrospective Streamflow Depletion Analysis" form showing the tabs $A$, the "I. Select Pumping Plan," $B$, the "II. Run Analysis," and $C$, the "III. View Output tab-."57

31. "Output Information" form showing the depletion-analysis results as a $A$, monthly minimum time series table and $B$, monthly minimum flow-duration table ....58

32. The "Rank Correlation Analysis" form $A$, as it opens and $B$, after completing an analysis. 
33. "Hydrologic Drought-Projection Analysis" form showing $A$, the initial view of the "I. Set Initial Conditions" tab for a date without data in the HyDroDSS, $B$, the view of the "I. Set Initial Conditions" tab for a date with data in the HyDroDSS, $C$, a view of the "II. Select Pumping Plans" tab, and D, a view of the "III. Run Analysis and View Output" tab.

34. "Output Information" form showing hydrologic drought-projection results for $A$, the analysis header information, $B$, the flow-duration or flow-quantile output table, and $C$, a position analysis trace table

35. Map showing location of the Hunt River Basin and pumping wells in the HuntAnnaquatucket-Pettaquamscutt stream-aquifer system and the locations of hydrologic monitoring stations in Rhode Island

36. Graph showing total monthly withdrawals from all North Kingstown Water Department production wells, the nonparametric seasonal Kendall trend line, and non-parametric Kendall-Theil regression lines for March and July data for the period 1978-2008

37. Graph showing simulated response coefficients and well yields for the pumping wells in the Hunt River Basin..

38. Flow-duration curves showing the percentage of time measured daily mean streamflow was equaled or exceeded at USGS streamgages 01117000 Hunt River near East Greenwich, Rhode Island, and 01118000 Wood River at Hope Valley, Rhode Island, and the percentage of time estimated unaltered daily mean streamflow was equaled or exceeded at USGS streamgage 01117000 during the period from January 1, 1942 to December 31, 2009.

39. Graph showing Maintenance of Variance type 1 (MOVE.1) and Kendall-Theil Robust Line (KTRLine) regression equations between measured streamflows at USGS streamgage 01118000 , the Wood River at Hope Valley, Rhode Island, and estimated unaltered streamflows at USGS streamgage 01117000, the Hunt River near East Greenwich, Rhode Island

40. Boxplots showing the distributions of monthly withdrawals as fractions of total annual withdrawals $A$, from seven wells in the Hunt River Basin, central Rhode Island, during the period 1992-2008, and $B$, from four water-supply systems that withdrew primarily from groundwater sources in the Pawcatuck River Basin, southwestern Rhode Island, during the period 1995-2004

41. Graph showing conjunctive-management-model yield relations between potential allowable streamflow-depletion criteria and total annual groundwater withdrawals by using the specified withdrawal patterns from production wells ECD03, ECD09, ECD14, KC01, NK06, NK09, and NK10 in the Hunt River Basin, Rhode Island ...

42. Flow-duration curves showing the percentage of time estimated unaltered daily mean streamflow and streamflow with hypothetical depletions was equaled or exceeded at USGS streamgage 01117000 the Hunt River in central Rhode Island (1942-2009).

43. Time-series graph showing estimated unaltered streamflow and streamflow with hypothetical depletions at USGS streamgage 01117000 on the Hunt River in central Rhode Island (1990-2000)

44. Graphs showing monthly serial rank correlation coefficient values, the median rank correlation for each time lag, and the maximum and minimum confidence intervals for each time lag between estimated monthly minimum unaltered streamflows in the Hunt River at streamgage 01117000 and $A$, monthly precipitation at monitoring station 376698 at T.F. Green Airport near Providence, Rhode Island, $B$, monthly groundwater levels at USGS monitoring well RI-SNW 6 in South Kingstown, Rhode Island, and C, monthly minimum streamflows at USGS streamgage 01118000 near Hope Valley, Rhode Island. 
45. Monthly minimum flow-duration curves showing drought-projection results for August 2005 at USGS gaging station 01117000 on the Hunt River that were made with the information that was available at the beginning of $A$, April 2005, $B$, May 2005, $C$, June 2005 , and $D$, July 2005 .

\section{Table}

1. Duration percentiles for data collected at two precipitation and two streamflow stations, March-August 2005.

\section{Conversion Factors, Datum, and Abbreviations}

Inch/Pound to SI

\begin{tabular}{|c|c|c|}
\hline Multiply & By & To obtain \\
\hline \multicolumn{3}{|c|}{ Length } \\
\hline foot $(\mathrm{ft})$ & 0.3048 & meter $(\mathrm{m})$ \\
\hline \multicolumn{3}{|c|}{ Area } \\
\hline square mile $\left(\mathrm{mi}^{2}\right)$ & 259.0 & hectare (ha) \\
\hline square mile $\left(\mathrm{mi}^{2}\right)$ & 2.590 & square kilometer $\left(\mathrm{km}^{2}\right)$ \\
\hline \multicolumn{3}{|c|}{ Volume } \\
\hline gallon (gal) & 3.785 & liter $(\mathrm{L})$ \\
\hline gallon (gal) & 0.003785 & cubic meter $\left(\mathrm{m}^{3}\right)$ \\
\hline million gallons (Mgal) & 3,785 & cubic meter $\left(\mathrm{m}^{3}\right)$ \\
\hline cubic foot $\left(\mathrm{ft}^{3}\right)$ & 0.02832 & cubic meter $\left(\mathrm{m}^{3}\right)$ \\
\hline \multicolumn{3}{|c|}{ Flow rate } \\
\hline cubic foot per second $\left(\mathrm{ft}^{3} / \mathrm{s}\right)$ & 0.02832 & cubic meter per second $\left(\mathrm{m}^{3} / \mathrm{s}\right)$ \\
\hline $\begin{array}{l}\text { cubic foot per second per square mile } \\
{\left[\left(\mathrm{ft}^{3} / \mathrm{s}\right) / \mathrm{mi}^{2}\right]}\end{array}$ & 0.01093 & $\begin{array}{l}\text { cubic meter per second per square } \\
\text { kilometer }\left[\left(\mathrm{m}^{3} / \mathrm{s}\right) / \mathrm{km}^{2}\right]\end{array}$ \\
\hline million gallons per day (Mgal/d) & 0.04381 & cubic meter per second $\left(\mathrm{m}^{3} / \mathrm{s}\right)$ \\
\hline
\end{tabular}

Temperature in degrees Celsius $\left({ }^{\circ} \mathrm{C}\right)$ may be converted to degrees Fahrenheit $\left({ }^{\circ} \mathrm{F}\right)$ as follows:

${ }^{\circ} \mathrm{F}=\left(1.8 x^{\circ} \mathrm{C}\right)+32$

Temperature in degrees Fahrenheit $\left({ }^{\circ} \mathrm{F}\right)$ may be converted to degrees Celsius $\left({ }^{\circ} \mathrm{C}\right)$ as follows:

${ }^{\circ} \mathrm{C}=\left({ }^{\circ} \mathrm{F}-32\right) / 1.8$

Vertical coordinate information is referenced to the North American Vertical Datum of 1988 (NAVD 88).

Horizontal coordinate information is referenced to the North American Datum of 1983 (NAD 83).

Altitude, as used in this report, refers to distance above the vertical datum.

Withdrawal rates from some production wells are reported in million gallons per month

$(\mathrm{Mgal} / \mathrm{mo})$ and in million gallons per year (Mgal/yr). 


\section{Abbreviations}

$\begin{array}{ll}\text { cfs } & \text { cubic feet per second (used in the program interface) } \\ \text { cfsm } & \text { cubic feet per second per square mile (used in the program interface) } \\ \text { DCP } & \text { drought-censoring percentile } \\ \text { DSS } & \text { decision-support system } \\ \text { HyDroDSS } & \text { hydrologic drought decision support system } \\ \text { KTRLine } & \text { Kendall-Theil robust line } \\ \text { MOVE.1 } & \text { maintenance of variance type 1 } \\ \text { NWIS } & \text { National Water Information Service } \\ \text { NOAA } & \text { National Oceanic and Atmospheric Administration } \\ \text { RDB } & \text { Relational database } \\ \text { RIDEM } & \text { Rhode Island Department of Environmental Management } \\ \text { RIWRB } & \text { Rhode Island Water Resources Board } \\ \text { USGS } & \text { U.S. Geological Survey } \\ \text { SREF } & \text { Streamflow Record Extension Facilitator } \\ \text { VB } & \text { Visual Basic }{ }^{\circledR} \\ \text { VBA } & \text { Visual Basic for Applications }{ }^{\circledR} \\ \text { WSSMP } & \text { Water Supply Systems Management Plan }\end{array}$




\title{
Hydrologic Drought Decision Support System (HyDroDSS)
}

\author{
By Gregory E. Granato
}

\section{Abstract}

The hydrologic drought decision support system (HyDroDSS) was developed by the U.S. Geological Survey (USGS) in cooperation with the Rhode Island Water Resources Board (RIWRB) for use in the analysis of hydrologic variables that may indicate the risk for streamflows to be below userdefined flow targets at a designated site of interest, which is defined herein as data-collection site on a stream that may be adversely affected by pumping. Hydrologic drought is defined for this study as a period of lower than normal streamflows caused by precipitation deficits and (or) water withdrawals. The HyDroDSS is designed to provide water managers with risk-based information for balancing water-supply needs and aquatic-habitat protection goals to mitigate potential effects of hydrologic drought.

This report describes the theory and methods for retrospective streamflow-depletion analysis, rank correlation analysis, and drought-projection analysis. All three methods are designed to inform decisions made by drought steering committees and decisionmakers on the basis of quantitative risk assessment. All three methods use estimates of unaltered streamflow, which is the measured or modeled flow without major withdrawals or discharges, to approximate a natural low-flow regime.

Retrospective streamflow-depletion analysis can be used by water-resource managers to evaluate relations between withdrawal plans and the potential effects of withdrawal plans on streams at one or more sites of interest in an area. Retrospective streamflow-depletion analysis indicates the historical risk of being below user-defined flow targets if different pumping plans were implemented for the period of record. Retrospective streamflow-depletion analysis also indicates the risk for creating hydrologic drought conditions caused by use of a pumping plan. Retrospective streamflow-depletion analysis is done by calculating the net streamflow depletions from withdrawals and discharges and applying these depletions to a simulated record of unaltered streamflow.

Rank correlation analysis in the HyDroDSS indicates the persistence of hydrologic measurements from month to month for the prediction of developing hydrologic drought conditions and quantitatively indicates which hydrologic variables may be used to indicate the onset of hydrologic drought conditions. Rank correlation analysis also indicates the potential use of each variable for estimating the monthly minimum unaltered flow at a site of interest for use in the drought-projection analysis. Rank correlation analysis in the HyDroDSS is done by calculating Spearman's rho for paired samples and the 95-percent confidence limits of this rho value. Rank correlation analysis can be done by using precipitation, groundwater levels, measured streamflows, and estimated unaltered streamflows. Serial correlation analysis, which indicates relations between current and future values, can be done for a single site. Cross correlation analysis, which indicates relations among current values at one site and current and future values at a second site, also can be done.

Drought-projection analysis in the HyDroDSS indicates the risk for being in a hydrologic drought condition during the current month and the five following months with and without pumping. Drought-projection analysis also indicates the potential effectiveness of water-conservation methods for mitigating the effect of withdrawals in the coming months on the basis of the amount of depletion caused by different pumping plans and on the risk of unaltered flows being below streamflow targets. Drought-projection analysis in the HyDroDSS is done with Monte Carlo methods by using the position analysis method. In this method the initial value of estimated unaltered streamflows is calculated by correlation to a measured hydrologic variable (monthly precipitation, groundwater levels, or streamflows from an index station identified with the rank correlation analysis). Then a pseudorandom number generator is used to create 251 six-month-long flow traces by using a bootstrap method. Serial correlation of the estimated unaltered monthly minimum streamflows determined from the rank correlation analysis is preserved within each flow trace. The sample of unaltered streamflows indicates the risk of being below flow targets in the coming months under simulated natural conditions (without historic withdrawals). The streamflow-depletion algorithms are then used to estimate risks of flow being below targets if selected pumping plans are used.

This report also describes the implementation of the HyDroDSS. The HyDroDSS was developed as a Microsoft Access ${ }^{\circledR}$ database application to facilitate storage, handling, and use of hydrologic datasets with a simple graphical user interface. The program is implemented in the database by using the Visual Basic for Applications ${ }^{\circledR}$ (VBA) programming language. Program source code for the analytical techniques is provided in the HyDroDSS and in electronic text files 
accompanying this report. Program source code for the graphical user interface and for data-handling code, which is specific to Microsoft Access ${ }^{\circledR}$ and the HyDroDSS, is provided in the database. An installation package with a run-time version of the software is available with this report for potential users who do not have a compatible copy of Microsoft Access ${ }^{\circledR}$. Administrative rights are needed to install this version of the HyDroDSS.

A case study, to demonstrate the use of HyDroDSS and interpretation of results for a site of interest, is detailed for the USGS streamgage on the Hunt River (station 01117000) near East Greenwich in central Rhode Island. The Hunt River streamgage was used because it has a long record of streamflow and is in a well-studied basin with a substantial amount of hydrologic and water-use data including groundwater pumping for municipal water supply.

\section{Introduction}

In the northeastern United States, the effects of hydrologic droughts - defined by streamflows that are lower than normal - commonly are the worst during the summer months when evaporation and transpiration magnify the effects of precipitation deficits. In many watersheds in this region, substantial quantities of groundwater are withdrawn from alluvial-valley aquifers that are in direct hydraulic connection with rivers, brooks, and streams. Much of the groundwater withdrawn from these aquifers is derived from depletion of streamflow as a result of captured discharge or induced infiltration. The physical response of streamflow to groundwater withdrawals at pumping wells determines the withdrawal strategies that may be used to help maximize the reliability of a water supply and balance groundwater withdrawals needed for water supply with aquatic-habitat protection goals. Streamflow depletion is of particular concern during periods of drought when streamflow is already low because of decreased rates of precipitation, groundwater recharge, and groundwater discharge. These natural processes also can be exacerbated by water-supply-demand patterns, which are characterized by increased withdrawals during periods of higher demand typically during the months of May through September with peak withdrawals usually during July (Granato and Barlow, 2005; Granato and Walter, 2011). Furthermore, management of groundwater wells must occur in advance of drought because groundwater withdrawals have a delayed impact on streamflow depletion (Barlow and Dickerman, 2001; Granato and Barlow, 2005; Granato and Walter, 2011).

Quantitative drought-planning methods are needed to assess and communicate the risk of being in a hydrologic drought condition. Currently (2011) many States in the region have drought-management plans that have a series of categorical drought indexes ranging from drought watches to extreme emergencies, which are used to implement increasingly stringent water-use restrictions (New York State Drought Management Task Force, 1987; Stern, 1990; New Jersey Department of Environmental Protection, 1991; Massachusetts Drought Management Task Force, 2001; Rhode Island Department of Administration, 2002; Connecticut Interagency Drought Work Group, 2003; Rhode Island Water Resources Board, 2003; Hayes, 2006; Pennsylvania Department of Environmental Protection 2010a, b; National Drought Policy Commission, 2011). In each state, drought-management thresholds are determined by a set of semiquantitative indicators that commonly include precipitation, groundwater levels, streamflows, reservoir levels, the Palmer drought index, a crop-moisture index, a soil-moisture index, and a fire-danger index. In most cases, the drought condition is determined, in part, by the number of months a hydrologic variable is below some threshold in comparison to normal conditions. One or more index values also are used to evaluate drought conditions. Many of these drought-management plans indicate that the different hydrologic variables and drought-index values may not be well correlated as drought conditions develop and subside. For this reason, the professional judgments of drought-management committees are needed to evaluate current conditions and make recommendations based on a suite of variable and potentially conflicting values to make decisions for one or more drought regions. These droughtmanagement plans indicate that there are economic costs for implementing drought-management measures, and that the costs rise substantially as more stringent management measures are implemented. None of these existing plans puts forth an algorithm for quantitatively calculating hydrologic drought risk, nor do they provide a means for assessing the balance between water supply and aquatic-habitat-protection goals. Most plans use streamflow and groundwater data from long-term USGS network sites. Where possible, the USGS selects network wells and streamgages at locations that are not heavily influenced by water withdrawals to estimate unregulated conditions. Therefore, the input data may not reflect potential effects of withdrawals at a given site. Also, none of these existing plans provides a means for assessing the probability that hydrologic drought conditions may be caused by water withdrawals in a given basin, nor do the existing plans provide a means for linking the timing and severity of water-use restrictions to the occurrence and magnitude of extreme low-flow events in a given basin.

Two water-supply concepts, safe yield and sustainable yield, are considered to be part of hydrologic drought planning measures. The concept of safe yield originated as an engineering and economic concept to design a water-supply system that will feasibly meet baseline water demands during the worst foreseeable drought (Linsley and others, 1975; Winter and others, 1998; Alley and others, 1999; Heath, 2004; 
Waldron and Archfield, 2006; Archfield and others, 2010). Over time the definition of safe yield was expanded beyond minimum service objectives to encompass the objective to balance water-supply needs with ecological protection goals, commonly by meeting a specified minimum-streamflow target (Barlow and Dickerman, 2001; Granato and Barlow, 2005; Archfield and others, 2010; Granato and Walter, 2011). This approach, however, has evolved into a sustainable yield approach that includes streamflow-maintenance objectives to approximate natural flows for the entire flow-duration curve (Poff and others, 1997; Sophocleous, 2000; Alley and Leake, 2004; Maimone, 2004; Archfield and others, 2010). For groundwater supplies, however, Granato and Barlow (2005) and Granato and Walter (2011) demonstrated that the nature of streamflow depletions caused by groundwater withdrawals, the annual cycle of water-use patterns, and the annual variations in streamflows in this region make it feasible for properly managed allowable-depletion objectives to be used to meet sustainable yield objectives for groundwater supplies in alluvial-valley aquifers that are in direct hydraulic connection with rivers, brooks, and streams in the northeastern United States.

Decision-support systems (DSSs) are needed to provide actionable information to assess and mitigate potential hydrologic drought conditions. DSSs are commonly described as interactive computer programs that integrate models and complex data to help managers make planning-level decisions for complex situations that may be rapidly changing and not well defined in advance. In many areas, a DSS is needed to quantify drought risk and to demonstrate or validate the need for implementing drought-management measures. A DSS provides a standard method to demonstrate the potential effectiveness (and limitations) of various levels of water-conservation measures and will therefore provide information necessary for defensible recommendations for implementing the water-use restrictions in various phases of a drought plan. For example, a DSS should indicate the information needed to manage a system, the decision risks, the timeframe for making droughtmanagement decisions, the potential severity of the decisions, and factors that limit the response. Well-constructed surfacewater or groundwater models may provide the best estimates of hydrologic conditions under various management plans, but such models need considerable support by expert modelers to update the model with new data, recalibrate the model, run the model, and interpret complex output values. Many organizations do not have the resources to support such efforts on a continuing basis, especially if multiple drought regions with multiple basins have critical sites of interest (which are defined herein as data-collection sites on streams that may be adversely affected by pumping) for streamflow management. DSSs, however, commonly are designed for managers rather than modelers with the underlying models and statistics integrated behind a user interface.
DSSs for surface-water reservoir systems have been developed to meet quantitative drought-planning needs (Hirsch, 1978, 1979, 1981a,b; Dunne and Tasker, 1996; Tasker and Dunne, 1997; Ito and others, 2001; Srinivas and Srinivasan, 2005). Assessments and forecast of drought risk commonly are used to estimate the potential effects of drought and to inform decisions for managing reservoirs under normal and projected drought conditions. The management decisions are designed to balance considerations for safety, water supply, and ecological flow releases (Hirsch, 1978, 1979, 1981a,b; Dunne and Tasker, 1996; Tasker and Dunne, 1997). However, DSSs for assessing and forecasting drought risk and for managing groundwater withdrawals are not commonly used.

This report describes the theory, implementation, use, and interpretation of results from the hydrologic drought decisionsupport system (HyDroDSS). HyDroDSS was developed by the U.S. Geological Survey (USGS) in cooperation with the Rhode Island Water Resources Board (RIWRB) for use in the analysis of hydrologic variables that may indicate the risk for streamflows to be below user-defined flow targets at a designated site of interest. HyDroDSS was designed to help inform water-management decisions for stream-aquifer systems where withdrawals are predominately made from groundwater sources. Variables that may indicate the risk for being in a hydrologic drought condition at a designated site of interest include precipitation, groundwater levels, measured streamflows, estimated streamflows, and pumping volumes. The process for developing drought-risk assessments with these hydrologic variables is described with the governing equations and numerical methods. Step-by-step use of the program's graphical user interface is illustrated. Formats of input data and output results are described. A case study for USGS streamgage 01117000, the Hunt River near East Greenwich, Rhode Island, is provided to demonstrate use of the HyDroDSS for a basin with a substantial amount of groundwater pumping for municipal water use.

The HyDroDSS was developed as a Microsoft Access ${ }^{\circledR}$ database application to facilitate storage, handling, and use of hydrologic datasets with a simple graphical user interface. The program is implemented in the database by using the Microsoft Visual Basic for Applications ${ }^{\circledR}$ (VBA) programming language. Program source code for the analytical techniques is provided in the HyDroDSS and in electronic text files accompanying this report. Program source code for the graphical user interface and for data-handling code, which is specific to Microsoft Access ${ }^{\circledR}$ and the HyDroDSS, is provided in the database. An installation package with a run-time version of the software is available with this report for potential users who do not have a compatible copy of Microsoft Access ${ }^{\circledR}$. Administrative rights are needed to install this version of the HyDroDSS. 


\section{Theory and Implementation}

The HyDroDSS is designed to provide water managers with risk-based information necessary to mitigate the effects of hydrologic drought. The HyDroDSS includes methods for retrospective streamflow-depletion analysis, rank correlation analysis, and drought-projection analysis. All three methods use estimates of unaltered streamflow, which is the measured or modeled flow without major withdrawals or discharges, to approximate a natural low-flow regime and calculated streamflow depletions to model the effects of withdrawals and discharges on this low-flow regime. All three methods are designed to inform decisions made by drought steering committees and decisionmakers on the basis of quantitative risk assessment.

\section{Retrospective Streamflow-Depletion Analysis}

Retrospective streamflow-depletion analysis can be used by water-resource managers to evaluate relations between withdrawal plans and the potential effects of withdrawal plans on streams at one or more sites of interest in an area. Retrospective streamflow-depletion analysis indicates the historical risk of flow being below user-defined targets if different pumping plans were implemented for the period of record. Retrospective streamflow-depletion analysis also indicates the risk for exacerbating or creating hydrologic drought conditions caused by the use of a pumping plan. For example, Granato and Barlow (2005) and Granato and Walter (2011) used retrospective streamflow-depletion analyses to demonstrate the potential effects of applying different conjunctive water-withdrawal management plans to the historical record of streamflows at different sites of interest.

The method used to implement the retrospective streamflow-depletion analysis is based on the assumption that the rate of streamflow depletion at each site of interest is a linear function of the rate of groundwater withdrawal at each production well. By assuming linearity, total streamflow depletion at a site of interest can be estimated by summation of the individual streamflow depletions caused by each well. Groundwater models commonly are used to calculate streamflow depletion by wells (Gorelick and others, 1993; Ahlfeld and Mulligan, 2000; Barlow and Dickerman, 2001; Granato and Barlow, 2005; Granato and Walter, 2011) and can be used to estimate streamflow response coefficients for a pumping well. Response coefficients from analytical models also can be used. Barlow (2000) developed the program STRMDEPL to calculate streamflow depletion by wells by using analytical solutions. This program has been used to do retrospective streamflow-depletion analyses by a number of studies (Zarriello and Ries, 2000; Reeves, 2008; Archfield and others, 2010). With either method, actual pumping records are used with measured streamflow values to calculate an estimated unaltered streamflow. Then different pumping strategies can be tested to estimate potential effects of these plans on estimated unaltered flows. The estimated streamflow altered by pumping is calculated by subtracting net depletions from the unaltered streamflows. The estimated streamflow altered by pumping indicates the risk of being below some target flow under different plans with respect to the estimated unaltered streamflow.

\section{Response Coefficients}

Groundwater models developed for watershed assessments can be used to develop response coefficients used by HyDroDSS to calculate depletions. Standard methods for calculating response coefficients have been developed and tested for the formulation of conjunctive management models for sites of interest in the northeastern United States (for example, Male and Mueller, 1992; Mueller and Male, 1993; Barlow and Dickerman, 2001; DeSimone and others, 2002; Barlow and others, 2003; DeSimone, 2004; Eggleston, 2004; Granato and Barlow, 2005; Granato and Walter, 2011). Calibrated transient groundwater models are developed and used to calculate depletions with a dynamic-equilibrium simulation method, in which a characteristic streamflowdepletion response is calculated in each month to a unit withdrawal from a potential groundwater-pumping site in the model area. Model runs are done for each groundwaterpumping site to isolate effects of pumping at that site. Water withdrawals from and discharges to the stream-aquifer system may be used to calculate depletions. Discharges to the stream are modeled as negative depletions, which reflect the increases in flow. A 5-year dynamic-equilibrium simulation is commonly done for each pumping site to ensure that there is no net change in storage in the simulated system over the average annual hydrologic cycle; this approach isolates the effect of the unit withdrawal on subsequent depletions (Barlow and Dickerman, 2001). Models also are used to calculate response coefficients for different withdrawal rates and different seasons.

In each simulation, the withdrawal rate for one of the wells was specified in the groundwater model for a duration of one month; at the end of the month, the withdrawal rate at the well was returned to 0 . The single-month increase in withdrawals is referred to as the unit withdrawal $Q w_{i}^{*}$ at well $i$. The amount of streamflow depletion resulting from the unit withdrawal was determined by subtracting streamflow rates calculated by the model with the unit withdrawal active from those calculated by the model without any withdrawals. Streamflow-depletion responses to the unit withdrawals are defined as $Q s d^{*}{ }_{j, i, t}$, in which the subscripts indicate that the streamflow depletion at the stream site of interest $j$ in response to a withdrawal at well $i$ (in month 0 ) occurs in month $t$.

Streamflow-depletion response coefficients $\left(r_{j, i, t}\right)$ are defined as the dimensionless ratio of monthly depletion to unit withdrawals expressed as

$$
r_{j, i, t}=\frac{Q s d_{j, i, t}^{*}}{Q w_{i}^{*}}
$$


The response coefficients can range from 0.0 to 1.0 . A response of 1.0 in the first month of withdrawals indicates that all of the water removed by the well can be accounted for as streamflow depletion in the first month. Similarly, surface-water withdrawals or discharges at a site on the stream are assigned a response coefficient of 1.0 in the first month of withdrawals or discharges because the entire withdrawal or discharge occurs instantly as a streamflow depletion or negative depletion as water is pumped from or to the stream, respectively. If a well causes depletions in only one stream, the sum of the response coefficients for that stream would be almost 1.0; the remainder would be attributable to minor reductions in riparian evapotranspiration under dynamic equilibrium. Similarly, if a well affects streamflow in more than one stream, the sum of the response coefficients from the affected streams would be about 1.0. Response coefficients for groundwater withdrawals may represent depletions caused by intercepting groundwater that would otherwise have discharged to the stream in the current and subsequent months and depletions induced directly from the stream (by lowering groundwater levels below the local stream stage) (Granato and Barlow, 2005; Granato and Walter, 2011).

Factors that affect the values of the response coefficients for pumping wells are the relative positions of the withdrawal wells and the streamflow-constraint sites (including the vertical positions of the screened intervals of the wells), the geometry and hydraulic properties of the aquifer, the streambed conductance, and other physical characteristics of the streams as simulated with the groundwater models (Barlow and Dickerman, 2001; Granato and Barlow, 2005; Granato and Walter, 2011). Graphs of the response coefficients for sites of interest indicate substantial variability in the quantity and timing of streamflow-depletion responses to the simulated unit withdrawals. A streamflow-constraint site is a location on the stream with data that is used to calculate response coefficients for use with conjunctive management models and the DSS. The subset of potential constraint sites that are analyzed for assessing the effects of hydrologic drought are identified as sites of interest in this report.

Response-coefficient graphs for hypothetical well sites in the Pawcatuck River Basin in central Rhode Island by Granato and Walter (2011) illustrate the effect of well distance on the temporal distribution of streamflow depletions by unit withdrawals from pumping wells (fig. 1). Hypothetical well 1 , which is modeled as being 125 feet (ft) from the river, has a relatively rapid effect on depletions. The initial response coefficient for this well is 0.92 , indicating that about 92 percent of the streamflow depletion occurs in the river during the first month after a groundwater withdrawal is made from this hypothetical well. The response-coefficient graph for this hypothetical well indicates that depletions decrease exponentially to 0 during the 4 months after a groundwater withdrawal is made. The rate of decrease is greater for this well than for depletions from wells farther from the stream but slower than for a surface-water withdrawal. Hypothetical well 2 is farther from the river (about $375 \mathrm{ft}$ ) than hypothetical well 1 , and the response coefficients for this well indicate a slower streamflow response to withdrawals than for hypothetical well 1 . The initial response coefficient for hypothetical well 2 is 0.43 , indicating that about 43 percent of the streamflow depletion occurs in the river during the first month after a groundwater withdrawal is made. Depletions caused by the withdrawal from this hypothetical well decrease exponentially during the 12 months after a groundwater withdrawal is made. Hypothetical well 3 is distant from the river (about 2,875 ft), and the initial response coefficient for this well is only about 0.16 , indicating that about 16 percent of the streamflow depletion from this hypothetical well occurs during the first month after a groundwater withdrawal is made. The peak response (about 0.26 ) occurs in the second month, and depletions continue for about 11 more months, after a groundwater withdrawal is made.

If a groundwater model is not available for a site of interest, then analytical solutions also can be used to develop response coefficients used by HyDroDSS to calculate streamflow depletions. These solutions can be developed by inputting a unit withdrawal and calculating subsequent depletions as in equation 1. However, using calibrated groundwater models to calculate response coefficients is vastly superior to using the analytical solutions for several reasons. A number of simplifying assumptions are used to formulate the analytical solutions (Barlow, 2000; Reeves, 2008). The generalized two-dimensional aquifer properties must be estimated by using professional judgment rather than being derived from well-established methods for calibration of three-dimensional groundwater models. Use of calibrated groundwater models also is superior to use of analytical solutions because calibrated groundwater models better define the actual source of water to pumping wells. When analytical solutions are used, the partitioning of depletions from wells that capture water from more than one stream or that capture water that would discharge to the stream below the site of interest also must be estimated by using professional judgment without knowledge of the actual partition of depletion at such sites. The importance of this distinction between use of an analytical solution and use of a calibrated groundwater model is illustrated by the fact that all three USGS studies that developed response coefficients for use in the conjunctive management of water withdrawals in Rhode Island found one or more pumping-well sites that caused depletions in streams on the other sides of surface-water divides (Barlow and Dickerman, 2001; Granato and Barlow, 2005; Granato and Walter, 2011). Furthermore, Granato and Walter (2011) found pumping-well sites that caused depletions in streams below the site of interest.

\section{Streamflow Depletions}

The total streamflow depletion at a site of interest during any given month $(t)$ may be computed as the sum of individual streamflow depletions because of the assumed linearity of the system. The HyDroDSS calculates the total streamflow depletion as 


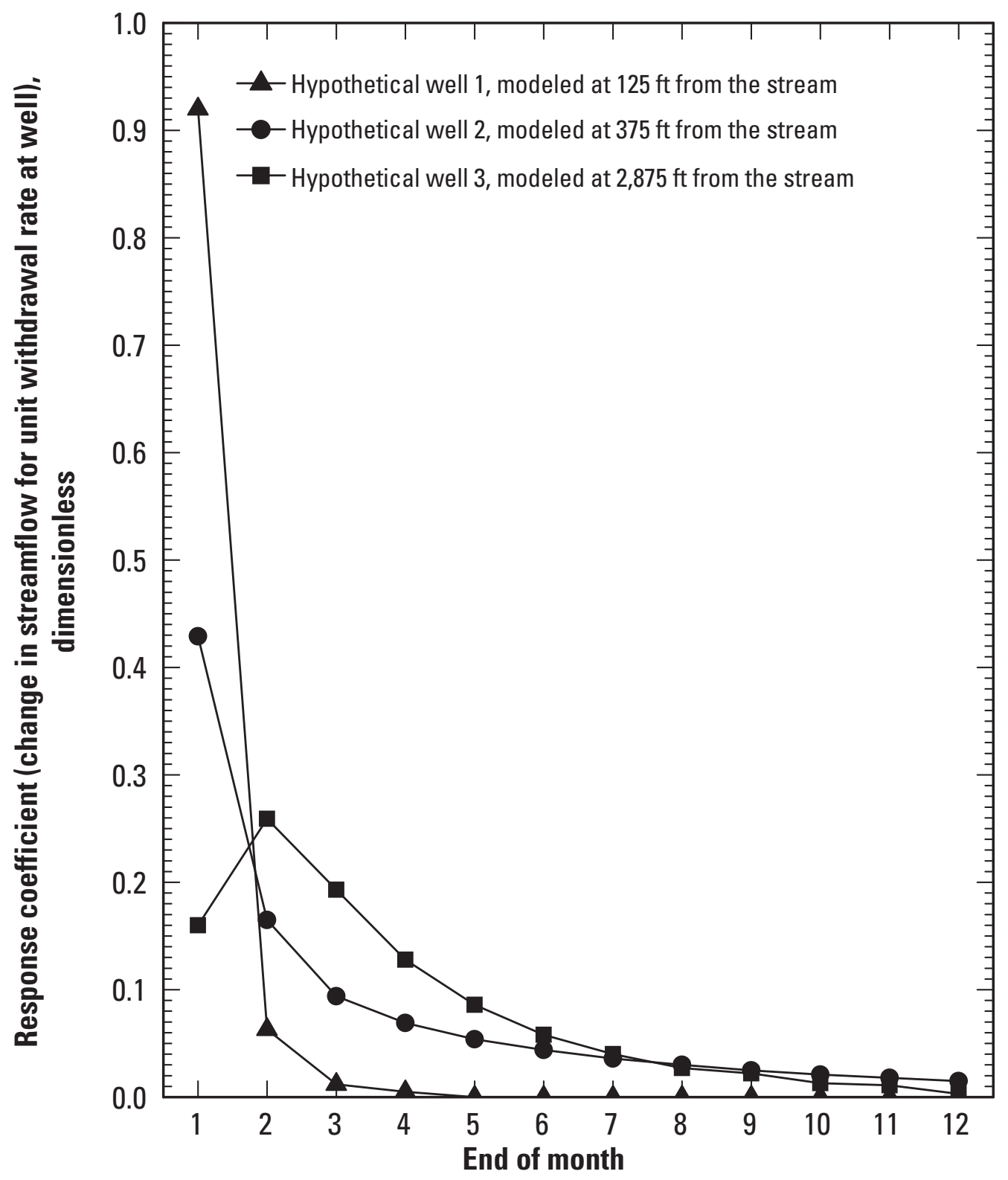

Figure 1. Selected examples of simulated response coefficients for three hypothetical wells at different distances from tributaries to the streamflow-constraint site PAWCD on the Pawcatuck River, which is below the confluence with the Beaver River in southwestern Rhode Island (modified from Granato and Walter, 2011). Graphs show the fraction of the unit withdrawal from each well that is evident as streamflow depletion at the end of each month after the withdrawal. 


$$
Q S d_{j, t}=\sum_{i=1}^{N W} \sum_{k=1}^{12} r_{j, i, k} Q w_{i, k^{\prime}}
$$

where

$$
\begin{array}{cc}
Q s d_{j, t} & \begin{array}{c}
\text { is the streamflow depletion at each site of } \\
\text { interest }(j) \text { on a stream for each month }(t),
\end{array} \\
R_{j, i, k} & \begin{array}{c}
\text { is the response coefficient for the site of } \\
\text { interest }(j) \text { for each pumping site }(i) \text { in the }
\end{array} \\
& \text { current and prior months }(k), \\
Q w_{i, k^{\prime}} & \begin{array}{c}
\text { is pumping from one or more pumping sites } \\
(i) \text { in the current and prior months }\left(k^{\prime}\right), \text { and }
\end{array} \\
N W & \begin{array}{l}
\text { is the number of wells (or pumping sites). }
\end{array}
\end{array}
$$

Equation 2 is used to calculate the total net streamflow depletion at a site of interest ( $j$ ); this equation may include effects of discharges or injections to the stream-aquifer system. In this case the pumping term $\left(Q w_{i, k}\right)$ would be given a negative sign because discharges or injections to the stream-aquifer system would result in a net reduction in streamflow depletions.

Depletions from some pumping sites may persist for many months after withdrawals are made (fig. 1). Therefore, a two-part definition of the monthly pumping index number $k$ ' is necessary to apply the correct response coefficient to each withdrawal in the current month and in the preceding months in equation 2. If the calendar month $(t)$ is less than or equal to the response coefficient month $(k)$, then the applicable pumping month $\left(k^{\prime}\right)$ is calculated as

$$
k^{\prime}=t-k+1, \text { for } t-k+1>0 .
$$

For example, if the calendar month is December $(t=12)$, the first response coefficient $(k=1)$ is applied to the pumping in December ( $k^{\prime}=12$ calculated by using equation 3 ), the second response coefficient $(k=2)$ is applied to the pumping in November ( $k^{\prime}=11$ calculated by using equation 3 ) and so forth. If the calendar month is earlier than December, then one or more response coefficients must be applied in equation 2 to pumping that occurred in the previous year. Thus the pumping index number $\left(k^{\prime}\right)$ must be calculated as

$$
k^{\prime}=12+(t-k+1), \text { for } t-k+1 \leq 0 .
$$

For example, if the calendar month is February $(t=2)$, the first response coefficient $(k=1)$ is applied to the pumping in February $\left(k^{\prime}=2\right.$ calculated by using equation 3$)$, and the second response coefficient $(k=2)$ is applied to the pumping in January ( $k^{\prime}=1$ calculated by using equation 3$)$. However, the third response coefficient $(k=3)$ would produce a pumping index of 0 using equation 3 , so equation 4 is used to calculate the pumping index $\left(k^{\prime}=12\right)$.

If withdrawals or discharges made at a pumping site are constant from month to month, then the net depletions caused by this pumping will stabilize to a constant value once a steady-state condition has been established. The time period to reach this dynamic equilibrium depends on the response coefficients. For example, depletions from hypothetical well 1 would reach a dynamic equilibrium equal to withdrawals in the fourth month after the onset of constant-rate pumping because the response coefficients used in equation 2 for this well decay to 0 by the fifth month after a unit withdrawal (fig. 1). Similarly, the time period to reach dynamic equilibrium for withdrawals from hypothetical well 3 is 12 months because the response coefficients used in equation 2 for this well decay to 0 by the 13th month after a unit withdrawal. The solution to equation 2 is commonly much more complex than the one-well steady-state solution because, in the northeastern United States, multiple pumping sites with time-varying pumping rates commonly affect a stream site of interest. In this situation, the HyDroDSS can be useful to decisionmakers because manual implementation of equation 2 for a period of record in excess of a few years can be burdensome even if software such as a spreadsheet is used.

If withdrawals or discharges made at a pumping site are not constant from month to month, then the net depletions caused by this pumping will stabilize to an annual cycle of variable values once a steady-state condition has been established. Groundwater withdrawals made by water suppliers in the northeastern United States commonly follow a pattern in which withdrawals peak during summer months (Granato and Barlow, 2005; Archfield and others, 2010; Granato and Walter, 2011). For example, Granato and Walter (2011) compiled water-withdrawal data for the period 1995-2004 from four water-supply systems that withdraw primarily from groundwater sources in the Pawcatuck River Basin, southwestern Rhode Island. Their findings indicate that, on average, a well with an annual average withdrawal rate of 1 million gallons per day $(\mathrm{Mgal} / \mathrm{d})$ would be making withdrawals at a rate of about $0.865 \mathrm{Mgal} / \mathrm{d}$ during the months of January, February, March, April, November, and December. On average, this well would be making withdrawals at a rate of about 1.07, 1.17, 1.34, $1.23,1.06$, and $0.931 \mathrm{Mgal} / \mathrm{d}$ during the months of May, June, July, August, September, and October, respectively.

Figure 2 demonstrates the depletions calculated by using equation 2 with the response coefficients for each of the hypothetical wells 1,2 , and 3 that are shown in figure 1 . This graph shows the monthly pumping and depletions that would occur at dynamic equilibrium if these hypothetical wells were pumped at an annual average rate of $1 \mathrm{Mgal} / \mathrm{d}$ (about 1.55 cubic feet per second $\left(\mathrm{ft}^{3} / \mathrm{s}\right)$ ) following the monthly municipal-withdrawal ratios calculated by Granato and Walter (2011). Depletions from hypothetical well 1 are about equal to withdrawals during the months with constant pumping rates (December through April) because, as the response coefficients indicate, the remaining depletions from the pumping in the previous months are about equal to the differences between pumping and depletion in the current month (fig. 1). Depletions from hypothetical well 1 are smaller than pumping volumes in the months when pumping volumes increase (May through July) because of the time-lag response to the increasing pumping (fig. 2). Depletions exceed pumping volumes in the months when pumping volumes decrease (August through October) because 


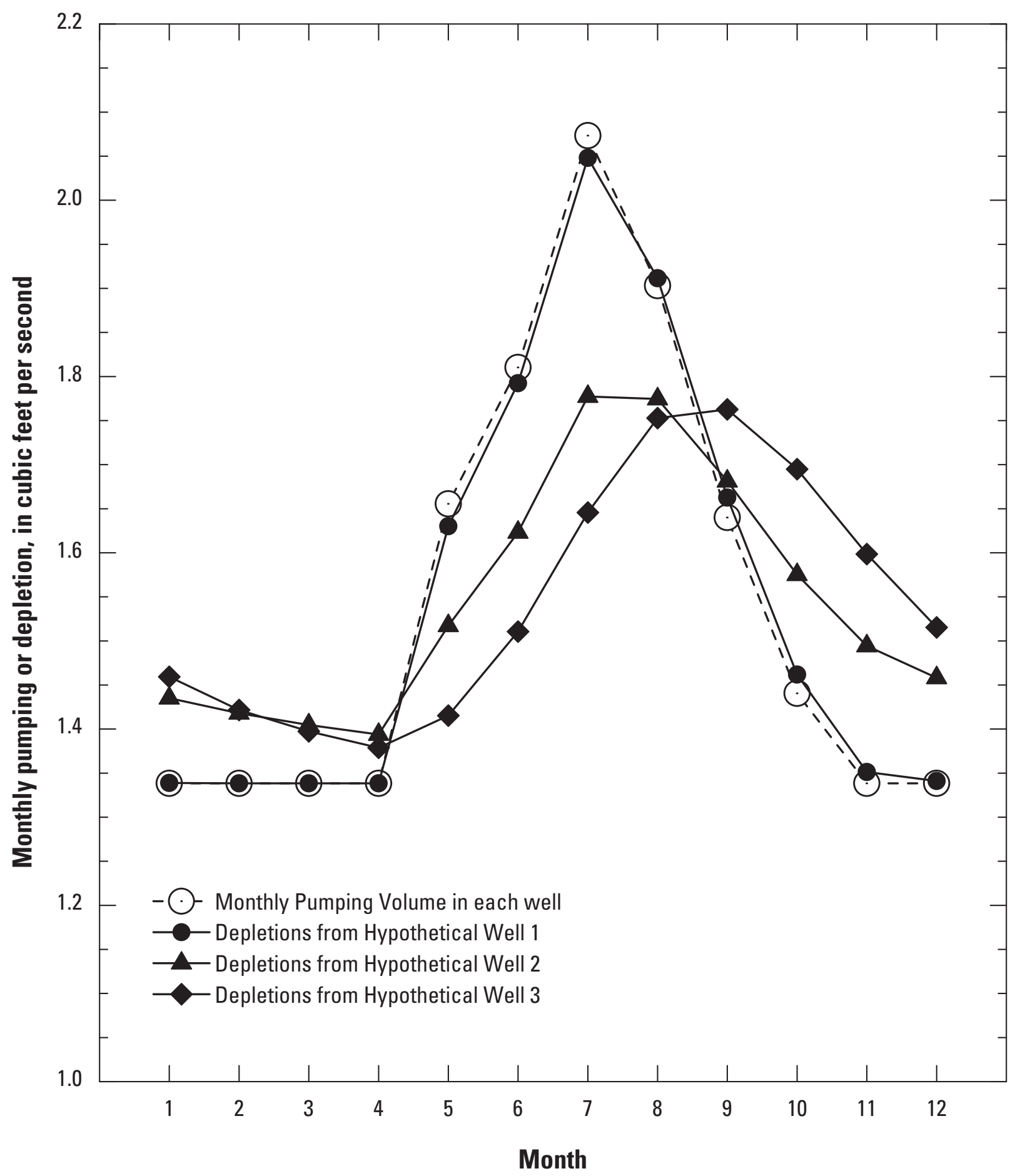

Figure 2. Examples of simulated monthly pumping and depletions from three hypothetical wells at different distances from tributaries to the streamflow-constraint site PAWCD on the Pawcatuck River in southwestern Rhode Island. The graph shows the monthly pumping volume and depletion that would occur if each well were pumped at an annual average rate of $1 \mathrm{Mgal} / \mathrm{d}$ (about $1.55 \mathrm{ft}^{3} / \mathrm{s}$ ) by using the municipal pumping pattern defined by Granato and Walter (2011). 
depletions from the previous months exceed the current difference between pumping and depletions. Response coefficients for hypothetical wells 2 and 3 indicate a slower and more subdued response to pumping than for hypothetical well 1 (fig. 1). Depletions from both these wells also show a slower and subdued response to changes in pumping (fig. 2). Depletions from hypothetical wells 2 and 3 are larger than pumping volumes in all months except May through August because the depletions from these summer highpumping months are spread over the rest of the year. Peak depletions in hypothetical wells 2 and 3 are about 80 percent of the peak pumping in July, but because of the delay, they exceed pumping in September, when streamflows can be at their lowest in the northeastern United States (Barlow and Dickerman, 2001; Granato and Barlow, 2005; Bent and others, 2011; Granato and Walter, 2011). The sums of the individual monthly pumping volumes and depletions calculated by using equation 2 for these three wells are shown in figure 3 . Monthly depletions are used to estimate low flows for the drought-projection analysis and are used in the first step of the retrospective streamflow-depletion analysis.

The HyDroDSS uses interpolated daily depletion values calculated from monthly depletions for use in the retrospective streamflow-depletion analysis to estimate potential effects of different pumping plans on the historical mean daily flow record. In reality, pumping wells may have constantly varying pumping rates, but the slow response times from pumping to depletion for most groundwater wells dampen the effects of such variations so that average monthly pumping rates may be used for simulation in each month (Barlow, 1997; Granato and Barlow, 2005; Granato and Walter, 2011; Masterson, 2011). Furthermore, limitations in available data and groundwater-modeling methods necessitate use of the interpolation approach. Water-use data in the northeastern United States commonly are available as total monthly, total quarterly, or total annual withdrawals. For example, Archfield and others (2010) reported that records for about 84 percent of sites in the Massachusetts water-use database report pumping volumes as annual totals, and about 16 percent report these data as monthly totals. In Rhode Island, the 28 major water suppliers report total monthly pumping as part of RIWRB's implementation of the Rhode Island Water Supply System Management Plan (Kathleen Crawley, Rhode Island Water Resources Board (RIWRB), oral commun., 2010). Groundwater models commonly are calibrated and run by using monthly time steps (Barlow and Dickerman, 2001; DeSimone and others, 2002; Barlow and others, 2003; DeSimone, 2004; Eggleston, 2004; Granato and Barlow, 2005; Granato and Walter, 2011; Masterson, 2011). Monthly depletions, however, may not be suitable for daily-flow analysis. For example, monthly depletions in figure 3 skip from $4.93 \mathrm{ft}^{3} / \mathrm{s}$ on June 30 th to $5.47 \mathrm{ft}^{3} / \mathrm{s}$ on July 1st, which could represent a substantial change in flow for a small stream in base-flow recession. Calculating daily depletions by interpolating between monthly depletions precludes such day-to-day jumps in depletion and is consistent with theory and observations of relations between groundwater withdrawals and depletions (Barlow, 1997, 2000; Granato and Barlow, 2005; Reeves, 2008; Granato and Walter, 2011; Masterson, 2011). Monthly depletions represent conditions at the end of the month because groundwater models commonly are calibrated to output the results of analysis at the end of each monthly time step, and because depletions change after withdrawal rates change. Thus, the HyDroDSS was designed to use forward interpolation to calculate the daily depletion from the monthly depletion so that the daily depletion would equal the monthly depletion at the end of the month (fig. 3). This approach approximates the time lag of depletions and maintains the mass balance of withdrawals and depletions defined by the response coefficients.

The HyDroDSS includes a simple accounting method to approximate conditions in which depletions exceed available streamflow. Once withdrawals cause depletions that exceed streamflow, then the groundwater that is pumped must come from aquifer storage (Winter and others, 1998; Heath, 2004; Masterson, 2011). Recharge to the aquifer must replenish depletions from storage to reestablish base flows between storms. If depletions exceed estimated unaltered streamflow, the HyDroDSS adds the difference between available daily flow and depletion to a running sum of accumulated excessdepletions. When this occurs, the HyDroDSS assigns a daily flow value of $0.0001 \mathrm{ft}^{3} / \mathrm{s}$ to facilitate plotting values on logarithmic scales (the USGS does not commonly report streamflow values below $0.01 \mathrm{ft}^{3} / \mathrm{s}$ ). Once the estimated unaltered streamflow exceeds the daily depletion for a given day, the excess streamflow is subtracted from the accumulated excess depletions. If the estimated unaltered daily flow is less than or equal to the accumulated excess depletions, then the streamflow output for that day equals $0.0001 \mathrm{ft}^{3} / \mathrm{s}$. If that daily flow exceeds the accumulated excess depletions, then the streamflow output for that day equals the difference between the daily flow and the accumulated excess depletions.

\section{Calculating Estimated Unaltered Streamflow}

Estimates of unaltered streamflows for a long period of record are needed to assess potential effects of different withdrawal strategies on flows at a site of interest to capture the long-term variability in altered and unaltered flows. Several methods may be used to develop unaltered-streamflow estimates for gaged and ungaged sites depending on the situation and available data. These methods include use of flow ratios, regression on basin characteristics, record extension, and flow models. Several of these methods require a long period of record from one or more suitable index sites. A suitable index site is defined herein as a site with a hydrologically similar upstream basin that has no depletion or has minimal depletions (defined herein as depletions that are less than or equal to about 1 percent of low-flow values). The HyDroDSS does not calculate the estimated unaltered streamflow record because one or more of these methods may be most suitable for a given site of interest. The HyDroDSS, however, does have a simple graphical user interface for importing such a flow record. 


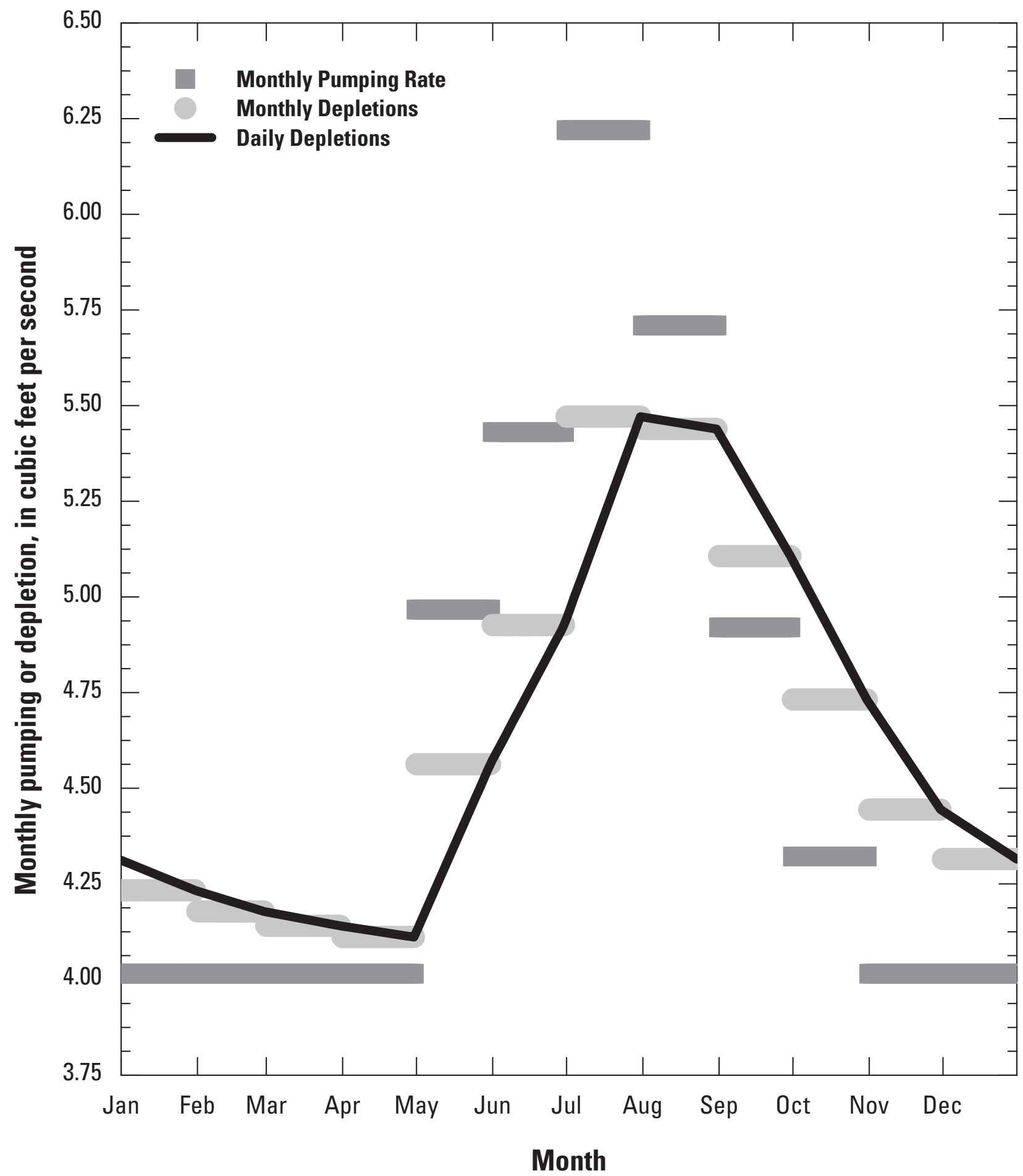

Figure 3. Examples of simulated sums of monthly pumping and depletion from three hypothetical wells at different distances from tributaries to the streamflow-constraint site PAWCD on the Pawcatuck River in southwestern Rhode Island. The graph shows the total monthly pumping volume, the resulting monthly depletions, and the interpolated daily depletion that would occur if each well were pumped at an annual average rate of $1 \mathrm{Mgal} / \mathrm{d}$ (about $1.55 \mathrm{ft}^{3} / \mathrm{s}$ ) by using the municipal pumping pattern defined by Granato and Walter (2011). 
The flow ratio is the simplest method and may be as accurate as other methods under the right conditions (Stedinger and others, 1993; Ries and Friesz, 2000; U.S. Geological Survey, 2002; Granato, 2010). The drainagearea ratio method uses the streamflow from an index basin to estimate streamflow at the site of interest by using the ratio of drainage areas between sites. Ries and Friesz (2000) compared regression on basin characteristics and the drainage-area-ratio method with maintenance of variance type 1 (MOVE.1) based flow correlation estimates for sites in Massachusetts. They found that drainage-area-ratio estimates were generally more accurate than regression on basin characteristics estimates for hydrologically similar basins with drainage areas within the range of about 0.3 to 1.5 times the index-site drainage area. Similarly, the U.S. Geological Survey (2002) documents the results of an analysis of sites in Pennsylvania that included 92 comparisons to examine the relative accuracy of the drainage-area-ratio and regression methods. This analysis indicates that, for hydrologically similar basins, 82 percent of the drainage-area-ratio estimates had absolute percent differences less than or equal to available regression estimates if drainage areas of the site of interest were within the range of about 0.3 to 3 times the index-site drainage area.

Regression on basin characteristics is a method for using physical, hydrological, and meteorological characteristics of basins with streamflow data to develop multivariate regression models that are used to predict selected flow statistics at any location along a stream in the area for which equations are developed (Thomas and Benson, 1970; Benson and Carter, 1973; Tasker and Stedinger, 1989; Ries and Friesz, 2000; Eng and others, 2005). Regression on basin characteristics is a commonly used method for estimating selected streamflow statistics at sites for which there is no streamflow data. Physical, hydrological, and geological information about the basins upstream of the streamgage are used to develop the multivariate regression equations to predict values of selected streamflow statistics at any site of interest within the study area. Drainage area (or contributing drainage area) is commonly the most significant variable for estimating streamflow statistics within a hydrologic region. The USGS has conducted many studies since the 1970s to define regression on basin characteristics and is currently (2012) in the process of developing online Streamstats applications for automatic basin delineation and flow prediction in cooperation with various state agencies (Ries and others, 2004). Streamflow estimates from regression equations may include substantial uncertainty, especially at extreme low and high flows. However, studies that develop regression on basin characteristics equations do not commonly produce a daily flow record but instead estimate specific statistical events. To produce a long-term daily (or monthly or annual) flow record, data from an index gage is needed to predict flows at the ungaged site of interest. Two methods may be used to translate the measured flows at the index site to the ungaged site: the parametric frequency-factor method and the percentile transfer method (commonly called QPPQ). The frequency-factor method uses the daily record of percentiles from an index gage with regression-derived estimates of parametric statistical moments - for example, the mean, standard deviation, and skew at the site of interest - to generate a flow record (Haan, 1977; Chow and others, 1988; Stedinger and others, 1993; Granato, 2010). Frequency-factor methods also may result in substantial flow-prediction errors for extreme low and high flows (Stacey Archfield, U.S. Geological Survey, oral commun., 2009). The nonparametric QPPQ method uses regression-derived estimates of the flow-duration statistics at the site of interest and the daily record of percentiles from an index gage to estimate a long-term flow record at the site of interest (Fennessey, 1994; Hughes and Smakhtin, 1996; Smakhtin, 1999; Smakhtin and Masse, 2000; Mohamoud, 2008; Archfield and others, 2010).

Record extension also is a useful method to estimate a long-term record of estimated unaltered flow values if limited unaltered streamflow measurements (or unaltered streamflow estimates) are available for the site of interest, and a long-term record is available for a hydrologically similar index site. For example, Granato and Barlow (2005) used MOVE.1 to do record extension with short-term and partial-record stations to estimate a long-term record of flows in the Big River Area in central Rhode Island so that they could do a postoptimization analysis of the potential effects of different conjunctivemanagement plans on low flows at different sites in the basin. The MOVE. 1 and MOVE. 3 regression methods commonly are used for record extension (Hirsch, 1982; Stedinger and others, 1993; Ries and Friesz, 2000). These methods have been incorporated into the Streamflow Record Extension Facilitator (SREF) program developed by the USGS (Granato, 2009). Sometimes relations between flows at a site of interest and an index site change over different magnitudes of flow (Ries and Friesz, 2000). For example, Eng and others (2011) determined that low-flow estimates commonly are biased high if the entire flow record is used to estimate flows at a site of interest. They recommend censoring paired high-flow values when developing regression equations for predicting low-flow values. In such cases, a multisegment regression model developed by using the nonparametric Kendall-Theil robust line (KTRLine) method (Granato, 2006) may be suitable for record extension.

Watershed models also are commonly used to estimate unaltered streamflows at a site of interest (Winter and others, 1998). Watershed models are useful in that the streamflow at a site of interest may be simulated under actual historical conditions, and unaltered streamflows can be estimated by removing pumping from the system (for example, Zarriello and Ries, 2000; Barlow and Dickerman, 2001; DeSimone, 2004; Masterson, 2011; Zarriello, 2011). Surface-water models commonly simulate the entire daily flow record at a fine time scale, which is better for simulating highly variable surface-water withdrawals and discharges, but such models use analytical approximations to estimate groundwater depletions (Barlow, 2000; Zarriello and Ries, 2000; Reeves, 2008; Zarriello, 2011). Groundwater models better represent the three-dimensional flow in the aquifer and discharge to streams, but such models are commonly used to estimate long-term 
average conditions by using monthly time steps (Barlow and Dickerman, 2001; Granato and Barlow, 2005; DeSimone, 2004; Masterson, 2011).

A combination of methods may be used to generate longterm mean daily flow records. For example, if a watershed model is available for an area of interest, then the estimated unaltered flows from the model can be used with recordextension techniques to generate a long-term record of daily flows by using streamflows from an index gage. Similarly, if there is a short-term record of pumping data, then response coefficients or analytical models can be used to estimate a short-term record of estimated unaltered streamflows. These estimated values can then be used with a record set from an index gage to extend the estimated record of unaltered streamflows.

A Visual Basic ${ }^{\circledR}$ computer program (RespDep.exe) was written in support of the HyDroDSS development effort to calculate streamflow depletions and a daily record of estimated unaltered streamflows by using response coefficients from groundwater models, historical streamflow, and historical pumping records. The program may be used to estimate the effects of withdrawals on streamflow or unaltered streamflows without depletions from withdrawals. This program is provided with the source code and example input and output files as part of the digital media accompanying this report.

\section{Interpreting Results of the Retrospective Streamflow-Depletion Analysis}

The retrospective streamflow-depletion-analysis module provides planning-level information to inform decisions about the potential utility of different streamflow-maintenance rules and the potential effectiveness of different management options for mitigating hydrologic drought conditions. This module provides a table of values with output as a historical time series or as flow-duration-curve statistics. Both output selections include the estimated unaltered and depleted streamflows. The time series output indicates what historical conditions would have resulted in daily flow values that are below some target streamflows with and without depletions specified in a given plan. The time-series output indicates the temporal frequency and duration of low-flow events during the historical record. The flow-duration curve output indicates the statistical duration of low-flow events.

Decisionmakers can use response coefficients and streamflow-depletion curves generated by using the streamflow-depletion module for qualitative or quantitative management of withdrawals to mitigate potential effects of hydrologic drought. For example, examination of the response coefficients (fig. 1) and the resultant depletion pattern (fig. 2) indicates that, if sufficient pumping capacity is available from a network of wells, hypothetical well 1 may be used in advance of seasonal dry months and in the early stages of a developing hydrologic drought condition. If it is necessary to implement reductions in pumping, then the rapid response in streamflow depletions to changes in pumping at this hypothetical well site will result in proportionately large reductions in depletions (fig. 1). Also, the response coefficients for this well indicate that only a small proportion of residual depletions caused by pumping from this well carry over into subsequent months (figs. 1, 2). Hypothetical well 2 also may be useful as a pumping site at the beginning of a seasonal dry period or drought for these reasons. Hypothetical well 3 may be useful as a pumping site during dry months because the long streamflow-depletion response time pushes a substantial proportion of depletions from pumping in the current month off into the subsequent months (figs. 1, 2). The retrospective streamflow-depletion module in the HyDroDSS allows for a semiquantitative pumping-management approach. Decisionmakers can enter actual or hypothetical withdrawals (for example, pumping volumes from a previous year or adjusted for feasible water-conservation reductions) to see the potential effects on depletions. The different response functions for different pumping sites also provide a means for fully quantitative conjunctive management of water withdrawals by using optimization methods (Barlow and Dickerman, 2001; Granato and Barlow, 2005; Granato and Walter, 2011).

A flow-duration curve is a cumulative frequency curve showing the percentage of time during which a selected streamflow was equaled or exceeded in the historical record (Searcy, 1959; Helsel and Hirsch, 2002). The percentiles in a flow-duration curve are assigned by ranking streamflows in descending order and calculating percentiles by using a plotting-position formula. The HyDroDSS uses the Cunnane (1978) plotting-position formula for percentiles expressed as

$$
P P=\left(\frac{I_{i}-0.4}{N+0.2}\right)
$$

where

$$
\begin{aligned}
P P & \text { is the calculated plotting position, } \\
I_{i} & \text { is the rank of the } i^{\text {th }} \text { value, and } \\
N & \text { is the number of values in a dataset. }
\end{aligned}
$$

Percentiles are obtained by multiplying the plotting position by 100 percent. This formula is designed so that the minimum plotting-position value will be greater than 0 , and the maximum value will be less than 1 , because, in most cases, the available period of record probably does not include the smallest or largest possible value. The formula also is designed so that the minimum and maximum possible values approach 0 and 1 as the total number of values increase. The Cunnane plotting-position formula was selected because this formula is recommended for use in analysis of hydrological data (Helsel and Hirsch, 2002). The HyDroDSS calculates percentiles as fractions (in the range between 0 and 1 ) or as percentages (in the range between 0 and 100). The HyDroDSS does not compute tied ranks for display of flow-duration curves as output from the retrospective streamflow-depletion-analysis module. As a result, tied values will appear as a plateau on the flow-duration curve rather than as a single point with many tied values. 
The flow-duration-curve output is designed to provide statistical information about the relative risk of using different depletion criteria and their associated withdrawal plans and the resultant effects on instream flows. Land and water managers may use such information to select withdrawal plans for different years based on drought projections and water needs to meet ecological protection goals. The HyDroDSS will output estimated streamflows in cubic feet per second or cubic feet per second per square mile. The former provides information about the absolute effect of different water-management options, whereas the latter option provides information about the normalized effect of different water-management options. The latter option also facilitates comparison with streamflowmaintenance criteria, which are commonly normalized by drainage area.

A hypothetical example was selected to demonstrate use of the retrospective streamflow-depletion-analysis module. This example uses the estimated unaltered streamflow in the Hunt River for the 1942-2009 period with depletions from wells with the hydraulic characteristics of hypothetical wells 1, 2, and 3 (fig. 1). The effect of pumping (streamflow with depletion) was calculated as if each well were pumped at an annual average rate of $1.5 \mathrm{Mgal} / \mathrm{d}$ (about $2.325 \mathrm{ft}^{3} / \mathrm{s}$ ) with a peak rate of $2.0 \mathrm{Mgal} / \mathrm{d}$ (about $3.1 \mathrm{ft}^{3} / \mathrm{s}$ ) in July by using the municipal-pumping pattern defined by Granato and Walter (2011). The resulting flow-duration curves are shown in figure 4 with respect to a streamflow value of 0.18 cubic feet per second per square mile $\left(\mathrm{ft}^{3} / \mathrm{s} / \mathrm{mi}^{2}\right)$ that is equal to onehalf the estimated 7-day 10-year (7Q10) low-flow value of $0.36 \mathrm{ft}^{3} / \mathrm{s} / \mathrm{mi}^{2}$ (Gardner Bent, U.S. Geological Survey, written commun., 2011). The flow-duration curve indicates that the potential effect of depletions from this pumping scenario is within about 15 percent of the estimated unaltered streamflows at flow values above $1.55 \mathrm{ft}^{3} / \mathrm{s} / \mathrm{mi}^{2}$, which represents a flow duration of about 47.9 percent. Unaltered and depleted streamflow values diverge substantially below these values. Figure 4 indicates that among the population of streamflows with depletion, the $0.18 \mathrm{ft}^{3} / \mathrm{s} / \mathrm{mi}^{2}$ value has a flow duration of about 92.5 percent, meaning that about 7.5 percent of mean daily flows will be less than or equal to this hypothetical flow criterion if the three-well pumping plan were used for the entire 1942-2009 period. The flow-duration curve indicates the absolute risk of being above or below any specified flow value, but it does not indicate the frequency and duration of periods of time with low-flow excursions below a selected flow value.

The time-series output from the HyDroDSS does provide planning-level information about the frequency and duration of low-flow excursions below a selected flow value for a given set of wells and a given pumping plan. For example, figure 5 shows the historical time series of estimated unaltered and depleted values under the same conditions described for figure 4. Only part of the total record (1960 through 1999) is shown to facilitate visual inspection of this part of the estimated historical record. The graph shows that there are no flow excursions below the $0.18 \mathrm{ft}^{3} / \mathrm{s} / \mathrm{mi}^{2}$ value during this period for the estimated unaltered streamflows, but there are low-flow excursions among the streamflows with depletions in 23 of the 40 years displayed on figure 5 . The figure indicates that about 9 of these excursions were of relatively short duration - less than seven days - and about 14 were longer than a week. Five excursions resulted in low flows that were less than or equal to the USGS's minimum nonzero flow reporting limit of $0.1 \mathrm{ft}^{3} / \mathrm{s}$ (about $0.00437 \mathrm{ft}^{3} / \mathrm{s} / \mathrm{mi}^{2}$ for USGS streamgage 01117000).

The retrospective streamflow-analysis output can be used with hydrologic data such as precipitation, groundwater levels, and index-station streamflows to examine the conditions that may be used to implement water-management strategies that would reduce the risk for such low-flow excursions. Similarly, this analysis output can be used to help identify pumping plans that may reduce low-flow excursions to an acceptable level. If ecological objectives cannot be met while meeting water supply needs by using withdrawals from the basin above the site of interest, then the retrospective streamflow-analysis output can be used to demonstrate the need for alternate water supply sources.

\section{Limitations}

First, it must be remembered that the HyDroDSS retrospective streamflow-depletion analysis module is designed to provide planning-level estimates of unaltered streamflows and streamflows with depletion over the historical period of record. Planning-level estimates are commonly defined as the results of analyses used to evaluate broad policy measures. Planning-level estimates are recognized to include substantial uncertainties (commonly orders of magnitude) in all aspects of the decisionmaking process. Uncertainties in the results of retrospective streamflow-depletion analysis module include the quality of the unaltered flow estimate, uncertainty in model-calculated response coefficients, the calculation of daily depletions from monthly withdrawal and discharge data, and the validity of the assumption that the historical data may represent future conditions. Therefore, the magnitude and frequency of low-flow excursions should be interpreted as estimates of potential effects. Furthermore, statistics derived from a historical period may not represent the probability of similar low-flow excursions in the future. Several factors limit the applicability of monthly average withdrawals for daily streamflows. The streamflow-depletion algorithms in the HyDroDSS were designed from monthly average withdrawals. In most cases, this time scale will be sufficient for groundwater withdrawals or discharges; however, some exceptions are possible. A monthly time scale may not be suitable for estimating minimum flows if surface-water withdrawals or discharges vary substantially at short time scales. For example, irrigation withdrawals from surface water may be very large and last for only a few hours for several days in each month (Bent and others, 2011; Granato and Walter, 2011). Surface-water-withdrawal sites should be assigned a response coefficient of 1.0 because the entire withdrawal occurs instantly as a streamflow 

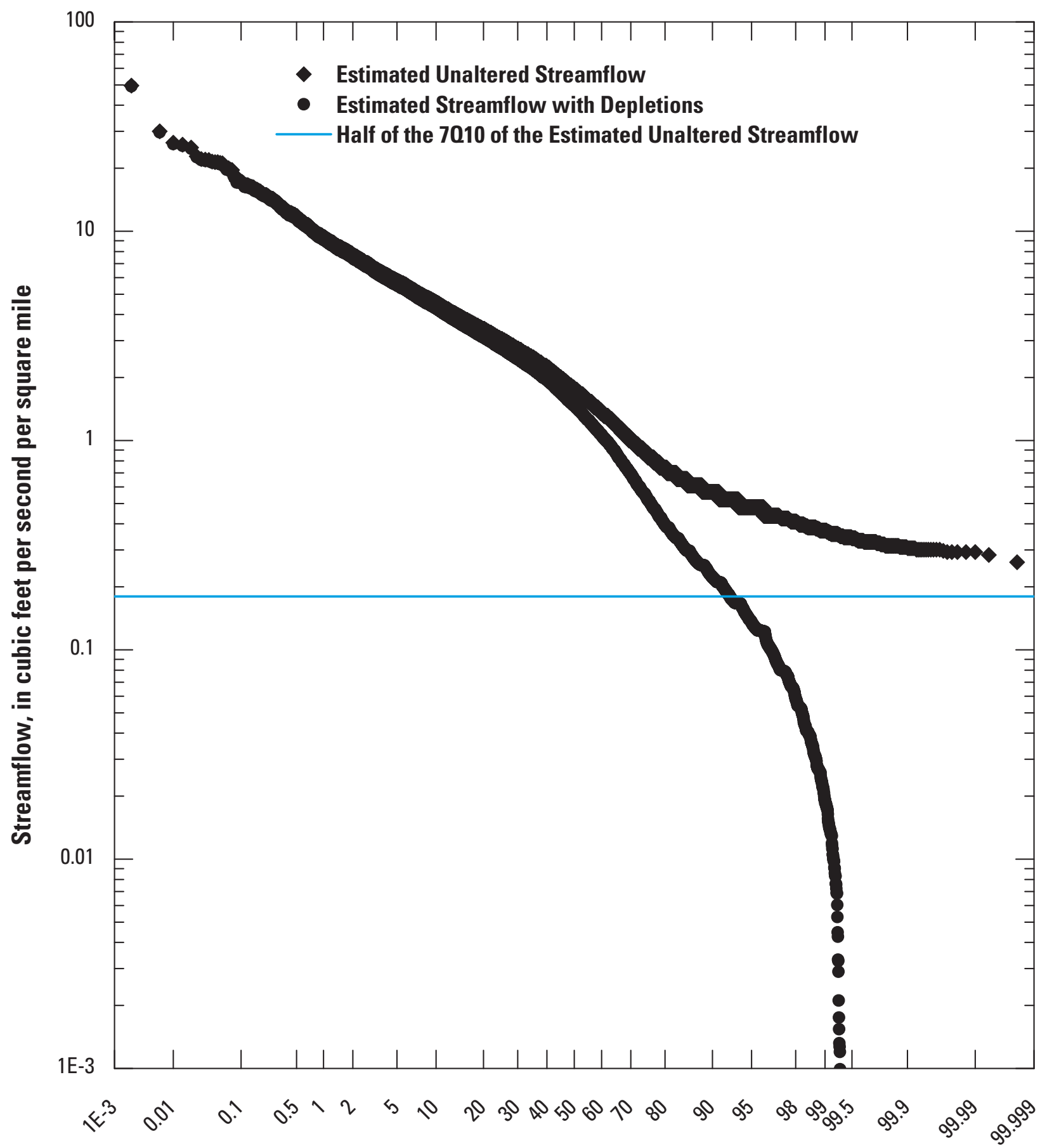

Percentage of time estimated streamflow was equaled or exceeded

Figure 4. Flow-duration curves showing the percentage of time estimated unaltered daily mean streamflow and streamflow with hypothetical depletions was equaled or exceeded at USGS streamgage 01117000 on the Hunt River in central Rhode Island (1942-2009). Streamflow depletions are caused by pumping at wells with the same response coefficients as hypothetical wells 1, 2, and 3 in figure 1. Pumping rates for these wells follow the municipal-demand pattern with average annual withdrawals of about 1.5 million gallons per day and peak-monthly withdrawals that are about 2 million gallons per day. 


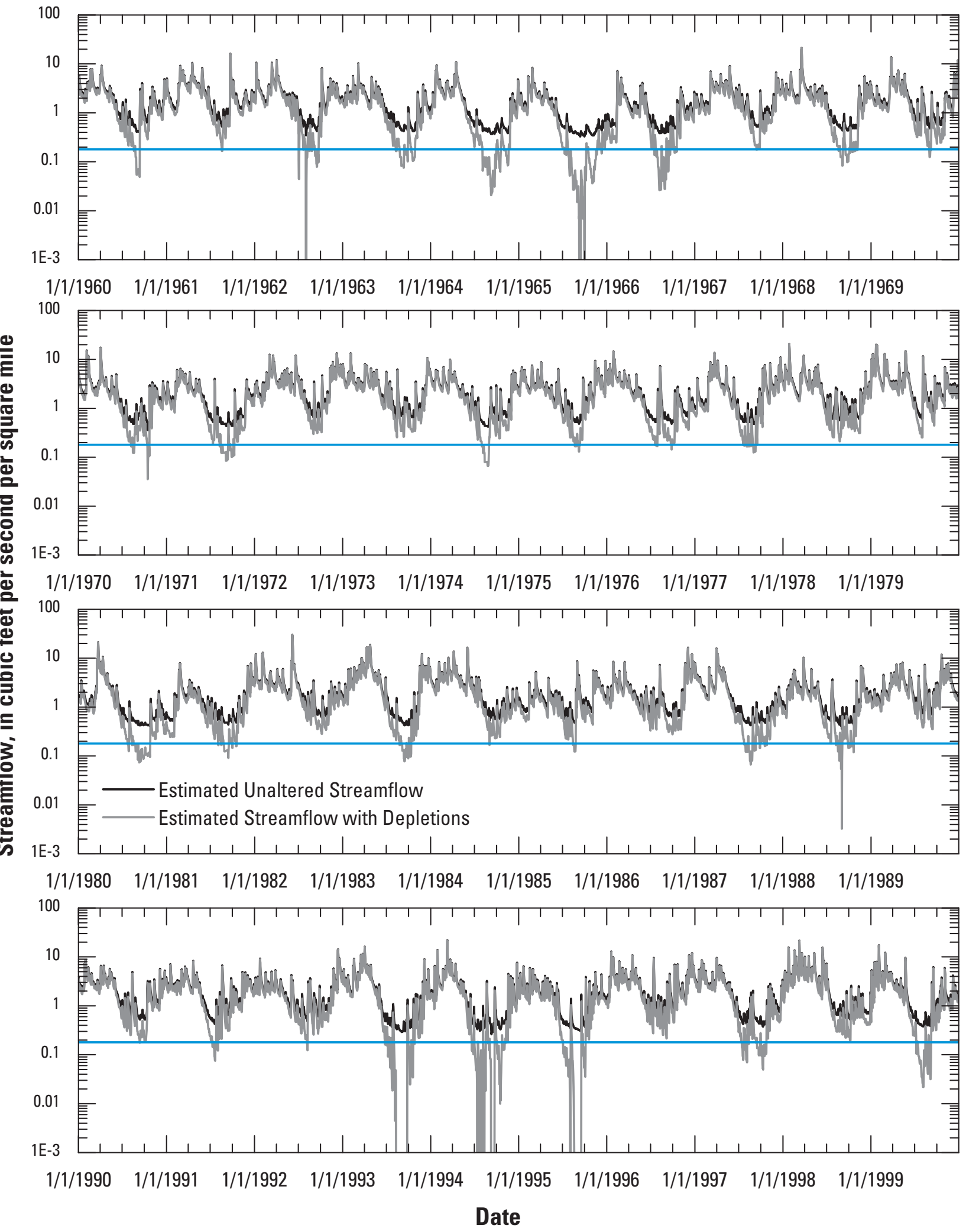

Figure 5. Time series graph showing estimated unaltered streamflow and streamflow with hypothetical depletions at USGS streamgage 01117000 on the Hunt River in central Rhode Island (1960-1999). Streamflow depletions are caused by pumping at wells with the same response coefficients as hypothetical wells 1,2, and 3 in figure 1 . Pumping rates for these wells follow the municipal-demand pattern with average annual withdrawals of about 1.5 million gallons per day and peak monthly withdrawals that are about 2 million gallons per day. 
depletion as water is pumped from the stream, but the effect of the monthly average surface-water withdrawals may be minor in comparison to periodic short-term high-volume withdrawals that actually may occur. However, the effect of droughtmitigation measures to limit such withdrawals during periods of extreme low flows also is instantaneous. Groundwater response times ensure that the monthly response coefficients are more suitable for using monthly average withdrawals from wells, but the suitability of using straight-line interpolation for the month may be affected if a well is operated for only part of a month.

The HyDroDSS calculates depletions by using equation 2 based on a one-year annual cycle of response coefficients (eqs. 3, 4). Therefore, response coefficients for pumping wells that have effects on depletion exceeding 12 months after a unit withdrawal must be reproportioned to a 12 -month cycle. This modification may be a substantial limitation for areas with large stream-aquifer systems with wells that have response times that greatly exceed 12 months. Conjunctive-management studies in the northeastern United States, however, indicate that 12-month response times are sufficient for modeling the effects of pumping on depletions even in large stream-aquifer systems (Barlow and Dickerman, 2001; DeSimone and others, 2002; Barlow and others, 2003; DeSimone, 2004; Eggleston, 2004; Granato and Barlow, 2005; Granato and Walter, 2011). For example, Granato and Walter (2011) developed conjunctive-management models and did postoptimization assessments by using retrospective streamflow-depletion analysis for basins as large as 204 square miles $\left(\mathrm{mi}^{2}\right)$. The magnitude of depletions during long lag times beyond 12 months is expected to be minor because the streamflow depletions commonly exhibit an exponential decay in magnitude after the peak depletion.

The depletion analysis is dependent on the assumption of linearity in the response of streamflows to depletions. Once streamflow approaches zero, or groundwater levels fall enough to decouple the stream from the aquifer, all water that is captured by the well comes from aquifer storage. This causes groundwater drawdowns that change the saturated thickness and therefore the transmissivity of the aquifer, which may affect the assumption of linearity and therefore the relation between pumping and depletion. The HyDroDSS uses a simple depletion-accumulation algorithm to partially account for depletions from aquifer storage during zero-flow events. This algorithm adds depletions in excess of available streamflow until streamflow exceeds the accumulated depletions. A storm may provide enough flow to zero out the accumulated depletions without recharging the aquifer enough to bring up groundwater levels and reestablish the connection between the stream and the underlying aquifer.

The depletion analysis also is dependent on the assumption that the site of interest is representative of available flows at the point of maximum depletions. In Rhode Island, groundwater-modeling studies in Rhode Island have shown accumulation of streamflows with and without withdrawals and accumulation of depletions as a function of river mile along the main stem of rivers in the model areas at steady state (Barlow and Dickerman, 2001; Granato and others, 2003). These analyses show that depletions are propagated downstream from the point of maximum depletion, but accumulation of groundwater discharge and inflows from tributaries downstream of this point may mask extreme low flows upstream of the point of interest. In this case, establishment of an additional site of interest upstream at the point of maximum depletion and either measurement or estimation of flows for this new site of interest might be necessary.

Interpretation of results of the retrospective streamflowdepletion analysis is based on the standard assumption that the historical record of streamflow can be used to estimate future conditions (known as stationarity), but recent research indicates that streamflow regimes may be changing with time (Lins and Slack, 1999, 2005; McCabe and Wolock, 2002; Hayhoe and others, 2007; Milly and others, 2008; Lins and others, 2010; Hodgkins and Dudley, 2011; Galloway, 2011). Results for different flow percentiles are mixed, but streamflow-trend studies generally indicate that low flows have increased or are increasing at many index gages in the northeastern United States. Some studies, however, indicate that the frequency and severity of drought in the United States may change with time. Although the assumption of stationarity is in question, hydrologic research has yet to provide an unambiguous alternative on which to base water-management decisions (Milly and others, 2008; Brekke and others, 2009; Lins and others, 2010; Galloway, 2011). Adaptive-management approaches are currently being recommended for use in making water-resource decisions because of uncertainties in future water-resource conditions and the lack of proven methods for dealing with these uncertainties (Brekke and others, 2009). Although the retrospective streamflow-depletion analysis in the HyDroDSS is based on the assumption of stationarity, it also is designed to be able to use such adaptivemanagement approaches. First, the HyDroDSS is designed to incorporate new hydrologic data as it becomes available and to include this data in future retrospective streamflow-depletion analyses. Second, the HyDroDSS is designed to use a longterm record of estimated unaltered streamflows that has been imported into the database. Watershed models or stochastic models can be used to generate such records for a simulated historical period under different assumptions about potential changes in future streamflow regimes. One or more such records can be imported into the HyDroDSS, and the results of different pumping plans can be evaluated on the basis of these different estimates.

\section{Rank Correlation Analysis}

Rank correlation analysis can be used to select index sites for predicting hydrologic conditions at a site of interest. Rank correlation analysis of time series data can be used to evaluate different types of hydrologic data for predicting future conditions. Rank correlation analysis can be used by water-resource 
managers to evaluate relations between values of different hydrologic variables measured at different sites, or relations between current and future values of each hydrologic variable at a selected site. Relations between values of different hydrologic variables measured at different sites indicates which sites and which variables may be used to estimate hydrologic drought at a site of interest. Variables that show strong correlations with measurements made at a site of interest are good indicators for estimating data at that site. Relations between current and future values of each hydrologic variable at a selected site indicate the persistence of different hydrologic variables from month to month. Variables that show strong correlations with measurements made in the following months are good indicators for predicting the evolution of hydrologic drought conditions.

Rank correlation analysis in the HyDroDSS is done by calculating Spearman's rho for paired samples and the 95-percent confidence limits of each rho value. In the HyDroDSS, rank correlation analysis can be done by using precipitation, groundwater levels, measured streamflows, and estimated unaltered streamflows. Rank correlation analysis was selected for estimating correlations between hydrologic variables in the HyDroDSS because this method is robust to differences in the distribution of input variables and, unlike the parametric Pearson's $r$, the rank correlation value is not dependent on the linearity of the relation between variables (Hann, 1977; Press and others, 1992; Helsel and Hirsch, 2002). Each of the primary variables for evaluating hydrologic drought (precipitation, groundwater levels, and streamflow) has a different probability distribution, and thus relations between variable pairs are likely to be nonlinear. Furthermore, using the ranks of data to calculate the correlation coefficients is consistent with use of the nonparametric bootstrap method used in the drought-projection analysis in the HyDroDSS.

Correlation analysis is a method to quantify the type and strength of relations between two variables (Haan, 1977; Press and others, 1992; Helsel and Hirsch, 2002). Correlation coefficients commonly are dimensionless and are scaled to be in the range of -1 to 1 , inclusive. The sign of the correlation coefficient indicates the type of relation. A positive sign indicates that one variable generally increases as the other increases; a negative sign indicates that one variable generally decreases as the other increases; and a value of 0 indicates that variations in the two variables are totally unrelated. The strength of relations between pairs of variables is indicated by the values of the correlation coefficients. The relation between two variables goes from random association (no relation) to monotonic covariance as the absolute value of the correlation coefficient increases from 0 to 1 . For example, figure 6 shows the results of eight Monte Carlo experiments, each using 500 paired uniform random numbers. The results of the experiments demonstrate the amount of scatter that may be associated with different correlation coefficient values. The diagonal line in each graph indicates the perfect 1-to-1 relation that would be evident if the correlation coefficient were equal to 1 . The graphs indicate the increasing scatter in the paired values as the correlation coefficient (in this case Spearman's rho) decreases. Scatter in the relation is considerable on almost all of the graphs, even on the graph representing a rho value as high as 0.85 . Furthermore, the relation between variables appears to be almost random in the graph representing a rho value as high as 0.45 (absent the 1-to- 1 line). Relations between variables for negative rho values would show the same scatter, but the trend would be from the upper left to the lower right in each graph. The statistical significance of the correlation coefficient is a function of the absolute value of the coefficient and the sample size. Figure 6 indicates that it is more difficult to distinguish between an actual correlation and an accidental correlation caused by random sampling as the absolute value of the correlation decreases, even with large sample sizes.

It is important to note that the correlation coefficient is not a measure of a causal relation between variables. Variation in one variable may cause changes in another. For example, decreasing precipitation may be one factor causing decreases in streamflow (other factors may include increases in dryperiod evapotranspiration and increases in water withdrawals). Both variables may be affected by a third. For example, increases in streamflow and groundwater levels may be affected by increases in precipitation. An apparent correlation also may occur purely by chance. Confidence intervals for rho values, which are a function of the rho value and sample size, indicate the likelihood that a calculated rho value is due to chance.

\section{Calculating Rank Correlations and Confidence Intervals}

To compute Spearman's rho, the data for the two selected variables $x$ and $y$ are ranked independently, and the correlation of the ranks is computed (Hann, 1977; Press and others, 1992; Helsel and Hirsch, 2002). The HyDroDSS uses database queries and Visual Basic ${ }^{\circledR}$ implementations of algorithms based on the approaches described by Press and others (1992). To calculate the ranks the data are sorted and ranked from 1 to the number of data points $(N)$. Tied data values are assigned a mid-rank, which is the average of the preceding and following ranks. For example, if a dataset has two tied values in the 8th and 9th ranks, then the midrank would be the average of the 7th and 10th ranks (8.5); if the dataset has three tied values in the 8th, 9th, and 10th ranks, then the midrank would be the average of the 7th and 11th ranks (9), and so forth. Once the ranks $R x_{i}$ and $R y_{i}$ are computed for each $x_{i}$ and $y_{i}$ value, the sum of squared differences of ranks $(D)$ can be calculated as

$$
D=\sum_{i=1}^{N}\left(R x_{i}-R y_{i}\right)^{2}
$$




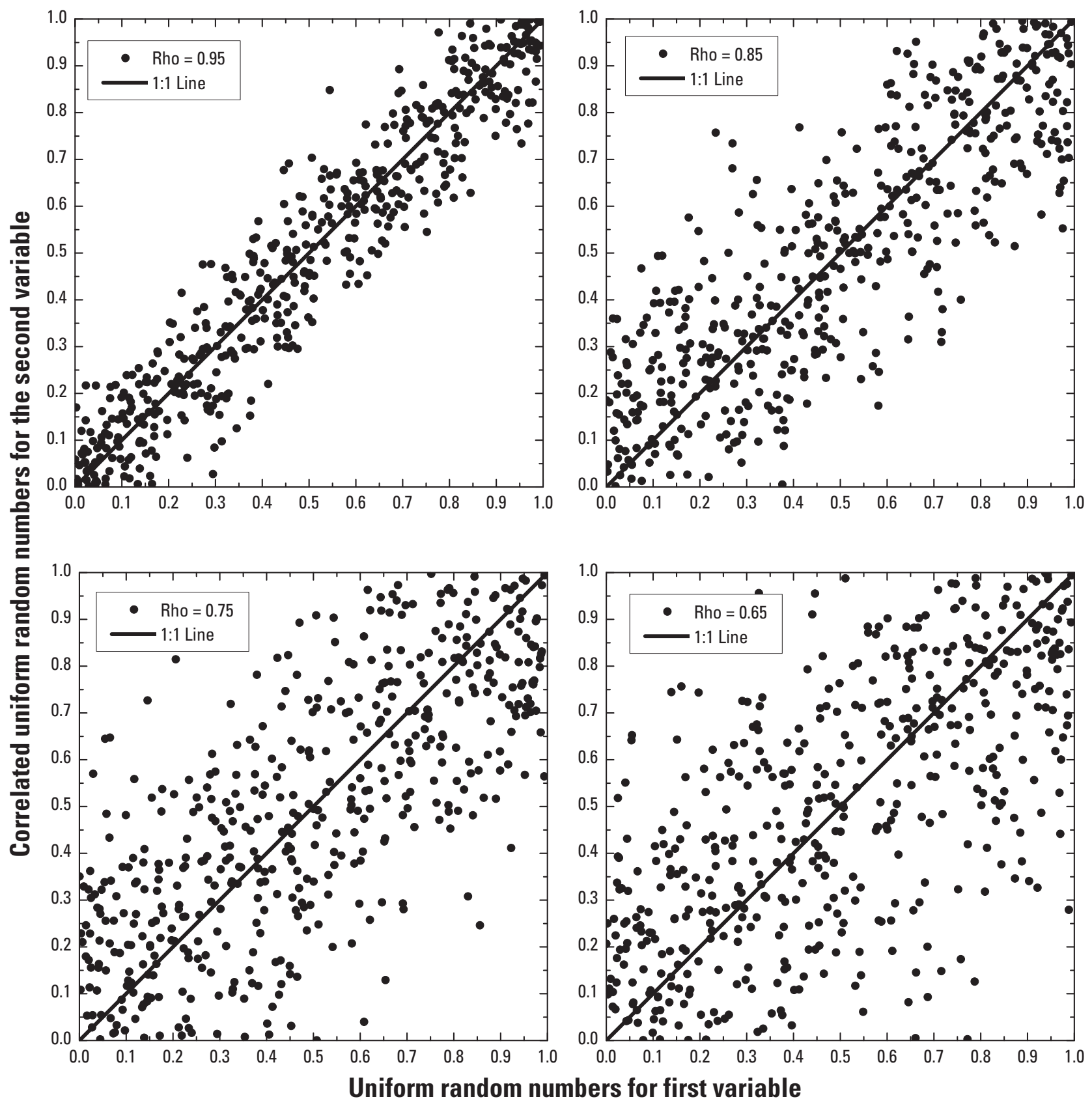

Figure 6. The results of a Monte Carlo analysis to demonstrate scatter of paired uniform random-number samples around a one-to-one relation for eight different values of the correlation coefficient. Each sample consists of 500 paired uniform random numbers in the range between 0 and 1. 

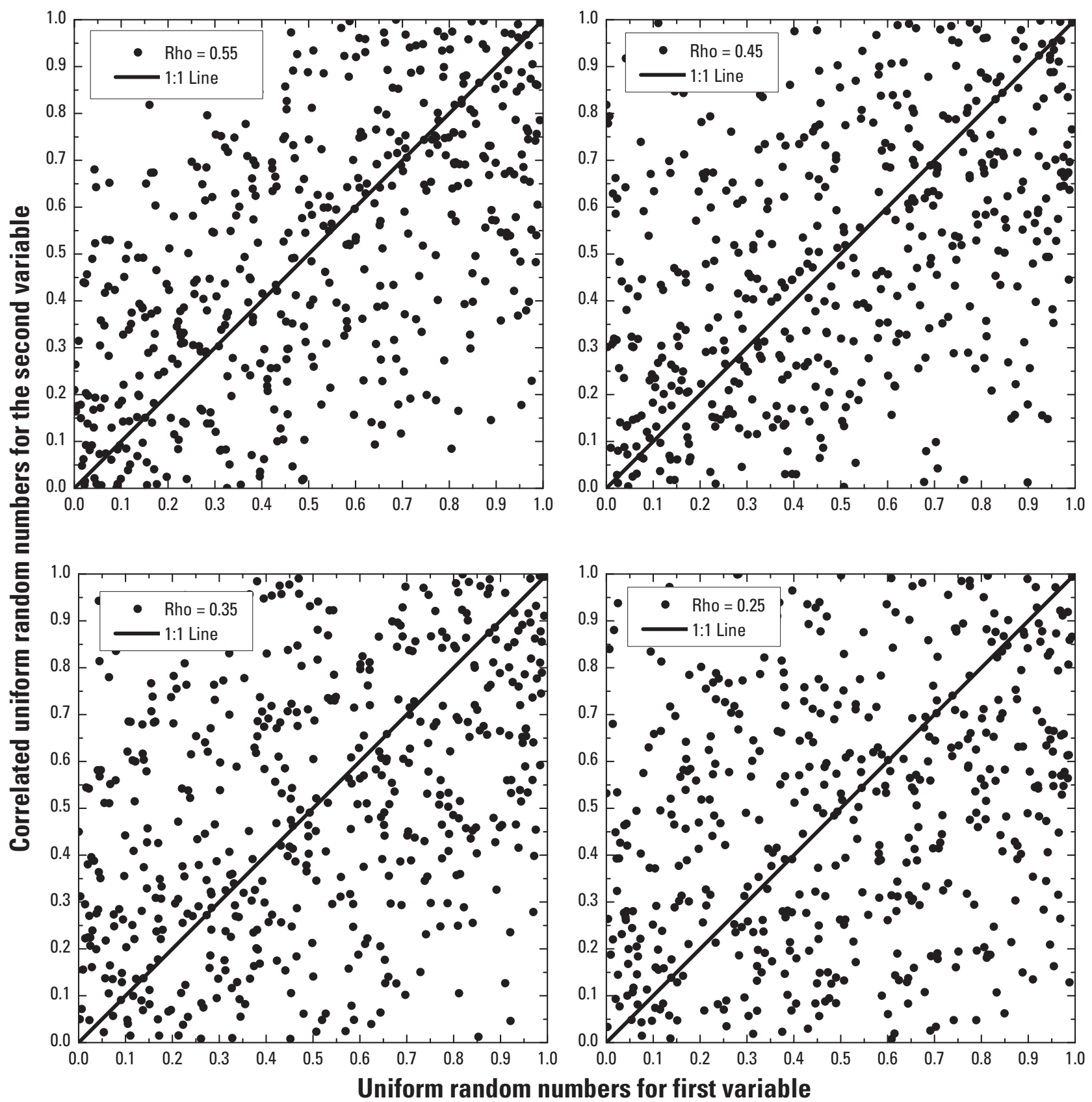

Figure 6. The results of a Monte Carlo analysis to demonstrate scatter of paired uniform random-number samples around a one-to-one relation for eight different values of the correlation coefficient. Each sample consists of 500 paired uniform random numbers in the range between 0 and 1.-Continued 
If there are no tied values, then the equation to calculate rho is simply

$$
r h o=1-\frac{6 D}{N^{3}-N} .
$$

If there is a positive correlation, the higher ranks of $x$ will be paired with the higher ranks of $y$, the differences between $R x_{i}$ and $R y_{i}$ will be small, and the fractional part of equation 7 will approach 0 . If there is a negative correlation, the higher ranks of $x$ will be related to lower ranks of $y$, the differences between $R x_{i}$ and $R y_{i}$ will be large, and the fractional part of equation 7 will approach 2 . If there is no correlation, the differences between $R x_{i}$ and $R y_{i}$ will approach the average difference, and the fractional part of equation 7 will approach 1.

If the ranks are tied, then a correction must be made for each group of ties. If $T R x_{k}$ is the number of ties in the $k$ th group of $R x$ ties, and $T R y_{m}$ is the number of ties in the $m$ th group of $R y$ ties, then rho is calculated with the corrections for ties as

$$
r h o=\frac{1-\frac{6}{N^{3}-N}\left[D+\frac{1}{12} \sum_{k}\left(T R x_{k}^{3}-T R x_{k}\right)+\frac{1}{12} \sum_{m}\left(T R y_{m}^{3}-T R y_{m}\right)\right]}{\left[1-\frac{\sum_{k}\left(T R x_{k}^{3}-T R x_{k}\right.}{N^{3}-N}\right]^{1 / 2}\left[1-\frac{\sum_{m}\left(T R y_{m}^{3}-T R y_{m}\right)}{N^{3}-N}\right]^{1 / 2}}(8)
$$

If no ranks are tied, then the $T R x_{k}$ and $T R y_{m}$ terms reduce to 1 , and equation 8 is equivalent to equation 7 .

The HyDroDSS calculates the 95-percent confidence limits of each rho value to determine the range of likely values of the actual rank correlation coefficient and to determine if the calculated value is significantly different from 0 . Confidence intervals for rho can be estimated by using methods developed for Pearson's $r$ because Spearman's rho is analogous to Pearson's $r$ between the ranks of the samples (Haan, 1977; Caruso and Cliff, 1997; Helsel and Hirsch, 2002). The confidence interval is calculated from the sample size and the value of rho by using the Fisher's $\mathrm{Z}$ transformation method (Fisher, 1924; Haan, 1977; Caruso and Cliff, 1997). The equation

$$
Z=0.5 \times \ln \left(\frac{1+R}{1-R}\right)=\operatorname{arctanh}(R)
$$

is used to convert the correlation coefficient $r$ to the normally distributed variable $Z$, which has a standard error $S E_{z}$ of

$$
S E_{Z}=\frac{1}{\sqrt{N-3}} .
$$

By using the large sample approximation, the 95-percent confidence intervals $\left(\mathrm{CI}_{z}\right)$ for $Z$ are calculated as

$$
C I_{Z}=Z \pm 1.96 \times S E_{Z}
$$

and retransformed by using the equation

$$
C I_{R}=\frac{\exp \left(2 C I_{Z}\right)-1}{\exp \left(2 C I_{Z}\right)+1}=\tanh \left(C I_{Z}\right) .
$$

The HyDroDSS also calculates the probability that the rho value is statistically different from 0 . First, the normal variate $(K)$ is calculated by using the Fisher's $Z$ transformation of the correlation coefficient and the number of samples $(N)$ by using the equation

$$
K=\frac{\operatorname{Abs}(Z)}{\sqrt{\frac{1}{N-3}}} .
$$

Then the two sided $p$-value is calculated from $K$ as

$$
p=2 \times\left(1-P_{N}(K)\right),
$$

where $P_{N}(K)$ is an inverse normal distribution function. The resulting $p$-value can be used to assess the statistical significance of the calculated rho value.

\section{Interpreting Results of the Rank Correlation Analysis}

The rank correlation analysis module provides planninglevel information on the potential utility of different variables for predicting hydrologic drought, information for the selection of index sites and index variables, and serial correlation values for conducting the drought-projection analysis. This module provides an output matrix of monthly values of the Spearman's rank correlation coefficients (rho), upper and lower 95-percent confidence interval values, the probability that calculated rho values are different from zero, and the number of data points used to calculate each statistic. This module provides results as tab-delimited text in output formats that are described in detail in the section of this report on the use of the HyDroDSS.

Rank correlation analysis in the HyDroDSS indicates relations between hydrologic measurements in space and time. Spatial relations can be examined because correlations between datasets collected at different sites indicate which sites in what locations may be best suited for predicting conditions at a site of interest. This type of analysis is commonly known as cross correlation analysis. Correlations in time during the period of record also can be examined because correlations between hydrologic variables in one month and the following 11 months indicate the persistence of different hydrologic variables from month to month for the prediction of developing drought conditions. This type of analysis is commonly known as serial correlation analysis. Rank correlation analysis in space and time also indicates the potential for each variable measured at each station to estimate monthly 
minimum unaltered flows at a site of interest for use in the drought-projection analysis.

A hypothetical example using sites in the Pawcatuck River Basin in southwestern Rhode Island identified by Bent and others (2011) was selected to demonstrate interpretation of results from the rank correlation analysis module. Precipitation data from National Weather Service climate station 374266 in Kingston, groundwater data from USGS monitoring well RI-EXW 6 in Exeter, R.I., and streamflow data from USGS streamgage 01118000 on the Wood River at Hope Valley, R.I., were selected for analysis. Rank correlation values between precipitation and groundwater levels, precipitation and streamflow, and groundwater levels and streamflow for the months of March through the following February are shown in figure 7 with the associated upper and lower 95-percent confidence limits, and the statistical significance $(p)$ value. This period was selected because the March data would be the most current available when the Rhode Island Drought Steering Committee commonly begins the annual drought-planning cycle in April (Kathleen Crawley, RIWRB, oral commun., 2010).

The top panel (fig. 7A) indicates relations between total precipitation in March and groundwater levels in March and the following 11 months. These correlations are negative because groundwater levels are measured as the depth to the water table in feet below land surface. Although groundwater levels rise with increasing precipitation and recharge, the depth to water decreases under these conditions. The rank correlations between total precipitation in March and groundwater levels are statistically significant (the 95-percent confidence limit does not include a rho of 0 ) from March through June. This relation may indicate that precipitation in March helps sustain groundwater levels throughout the spring, or perhaps that both variables are affected by the same seasonal weather patterns. Although the correlation coefficients in the first 4 months are statistically significant, they are fairly weak, ranging from -0.61 in March to about -0.29 in June. The considerable scatter in data for rho values of this magnitude is shown in figure 6 . The low values of rho and the large 95-percent confidence intervals, which span a rho value of 0 , indicate random variation between these variables for the months of July through February. Therefore, the predictive strength of total monthly precipitation in March for groundwater levels is weak for the selected sites.

The middle panel (fig. 7B) indicates relations between total precipitation in March and monthly minimum streamflows in March and the following 11 months. The rank correlation between total precipitation in March and monthly minimum streamflow in March is low (about 0.16) and not statistically significant at the 95-percent confidence limit. The rank correlation between total precipitation in March and monthly minimum streamflow in April, however, is substantially higher (about 0.45 ) and statistically significant at the 95-percent confidence limit. The low values of rho and the large 95-percent confidence intervals, which span a rho value of 0 , indicate random variation between these variables for March and for the months of May through February.

The lower panel (fig. 7C) indicates relations between groundwater levels in March and monthly minimum streamflows in March and the following 11 months. The rank correlations between groundwater levels in March and monthly minimum streamflows in March and April are low (about -0.36 and -0.40 , respectively) and statistically significant at the 95 -percent confidence limit. The low values of rho and the large 95-percent confidence intervals, which span a rho value of 0 , indicate random variation between these variables for the months of May through February.

Rho values in figure 7 indicate that, for these sites in the Pawcatuck River Basin in Rhode Island, the hydrologic data from March (available at the April drought-planning meeting) provide little if any predictive information for estimating conditions during the critical low-flow months of July, August, and September. Analysis shows that month-to-month correlations between variables are higher during the summer months, but the persistence of significant correlations for these sites is consistently short - only a few months. Thus, rank correlations between hydrologic variables for these sites indicate that month-to-month changes in hydrologic variables affect hydrologic drought (monthly minimum streamflows) more than seasonal patterns.

A hypothetical example using data from the USGS streamgage 01118000 , the Wood River at Hope Valley, in the Pawcatuck River Basin, R.I., was selected to demonstrate interpretation of serial-correlation analysis by using the output from the rank correlation analysis module. Rank correlation values between monthly minimum streamflows in March, April, and May and monthly minimum streamflows in the following 11 months are shown in figure 8 with the associated upper and lower 95 -percent confidence limits and the statistical-significance $(p)$ values.

These serial-correlation graphs (fig. 8) indicate increasing and more statistically significant relations among monthly minimum streamflows as the spring season evolves from March through May at this streamgage. Monthly minimum streamflows in March (fig. 8A) are not highly correlated with monthly minimum streamflows in subsequent months. Only the correlations to April and November are statistically significant at the 95-percent confidence interval. Rank correlations using monthly minimum streamflows in April (fig. 8B) are stronger than correlations using March monthly minimum flows. Serial correlations made by using the April data with the data from May, June, and July also are statistically significant at the 95-percent confidence interval. Serial correlations made by using the May data with the data from June, July, August, and September are stronger than similar correlations made by using March or April data and statistically significant at the 95-percent confidence interval (fig. 8C). Comparison of the correlation coefficients in these graphs (fig. 8) with the amount of scatter shown on figure 6 indicates that there is substantial uncertainty in the evolution of spring and summer streamflows measured at 


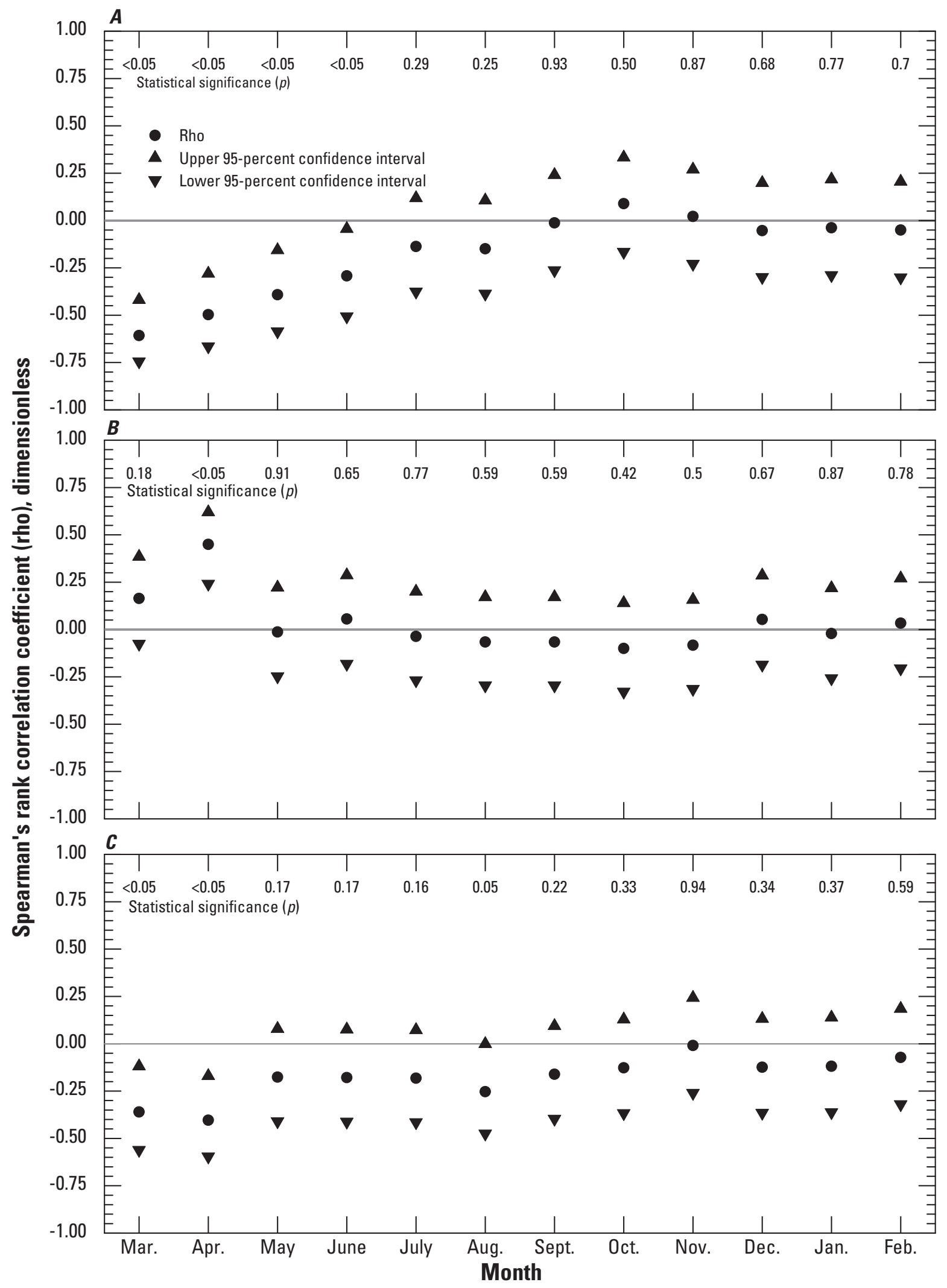

Figure 7. Rank correlation coefficients and confidence intervals for the months of March through the following February during the period 1942-2009 between $A$, precipitation and groundwater levels, $B$, precipitation and monthly minimum streamflow, and $C$, groundwater levels and monthly minimum streamflow. 


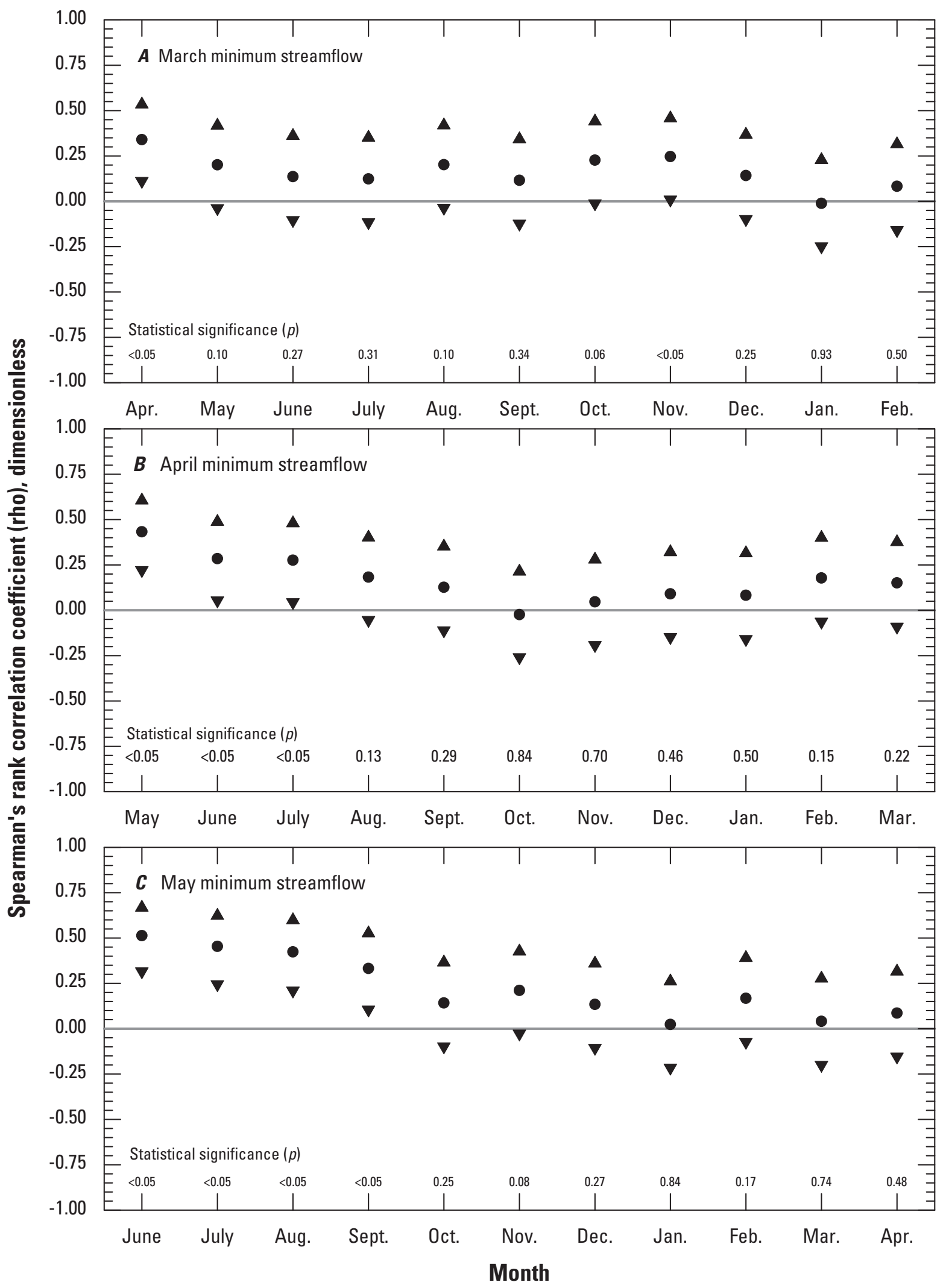

Figure 8. Serial rank correlation coefficient values and confidence intervals for monthly minimum streamflows at USGS streamgage 01118000 the Wood River at Hope Valley, Rhode Island, $A$, for March with values from April through the following February, $B$, for April with values from May through the following March, and $C$, for May with values from June through the following April during the period 1942-2009. 
this streamgage during the 1942-2009 period. The statistical significance of serial correlation values indicates that the persistence of monthly minimum streamflows is about 1-4 months and varies with season. Lag-1 correlations, which are the correlation of data from one month to the next, continue to improve into the summer season for monthly minimum flows measured at this streamgage. The summer-season lag-1 correlations (not shown in fig. 8) are 0.748 for June to July, 0.765 for July to August, and 0.773 for August to September.

Thus, the rank correlation analysis can be used with hydrologic data such as precipitation, groundwater levels, and index-station streamflows to examine correlations that may indicate which variables may be predictive of summer low flows. The rank correlation analysis also indicates the uncertainties of different decision horizons. For example, figures 7 and 8 indicate that decisions made during an April droughtcommittee meeting are made with considerable uncertainty about future conditions, and that uncertainties decrease as the season evolves. The results of the rank correlation analyses also may indicate which hydrologic variable best predicts estimated unaltered streamflow at a site of interest in any given month; this variable may then be used to initiate the droughtprojection analysis. The results of the rank correlation analysis also indicate the degree of certainty for drought projection.

\section{Limitations}

The primary limitation of the rank correlation analysis is that correlation is not equivalent to causation. It may be tempting to assume that higher precipitation or higher groundwater levels may yield higher monthly minimum flows in subsequent months, but these hydrologic variables may covary because of external forcing functions (Brekke and others, 2009). Knowledge of correlations is useful, and strong correlations can be used to make predictions by using the ranks of available hydrologic variables, but physical conclusions about relations between variables may be in error.

As with the retrospective streamflow-depletion analysis, interpretation of the results of the rank correlation analysis is based on the standard stationarity assumption that historical hydrologic records can be used to estimate future conditions (Lins and Slack, 1999, 2005; McCabe and Wolock, 2002; Hayhoe and others, 2007; Milly and others, 2008; Brekke and others, 2009; Lins and others, 2010; Hodgkins and Dudley, 2011; Galloway, 2011). Changes in climate may affect precipitation, evapotranspiration, and eventually the temperature and viscosity of groundwater, which may affect serial correlation at a given site and correlations between sets of hydrologic data collected at different sites. Although the rank correlation analysis module in the HyDroDSS is based on the assumption of stationarity, it also is designed to use adaptive-management approaches recommended for water-resources planning (Brekke and others, 2009). The HyDroDSS is designed to incorporate new hydrologic data as it becomes available and to include this data in future rank correlation analyses.

\section{Drought-Projection Analysis}

Drought-projection analysis can be used by waterresource managers to evaluate the risks for estimated unaltered streamflows and streamflows with depletion to fall below a given flow target. The drought-projection analysis provides planning-level estimates of the probability that monthly minimum streamflows will be below any user-defined thresholds with and without streamflow depletions caused by withdrawals. Drought-projection analysis indicates the risk for a hydrologic drought condition during the current month and the five following months with and without pumping. Droughtprojection analysis also indicates the potential effectiveness of water-conservation methods for mitigating the effect of withdrawals in the coming months on the basis of the risk of unaltered flows that are below streamflow targets and the amount of depletion caused by different pumping plans. This analysis can be run multiple times under the same conditions to evaluate the effectiveness of different pumping plans for mitigating the effects of pumping during drought conditions. The drought-projection analysis also can be applied during drought-committee training sessions to foster a deeper understanding of drought risk by doing drought projections with the historical record and comparing the results to the actual outcomes for a given year.

The HyDroDSS drought-projection analysis module uses a Monte Carlo method known as position analysis. The simulation is started with a known current condition, and a numerical random number generator estimates random paths that simulate evolving hydrologic conditions in the coming months by creating a series of month-to-month variations in streamflow to a reservoir; these variations are known as flow traces (Hirsch, 1979, 1981a,b; Dunne and Tasker, 1996; Tasker and Dunne, 1997; Tasker, 1999). Hirsch (1978, 1979, 1981a,b) developed and tested the position analysis method for forecasting surface-water flows to estimate risks of depleting reservoir-storage volumes under different management strategies and dry conditions. Hirsch $(1979,1981 \mathrm{a}, \mathrm{b})$ used parametric Monte Carlo methods to generate flow traces by simulating the stochastic portion of month-to-month changes in flow by using a lognormal probability distribution. Dunne and Tasker (1996) developed a nonparametric version of the position analysis method. Rather than modeling month-tomonth changes in flow by using a probability distribution, they used a method known as bootstrap analysis. Bootstrap analysis is done by randomly drawing values, with replacement, from a sample of measured values for a given variable (Efron, 1979; Dunne and Tasker, 1996; Vogel and Shallcross, 1996; Tasker and Dunne, 1997; Tasker, 1999). Vogel and Shallcross (1996) compared parametric methods, such as those used by Hirsch, and nonparametric bootstrap methods and found that, in their experiments, bootstrap methods always yielded lower root-mean-square errors than the parametric methods. Dunne and Tasker (1996) used the bootstrap method to resample differences, which they called innovations, in month-to-month streamflows. In their application of the position analysis 
method, Dunne and Tasker (1996) started with the known initial condition and applied a random sample of these innovations in each month to develop a set of possible flow traces. As with Hirsch's parametric methods, the result of the bootstrap method is a sample of endpoint values that can be used to assess the risk for being below a desired limit. These models incorporate reservoir-management strategies by adjusting reservoir-storage volumes to account for diversions, withdrawals, and releases. These models support reservoir management because decisionmakers can run various scenarios to assess effects of different options.

\section{Calculating the Initial Streamflow for the Drought-Projection Analysis}

The first step in the position analysis method is to define the starting position from which flow traces can be generated. The initial unaltered streamflow value is generated for the month preceding the analysis. For example, if an analysis is done for a drought-committee meeting in April, then data from March is used to estimate the March starting position. In the HyDroDSS, the initial unaltered streamflow value must be estimated from available hydrologic data because it cannot be measured directly. The HyDroDSS provides three methods for specifying the initial unaltered streamflow value at a site of interest. The first method is a percentile transfer method using measured precipitation, groundwater levels, or index streamflows as the predictor. The second method is regression using index streamflows as the predictor. The third method is the entry of a user-defined value as the initial unaltered streamflow value at a site of interest.

The percentile transfer method is based on the assumption that the percentiles of measurements of hydrologic variables at two sites covary perfectly. Using this assumption, a measured value at an index station is converted to a percentile by using the plotting positions of all values at that index site. That percentile is then used to select an unaltered streamflow value for the site of interest. The HyDroDSS will calculate estimates based on percentile transfer for a site of interest from index data if the correlation analysis for the index site has been run and the hydrologic data for the selected month have been imported for the site of interest. The rank correlation coefficient calculated by using the rank correlation analysis module in the HyDroDSS indicates which hydrologic variable and which index monitoring site are best suited for this analysis. Figure 9 is an example of the application of the percentile transfer method to estimate monthly minimum streamflows at the USGS streamgage 01118000, the Wood River at Hope Valley, by using the plotting positions of groundwater levels measured at USGS monitoring well RI-EXW 6. Groundwater levels and associated plotting position percentiles are graphed in the upper-left panel. A scatterplot of the plotting position percentiles for groundwater levels and streamflows is in the lower left panel. Streamflows and associated plotting position percentiles are graphed in the lower right panel. Follow four steps to graphically estimate a streamflow from a groundwater level: first, start with the groundwater level, and follow a horizontal line to the associated plotting position percentile (I); second, follow a vertical line down to the one-to-one line (II); third, follow a horizontal line of the associated streamflow percentile (III); and fourth, follow the vertical line down to the associated monthly minimum flow value (IV). The HyDroDSS follows the same process by querying the associated data values and, if necessary, interpolating between the tabled values of percentiles and hydrologic values to estimate streamflow at a site of interest.

Three examples for June 1957, 1991 and 1998 were selected from the 1949-2009 period to demonstrate the percentile transfer method (fig. 9). The rank correlation coefficient between June groundwater levels at USGS monitoring well RI-EXW 6 and monthly minimum June streamflow values measured at USGS streamgage 01118000 is -0.72 . Thus, the one-to-one line of perfect agreement has a negative slope (-1), and the scatter of percentile values around the line of perfect agreement in the lower left panel of figure 9 is substantial. The first year selected as an example is 1957; groundwater levels are extremely low (the distance from land surface to the water table is large for this well). The monthly minimum streamflow in June 1957 also was low. The streamflow and groundwater plotting positions are near the one-to-one line, so the resulting percentile transfer estimate is close to the actual monthly minimum streamflow for that month. The monthly minimum streamflow for June 1957 is tied with the streamflow for June 1965, so the flow had to be interpolated from the index groundwater percentile. Data from June 1991 were selected because groundwater levels were near median values, and the monthly minimum streamflow was extremely low. In this case, the initial condition for the drought-projection analysis (about $61 \mathrm{ft}^{3} / \mathrm{s}$ ) would be much higher than the actual value measured in 1991 (about $31 \mathrm{ft}^{3} / \mathrm{s}$ ). Data from June 1998 were selected because groundwater levels during this month were the second highest measured during the 1949-2009 period. Although streamflows also were high in June 1991, differences between the estimated (about $141 \mathrm{ft}^{3} / \mathrm{s}$ ) and actual (about $111 \mathrm{ft}^{3} / \mathrm{s}$ ) monthly minimum values are still large. For drought-planning analyses, however, differences between estimated and actual values for highflow months are less critical than for low-flow months. The plotting position percentile for the water level measured at USGS monitoring well RI-EXW 6 in June 1991 was much higher than plotting position percentiles for precipitation and streamflow data and was substantially higher than plotting position percentiles for groundwater-level measurements made in nearby index wells. Therefore, the initial flow estimate from the groundwater level in RI-EXW 6 is identifiable as an outlier in comparison to estimates made by using the plotting position percentiles for other hydrologic-monitoring sites. Values estimated from different sources can be compared because the HyDroDSS provides a percentile transfer flow estimate from one or more precipitation-measurement sites, groundwater-monitoring wells, and index streamgages. 


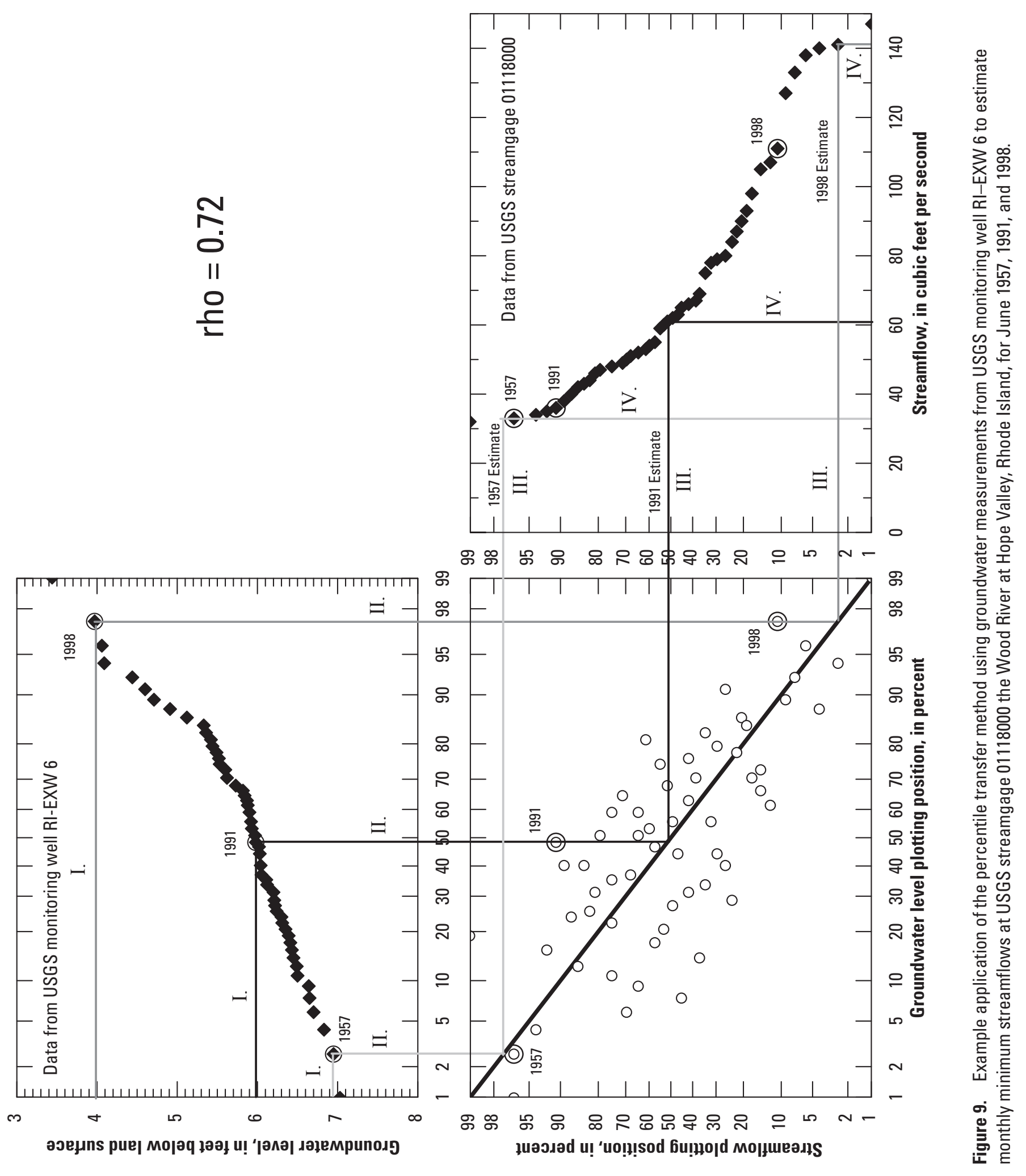


The second method for estimating a starting position from which flow traces can be generated in the HydroDSS is regression by using index streamflows as the predictor. In this method, a flow statistic is estimated by using a regression equation between streamflows at an index site and a site of interest. This method is commonly known as record augmentation (Hirsch, 1982; Stedinger and others, 1993; Ries and Friesz, 2000; Granato, 2009). In HyDroDSS, the monthly minimum flow at the site of interest in a given month is estimated from the monthly minimum flow at the index site. The HyDroDSS is designed so that one or more index streamgages can be associated with one or more sites of interest by defining regression relations. The HyDroDSS is designed to accept one-, two-, or three-segment regression lines that quantify relations between measured flow at the index site and estimated unaltered streamflow at the site of interest. One-segment regression equations can be developed by using the MOVE. 1 or MOVE. 3 methods with the SREF program (Granato, 2009). Multisegment regression models can be developed by using the nonparametric KTRLine program (Granato, 2006). The HyDroDSS will calculate regressionbased estimates for a site of interest from index data if a regression equation has been entered, and monthly minimum streamflow data for the selected month have been imported for the index gage.

The third method for estimating a starting position from which flow traces can be generated is the user-defined option. Several potential methods can be used to generate a user-defined estimate. For example, the mean or median of estimates made by using data from different index sites can be calculated and entered as the user-defined option. If complete pumping data are available, estimated unaltered streamflows also can be calculated from measured streamflow at the site of interest by using response coefficients. An updated hydrologic watershed model also may be used to estimate the monthly minimum unaltered flow.

\section{Calculating Future Streamflows for the Drought- Projection Analysis}

The HyDroDSS uses Monte Carlo methods to generate a sample of estimated monthly minimum unaltered streamflows for the selected month and the five subsequent months, and it uses the streamflow-depletion-analysis methods to estimate the effect of pumping on the probability that actual streamflows will be below flow targets (fig. 10). Once the initial position is calculated, the drought-projection-analysis module uses two random-number-generating algorithms to develop plotting positions for 251 flow traces that originate at the plotting position of the initial flow estimate. For each trace, the drought-projection-analysis module does a 6-month projection to provide estimates at the onset of a drought season without projecting too far into the future. The Monte Carlo algorithms generate correlated random numbers to maintain the lag-1 correlations from one month to the next between monthly minimum unaltered streamflows at the site of interest. The selected flow traces can be modified by specifying a 90 -day precipitation forecast and an associated drought-censoring percentile (DCP), which is used to filter out percentiles that do not meet the forecast. The selected percentiles are used to select an unaltered-flow estimate by interpolation by using a hybrid bootstrap method. Monthly depletions are calculated and subtracted from the unaltered streamflow estimates. The theory and implementation of the Monte Carlo algorithms are described in detail in appendix 1.

The HyDroDSS generates correlated random numbers by using an algorithm developed by Mykytka and Cheng (1994). Implementation of this algorithm is described in appendix 1 . The secondary uniform random variate is calculated from the primary uniform random variate and an intermediate uniform random variate as a function of the rank correlation coefficient. The correlation of the uniform random variates is equal to the rank correlation of these variates because the ranks are the products of the values of the variates plus plotting-position adjustments and the number of variates to be generated plus a plotting-position adjustment. The generalized equation for producing correlated uniform variates is

$$
Y_{3} U_{t+1}=f\left[\rho^{\prime} \times X U_{1}+\sqrt{1-\left(\rho^{\prime}\right)^{2}} \times Y_{2} U_{t+1}+0.5 \times\left(1-\rho^{\prime}-\sqrt{1-\left(\rho^{\prime}\right)^{2}}\right)\right],
$$

where

$$
\begin{aligned}
& Y_{3} U_{i+1} \quad \text { is the value of the output } U_{01} \text { variate for the } \\
& \text { next month }(i+1) \text {, } \\
& \rho \quad \text { is the absolute value of the correlation } \\
& \text { coefficient, } \\
& X U_{i} \quad \text { is the } i \text { th value of the input } U_{01} \text { variate for the } \\
& \text { current month, } \\
& Y_{2} U_{i+1} \quad \text { is the } i \text { th value of an intermediate } U_{01} \text { variate } \\
& \text { for the next month }(i+1) \text {, and } \\
& f[] \quad \text { is a transformation function that depends on } \\
& \text { the value of } Y_{2} U_{i+1} \text {. and the sign of } \rho \text {. }
\end{aligned}
$$

The MRG32K3 random-number algorithm (L'Ecuyer, 1999) was implemented in Microsoft Visual Basic ${ }^{\circledR}$ (VB) for use with HyDroDSS because the native random-number generators in VB and Microsoft Visual Basic for Applications ${ }^{\circledR}$ (VBA) used in the Microsoft Office ${ }^{\circledR}$ programs fail to meet basic standards for random-number generators (L'Ecuyer and Simard, 2007; McCullough, 2008). The MRG32K3 generator produces seemingly random numbers by using the remainder of integer division by using the previous value in the series of values generated. The initial values are known as the random seeds (Devroye, 1986; Press and others, 1992; L'Ecuyer, 1999; Saucier, 2000; Gentle, 2003; L'Ecuyer and Simard, 2007; Granato, 2013). A random-seed management algorithm was developed for HyDroDSS to ensure that each droughtprojection analysis would be repeatable. The HyDroDSS has a random-seed lookup table. By default, it generates a random selection for the random-seed lookup table index number each time the drought-projection form is loaded, but the user can manually select an index number on the form to rerun 


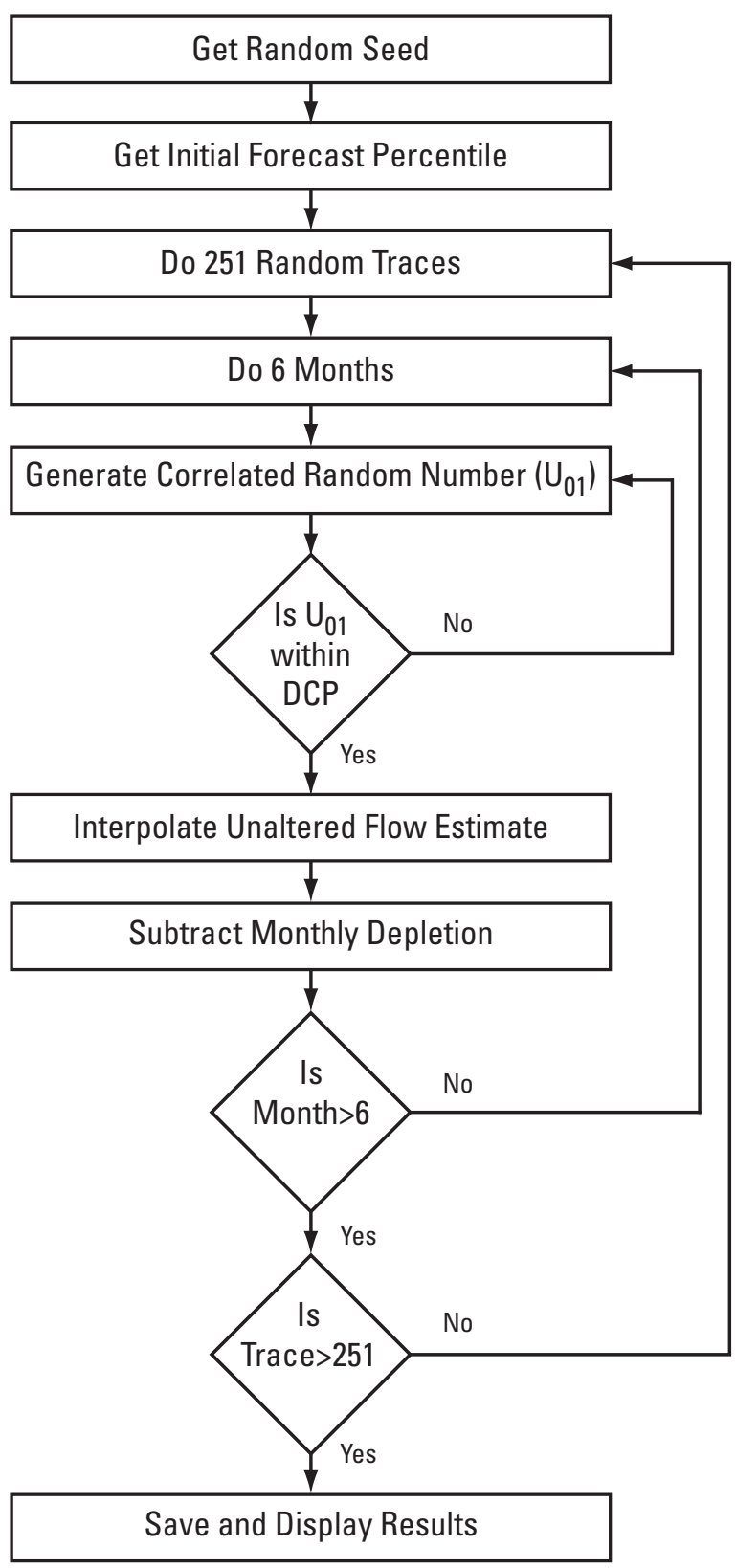

Figure 10. Conceptual schematic diagram for the drought-projection analysis using Monte Carlo methods. DCP is the drought censoring percentile. 
the same analysis. The random-seed index number is printed in the drought-projection-analysis results to document the selected value.

If the 90-day precipitation-forecast option is used in an analysis, the new $U_{i+1}$ value must be within the bounds defined by the DCP. The $U_{i+1}$ values generated are rejected if they are outside the range defined by the DCP, and new values are generated until they are within the acceptable range. Thus, the DCP determines the limits on the plotting positions (and therefore, estimated streamflows) generated by the model for the first 3 months of the analysis. If the precipitation forecast is below normal, then values above the DCP will be rejected (fig. 10). For example, if a below-normal condition is selected with a 25-percent censoring limit, then flows will be generated by using the lower 75 percent of plotting position values, and any uniform random variate above 0.75 will be rejected for the first 3 months. Conversely, if the precipitation forecast is above normal, then values below the DCP will be rejected. For example, if an above-normal condition is selected with a 25 -percent censoring limit, then flows will be generated by using the upper 75 percent of plotting position values, and any uniform random variate below 0.25 will be rejected for the first 3 months. If a normal condition is selected, the DCP is not used in the projection analysis.

Figure 11 shows six example populations of the 251 flow traces generated by the HyDroDSS drought-projection analysis module for the months of May through November. These projections were made by using a starting month of June, so the initial position is based on hydrologic data from May. The first three examples show the traces from an initial position of 0.705 , which represents an above-normal initial condition, and the second three examples show the traces from an initial position of 0.358 , which represents a belownormal initial condition. Ninety-day precipitation forecasts of normal conditions, below-normal conditions, and abovenormal conditions are shown with a DCP of 25 percent. These examples demonstrate that under normal conditions (figs. 11A, D) the starting positions have a substantial effect on the plotting positions generated in the first month, and this effect is damped out by random variation in the following months. In figure $11 \mathrm{~A}$, there are relatively few extreme low flows in the first 3 months, and the average plotting positions in these months are about $0.69,0.65$, and 0.6 (an unbiased sample would have an average rank of 0.5 ). In figure 11D, there are relatively few extreme high flows in the first 3 months, and the average plotting positions in these months are about $0.38,0.41$, and 0.45 . More extreme starting positions would be expected to have a greater and more persistent effect on plotting positions in subsequent months than starting positions near the median plotting position (0.5). The plotting positions for the below-normal precipitation forecasts (figs. 11B, E) show the effect of censoring high percentiles in the first 3 months (approximately 90 days) with average plotting positions in these months of about $0.56,0.49$, and 0.44 for the initial starting position of 0.71 and about $0.37,0.36$, and 0.39 for the initial starting position of 0.36 . In both cases, however, the plotting positions return to near-normal hydrologic conditions by the 5th month of the projection. Similarly, the plotting positions for the above-normal precipitation forecasts (figs. 11C, F) show the effect of censoring low percentiles in the first 3 months with average plotting positions in these months of about $0.69,0.66$, and 0.65 for the initial starting position of 0.71 and about $0.45,0.53$, and 0.58 for the initial starting position of 0.36 . As with the belownormal forecast, the plotting positions return to near-normal hydrologic conditions by the 5th month of the projection. In this example, the lag-1 serial correlations for May, June, July, August, September and October were 0.552, 0.798, 0.770, $0.763,0.681,0.708$, respectively. Higher serial correlation values would tend to extend and strengthen the effect of the initial position and forecast censoring levels, and lower serial correlation values would tend to have opposite effects.

The HyDroDSS uses a hybrid bootstrap method to sample from all possible monthly minimum flows within the range of the available sample of estimated unaltered streamflows. Bootstrap methods simulate data by numerically sampling from available data values. Sample percentiles are generated by using the random-number generator, and an associated flow is selected from available data. If the generated percentile equals a sample percentile, then the associated streamflow is selected. If the generated percentile value falls between two sample percentile values, however, interpolation by percentiles is used to calculate a streamflow value from adjacent streamflow values. As with regular bootstrapping, however, a value outside the range of input values cannot be selected because percentiles outside the range of available sample percentiles are set equal to the minimum or maximum value. The hybrid bootstrap method used by the HyDroDSS is sampling with replacement, but it is sampling from the population defined by the available sample. This hybrid bootstrap method, also known as stochastic interpolation, is more sophisticated than regular bootstrapping because it will generate new data points within the range defined by the sample (Saucier, 2000). Variables generated by a pure bootstrap method are discrete because they are limited to the exact values of the sample (Saucier, 2000; Gentle, 2003). Streamflow, however, is a continuous random variable, and the hybrid bootstrap will maintain this property without the uncertainty of applying any selected probability distribution. The streamflow with depletion is calculated by subtracting the monthly depletion from all estimated unaltered flows for each month in the depletion analysis.

The HyDroDSS then calculates the posterior probability of each flow value to provide the risk-based information needed to help evaluate the potential need for droughtmitigation measures. The posterior probability is defined herein as the plotting position or percentile of each streamflow that is calculated on the basis of the percentile of the initial condition and the precipitation forecast. The plotting position values are calculated by using the Cunnane plotting position formula (eq. 5) as if the generated values represent the available sample of historical flows. For example, if a DCP 

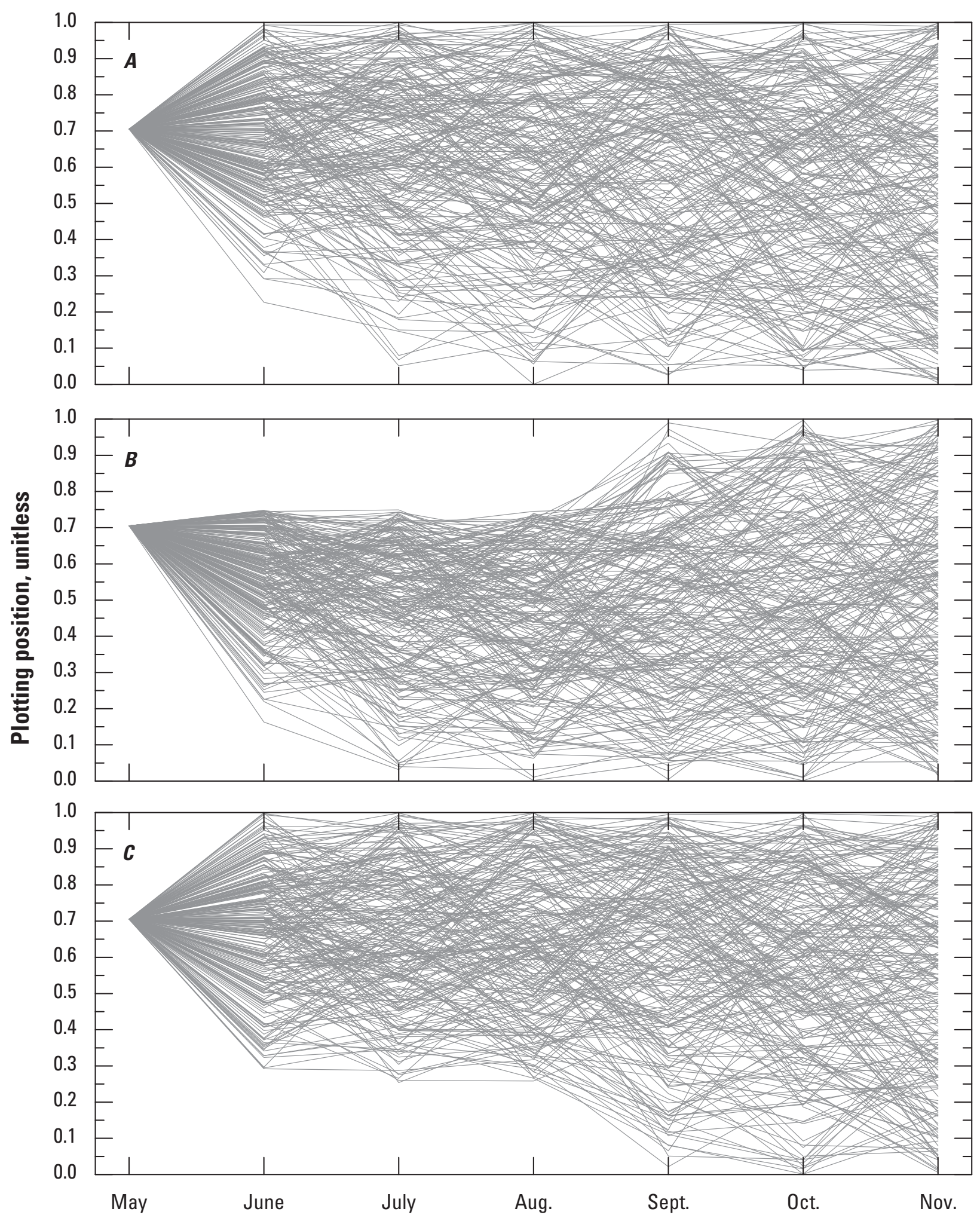

Month

Figure 11. 251 random-number traces generated by the HyDroDSS drought-projection analysis module with an initial position of 0.705 and a 90 -day precipitation forecast of $A$, normal conditions, $B$, below-normal (dry) conditions, and $C$, abovenormal (wet) conditions and an initial position of 0.358 with a forecast of $D$, normal conditions, $E$, below-normal conditions, and $F$, above-normal conditions. A drought-censoring percentile of 0.25 was used. 

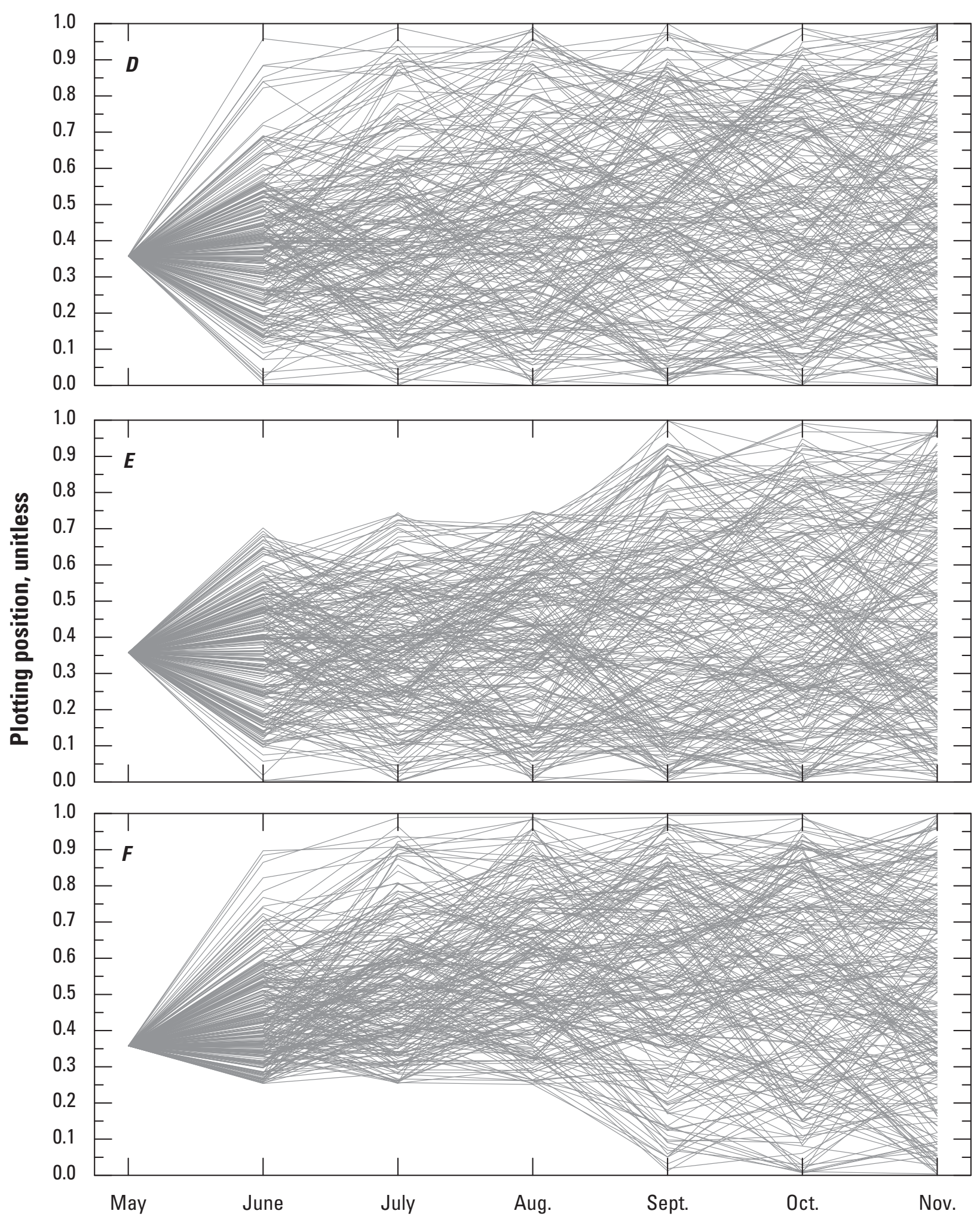

Month

Figure 11. 251 random-number traces generated by the HyDroDSS drought-projection analysis module with an initial position of 0.705 and a 90 -day precipitation forecast of $A$, normal conditions, $B$, below-normal (dry) conditions, and $C$, abovenormal (wet) conditions and an initial position of 0.358 with a forecast of $D$, normal conditions, $E$, below-normal conditions, and $F$, above-normal conditions. A drought-censoring percentile of 0.25 was used.-Continued 
of 25 percent were selected, then the population plotting positions would range from greater than or equal to 25 percent to less than 100 percent, whereas the sample percentiles for the 251 position analysis trials could range from 0.24 to 99.76 percent, based on the Cunnane plotting position formula (eq. 5), if the maximum and minimum values were not tied.

\section{Interpreting Results of the Drought-Projection Analysis}

The drought-projection analysis module provides planning-level information to inform decisions about the potential need to implement hydrologic drought-mitigation measures. This module also indicates the potential effectiveness of different management options for mitigating hydrologic drought conditions. The results of the projection analysis should be considered as rough planning-level estimates because of the many uncertainties in generating the initial flow values, projecting these flows into the following months, and applying a monthly depletion. These estimates also are made on the assumption that the range and month-to-month correlations of flows in the historical record are sufficient for estimating future conditions.

The drought-projection analysis module provides several tables of values with outputs as flow traces, flow-durationcurve statistics, or quantile-plot statistics. The flow traces document the projected values in the order that they are generated. The flow-duration-curve statistics indicate the probability that the monthly minimum flow will be greater than or equal to a given value (the values are ranked in descending order). The quantile-plot statistics indicate the probability that the monthly minimum flow will be less than or equal to a given value (the values are ranked in ascending order). All three selections include the estimated monthly minimum unaltered and depleted streamflows.

The flow-trace output indicates the potential evolution of hydrologic drought conditions from an initial condition with different 90-day precipitation forecasts. Figure 11 is an example of the flow-trace output for the plotting positions. The estimated unaltered streamflows and depleted streamflows can be examined by using similar graphs to see if and when these flows may fall below desired levels. Information about the time horizon for a potential low-flow excursion can be used by a drought committee to evaluate deadlines for implementing drought-mitigation measures. For example, if an April drought projection reveals a substantial number of flow traces that are below a desired streamflow value in September, a drought committee may want to wait for a revised projection estimate from May. If, however, the April projection reveals a substantial number of flow traces that are below a desired streamflow value in May, then a drought committee may want to make recommendations for implementing droughtmitigation measures immediately. Such decisions should be made with the knowledge that drought projections will change with each passing month as the initial conditions and precipitation forecasts change.

The flow-duration-curve statistics and quantile-plot statistics both provide quantitative information about risks for low-flow excursions. Once the drought-projection analysis has been run, the user can examine the output table or a graph of output-table results to determine the probability that estimated unaltered streamflows and streamflows with depletions are below selected flow targets. Graphs are a good visual summary that provide a better overall assessment, but the table output is more useful for determining precise probabilities for a given flow value. If the flow-duration option is selected with a percentage output, then the percentages on the figure or table indicate the risk for a flow being above a given value, and the risk of a flow being below that value would be 100 minus the duration percentile. If the quantile-plot statistics are selected, however, the percentiles would be reversed. If fractions were selected for outputs rather than percentages, the range of probabilities would be between zero and one.

For example, figure 12 shows selected results of the projection-analysis traces in figure 11 as flow-duration curves. In figure 12, the samples of monthly minimum streamflows for each month are selected, ranked, and assigned probabilities by using the Cunnane formula (eq. 5). The above-normal, normal, and below-normal precipitation forecasts for the 70.5th-percentile starting position (defined herein as the high-wet, high-normal, and high-dry scenarios, respectively) and the below-normal precipitation forecast for the 35.8th-percentile starting position (defined herein as the low-dry scenario) were selected as examples for comparison of low-flow risks. To assess the risk of a low-flow excursion, select a low-flow limit on the Y (vertical) axis, follow that value across to a data point, and read the probability from the $\mathrm{X}$ (horizontal) axis on figure 12. For example, if a low-flow excursion were hypothetically defined as any flow below $0.5 \mathrm{ft} 3 / \mathrm{s} / \mathrm{mi}^{2}$, then the X-axis values on the flow-duration curve of estimated unaltered streamflows for the low-dry scenario are about 99.6, 76.3, 38.5, and 32.7 percent for June, July, August, and September, respectively. This indicates that the risk for a flow excursion below $0.5 \mathrm{ft} 3 / \mathrm{s} / \mathrm{mi}^{2}$ may be about $0.04,23.7,61.5$, and 67.3 percent, respectively. The minimum values on the flow-duration curves for the high-wet, highnormal, and high-dry scenarios in June do not fall below this hypothetical low-flow target. In this case, the risk of a flow excursion is estimated from the flow duration of the minimum value (about 99.76 percent) to be less than 0.24 percent. As with the low-dry scenario, the risks for the hypothetical flow excursion increase for the high-wet, high-normal, and high-dry scenarios as the summer season progresses in this example.

The flow-duration curve (or quantile-plot) statistics also provide general drought-mitigation planning information for decisionmakers. For example, comparison of the high-wet, high-normal, and high-dry scenario results with the low-dry scenario results indicates that the effect of the starting position may be more important than the precipitation forecast for predicting potential low-flow excursions in this example (fig. 12). 

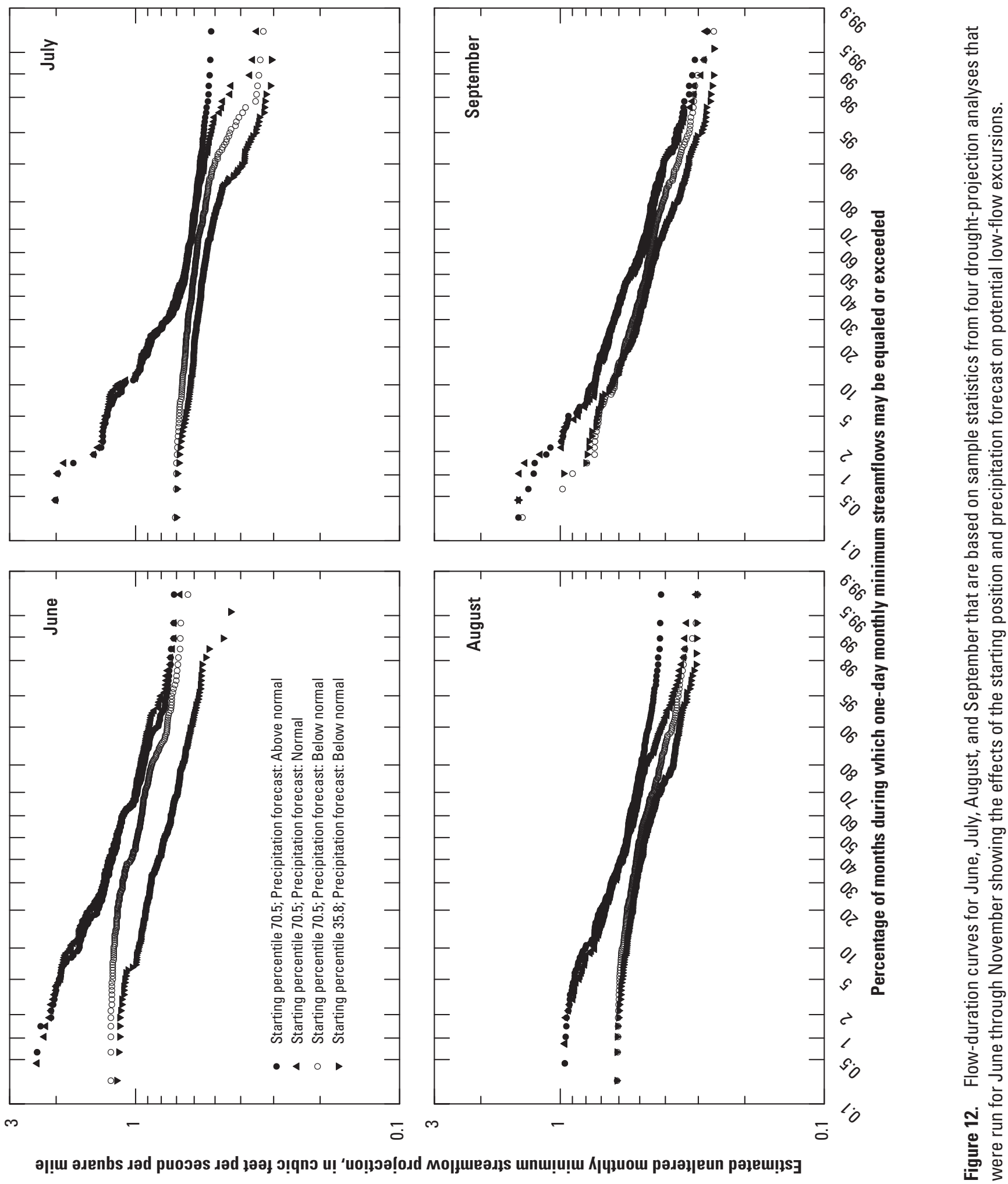

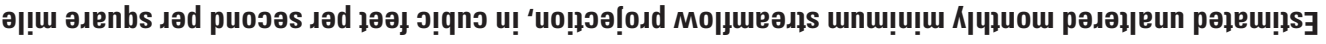
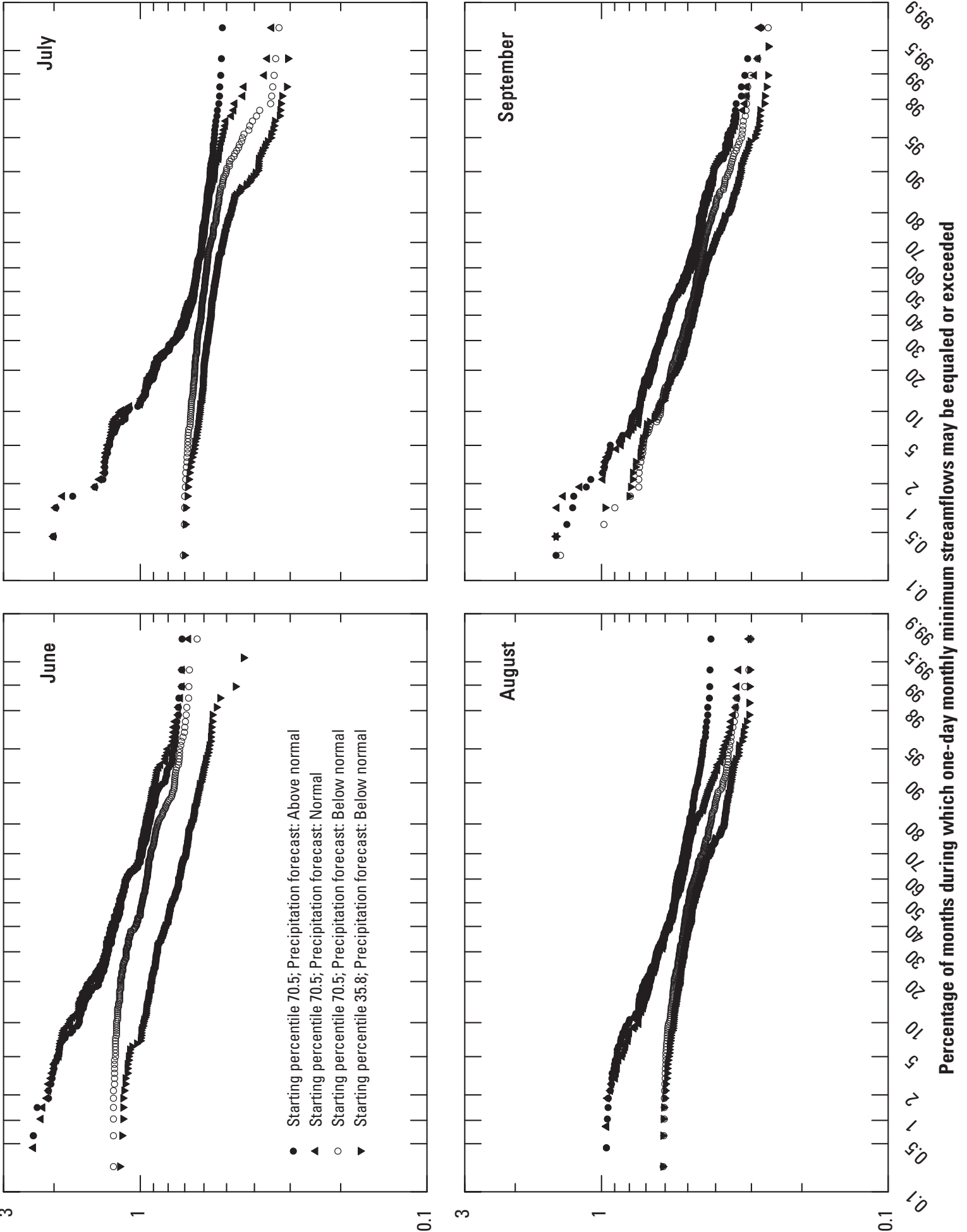
Many of the low flows in the low-dry scenario results are less than flows for the same durations in the other scenarios, and percentages of low-flow excursions are greater in the low-dry scenario results than in the other scenarios. These graphs also show that the magnitude of flows and risk for low-flow excursions among the different scenarios converge substantially in the fourth month of the drought projection (fig. 12). This trend continues into the fifth and sixth months of this example drought projection.

Comparisons of the high-normal and high-dry scenario results from this example also indicate that the monthly minimum flows are much higher under the high-normal scenario than the higher flows estimated in the high-dry scenario, but the magnitudes of the lowest flows are not substantially different (fig. 12). Among monthly minimum unaltered streamflows, the risks for a hypothetical low-flow excursion (below $0.5 \mathrm{ft}^{3} / \mathrm{s} / \mathrm{mi}^{2}$ ) in August are much less for the high-normal (about 31 percent) than for the high-dry (about 51 percent) scenario. However, the differences in the magnitudes of these unaltered low flows are small and may be irrelevant if the magnitudes of the depletions are large (fig. 13). For example, if depletions are calculated from three wells with the same response coefficients as hypothetical wells 1,2 , and 3 in figure 1, and pumping rates for these wells follow the municipal-demand pattern with average annual withdrawals of about $1.5 \mathrm{Mgal} / \mathrm{d}$ and peak monthly withdrawals of about $2 \mathrm{Mgal} / \mathrm{d}$ in July, then the risks for low-flow excursions would be more than 99 percent for the high-dry and high-normal scenarios (fig. 13). The risk of a zero-flow condition is about 4.2 percent for the high-dry scenario and about 3 percent for the high-normal scenario at this hypothetical stream site. If, however, these pumping rates are reduced by 20 percent in June and July, the risk of a lowflow excursion would be more than 99 percent for the high-dry and about 90 percent for the high-normal scenarios. However, the risk for a zero-flow condition is reduced to less than 0.24 percent for both the high-dry and high-normal scenarios.

\section{Limitations}

The drought-projection analyses are planning-level estimates that depend on many factors. The drought-projection analyses share many of the same limitations described for the retrospective streamflow analyses. These uncertainties apply to model-calculated response coefficients, compression of streamflow-depletion responses into a 1-year annual cycle, the assumption of linearity in the response of streamflows to depletions, the relation between streamflows at the site of interest and the point of maximum depletions, and the validity of the assumption that the historical data may represent future conditions. These uncertainties affect the quality of the unaltered-flow estimates and the potential effects of pumping on streamflows during drought conditions. The estimated unaltered streamflows are subject to errors and uncertainty in the underlying measurements and in analytical methods. Hydrologic measurement and modeling methods are most uncertain at the extremes. As with the limitations described for the retrospective streamflow-depletion analyses, the calculations done for the drought-projection analyses are most uncertain near the point of zero flow. Original streamflow records from the index gage and site of interest are subject to random and systematic measurement errors (Granato, 2010). Methods used to extend or augment flow records include considerable uncertainties (Granato, 2009). For these reasons, the results of the projection analyses should be viewed as comparative analysis tools rather than as quantitative prediction tools.

Interpretation of the results of the drought projection analysis also is based on the standard stationarity assumption that historical hydrologic records can be used to estimate future conditions (Lins and Slack, 1999; 2005; McCabe and Wolock, 2002; Hayhoe and others 2007; Milly and others, 2008; Brekke and others, 2009; Lins and others, 2010; Hodgkins and Dudley, 2011; Galloway, 2011). Although climate analyses indicate the possibility that the frequency and severity of droughts may change, the drought projection analysis module in the HyDroDSS is designed to estimate a population of short-term (1-6 months) hydrologic conditions. Furthermore, the drought-projection analysis module is designed to be used on a monthly basis and to incorporate new data as it becomes available. Therefore, the drought-projection analysis module in the HyDroDSS is designed to use adaptivemanagement approaches recommended for water-resources planning (Brekke and others, 2009).

\section{Use of the HydroDSS Graphical User Interface}

The HyDroDSS was developed as a Microsoft Access ${ }^{\circledR}$ database application to facilitate storage, handling, and use of hydrologic datasets with a simple graphical user interface. The program is implemented in the database by using the Microsoft $\mathrm{VBA}^{\circledR}$ programming language. The program has a menu-driven graphical user interface to facilitate data entry, processing, and output. When the HyDroDSS loads, a splash screen is launched to identify the program, sponsorship, and version of the application. This screen automatically leads to the Main Menu form (fig. 14). The main menu provides an explanation, version information, and a disclaimer. The main menu also provides a combobox to select the site of interest (the Hunt River near East Greenwich, R.I., on fig. 14). Once the site of interest is selected, the user can check data, manage data, or run one or more analyses. The user can exit the HyDroDSS by closing the database application or clicking the "Exit the DSS" button on the main menu. 


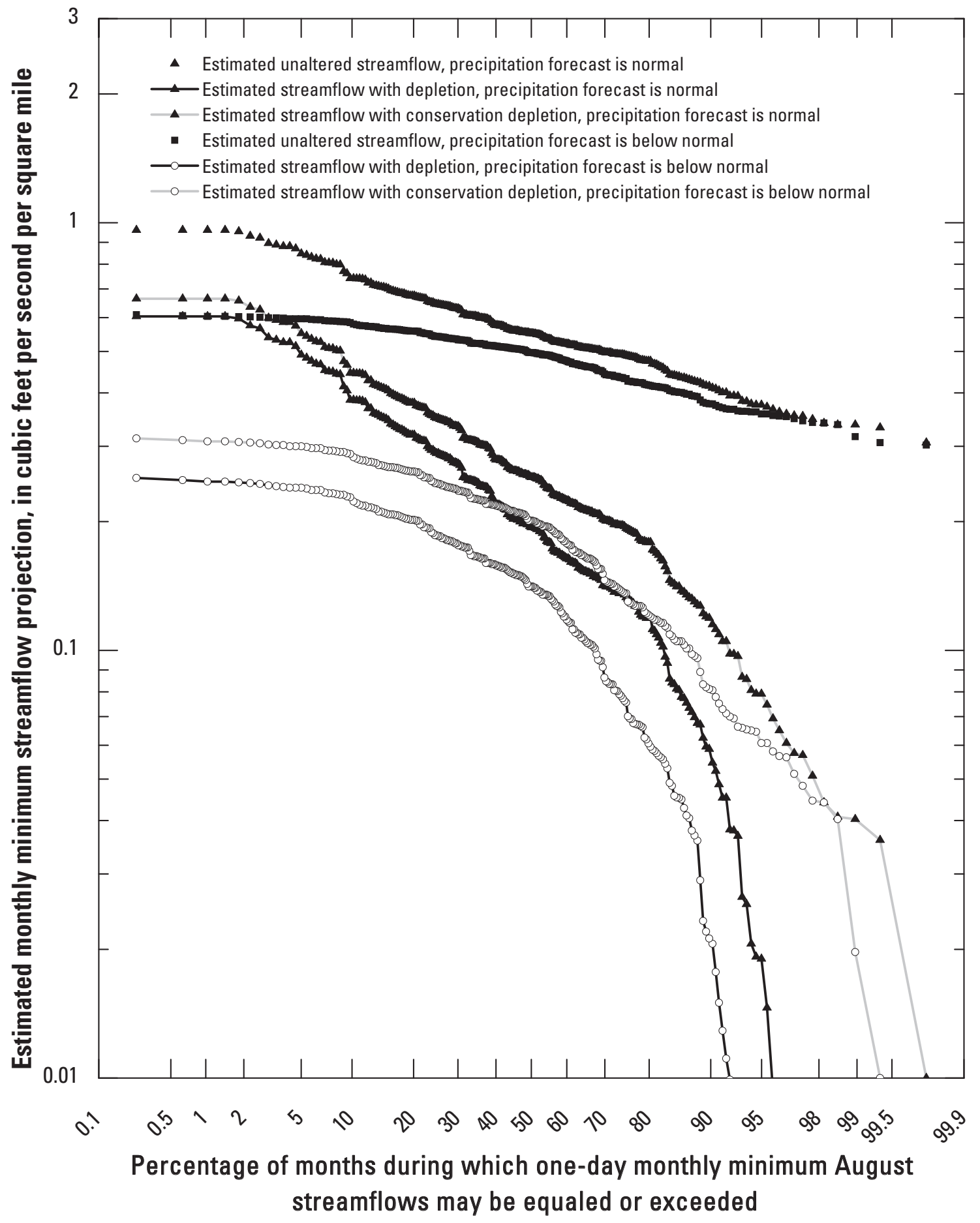

Figure 13. Flow-duration curve outputs for August from a June-through-November drought-projection analyses with and without streamflow depletions. The scenarios are based on a beginning monthly minimum flow duration of 70.5 percent in May with normal or below-normal precipitation forecasts. Depletions are caused by pumping at wells with the same response coefficients as hypothetical wells 1,2 , and 3 in figure 1 . Pumping rates for these wells follow the municipal-demand pattern defined by Granato and Walter (2011) with average annual withdrawals of about 1.5 million gallons per day and peak monthly withdrawals that are about 2 million gallons per day in July. Pumping rates for conservation-depletion values represent a 20-percent reduction in each monthly pumping rate, which is implemented in June. 


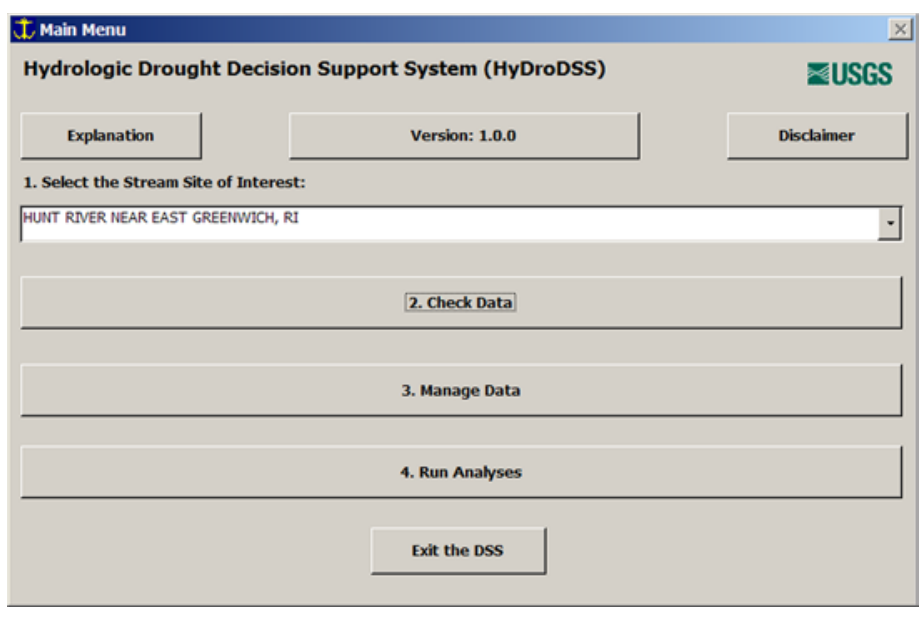

Figure 14. "Main Menu" form for the hydrologic drought decisionsupport system.

\section{Check Data}

The "Check Data" command button on the main menu (fig. 14) provides a method for assessing the data in the database for the selected stream site of interest to see if the data is current and complete. The HyDroDSS can do historical analyses with older data. You can do a rank correlation analysis, a retrospective streamflow-depletion analysis, or a historical drought-projection analysis without current data. You will, however, need to update the hydrologic data to do a drought-projection analysis from the current month. Checking the status of historical data also is important for the rank correlation and retrospective streamflow-depletion analyses because these analyses require an uninterrupted series of values within a common period of record. Short periods of estimated record can be used to fill any gaps in measured data for these analyses.

When the "Check Data" button is clicked, the database application runs five queries to identify and enumerate associated data and outputs this data to the information form (fig. 15). The first query enumerates the estimated unaltered streamflow data for the selected site of interest. This query obtains the starting and ending dates, the number of expected records (based on the difference in dates), and the number of cataloged values of estimated unaltered streamflow at the selected site of interest. The second query enumerates the measured streamflow data for all index streamgages associated with the selected site of interest. This query obtains the starting and ending dates, the number of expected records (based on the difference in dates), and the number of cataloged values of measured streamflow at each index site. The third query enumerates the measured monthly groundwater-level data for all USGS monitoring wells associated with the selected site of interest. This query obtains the starting and ending dates, the number of months in the period of record, and the number of cataloged groundwater-level values. The fourth query enumerates the measured monthly precipitation-volume data for all National Weather Service rain gages associated with the selected site of interest. This query obtains the starting and ending dates, the number of months in the period of record, and the number of cataloged monthly precipitation-volume values. The fifth query enumerates the measured monthly water-pumping data for all production sites associated with the selected site of interest. This query obtains the starting and ending dates, the number of months in the period of record, and the number of cataloged monthly pumping-volume values.

Once the queries are run, the results are sent to the "Output Information" form (fig. 15). When the form is opened, the focus is set on the output textbox, and the text is highlighted in black (fig. 15A). While the text is highlighted, the output information can be copied from the form by right-clicking the text and selecting "Copy" on the popup menu or by clicking the Ctrl-C keyboard combination. This information can then be pasted into another application. To read the information within the form, click the large font-size option, and view the output information in the textbox by using the scroll bar on the right (fig. 15B). The results can be saved to an output file by clicking the "Save Output" button, which will launch a common-dialog form (fig. 16) for saving the results in a userspecified text file. Once you are done reviewing the information, click the "Close" button to return to the main menu.

\section{Manage Data}

The "Manage Data" command button on the main menu (fig. 14) provides methods to edit and add data to the database for the selected stream site of interest. Clicking the "Manage Data" command button will open the "Data Management Menu" (fig. 17), which has nine options for editing and adding different types of hydrologic and pumping data. The "Data Management Menu" has command buttons that will let you "Exit the DSS," go to one of the nine specified data management forms (found under the heading "Select Data Type"), or return to the "Main Menu." The "Data Management Menu" is context sensitive because the "Explanation" and target data-management form change as you select different datamanagement options (found under the heading "Select Data Type"). For example, figure 17A shows the "Explanation" for the "Precipitation Data," and the command button reads "Go To Precipitation Data Form" because the "Precipitation Data" option is selected. Figure 17B, however, shows the explanation for "Groundwater Level Data," and the command button reads "Go To Groundwater Data Form" because the "Groundwater Level Data" option is selected. Once one of the option buttons under the heading "Select Data Type" is selected and the "Go To...Form" command button is clicked, you will be directed to the selected data-management form. 


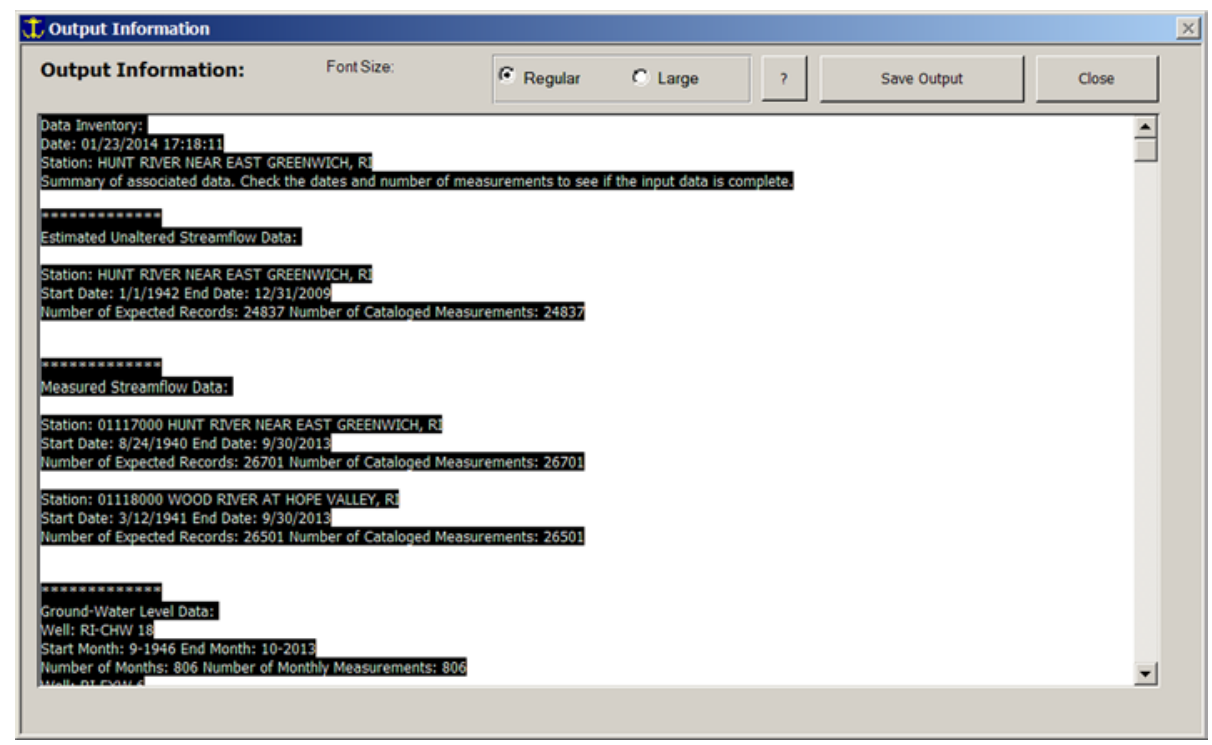

$B$

\begin{tabular}{l} 
Th Output Information \\
\hline Output Information: \\
\begin{tabular}{|l} 
Data Inventory: \\
Date: $01 / 23 / 2014$ 17:18:11 \\
Station: HUNT RIVER NEAR EAST GREENWICH, RI \\
Summary of associated data. Check the dates and number of measurements to see if the input data is complete. \\
$* * * * * * * * * * * *$ \\
Estimated Unaltered Streamflow Data: \\
Station: HUNT RIVER NEAR EAST GREENWICH, RI \\
Start Date: $1 / 1 / 1942$ End Date: $12 / 31 / 2009$ \\
Number of Expected Records: 24837 Number of Cataloged Measurements: 24837 \\
************** \\
Measured Streamflow Data: \\
Station: 01117000 HUNT RIVER NEAR EAST GREENWICH, RI \\
Start Date: $8 / 24 / 1940$ End Date: $9 / 30 / 2013$ \\
Number of Expected Records: 26701 Number of Cataloged Measurements: 26701 \\
Station: 01118000 WOOD RIVER AT HOPE VALLEY, RI \\
Start Date: $3 / 12 / 1941$ End Date: $9 / 30 / 2013$ \\
Number of Expected Records: 26501 Number of Cataloged Measurements: 26501
\end{tabular} \\
\hline
\end{tabular}

Figure 15. "Output Information" form with the results of the check-data analysis showing $A$, the initial view with text selected for copying and $B$, the large-text selection for reading on the screen. 


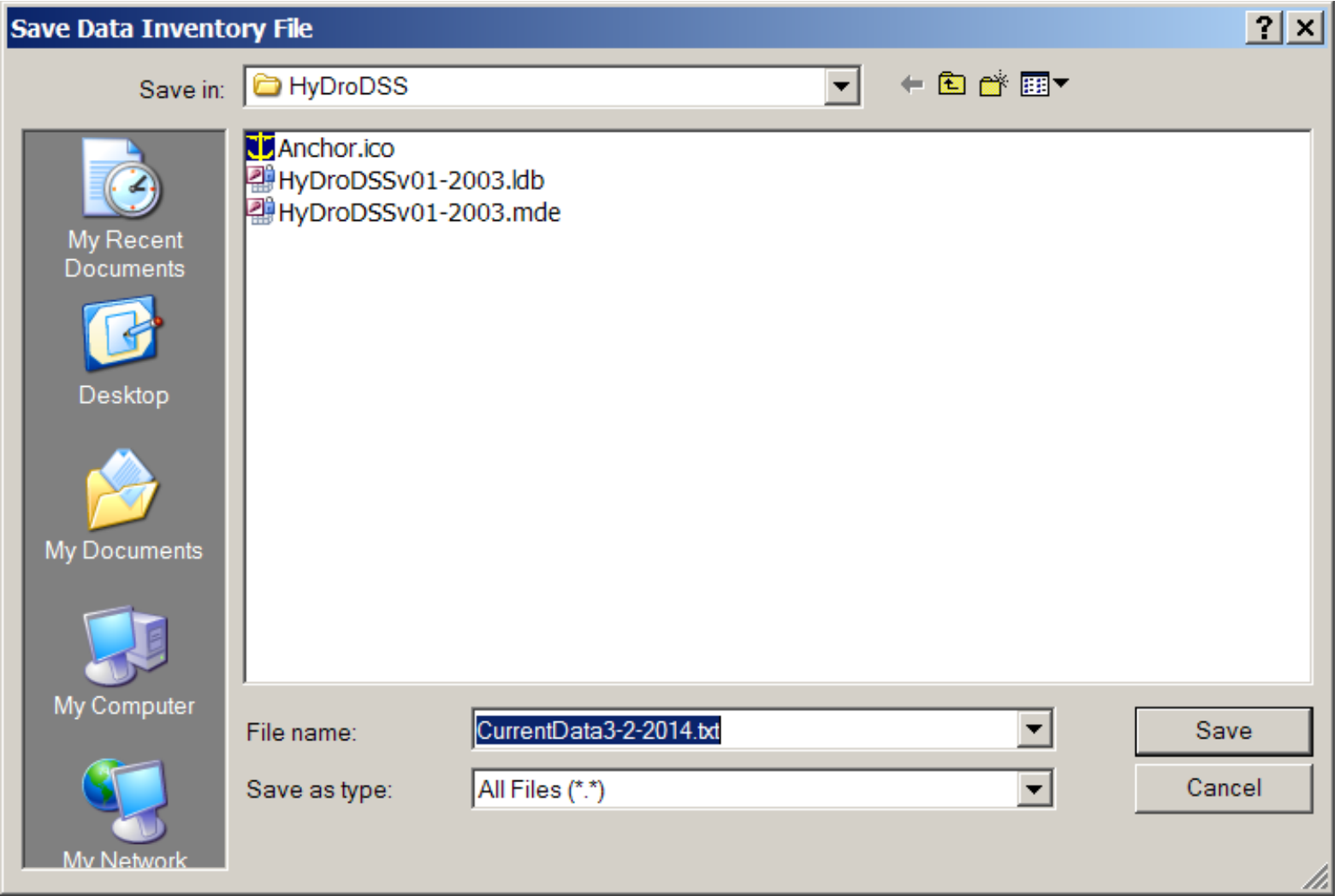

Figure 16. Common dialog form for saving the data inventory file from the check-data analysis. 
$\boldsymbol{A}$

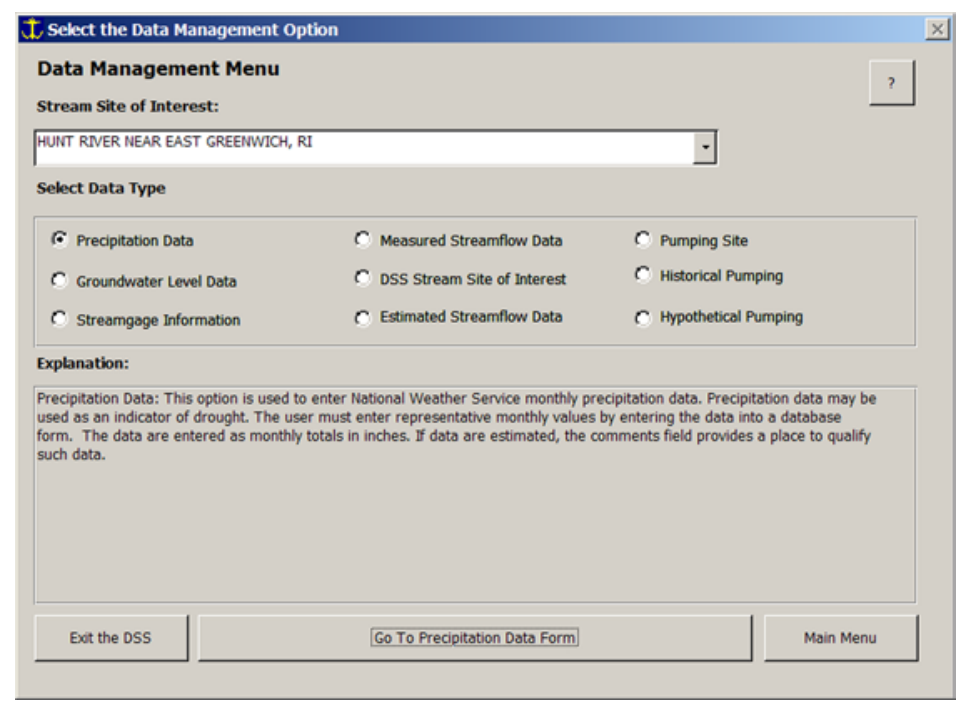

B

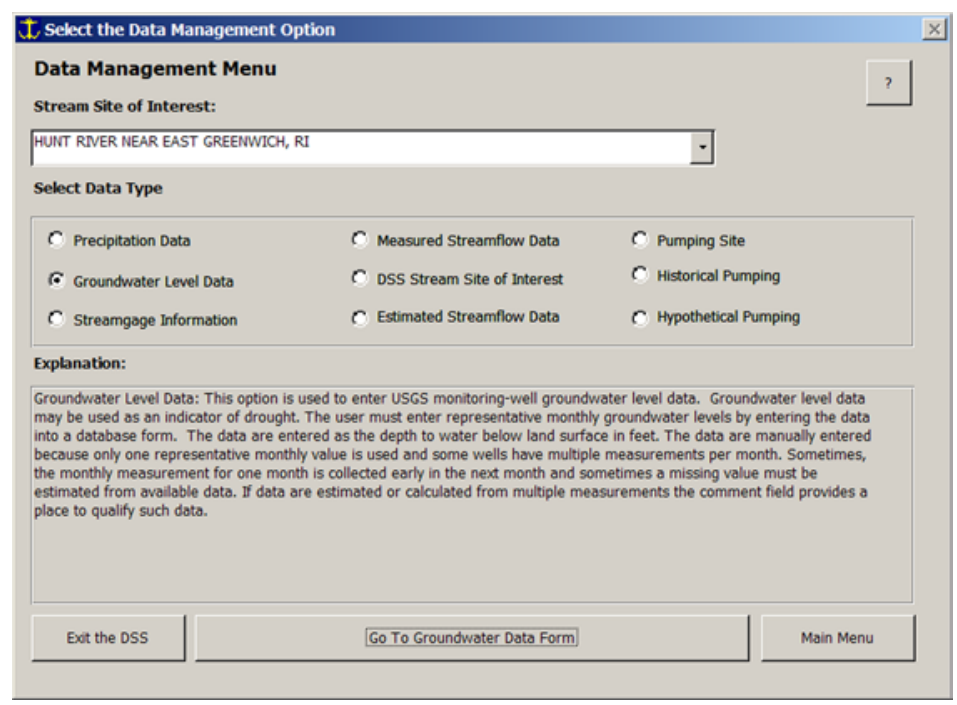

Figure 17. "Select the Data Management Option" form showing the "Data Management Menu" with $A$, "Precipitation Data" and $B$, “Groundwater Level Data" selected. 
All the data-management forms share three common features. Each form has a combobox in the upper-left quadrant for selecting the site associated with the input data. For example, the "Enter Precipitation Data" form showing the "National Weather Service Monthly Precipitation Data" has a combobox, "Select Weather Station" for selecting the desired weather station (fig. 18). Once a station is selected, all data that is entered is associated with the selected station. Each data-management form also has a help button (denoted by a question mark "?") in the upper-right quadrant. The help button opens a form with information about the type of data on the current data-management form. Each data-management form also has also has a "Close" button in the upper right quadrant, which will close the form and return to the "Data Management Menu." The data-management forms also have one or more help buttons (denoted by a question mark "?") that provide specific information about one or more data elements on a data-entry tab.

\section{Precipitation Data}

The "National Weather Service Monthly Precipitation Data" form is used to enter monthly precipitation data. Precipitation data may be used as a potential indicator of developing hydrologic drought conditions and as means of estimating the initial unaltered streamflow value for the drought-projection analysis. This data form (fig. 18) has two tabbed pages for data entry. The first tab titled "Data Values" is an interface for entering or editing total monthly precipitation totals in inches under the "Precipitation Value:" heading. The second tab titled "Weather Station Information" is an interface for entering or editing precipitation-monitoring-station information.

When this precipitation data form loads, the year, month, and precipitation total is displayed for the last month for which precipitation data have been recorded in the database for the selected station. Data for the preceding five months also are displayed. The "Move by Months" option on the lower left of the precipitation data-entry page can be used to set the scroll rate through the data. You can choose to scroll through the data in intervals of $1,3,6$, or 12 months at a time. The "Move Forward" and "Move Backward" command buttons will change the data in the input boxes as specified by the "Move by Months" selection. As you scroll through the data, missing values will be highlighted in yellow (fig. 18B). If you scroll beyond the current month, the data fields for future months will be grayed out and locked (fig. 18C). To enter or update data, type the monthly precipitation total in the associated "Precipitation Value:" textbox and any associated comments in the "Comment:" textbox. A comment may be used if some or all of the monthly precipitation total is estimated from data collected at another station. Once you enter or edit data, you may save the data by clicking the "Accept Updates" button. If you made a data-entry mistake but did not save these changes by clicking the "Accept Updates" button, you can undo edits and entries by clicking the "Cancel Changes" button.

The "Weather Station Information" tab on the "National Weather Service Monthly Precipitation Data" form provides an interface for editing or entering information about the weather stations cataloged in the database (fig. 18D). This data-entry tab provides data fields for recording a "NWS Station Name*:," a "Station Number:," a web address, and any "Comments:" that you may have about the data station. The station name is the information that will appear in the comboboxes identifying the precipitation-monitoring station ("Select Weather Station:") on this precipitation-data form, the "Rank Correlation Analysis of Hydrologic Drought Variables" form, and the "Hydrologic Drought-Projection Analysis" form. The station name is mandatory and must have at least 1 alphanumeric character and at most 65 characters including spaces between other characters. By default, the "Weather Station Information" tab is loaded with the "Edit Current" option selected. The "Edit Current" option is used to change data associated with the precipitation-monitoring station in the combobox at the top of the form. To enter a new station, click the "Add New" option. This option will clear the existing data fields for information about a new monitoring site. The "Accept Updates" command button will either update the information about the selected station or add the new station to the database and then update the station-selection combobox to reflect the changes. Leading and trailing spaces in input data are trimmed when the "Accept Updates" command button is clicked. If a new station is entered, this button also will clear the data on the "Data Values" tab and set the last date to the current month.

\section{Groundwater-Level Data}

The "Enter Groundwater Data" form showing the menu "Groundwater Well Data" is used to enter monthly groundwater-level measurements made at long-term USGS monitoring wells. Groundwater-level data may be used as a potential indicator of developing hydrologic drought conditions and as a means of estimating the initial unaltered streamflow value for the drought-projection analysis. The "Groundwater Well Data" form (fig. 19) has two tabbed pages for data entry. The first tab "Water Levels" is an interface for entering or editing the monthly groundwater level in feet below land surface. The second tab titled "Well Information" is an interface for entering or editing groundwater-monitoring-well information.

When the "Groundwater Well Data" form loads, the year, month, and groundwater level in feet below land surface are displayed for the last month for which groundwater-level data have been recorded in the database for the selected monitoring well. Data for the preceding five months also are displayed. The "Move by Months" options on the lower left of the "Water Levels" data-entry page can be used to set the scroll rate through the data. You can choose to scroll through the data in intervals of 1, 3, 6 or 12 months at a time. The "Move Forward" and "Move Backward" command buttons will change the data in the input boxes as specified by the "Move by Months" selection. As you scroll through the data, missing values will be highlighted in yellow (fig. 19B). If you scroll beyond the current month, the data fields for future months 

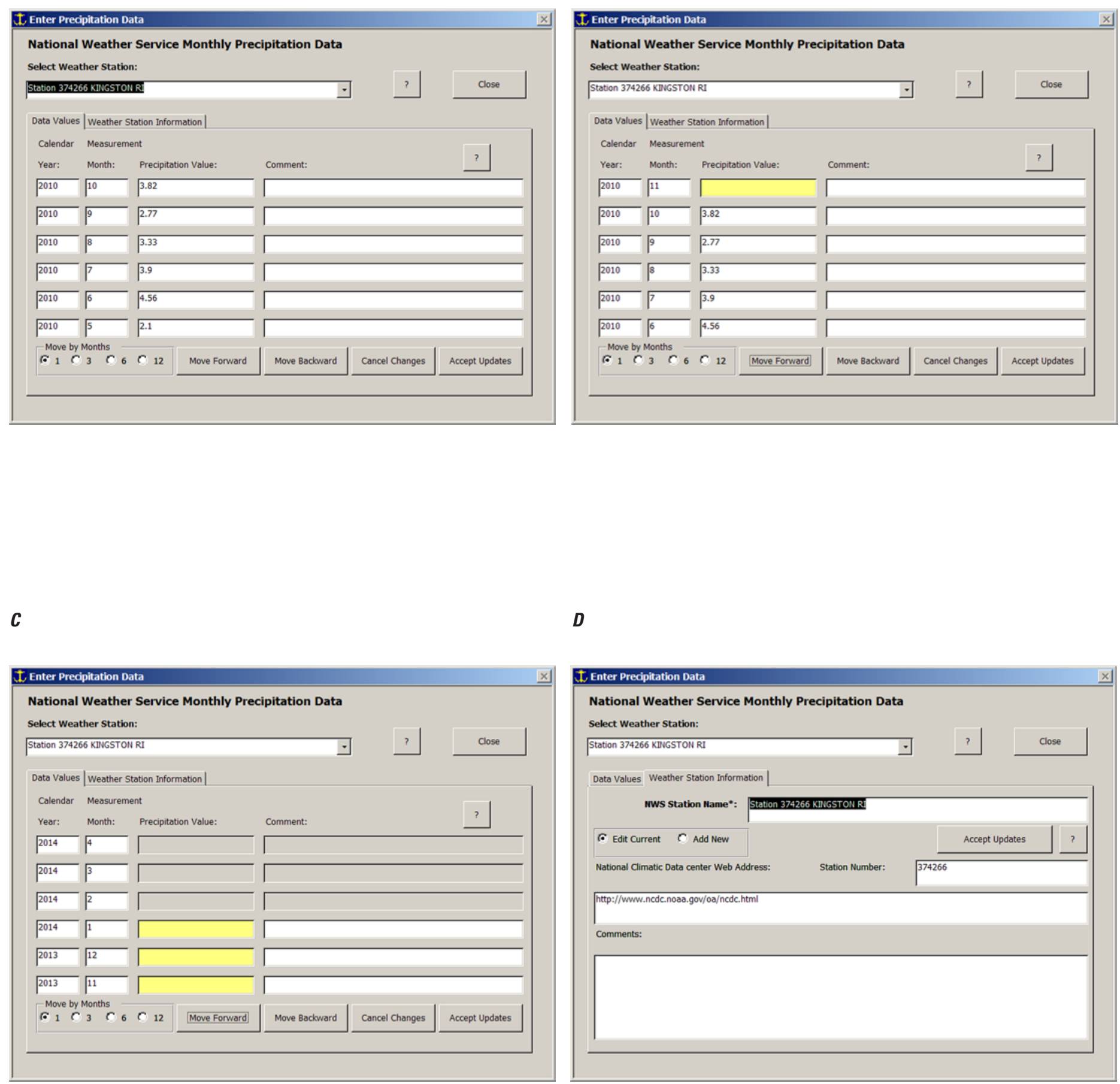

Figure 18. "Enter Precipitation Data" form showing $A$, the last value entered in the database for station $374266, B$, the highlighted field showing missing data for November 2010, $C$, the grey-colored and locked fields for future values (as of June 2014), and $D$, the weatherstation data page. 
A

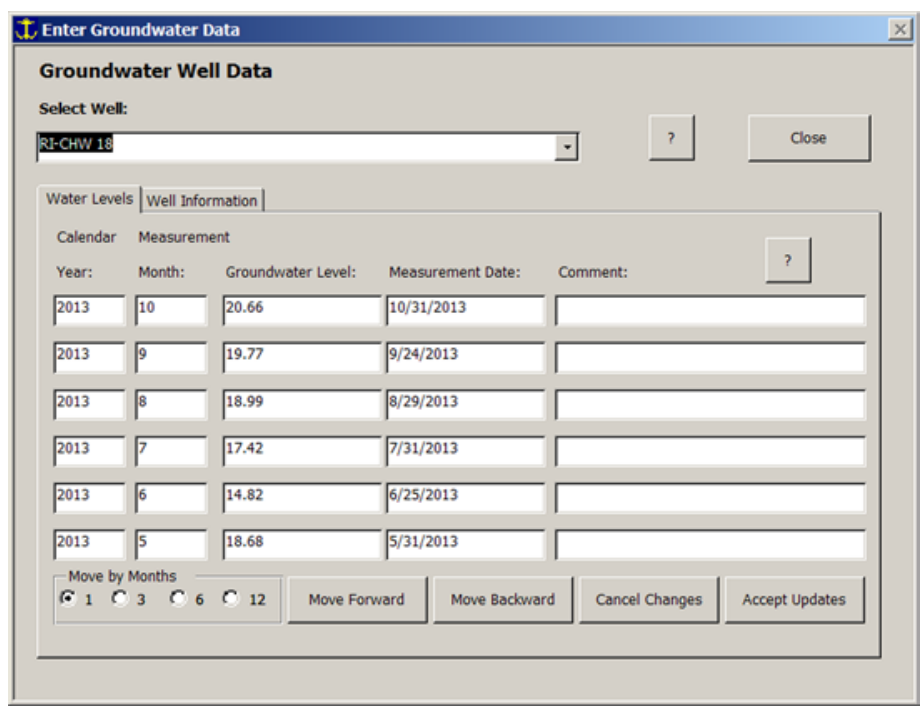

B

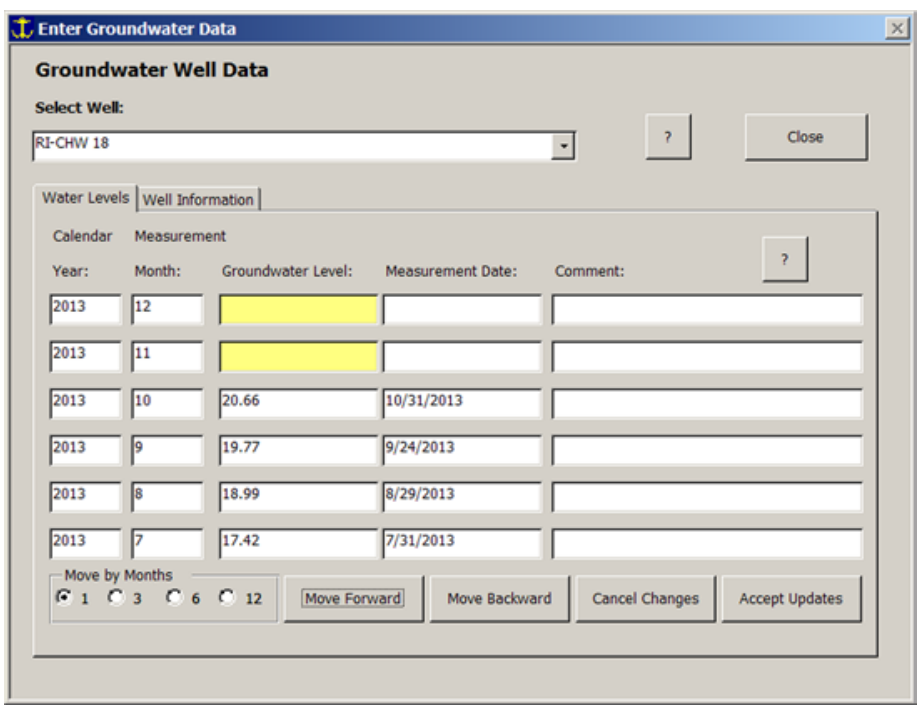

C

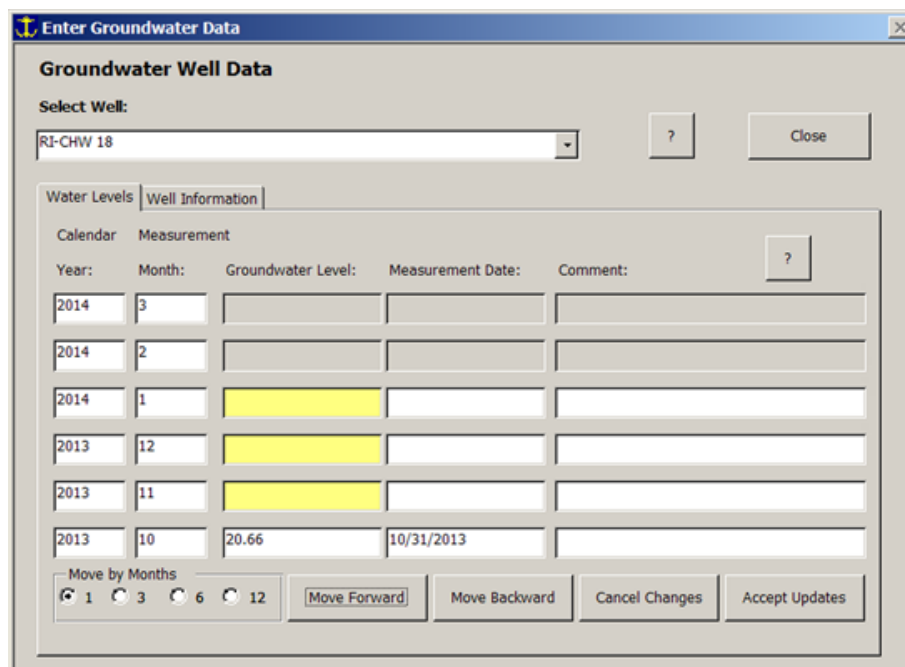

$\boldsymbol{D}$

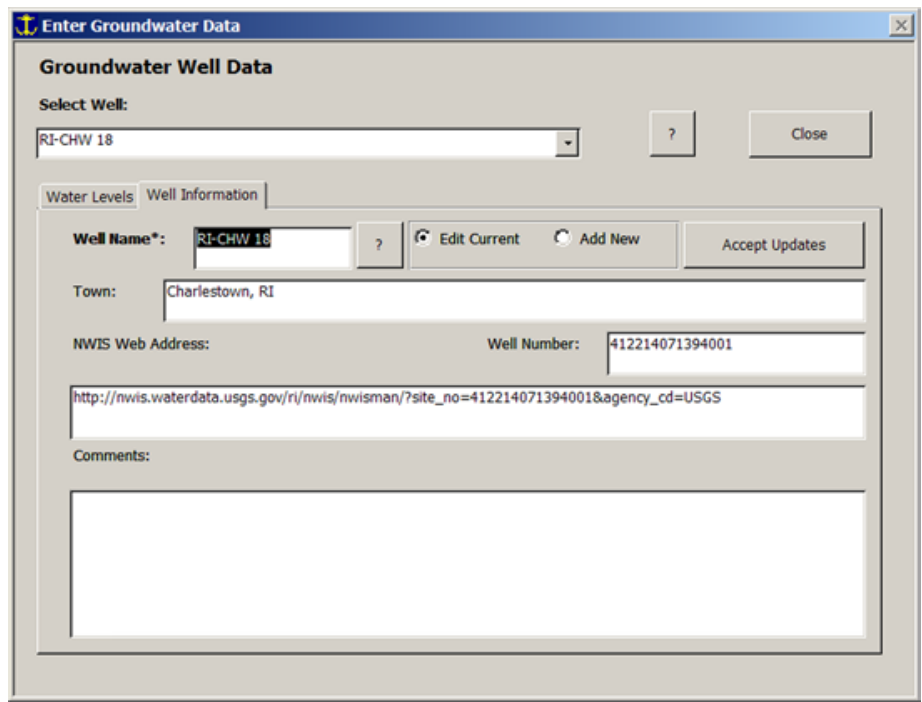

Figure 19. "Enter Groundwater Data" form showing the menu "Groundwater Well Data" with the "Water Levels" tab with $A$, the last value entered in the database for Well RI-CHW 18, $B$, the highlighted field showing missing data for November 2013, and $C$, the grey-colored and locked fields for future values (as of February 2014), and D, the "Well Information" tab with the monitoring-well name, town, National Water Information Service (NWIS) Web address, U.S. Geological Survey (USGS) well number and (empty) comment box. 
will be grayed out and locked (fig. 19C). To enter or update data, type the monthly groundwater level in the associated "Groundwater Level" textbox and any associated comments in the "Comment" textbox. A comment may be used if the monthly groundwater level is an average or median of multiple measurements, or if the value is estimated from data collected at another monitoring well. Once you enter or edit data, you may save the data by clicking the "Accept Updates" button. If you made a data-entry mistake and did not save these changes by clicking the "Accept Updates" button, you can undo edits and entries by clicking the "Cancel Changes" button.

The "Well Information" tab on the "Groundwater Well Data" form provides an interface for editing or entering information about the USGS monitoring wells cataloged in the database (fig. 19D). This data-entry tab provides data fields for recording a well name, a well number, an NWIS Web address, and any comments that you may have about the monitoring well. The well name is the information that will appear in the comboboxes identifying the groundwater-level monitoring well on the groundwater-level data form, the rank correlation analysis form, and the drought-projection analysis form. The well name is mandatory and must have at least 1 alphanumeric character and at most 65 characters including spaces between other characters. By default the "Well Information" tab is loaded with the "Edit Current" option selected. The "Edit Current" option is used to change data associated with the monitoring well in the combobox at the top of the form. To enter a new monitoring well, click the "Add New" option. This option will clear the existing data fields for information about a new monitoring well. The "Accept Updates" command button will either update the information about the selected station or add the new station to the database and then update the station-selection combobox to reflect the changes. Leading and trailing spaces in input data are trimmed when the "Accept Updates" command button is clicked. If a new station is entered, this button also will clear the data on the "Data Values" tab and set the last date to the current month.

\section{Streamgage Data}

The "Enter USGS Streamgage Information" form showing the "USGS Streamgage" data form is used to enter information and data about each streamgage in the HyDroDSS. A streamgage may be a site of interest and (or) an index gage that is used to estimate streamflows at the site of interest. Streamflow data associated with each streamgage may be used as a potential indicator of developing hydrologic drought conditions and as a means of estimating the initial unaltered-streamflow value at the site of interest for the drought-projection analysis. The streamgage-data form (fig. 20) has two tabbed pages for data entry. The first tab titled "Gage Information" is an interface for entering or editing information about the gage. The second tab titled "Index Gage Information" is visible and active for editing only when a streamgage is designated as an index site (when the checkbox for "Index Site" is checked; fig. 20A).
The "Gage Information" tab provides textboxes for entering or editing the "Name," the USGS "Gage Number*," the contributing "Drainage Area," and a "Description" of the selected streamgage. The "Gage Information" tab also has two checkboxes. The checkbox labeled "Index Site" is checked if the gage is an index site for prediction conditions at a site of interest. The second checkbox labeled "Site of Interest" is checked if the gage is a site of interest for doing one or more hydrologic drought analyses. By default, the "Gage Information" tab is loaded with the "Edit Current" option selected. The "Edit Current" option is used to change data associated with the streamgage in the combobox at the top of the form. To enter a new streamgage, click the "Add New" option. This option will clear the existing data fields for information about a new streamgage. The "Accept Updates" command button will either update the information about the selected station or add the new station to the database and then update the station-selection combobox to reflect the changes.

The "Index Gage Information" tab provides textboxes for entering a multisegment regression model for predicting streamflows at a site of interest from measured streamflows at the index gage. Each index gage can be used to predict streamflows at one or more sites of interest. You can enter regression equation coefficients for a one-, two-, or three-segment regression model. The HyDroDSS is designed to use regression models developed by using the common logarithms of streamflow values. The regression equations can be developed by using the Streamflow Record Extension Facilitator (SREF) (Granato, 2009), the Kendall-Theil Robust Line (KTRLine) program (Granato, 2006), or some other program. First, select a site of interest from the combobox "Site of Interest" on the "Index Gage Information" tab. Second, under the "No. of Equation Segments" option frame, select an option to specify the number of segments ("One," "Two," or "Three") in the regression model. Third, enter the intercept, slope, and maximum value of each segment of the regression model. To save the index-gage data, click the "Accept Updates" buttons on both pages of the form. You may repeat the process for each additional site of interest.

\section{Streamflow Data}

The "USGS Streamflow Data (Measured)" form is used to import long-term records of daily mean discharge values for selected Index Streamgages whose data have been entered into the HyDroDSS. The streamflow data may be used as a potential indicator of developing hydrologic drought conditions and as means of estimating the initial unaltered streamflow value at the site of interest for the drought-projection analysis. This form (fig. 21) has three data-input command buttons labeled "1. Read Input File," "2. Import Data," and "3. Update Monthly Minimums." The form also has a "File Type" option box, a textbox to display the input-data file location, a series of textboxes to display input-file metrics and HyDroDSS table metrics for each streamgage, and two "View Data" command buttons. This form has a command button for deleting all 


\section{$\boldsymbol{A}$}

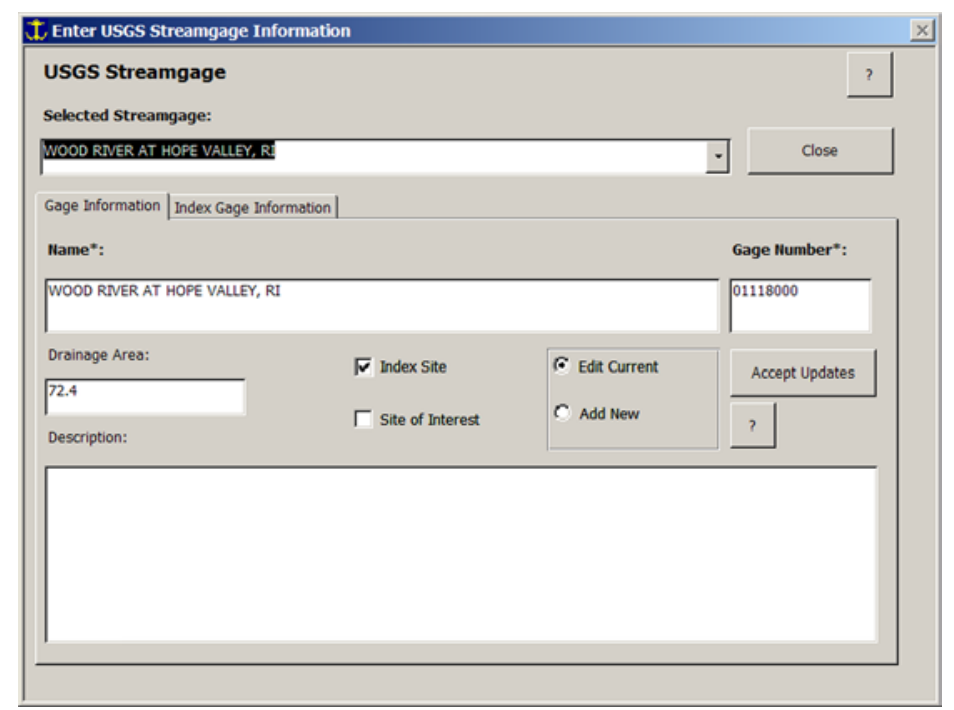

B

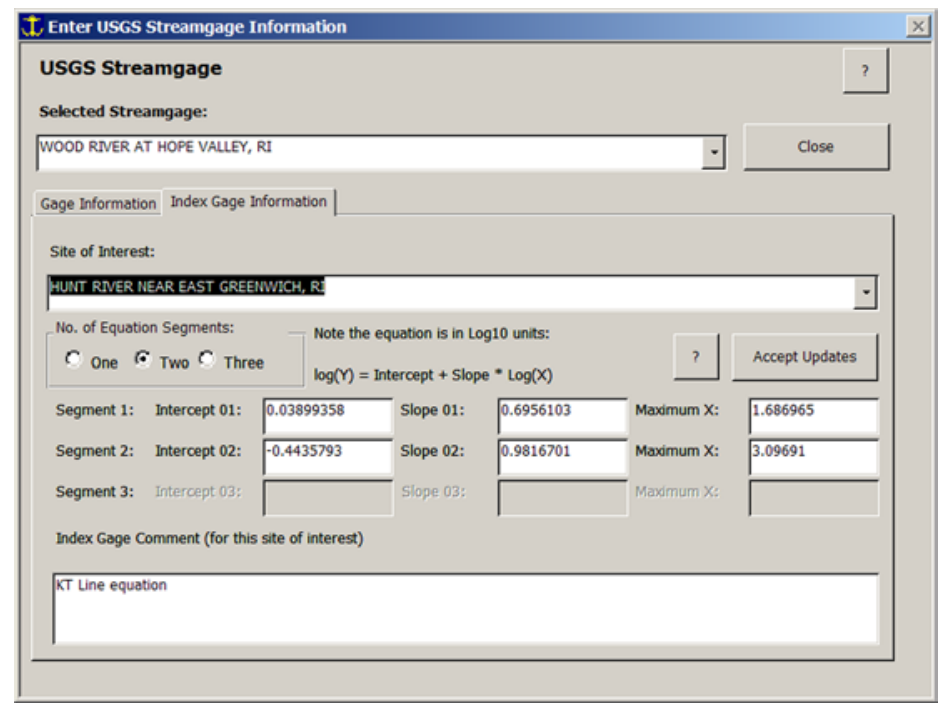

Figure 20. "Enter USGS Streamgage Information" form showing the USGS Streamgage form with $A$, the "Gage Information" tab and $B$, the "Index Gage Information" tab. 
A

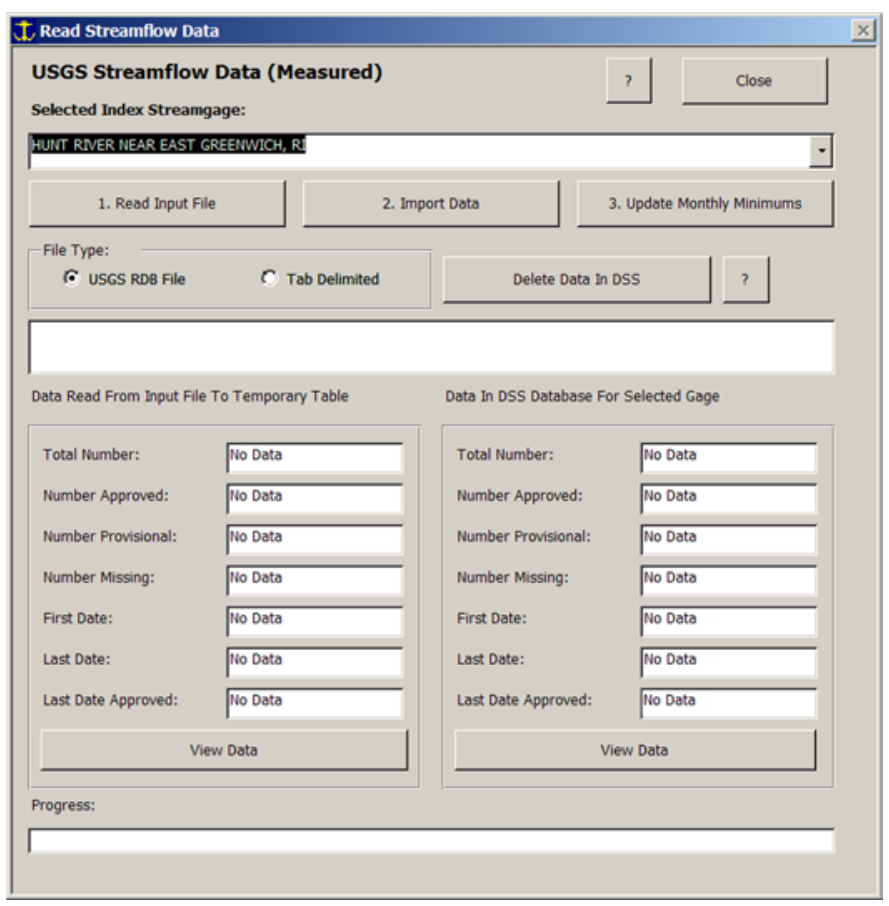

C

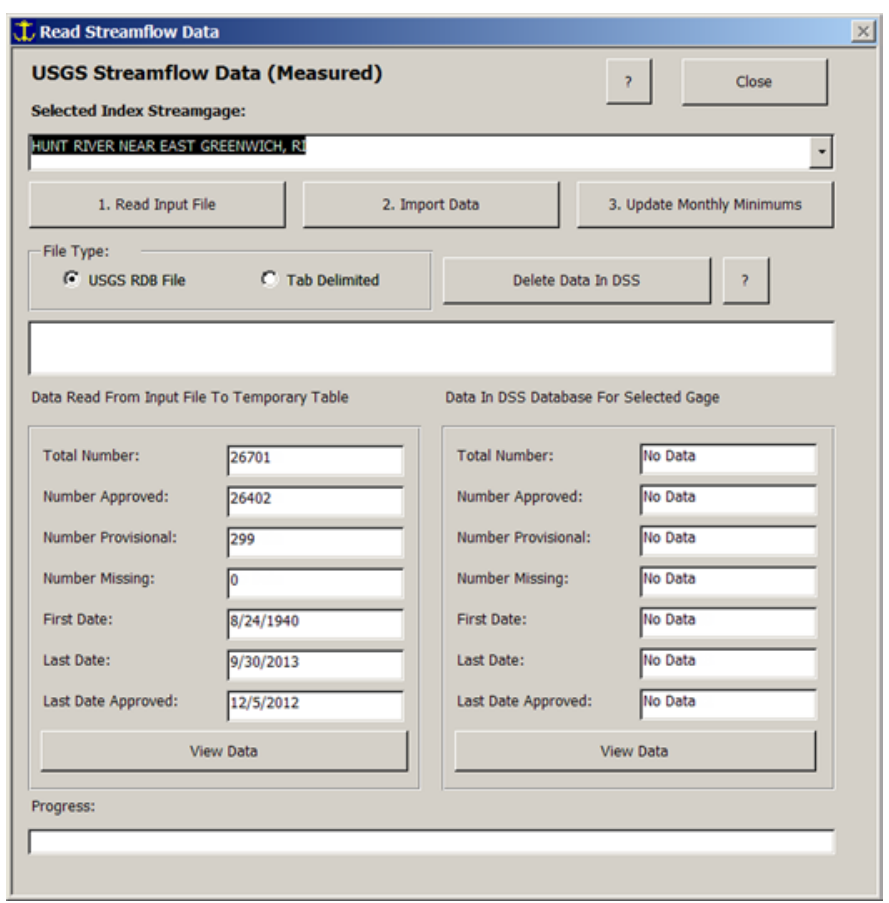

B

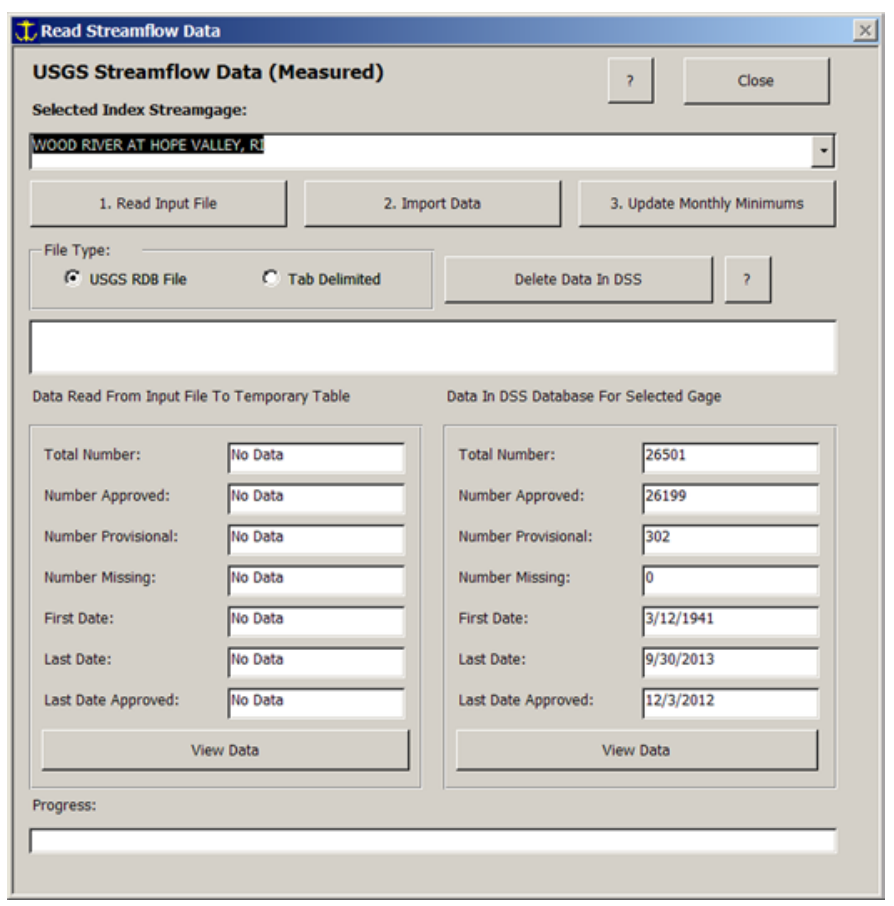

D

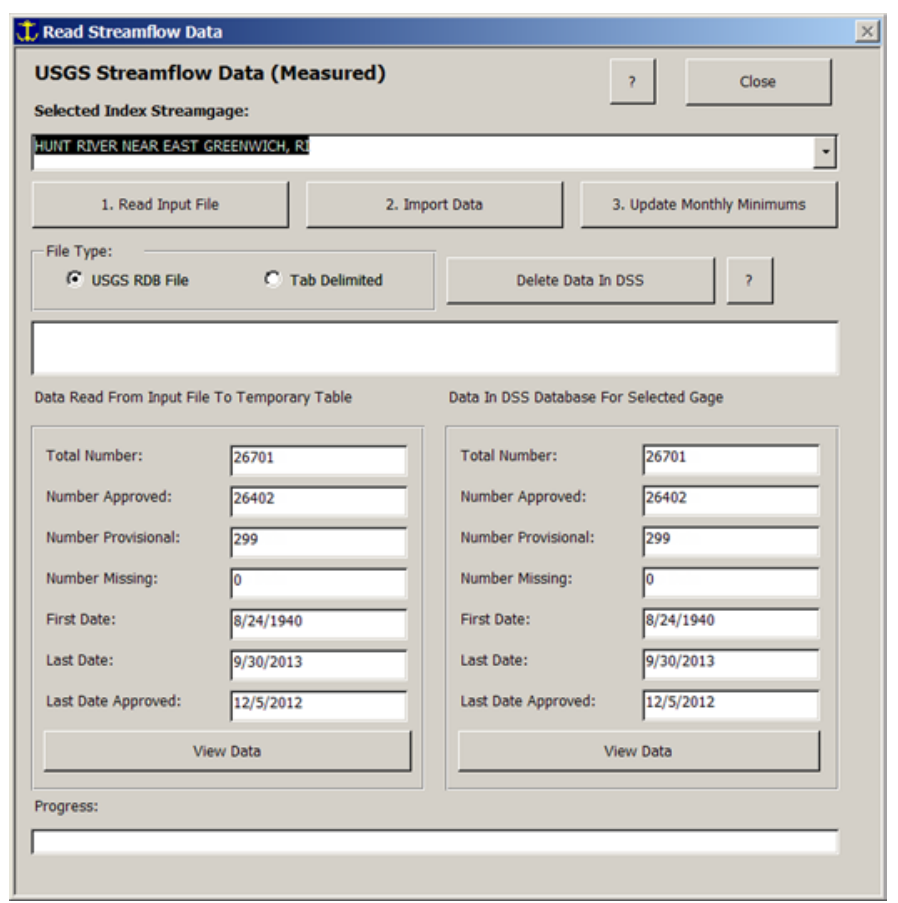

Figure 21. The "Read Streamflow Data" form showing the "USGS Streamflow Data (Measured)" form $A$, the initial view for a station without data in the HyDroDSS, $B$, the initial view for a station with data in the HyDroDSS, $C$, a view for a station with data that has been read from a file but not imported to the streamflow table, and $D$, a view for a station with data that has been read from a file and imported to the streamflow table. 
daily mean discharge values in the HyDroDSS for the selected streamgage ("Delete Data in DSS"). This command button may be used to refresh all streamflow values for the selected site, and it may be used as the first step for eliminating an index gage. This form will delete all records in the temporary table when it is closed (when the "Close" button is clicked). A message box will appear to remind you that these records will be deleted, because there may be some delay in reopening the data-management menu while these records are deleted. Some streamflow-data-management operations may take a minute or more because of the large size of the datasets; a "Progress" bar is provided on the bottom of this form to indicate that the HyDroDSS is working on the data.

The status of existing streamflow data for each streamgage in the HyDroDSS is indicated when the "USGS Streamflow Data (Measured)" form is loaded from the "Data Management Menu." Streamflow-table metrics for the selected streamgage are shown in the textboxes in the lower-right quadrant of the streamflow data form (fig. 21). The form indicates the "Total Number" of daily mean discharge values; the number of USGS approved values ("Number Approved"); the number of USGS provisional values ("Number Provisional"); the number of missing values ("Number Missing," calculated by subtracting the total number of values from the number of days in the record); the "First Date," and the "Last Date" in the record; and the most recent date of USGS approved values ("Last Date Approved"). If data have not been imported for a streamgage, then the text "No Data" will appear in each textbox (for example, fig. 21A). If data have been imported, then the textboxes for the imported numbers and dates will be populated (for example, fig. 21B).

To import or update data, select the input "File Type" ("USGS RDB File" or "Tab Delimited"), and then click the "1. Read Input File" command button. The HyDroDSS will read two types of daily mean streamflow files. The first option is labeled "USGS RDB File," and the second option is labeled "Tab Delimited." The USGS RDB format is the 2004 USGS National Water Information System (NWIS) Web relational database (RDB) format. This format consists of a number of explanatory header lines beginning with the pound symbol, two tab-delimited data-format lines, and then a tab-delimited daily mean streamflow data line for each day in the available record. The 2004 NWIS WEB RDB format includes the agency code (usually "USGS"), the 8 to 15 digit USGS station number, the date, a numeric streamflow value, and a data comment code. The comment codes are primarily " $\mathrm{A}$ " for approved records and "P" for provisional records and may include an "E" for estimated or other codes, such as "Ice" for ice-affected measurements. The 2004 NWIS WEB RDB format is used by the HyDroDSS because the newer formats may include text in the numeric fields and may have other fields in the record (such as daily-peak or low-flow values). The Get NWISQ program (Granato, 2009) can be used to get current records from NWIS WEB and reformat the raw files into the proper RDB format. The "Tab Delimited" format is a three-column tab-delimited text file. The first line of the tab-delimited text file should be the 8-to-15-digit USGS station number, a tab, and then the word "Streamflow." The rest of the file should be composed of tab-delimited daily mean streamflow data lines for each day in the available record. Each data line for the text file should be composed of the date, a numeric streamflow value, and a data-comment code. The tab-delimited text-file format may be used if you download the data and reformat USGS NWIS WEB data manually, or if you are using non-USGS streamflow data (in which case the station number should be fabricated to represent an equivalent station in USGS station-number format). Once the input-file format is selected, you may import the data by clicking the "1. Read Input File" command button. This command button will launch a common dialog form for selecting the appropriate streamflow input file (fig. 22). Once the file is selected, the "USGS Streamflow Data (Measured)" form will populate the input-file-name textbox in the middle of the form (fig. 21C), read the input file, identify input values that include the same date and station number as values that are already in the HyDroDSS, and, if there are no input errors, populate the temporary-table data metrics in the textboxes in the lower-left quadrant of the streamflow-data form (for example, fig. 21C). Once data are imported, you can view the data in the temporary table by clicking the "View Data" command button in the lower-left quadrant of the form. A query (qryViewImportedStreamTable01) will be created and launched to display the data (fig. 23).

Once the data are read in the temporary table and inspected, you can import them into the index streamflowdata table in the HyDroDSS by clicking the " 2 . Import Data" command button. This command button reads the temporary table, replaces all matching values in the streamflow-data table with the same station number and date, and adds all non-matching values to the streamflow-data table. The HyDroDSS replaces all matching values because it is assumed that provisional data will be replaced with approved data as the data is inspected and approved, and that any newer revised data will represent a better estimate of actual mean daily streamflows measured at the index gage than earlier data versions. Once this process is complete, the HyDroDSS populates the streamflow data metrics in the textboxes in the lower right quadrant of the "USGS Streamflow Data (Measured)" form (for example, fig. 21D). All the data in the streamflow data table for the selected index gage can be viewed by clicking the "View Data" command button in the lower-right quadrant of the form; a query (qryViewStreamTable01 will be created and launched) to display the data. This query is similar to the query "qryViewImportedStreamTable 01" shown in figure 23.

Once the data are read into the streamflow-data table, you can update the monthly minimum streamflow values for the index gage in the table "tblStreamflowMonthlyMinMeasured" in the HyDroDSS by clicking the "3. Update Monthly Minimums" command button on the "USGS Streamflow Data (Measured)" form (fig. 21). This command button runs queries to identify the monthly minimum streamflow for each 


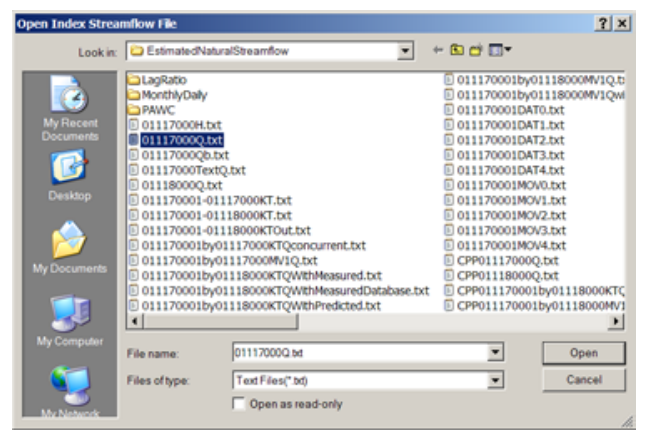

Figure 22. Common dialog form for reading the mean daily streamflow data file for an index gage.

\begin{tabular}{|c|c|c|c|}
\hline \multicolumn{2}{|c|}{ 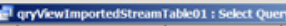 } & -10 & \\
\hline & miflowDate & & \\
\hline 01117000 & $8 / 24 / 1940$ & $18 \mathrm{~A}$ & \\
\hline & $8 / 25 / 1940$ & 15 A & \\
\hline 01117000 & $8 / 26 / 1940$ & $14 \mathrm{~A}$ & \\
\hline 01117000 & $8 / 27 / 1940$ & $13 \mathrm{~A}$ & \\
\hline 01117000 & $828 / 1940$ & $12 \mathrm{~A}$ & \\
\hline 01117000 & $829 / 1940$ & $12 \mathrm{~A}$ & \\
\hline 01117000 & $8 / 30 / 1940$ & $15 \mathrm{~A}$ & \\
\hline 01117000 & $8 / 31 / 1940$ & $13 \mathrm{~A}$ & \\
\hline 01117000 & $9 / 1 / 1940$ & $12 \mathrm{~A}$ & \\
\hline 01117000 & $9 / 2 / 1940$ & $12 \mathrm{~A}$ & \\
\hline 01117000 & $9 / 3 / 1940$ & $11 \mathrm{~A}$ & \\
\hline 01117000 & $9 / 4 / 1940$ & $11 \mathrm{~A}$ & \\
\hline 01117000 & 9/5/1940 & $11 \mathrm{~A}$ & \\
\hline 01117000 & $9 / 1940$ & $10 \mathrm{~A}$ & \\
\hline 01117000 & $9 / 7 / 1940$ & $9.5 \mathrm{~A}$ & \\
\hline 01117000 & $98 / 1940$ & $9.4 \mathrm{~A}$ & \\
\hline 01117000 & 99/1940 & $12 \mathrm{~A}$ & \\
\hline 01117000 & 9/10/1940 & $11 \mathrm{~A}$ & \\
\hline 01117000 & 9/11/1940 & $14 \mathrm{~A}$ & \\
\hline 01117000 & 9/12/1940 & $18 \mathrm{~A}$ & \\
\hline 01117000 & $9 / 13 / 1940$ & $15 \mathrm{~A}$ & \\
\hline 01117000 & 9/14/1940 & $12 \mathrm{~A}$ & \\
\hline 01117000 & 9/15/1990 & $11 \mathrm{~A}$ & . \\
\hline Record: in in 4 & 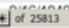 & & \\
\hline
\end{tabular}

Figure 23. Results of the query "qryViewImportedStreamTable01" showing mean daily streamflow values imported for streamgage 01117000 for the period August 24, 1940 through April 26, 2010. The query is launched by clicking the "View Data" command button on the "USGS Streamflow Data (Measured)" form. 
full month of data during the period of record. Updating the monthly minimum streamflow table makes the new values available for updating the rank correlation analysis and the drought-projection analysis for the site of interest.

\section{Stream Site of Interest}

The "Enter Site of Interest Information" form showing the "Decision Support System Stream Site of Interest" data form (fig. 24) is used to enter information and data about each site of interest in the HyDroDSS. Sites of interest are datacollection sites on streams that may be adversely affected by pumping. Estimated unaltered-streamflow data associated with each site of interest may be used as the input for a rank correlation analysis to identify hydrologic drought indicators. These data also may be used as the reference condition for a retrospective streamflow-depletion analysis. The estimated unaltered-streamflow data associated with each site of interest also are used for estimating potential monthly minimum streamflows in the drought-projection analysis. The "Decision Support System Site of Interest" form (fig. 24) has one page for data entry. This form provides textboxes for entering or editing the "Name," the contributing "Drainage Area," and a "Description" of the selected site of interest. This form also has a checkbox and a combobox for linking the site of interest with its definition as a streamflow-gaging station in the streamgage table. You may edit data for an existing site or add a new site to the DSS. If you add a new site, the site-selection combobox will be reinitialized to the value for the new site.

You may add new sites and select them for editing on the "DSS Stream Sites of Interest" form, but the currently selected site of interest may be set only from the main menu. The new site of interest will not appear in the comboboxes of the other data-management and analysis forms unless you go back to the "Main Menu" form to select the new site as the active site of interest. This main-menu control structure is designed to ensure that all data and analyses are assigned to the correct site of interest, which is specified at the beginning of a HyDroDSS analysis session.

\section{Estimated Unaltered-Streamflow Data}

The "Estimated Unaltered-Streamflow Data" input form (fig. 25) is used to import long-term records of daily mean discharge values for selected sites of interest that have been entered into the HyDroDSS. Estimated unaltered-streamflow data are estimates of historical streamflows for the site of interest that may have occurred without large-scale withdrawals or discharges. Estimated unaltered-streamflow data are used for the correlation analysis, the retrospective analysis, and the drought-projection analysis.

The estimated unaltered-streamflow data may be calculated from actual streamflow records by using calculated streamflow depletions, and it may be estimated for an index site by using various methods including the Streamflow
Record Extension Facilitator (SREF) (Granato, 2009), the Kendall-Theil Robust Line (KTRLine) program (Granato, 2006), or some other program. The estimated unalteredstreamflow data also may be calculated by using a watershed model. For example, Granato and Walter (2011) used an unaltered streamflow estimated by using a watershed model (Zarriello, 2011) to develop conjunctive-management models and retrospective streamflow analyses for the lower Wood River Basin and the Eastern Pawcatuck Basin in Rhode Island.

The "Estimated Unaltered Streamflow Data" form (fig. 25) looks and behaves like the "USGS Streamflow Data (Measured)" form (fig. 21). The "Estimated Unaltered Streamflow Data" form, however, reads and writes data by using the estimated unaltered-streamflow data table (tblStreamflowEstimated) and updates the associated monthly minimum flow table (tblStreamflowMonthlyMinEstimated). Both forms have three data-input command buttons, a filetype option box, a textbox to display the input-data file location, a series of textboxes to display input-file metrics and HyDroDSS-table metrics for each streamflow-gaging station, two "View Data" command buttons, and a command button for deleting streamflow data from the HyDroDSS. Both forms have a command button for deleting all daily mean discharge values in the HyDroDSS for the selected site. This command may be used to refresh all streamflow values for the selected site and as the first step for eliminating an index gage. The "Estimated Unaltered Streamflow Data" form will delete all records in the temporary table when it is closed, and a message box will remind you about a possible delay in reopening the "Data Management Menu" while these records are deleted. Some streamflow data-management operations may take up to a minute or more because of the large size of these datasets; a "Progress" bar is provided on the bottom of this form to indicate that the HyDroDSS is working on the data. Please see the "Streamflow Data" section of this manual for detailed instructions on how to use the "Estimated UnalteredStreamflow Data" form.

\section{Pumping Site}

The "Enter Pumping Site Data" form showing the "Pumping (Withdrawal or Discharge) Site Data" form is used to enter information and data about each pumping site in the HyDroDSS. Pumping sites are locations in the basin that have an effect on streamflow at the site of interest. A pumping site may be a withdrawal or discharge site related to offstream water use. Information about pumping sites includes the name, comments, and response coefficients for the site of interest. Response coefficients are dimensionless numbers that indicate the proportions of a monthly withdrawal that will be manifested as streamflow depletions in the current month and the following month. The HyDroDSS uses monthly time steps, so surface-water withdrawals are modeled with a response coefficient of 1 . If a pumping site (for example, a well near a groundwater divide) affects more than one stream 


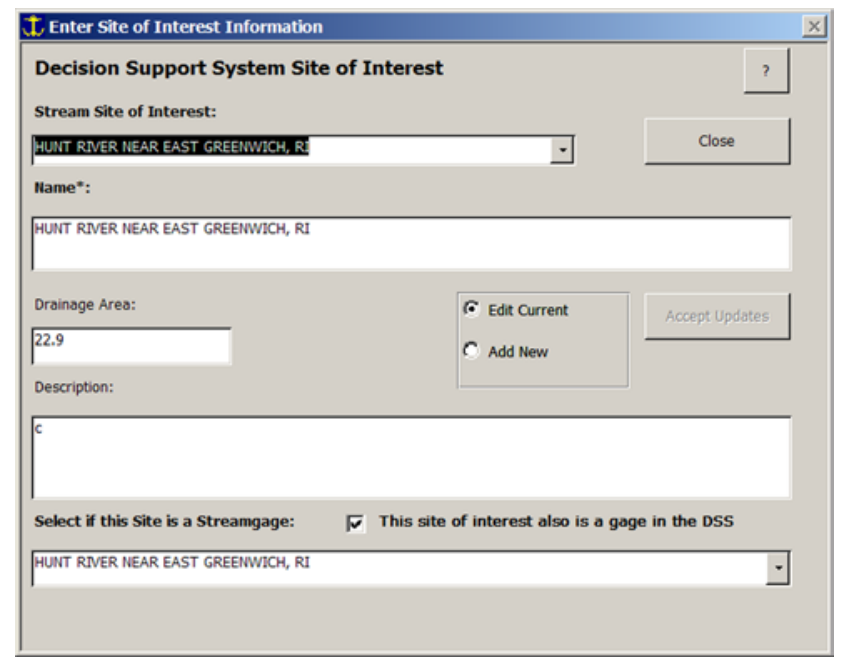

Figure 24. “Decision Support System Site of Interest” datamanagement form.

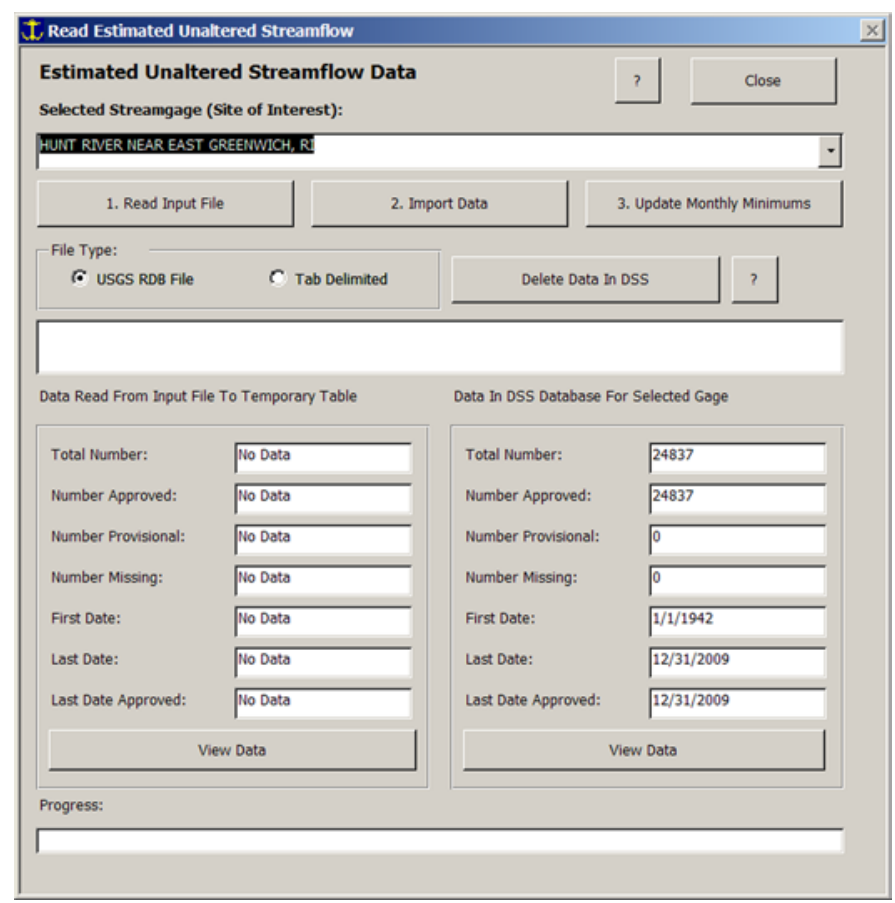

Figure 25. "Estimated Unaltered Streamflow Data" input form. 
site of interest, then the pumping site should be entered for each stream site of interest with the associated response coefficients.

The "Pumping (Withdrawal or Discharge) Site Data" form (fig. 26) has two tabbed pages for data entry. The first tab titled "Sites" is an interface for entering or editing information about the pumping site. The second tab titled "Response Coefficients" (fig. 26B) is an interface for entering or editing information about the response coefficients for the selected pumping site and site of interest.

The "Sites" tab provides textboxes for entering or editing the "Name*," the Water Supply Systems Management Plan (WSSMP) identification number ("WSSMP Database ID Number(s)") (Granato, 2004), and "Comments" about the pumping site. The pumping-site name may as long as 250 characters. The "WSSMP Database ID Number(s)" field is a text string that can be as long as 20 characters. This field can be used to store any alphanumeric pumping-site identification number within the length limit. By default the "Sites" tab is loaded with the "Edit Current" option selected. The "Edit Current" option is used to change data associated with the pumping site in the combobox at the top of the "Sites" tab. To enter a new pumping site, click the "Add New" option. This option will clear the existing data fields for information about a new pumping site. The "Accept Updates" button is disabled until a change is made in one of the textboxes and another textbox is clicked, the "Enter" key is pressed, or the "Tab" key is pressed on the keyboard. The "Accept Updates" command button will either update the information about the selected pumping site or add the new pumping site to the database and then update the station-selection combobox to reflect the changes. By default the form is loaded with the "View all pumping sites" checkbox unchecked. If the checkbox is unchecked, then only the pumping sites associated with the site of interest will appear in the "Withdrawal or Discharge Point" combobox. Once a site has been added to the database, the "View all pumping sites" checkbox will be checked, so that this new site can be selected for adding the response coefficients that associate a pumping site with a stream site of interest. Similarly, if a pumping site is entered for one site of interest, and it affects flow at another site of interest on the same stream or a neighboring stream, clicking the "View all pumping sites" checkbox will enable the user to add the response coefficients that define the hydrologic relationship between the pumping site and the stream.

The "Response Coefficients" tab provides textboxes for entering the response coefficients for the pumping site to define how it affects streamflow at the site of interest. The "Withdrawal Point Name" is provided on this tab as a reminder and to facilitate data entry. The response coefficients for 12 months must be entered. The "Accept Updates" data button is used to save the values on the form. The "Cancel Changes" button is used to reset the form with the original values for the pumping site. You can enter a pumping site on the "Sites" tab without defining response coefficients, but the site will not appear on the "Check Data" form for the selected site of interest unless response coefficients are assigned. You can come back to this form to enter the response coefficients for a site of interest at any time, but you must click the "View all pumping sites" checkbox to select the site from the combobox. As with the first tab, the "Cancel Changes" and "Accept Updates" buttons are disabled until a change has been made in a textbox and another textbox is clicked, and the "Enter" or the "Tab" key is pressed on the keyboard.

\section{Historical Pumping Data}

The "Historical Pumping (Withdrawal or Discharge) Data" form showing the "Historical Pumping (Withdrawal or Discharge) Data" form is used to enter or edit pumping data (including major withdrawals and discharges) that can be used to estimate unaltered streamflows at the site of interest. Historical pumping data also may be queried to generate various hypothetical pumping plans, which are based on different time periods. The historical pumping-data form (fig. 27) has two tabbed pages for data entry. The first tab titled "Withdrawals/Discharges" is an interface for entering or editing total monthly pumping in millions of gallons per month. The second tab titled "Site Information" is an interface for entering or editing withdrawal-site information.

When the "Historical Pumping (Withdrawal or Discharge) Data" form loads, textboxes for the "Year," "Month," and "Pumping, in Mgal/month" are displayed for the last month for which pumping data have been recorded in the database for the selected withdrawal or discharge site (fig. 27A). Data for the preceding five months also are displayed. The "Move by Months" options in the lower left quadrant of the "Withdrawal/Discharges" data-entry page can be used to set the scroll rate through the data. You can choose to scroll through the data in intervals of $1,3,6$, or 12 months at a time. The "Move Forward" and "Move Backward" command buttons will change the data in the input boxes as specified by the "Move by Months" selection. As you scroll through the data, missing values will be highlighted in yellow. If you scroll beyond the current month, the data fields for future months will be grayed out and locked. To enter or update data, type the monthly pumping total in the associated "Pumping, in Mgal/Month" textbox and any associated comments in the "Comment" textbox. Pumping data that represent discharges to the aquifer or the stream should be entered as negative numbers. Please note that such discharges may represent industrial or municipal wastewater, but should not include stormwater discharges. A "Comment" may be used to cite the source of the data or to indicate if some or all of the monthly pumping total is estimated. Once you enter or edit data, you may save the data by clicking the "Accept Updates" button. If you made a data-entry mistake and did not save the changes by clicking the "Accept Updates" button, you can undo edits and entries by clicking the "Cancel Changes" button.

The "Site Information" tab on the "Historical Pumping (Withdrawal or Discharge) Data" form provides an interface for editing or entering information about the pumping site 
$\boldsymbol{A}$

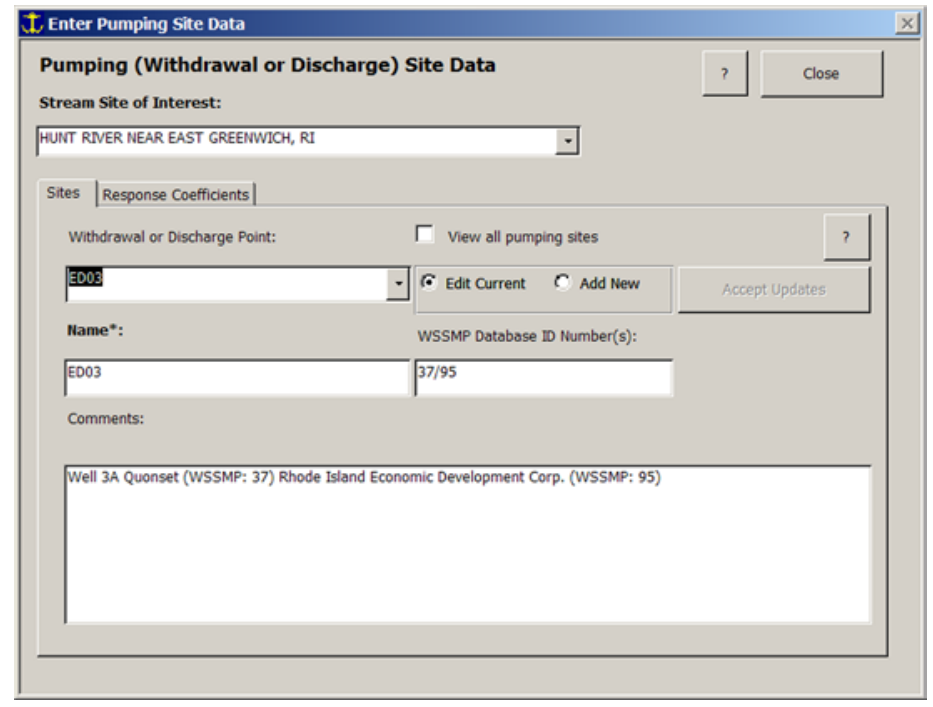

B

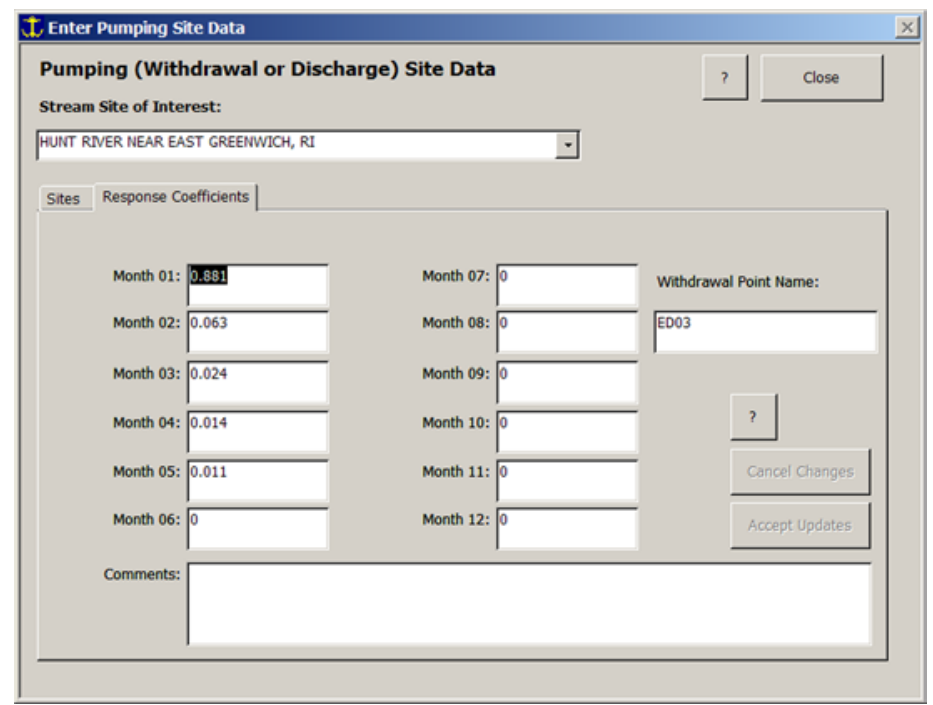

Figure 26. The "Pumping (Withdrawal or Discharge) Site Data" form showing $A$, the "Sites" information tab and $B$, the "Response Coefficients" data tab. 


\section{A}

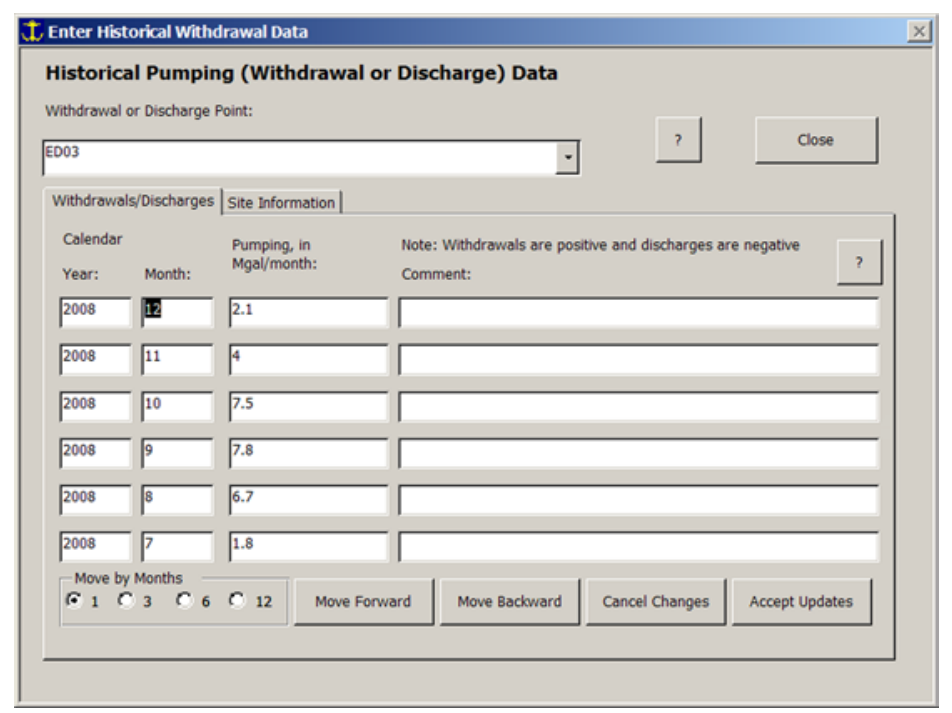

B

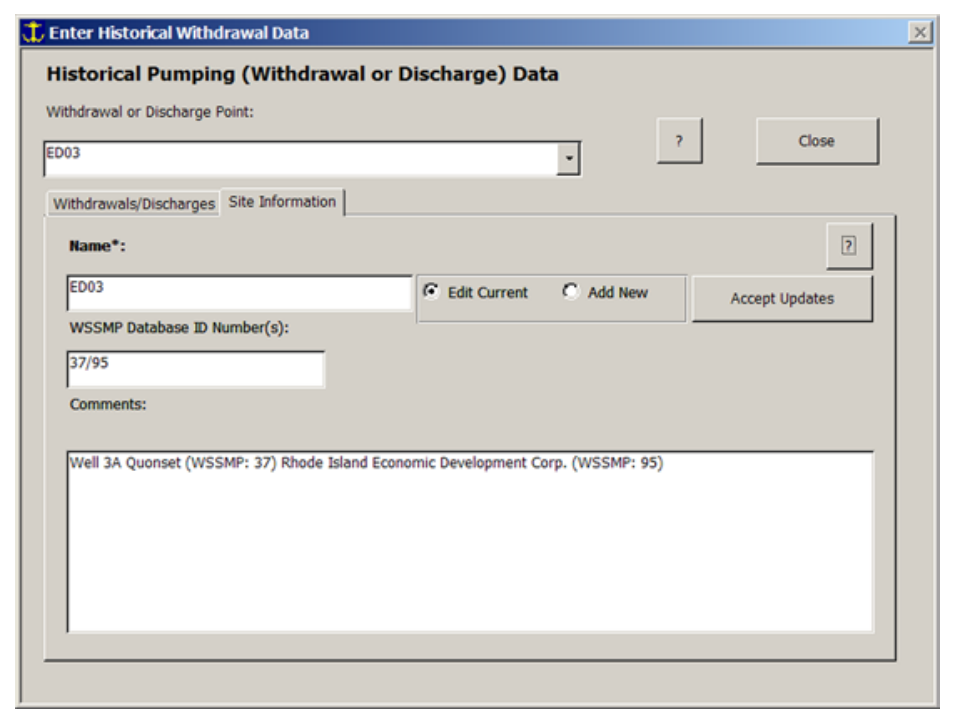

Figure 27. The "Historical Pumping (Withdrawal or Discharge) Data" form with $A$, the "Withdrawals/Discharges" tab and $B$, the "Site Information" tab. 
cataloged in the database (fig. 27B). This data-entry tab works the same way as described for the "Sites" tab on the "Pumping (Withdrawal or Discharge) Site Data" form (fig. 26) and interacts with the same table (tblWaterWithdrawalPoint) in the database. This tab is provided here on the historical pumpingdata form to facilitate data management.

\section{Hypothetical Pumping Data}

The "Hypothetical Pumping (Withdrawal or Discharge) Plan" data form (fig. 28) is used to enter or edit pumpingplan data (including major withdrawals and discharges) that will be used to calculate streamflow depletions. Hypothetical pumping values are used to run retrospective analyses to see how a given pumping plan would have affected the historical record of streamflows. Hypothetical pumping values also are used to calculate monthly depletions used in droughtprojection analyses to estimate the risk of streamflows being below desired values under different withdrawal plans. This form (fig. 28) has three tabbed pages for data entry. The first tab titled "Pumping Plan" is an interface for entering or editing information about each plan (fig. 28A). The second tab titled "Monthly Pumping Rates" is an interface for entering or editing pumping rates (in millions of gallons per day for each pumping site included in each pumping plan (fig. 28B). The third tab "Add/Remove A Site" (fig. 28C) provides a method for adding or removing a pumping site from the selected hypothetical pumping plan. Only pumping sites that have been identified as being associated with the current site of interest (on the "Pumping (Withdrawal or Discharge) Site Data" form, fig. 26) can be selected on the "Hypothetical Pumping (Withdrawal or Discharge) Plan" form. If a site is deselected, the pumping rates associated with the current hypothetical pumping plan are deleted.

The "Hypothetical Pumping (Withdrawal or Discharge) Plan" form loads all the pumping plans associated with the site of interest in alphabetical order by plan name (entered in the "Name*" textbox) and uses the first plan as the default (fig. 28A). The "Name*" is a required field; the name must consist of 1 to 250 characters, and the form field is large enough to hold about 45 characters. The "Pumping Plan" tab lets you specify a "Name*," a "Plan Type," a "Plan Type Description," and a "Plan Description." The "Plan Type Description:" is preloaded into the database to inform the "Plan Type" selection. Currently (HyDroDSS version 1.0.0, 2013) three types of hypothetical pumping plan options are in the database. The three "Plan Type" definitions are

- "Historical Year," which is an actual 12-month series of withdrawals derived from local water-use data (a historical record also may be the monthly average or median withdrawal rates for a time period);

- "Optimization," which is a 12-month series of withdrawals designed to meet conjunctive-management objectives developed by using optimization techniques; and
- "User-Defined," which is a 12-month series of withdrawals designed by the user for scenario testing (for example, a user-defined plan might be a historical record with some percentage reductions to represent conservation objectives in low-flow months).

You may add new plan types or edit plan-type information by editing the data in table "tdsHypotheticalPlanType." The "Plan Description" textbox lets you enter as much ancillary information about the plan as desired. For example, the "Plan Description" text could be a citation to the source of the pumping plan.

The "Monthly Pumping Rates" tab (fig. 28B) is the interface for selecting withdrawal or discharge points and for entering pumping rates for each point. On this form, pumping rates are entered in millions of gallons per day because the plan may be applied to different years, and total summer depletions during leap years might be different for some wells. As for historical pumping values, hypothetical pumping rates for discharges to the stream should have a negative sign. This tab also has a "Comments" field that may be used to annotate the pumping rates for a withdrawal or discharge point in a given pumping plan.

The "Add/Remove A Site" tab provides an interface for selecting a site and either adding it to or removing it from a hypothetical pumping plan (fig. 28C). This form has a combobox to select the well withdrawal or discharge point, A "Comments" textbox to display previously entered comments, and buttons to either add a site or remove a site. Removing a site will delete the pumping plan information but not the site information. The "Add A Site" button in figure $28 \mathrm{C}$ is disabled because all the sites related to the stream are already associated with the selected pumping plan.

\section{Run Analyses}

The "Run Analyses" command button on the "Main Menu" (fig. 14) provides methods to do hydrologic analyses for the selected stream site of interest. Clicking the "Run Analyses" command button will open the "Data Analysis Menu" (fig. 29), which shows three drought-analysis types in the "Select Analysis Type" option frame. The "Data Analysis Menu" has command buttons that will let you "Exit the DSS," go to the specified data-analysis form, or return to the "Main Menu." The "Data Analysis Menu" is context sensitive because the explanation and target data-analysis form change as you select different data-analysis options. For example, figure 29A shows the explanation for the retrospective streamflow-depletion analysis, and the command button reads "Go To Streamflow Depletion Analysis" because the retrospective streamflow-depletion analysis option is selected. Figure 29B shows the explanation for the rank correlation analysis, and the command button reads "Go To Rank Correlation Form" because the rank correlation option is selected. Figure 29C shows the explanation for the "Drought Projection" analysis, and the command button reads "Go To 


\section{A}

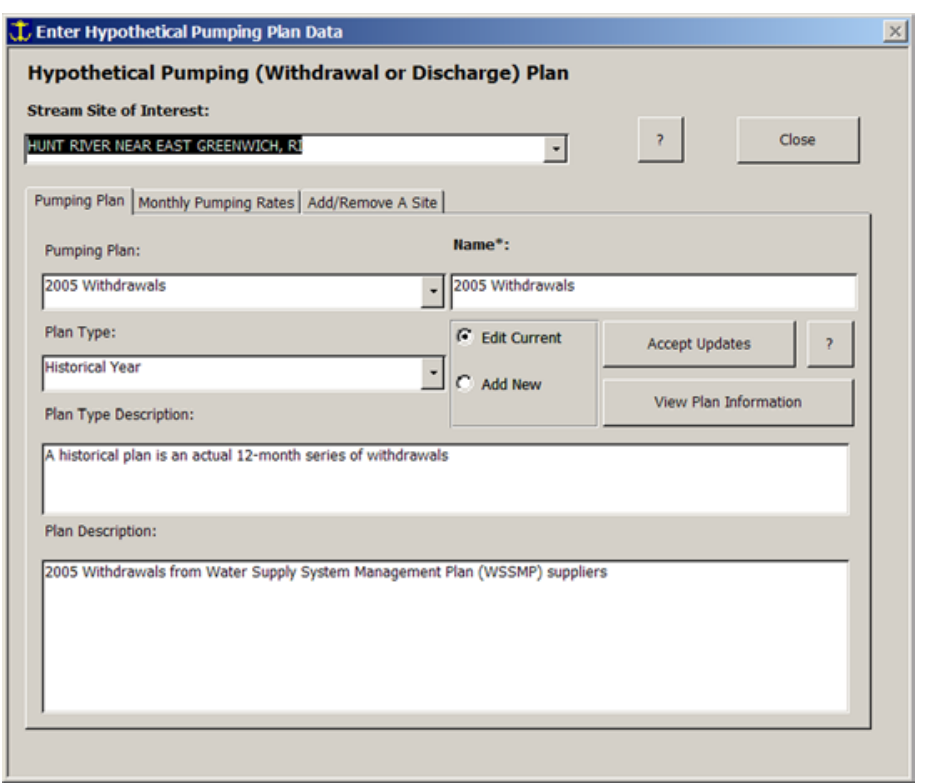

c

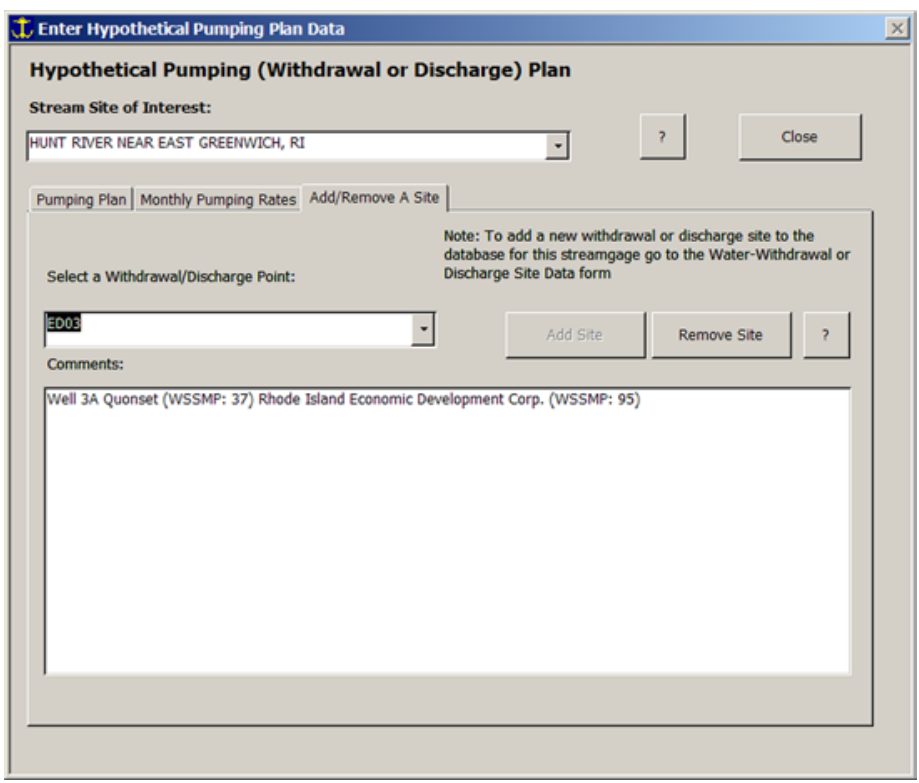

B

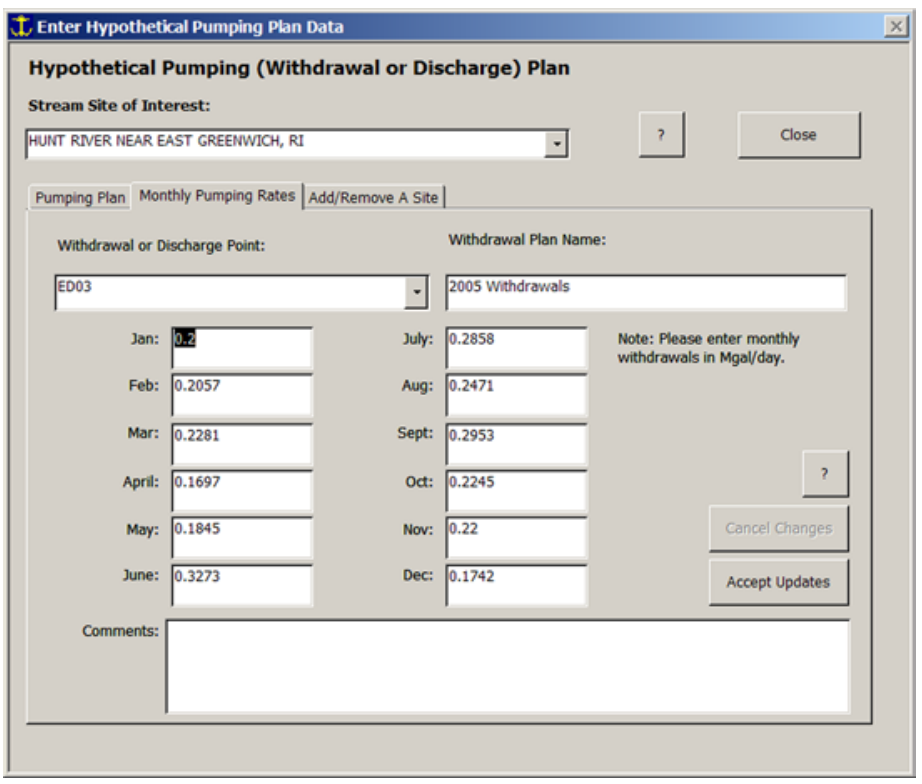

Figure 28. The "Hypothetical Pumping (Withdrawal or Discharge) Plan" form with $A$, the "Pumping Plan" tab, and $B$, the "Monthly Pumping Rates" tab, and $C$, the "Add/Remove A Site" tab. 
A

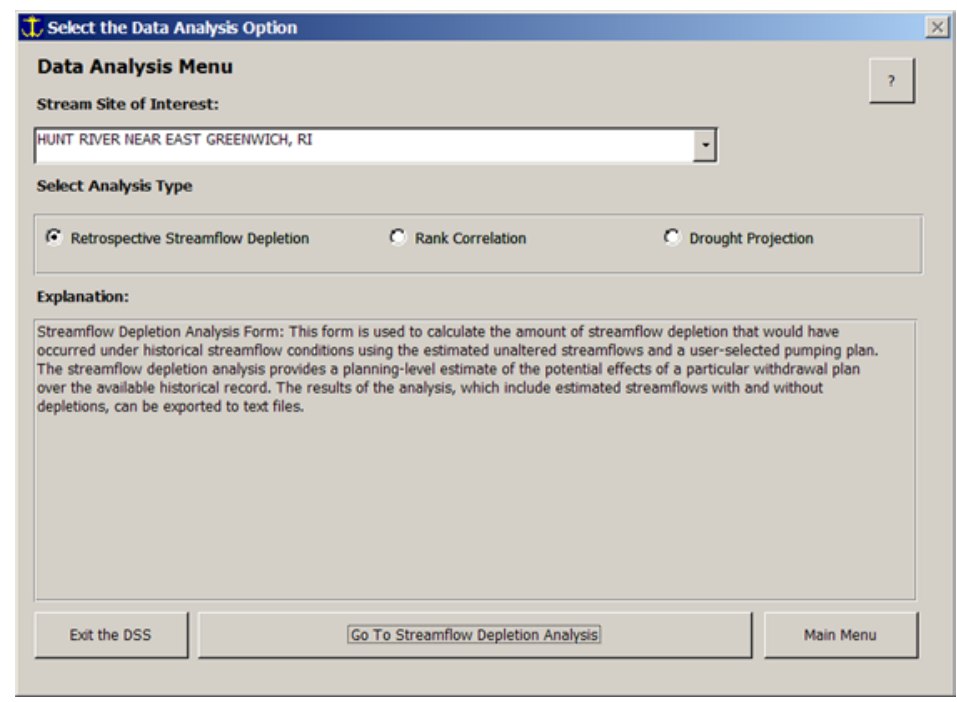

B

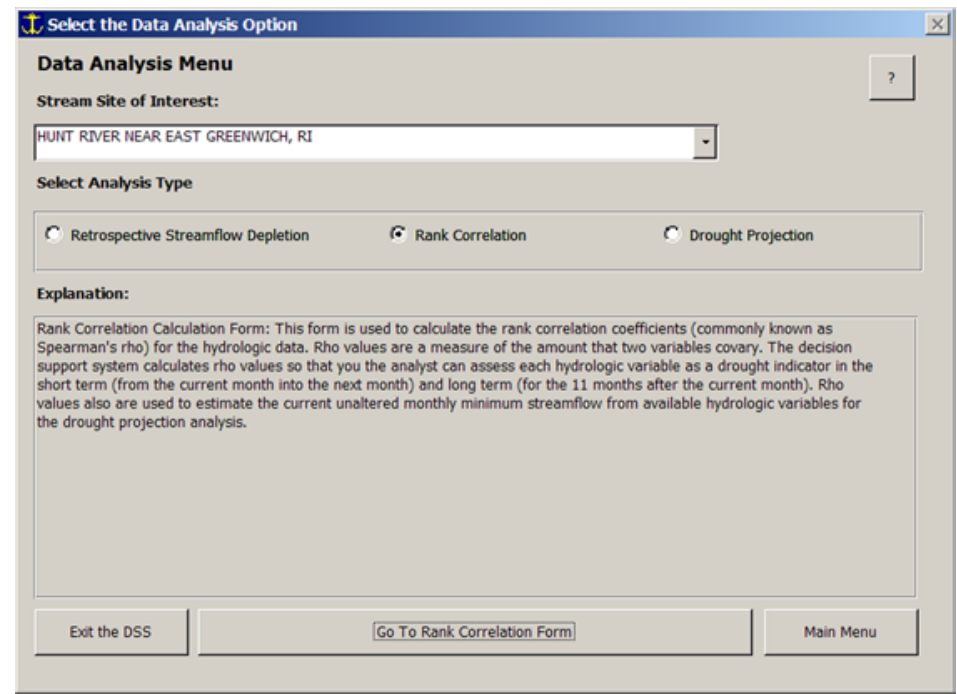

C

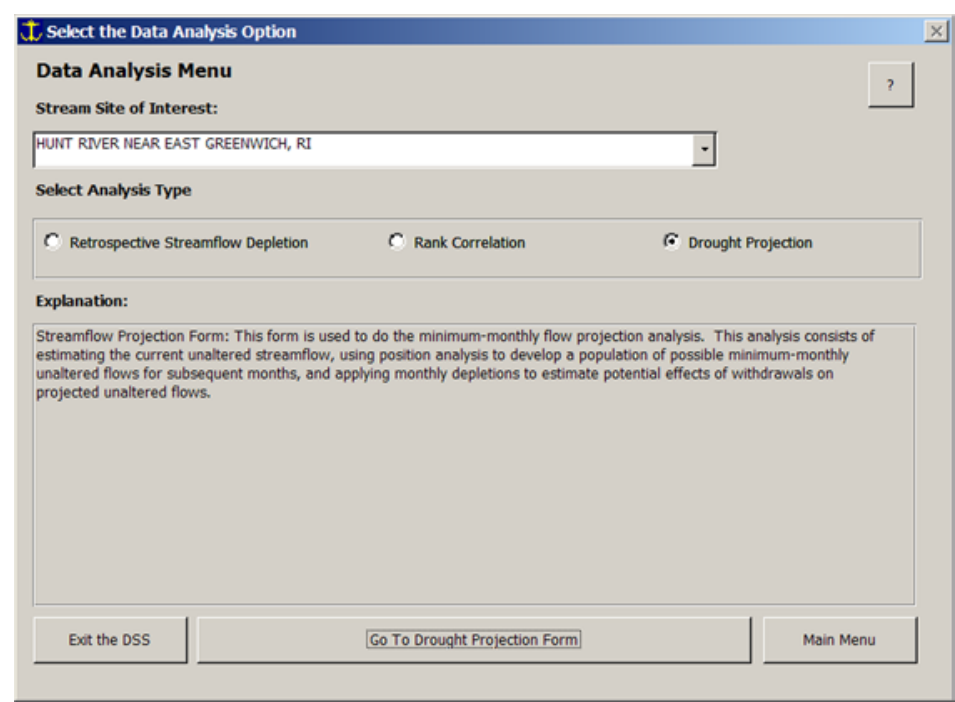

Figure 29. "Data Analysis Menu" with the $A$, "Retrospective Streamflow Depletion," $B$, “Rank Correlation," and $C$, “Drought Projection" options selected. 
Drought Projection Form" because the drought-projection option is selected. Once the option button is selected, and the "Go To..." form command button is clicked, you will be directed to the selected drought-analysis form.

All the drought-analysis forms share two common features. Each form has a help button (denoted by a question mark "?") in the upper right quadrant. The help button opens a form with information about the type of analysis selected. Each drought-analysis form also has a "Close" button in the upper right quadrant, which will close the form and return to the data-analysis menu. The streamflow-depletion and drought-projection analysis forms both have a combobox in the upper left quadrant, which displays the site of interest that was selected on the main menu. All the drought-analysis forms have one or more help buttons (denoted by question marks) that provide specific information about one or more analysis input elements.

\section{Retrospective Streamflow-Depletion Analysis}

The "Retrospective Streamflow Depletion Analysis" form (fig. 30) is designed to facilitate calculation of the effects of different pumping plans on the historical record of estimated unaltered streamflows. Two types of streamflow records are provided by the programs underlying this form: estimated unaltered streamflows and streamflows with calculated depletions. Five output options are available for these estimated flows. You may output a record of all daily flows, a record of monthly mean flows, and a record of monthly minimum flows. Each flow record may be exported as a time series or a flowduration curve. Flows may be exported in units of cubic feet per second or cubic feet per second per square mile ("CFS" or "CFSM" on the form).

The "Retrospective Streamflow Depletion" form has three tabbed pages for data analysis. The first tab titled "I. Select Pumping Plan" (fig. 30A) is an interface for selecting a pumping plan for analysis. The first tab for selecting a pumping plan has a "Select Pumping Plan" combobox, a "Plan Type" combobox, "Plan Type Description" and "Plan Description" textboxes, a command button labeled "?" for contextsensitive help, and a command button labeled "View Selected Plan Details" to provide more information about the selected plan. Clicking "View Selected Plan Details" opens an information form similar to figure 15 with detailed plan information. The detailed plan information includes the withdrawal-plan name, type, type description, and user-defined information. The detailed plan information also lists all the withdrawal points in the plan with the name, comments, and water-usedatabase identification numbers. Detailed plan information also includes monthly response coefficients and monthly mean pumping rates for each withdrawal point.

The second tab titled "II. Run Analysis" for running an analysis (fig. 30B) has information text, a command button labeled "?" for context-sensitive help, and a command button labeled "Run Analysis" to calculate and apply the streamflow depletions specified in the pumping plan. The "Run Analysis" command also activates the progress bar at the bottom of the form, which indicates that the program is running. Running the analysis also will enable the "III. View Output" command button on the third tab.

The third tab, titled "III. View Output" (fig. 30C), has three option boxes and six command buttons labeled "?" for context-sensitive help. The three option boxes are for selecting the type of output. The first option box ("1. Output Statistic") is used to select the flow statistic of interest. The second option box ("3. Output Type") is used to select a time-series output or a flow-duration curve output. The third option box ("4. Streamflow Units") is used to select output units as $\mathrm{ft}^{3} / \mathrm{s}$ or $\mathrm{ft}^{3} / \mathrm{s} / \mathrm{mi}^{2}$. The " 5 . View Output" command button opens the information form with the selected streamflow data (fig. 31). The output is tab-delimited text in a format that will facilitate use in a spreadsheet or graphing program. The time series output for the mean daily flows has three columns: the date, the estimated natural (unaltered) flow, and the estimated flow with depletion. The time series output for the monthly flow statistics ("Monthly Mean" and "Monthly Minimum") has four columns: the month, the year, the estimated natural (unaltered) flow, and the estimated flow with depletions (fig. 31A). The flow-duration curve output for the minimum monthly flows has four columns: the flow-duration percentile, the estimated natural (unaltered) flow, the flow-duration percentile, and flow with depletions. The flow-duration curve output for the minimum monthly flow statistics has seven columns: the month, the flow-duration percentile, estimated natural flow, and year of occurrence for the estimated natural (unaltered) flow, and the flow-duration percentile, the estimated flow with depletions, and the year of occurrence for the flow with depletions (fig. 31B). The output form allows you to copy the data from the textbox, or save the data in a text file. If, however, the time series or the flow-duration-curve output for the mean daily flow option is selected, and the record length is longer than about 16 years, the output form will not allow you to copy the data from the textbox because it can hold only 179,804 characters.

\section{Rank Correlation Analysis}

The "Rank Correlation Analysis" form is designed to facilitate analysis of available hydrologic data by calculating and outputting the rank correlation coefficient (Spearman's rho) (Helsel and Hirsch, 2002). Rank correlation coefficients are calculated by using paired data. Three types of rank correlation analyses can be done by using the output from this form. The first type of analysis is a serial correlation analysis. In this type of analysis, the same site is used as the first $(X)$ and second $(Y)$ site, and the results indicate how well values in one month may be used to estimate values at the same station in subsequent months. The second type of analysis is a crosscorrelation analysis, which indicates how well values at the one site $(X)$ may be used to estimate values at a second site $(Y)$ in the current month and in subsequent months. The third type of analysis is a moving bootstrap analysis, in which a sample 


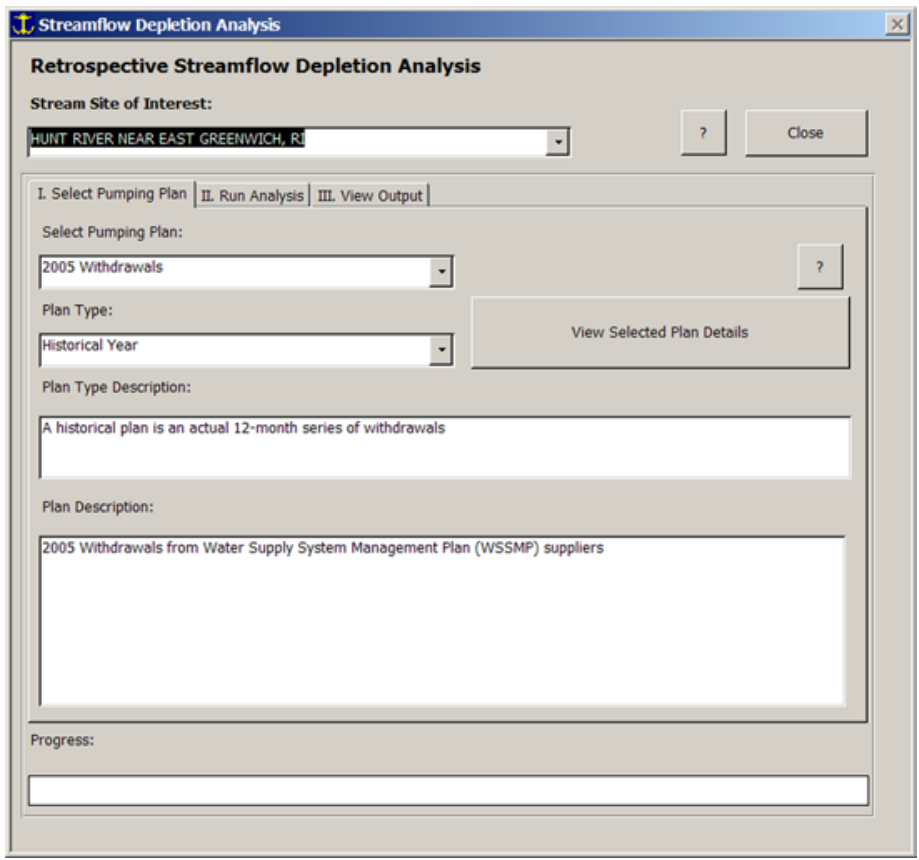

C

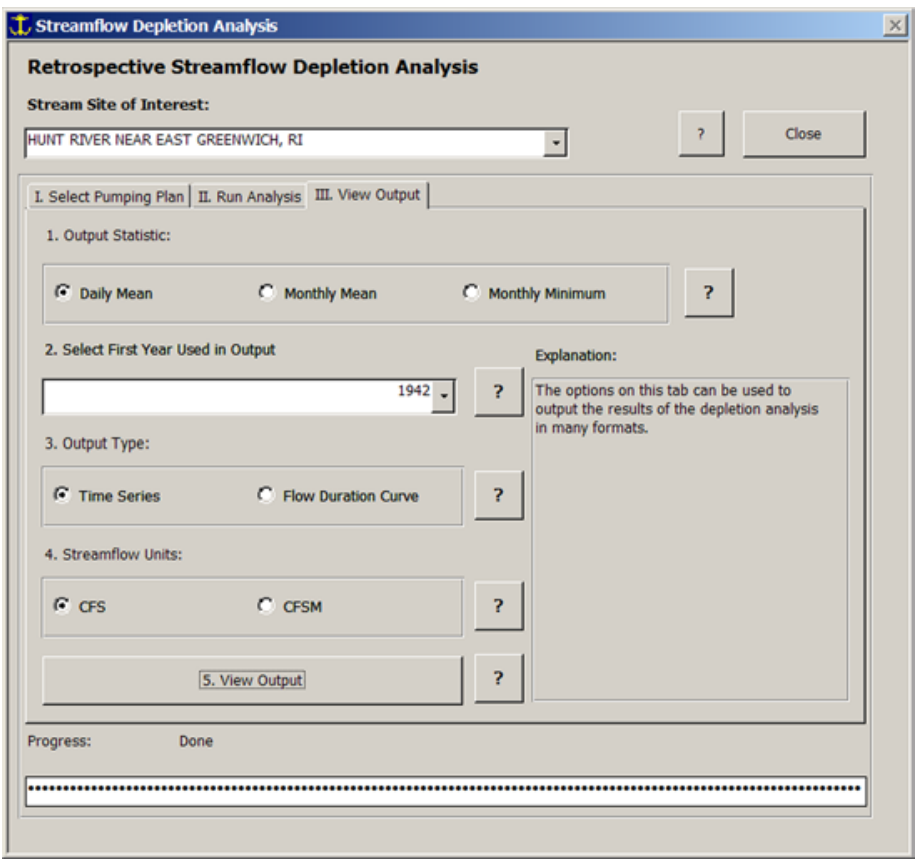

B

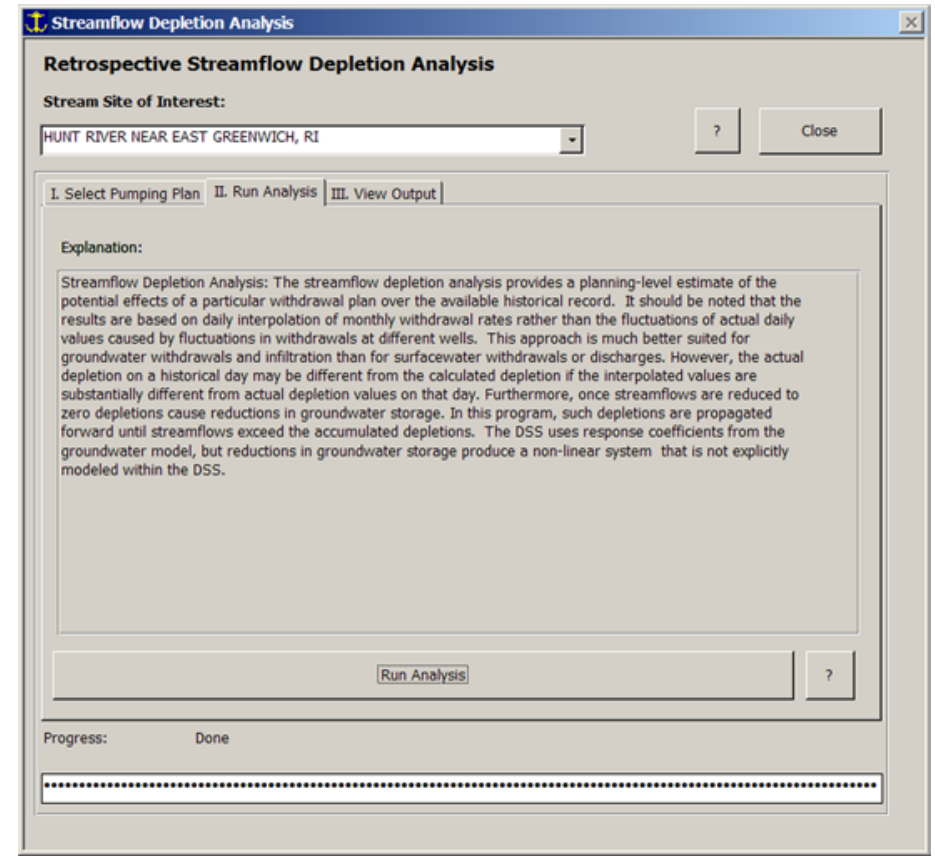

Figure 30. "Retrospective Streamflow Depletion Analysis" form showing the tabs $A$, the "I. Select Pumping Plan," $B$, the "II. Run Analysis," and $C$, the "III. View Output tab." 


\section{$\boldsymbol{A}$}

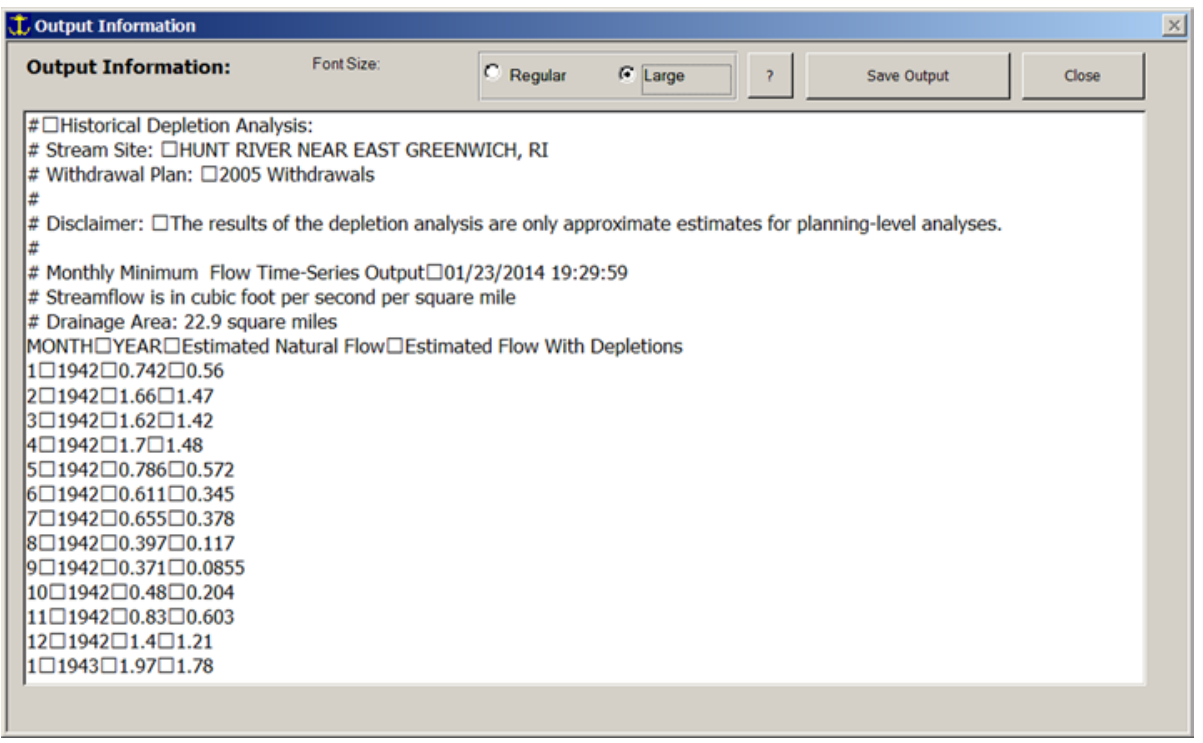

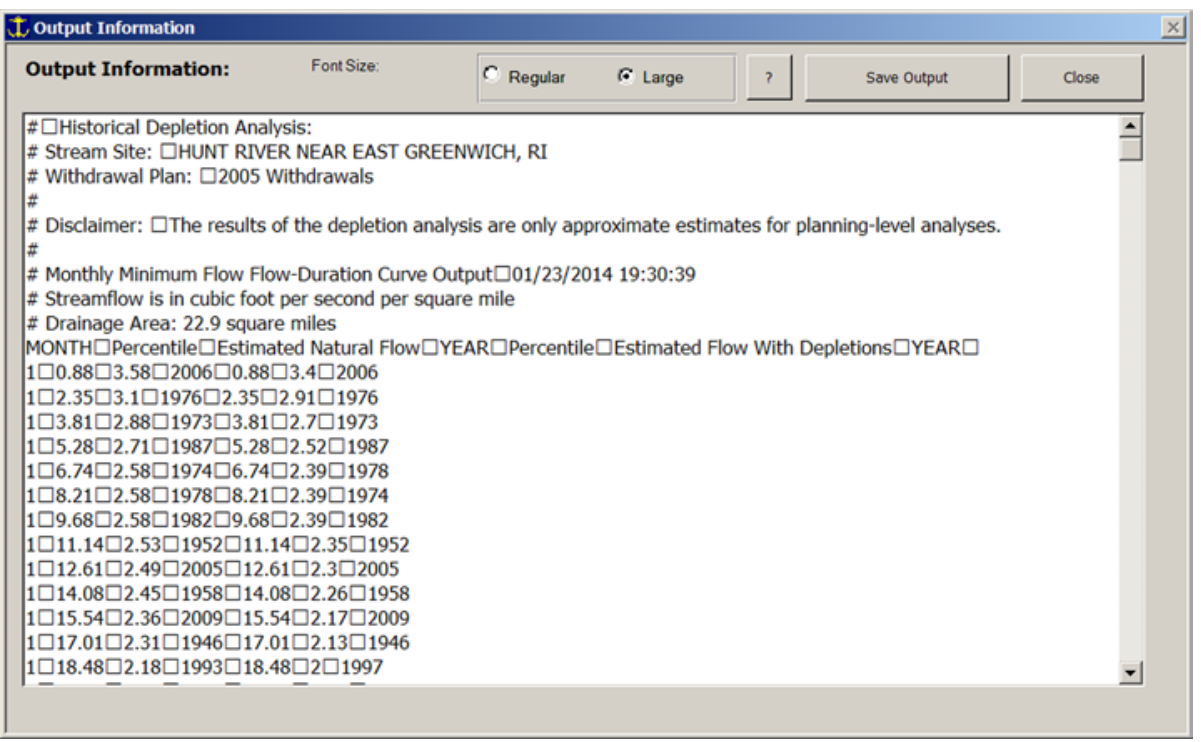

Figure 31. "Output Information" form showing the depletion-analysis results as a $A$, monthly minimum time series table and $B$, monthly minimum flow-duration table. 
of ranked values is generated from one month to the next by using serial correlation values, and statistics are calculated for each month by using the associated data values.

The "Rank Correlation Analysis of Hydrologic Drought Variables" form (fig. 32A) has an output textbox on the left side, which takes up most of the area of the form, and several controls on the right side. This form prints the output to the textbox as tab-delimited text to facilitate use with spreadsheets and graphing software. The controls on the right-hand side of the form provide the means to select variables, calculate rho values, save the results to an output file, and, if the second variable is estimated streamflow for the site of interest, to update the correlation table that is used for drought-projection analyses. There are two option boxes, "Select First Variable" and "Select Second Variable." Each option box has choices for precipitation, measured streamflow, groundwater, and estimated streamflow data. Two comboboxes, one for the "First Site Name" and one for the "Second Site Name" are used in the analysis. When you change the option-box selections, the associated comboboxes provide the associated list of data-collection stations or sites of interest. The lists of sites available also change with the different option boxes to reflect the type of data selected. The form has three choices for output formats in the "Select Output Format" option box. These choices are "Table" to produce output in correlationtable format, "Graph" to produce output in a format for making correlation graphs, and "Both" to produce output with both the table and graph formats.

The table format is designed to provide statistical tables for drought-analysis reports. This option produces five tables. The first table contains the calculated rank correlation values. The second table contains the upper 95-percent confidence intervals for the calculated rank correlation values. The third table contains the lower 95-percent confidence intervals for the calculated rank correlation values. The fourth table contains the significance probabilities $(p)$ of the calculated rank correlation values. The fifth table contains the numbers of values used to calculate the rank correlation values. Each table has 12 columns and 12 rows. The first column contains the month number (1 through 12 for January through December). The remaining columns contain the rank correlations between the values for the month in the first column and the month plus 0 through 11. For example, the first value of 0.975 in the upper left corner of figure 32B is the rank correlation between January data from the Wood River and estimated unaltered January (month +0$)$ streamflows in the Hunt River. In the next column, the value of 0.529 is the rank correlation between January data from the Wood River and estimated unaltered February $($ month +1$)$ streamflows in the Hunt River. The final value in the first row, -0.134 , is the rank correlation between January data from the Wood River and estimated unaltered December $($ month +11$)$ streamflows in the Hunt River. The next row contains the rank correlations for February streamflows in the Wood River with streamflows in the Hunt River for the months from February through January, and so forth. If the same site is selected for the $X$ and $Y$ stations, then the month +0 correlations will be one, and the subsequent values will indicate the serial persistence of hydrologic conditions at the site. If different sites are selected for the $X$ and $Y$ stations, then the month +0 correlations indicate the power of data from one site to predict hydrologic conditions at the second site in the current and subsequent months.

The "Graph" output format is designed to provide data in a table format that facilitates creation of rank correlation graphs for drought-analysis reports. The graph format has 7 columns and 144 rows. The first column contains the designated months for one dataset $(X)$, and the second column contains the designated months for the second dataset $(Y)$. The third column contains the calculated rank correlation values. The fourth column contains the upper 95-percent confidence intervals for the rank correlation values. The fifth column contains the lower 95-percent confidence intervals for the calculated rank correlation values. The sixth column contains the significance probabilities $(p)$ for the calculated rank correlation values. The seventh column contains the counts of values used to calculate the rank correlation values.

The form has three command buttons, "Calculate Monthly Rhos for Station(s)," "Save Results to File," and "Update Correlation Table" (fig. 32B). The "Save Results to File" and "Update Correlation Table" buttons are not enabled when the form loads (fig. 32A), but may be enabled after the analysis has been run (fig. 32B). The "Calculate Monthly Rhos for Station(s)" command button runs the correlation analysis program and also activates the progress bar at the bottom of the form, which will indicate that the program is running. The "Save Results to File" will be enabled after the analysis has been run. This command button opens a Windows common dialog form (similar to fig. 22) to provide an interface on which to save the file in a user-specified location. If the second station is an index site, then the "Update Correlation Table" command button will also be enabled after the analysis has been run. Clicking this button will update the rank-correlation values that will be used in the drought-projection analysis. The spreadsheet ExampleRhoGraphs.xls is provided as part of the digital media accompanying this report to display rank correlation analysis results in different formats.

\section{Drought-Projection Analysis}

The "Hydrologic Drought-Projection Analysis" form (fig. 33) is designed to facilitate estimation of a sample of possible monthly minimum unaltered streamflows and calculation of the effects of different pumping plans on the estimated streamflows. The drought-projection analysis provides a planning-level estimate of the probability that monthly minimum streamflows will be below any user-defined thresholds in the coming months with and without streamflow depletions caused by withdrawals. This form uses Monte Carlo methods to generate the ranks of projected flows from an initial position that is selected from several potential options by the user. Two types of streamflow records are provided by the programs underlying this form: the sample of estimated 
$\boldsymbol{A}$

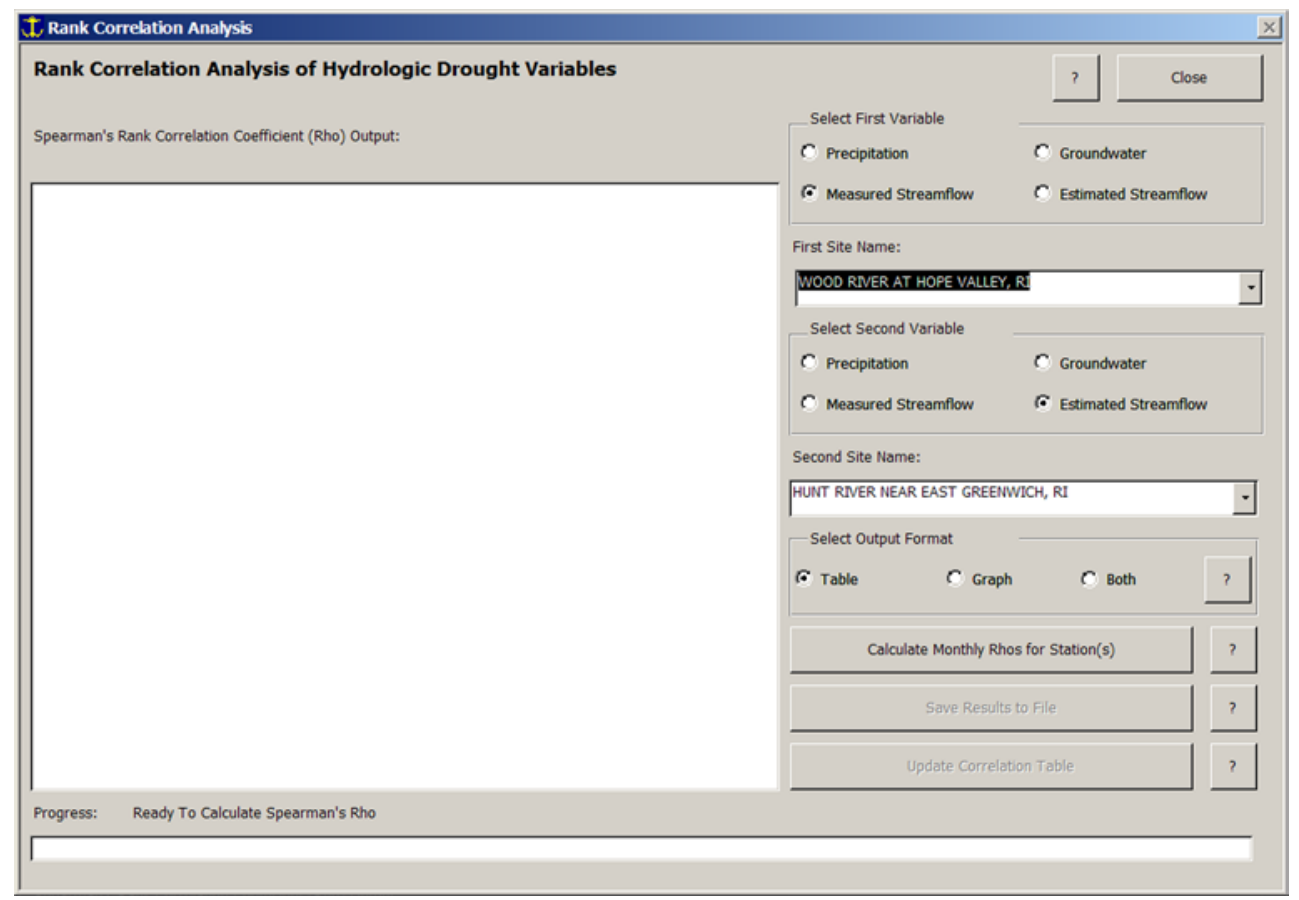

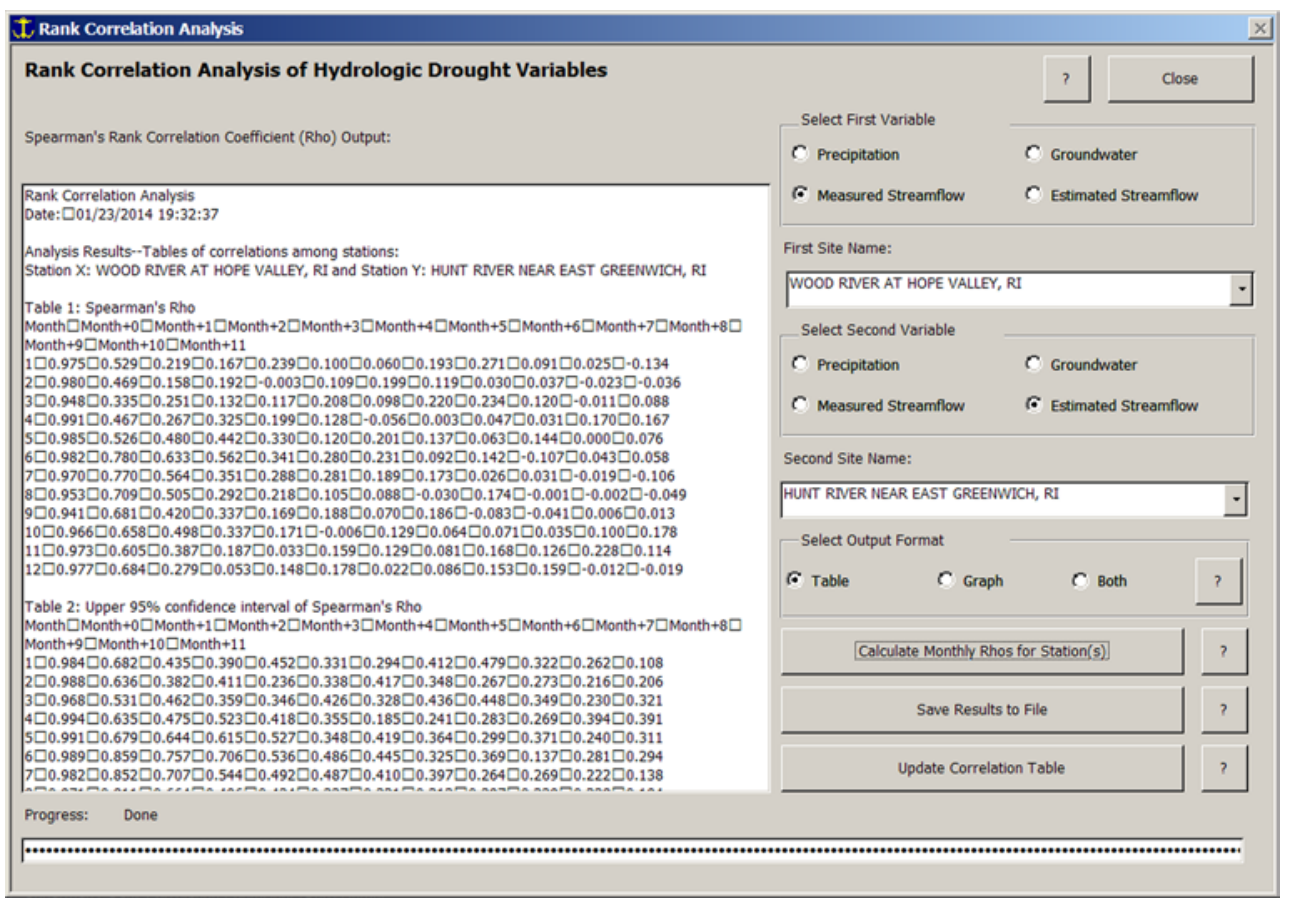

Figure 32. The "Rank Correlation Analysis" form $A$, as it opens and $B$, after completing an analysis. 

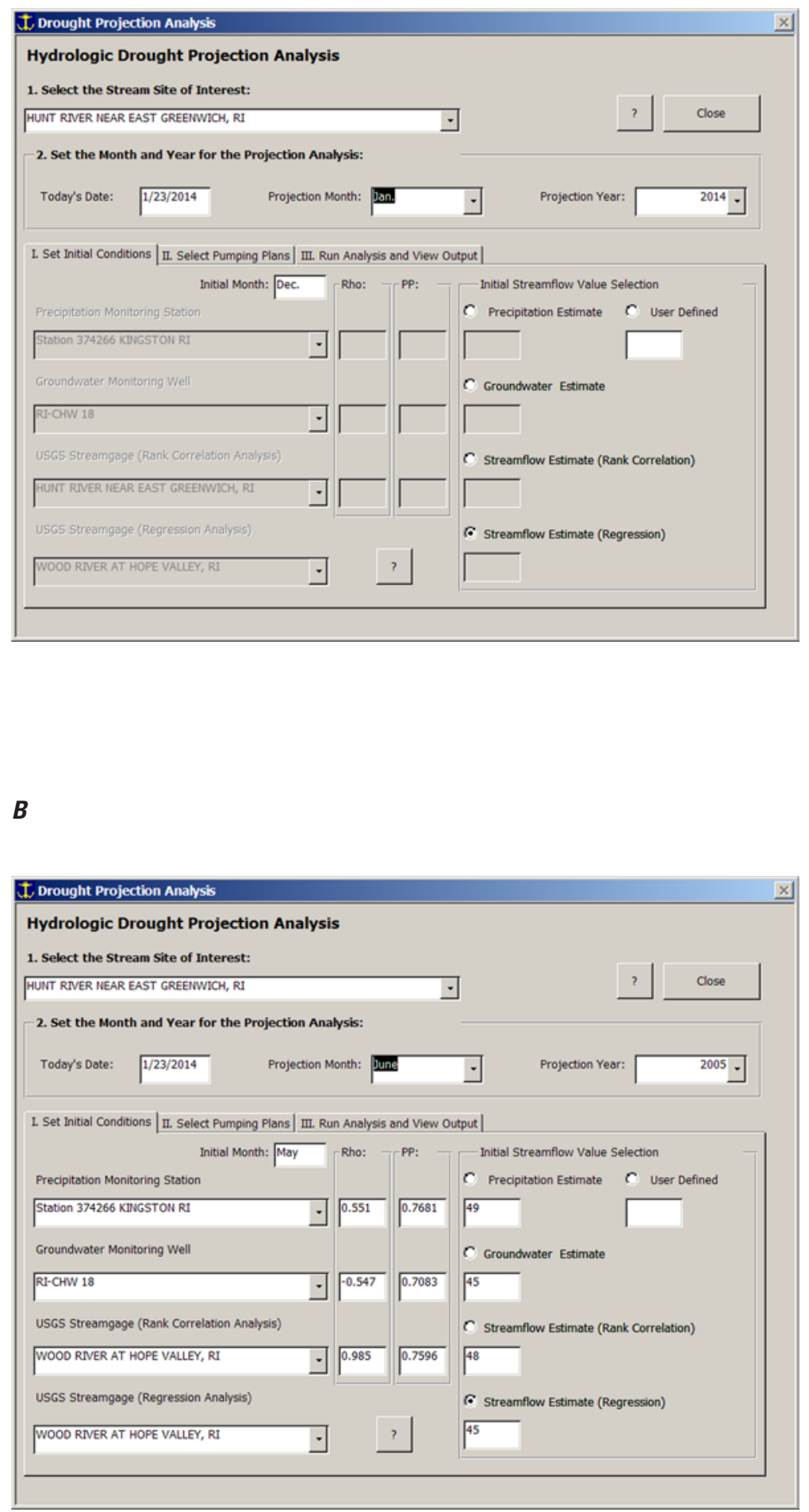

Figure 33. "Hydrologic Drought-Projection Analysis" form showing $A$, the initial view of the "I. Set Initial Conditions" tab for a date without data in the HyDroDSS, $B$, the view of the "I. Set Initial Conditions" tab for a date with data in the HyDroDSS, $C$, a view of the "II. Select Pumping Plans" tab, and $D$, a view of the "III. Run Analysis and View Output" tab. 

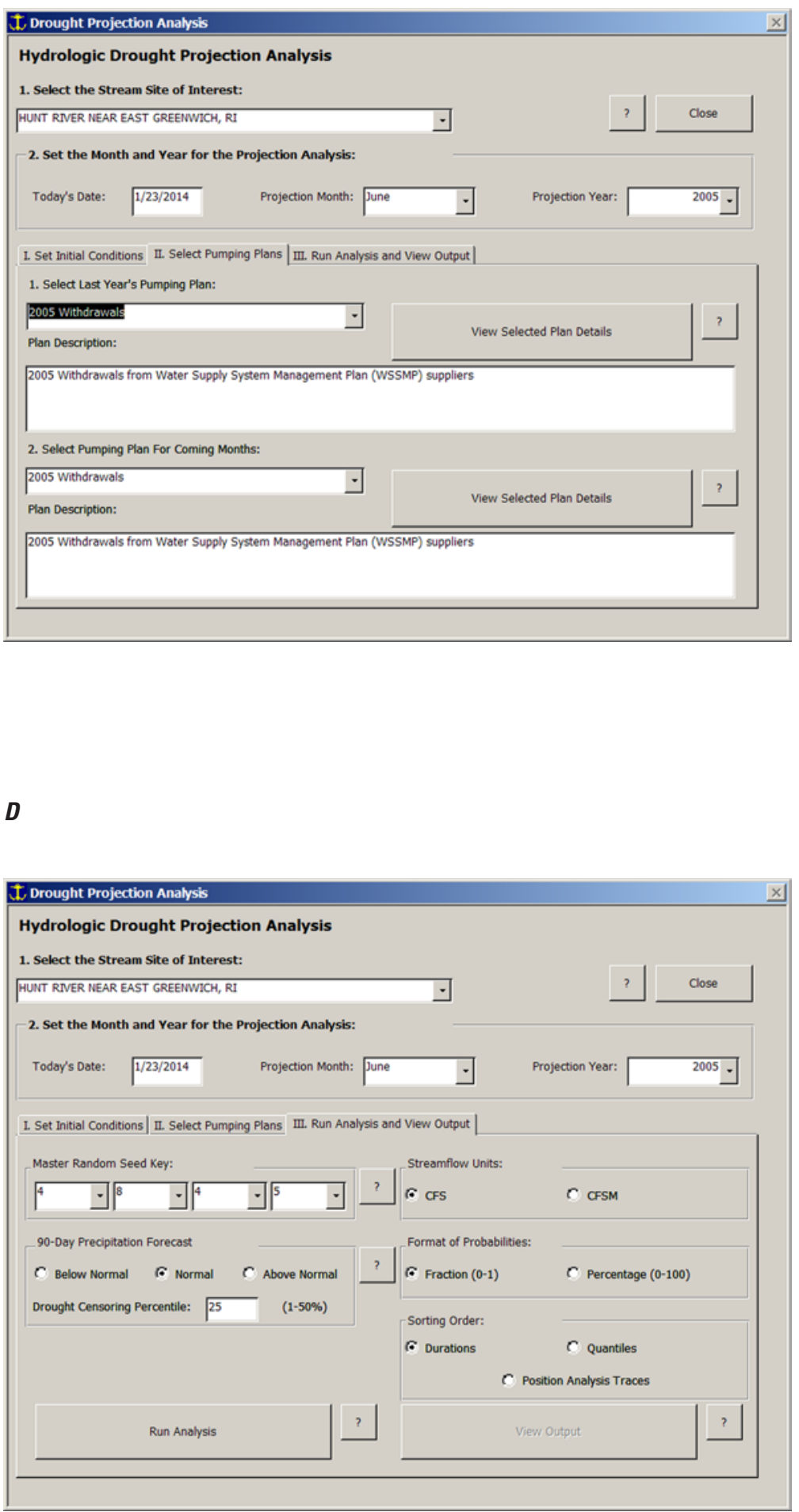

Figure 33. "Hydrologic Drought-Projection Analysis" form showing $A$, the initial view of the "I. Set Initial Conditions" tab for a date without data in the HyDroDSS, $B$, the view of the "I. Set Initial Conditions" tab for a date with data in the HyDroDSS, $C$, a view of the "II. Select Pumping Plans" tab, and $D$, a view of the "III. Run Analysis and View Output" tab.-Continued 
unaltered streamflows and the sample of streamflows with calculated depletions. A combobox on the top left corner of the form displays the site of interest, "1. Select the Stream Site of Interest," that was selected on the "Main Menu." Below is a textbox "Today's Date" showing the current date, a "Projection Month" combobox and a "Projection Year" combobox. The form will allow you to select a prior month or year, but not a future month. If data for one or more hydrologic predictors are not current in comparison to the selected projection month, then the associated selectors will be disabled, and the program will not run an analysis for the current time period (fig. 33A). If predictors are current, or a prior month and year is selected, then the associated selectors will be enabled and populated for selection (fig. 33B).

This form has three tabbed pages for forming a projection analysis model. The first tab titled "I. Set Initial Conditions" (fig. 33B) is an interface for selecting the initial position of the estimated unaltered streamflow for the month prior to the current month. The position analysis starts in the month prior to the selected current month because monthly measurements of the hydrological predictor variables are assumed to be unavailable for a drought planning meeting. Values of the hydrological predictor variables are provided because approved streamflow records and monthly pumping data also are assumed to be unavailable for direct calculation in time for a drought planning meeting. If data are available, you may select an estimate from a precipitation-monitoring station, a groundwater-monitoring well, or a USGS streamgage (by using rank correlation or a regression-estimate). You select a station from among available selections by using the comboboxes on the left side of the tab. After you select the data-collection sites, the rank correlation (rho) value of the site is displayed with the initial month's plotting position and the streamflow estimate for the site of interest based on data from the selected station. Once these values are calculated, you may select one of the estimates by clicking the associated option button. This tab also has a "User Defined" option, which may be used to enter any user-selected flow values. User-defined flow values may include the median or average of the other predictions on this form. The user-defined flow values also may be estimates of the unaltered-streamflow values from measured streamflow and pumping data if such data are available for the initial month. If any of the "Precipitation Estimate," "Groundwater Estimate," or "Streamflow Estimate (Rank Correlation)" options are selected, the initial position is calculated by using the plotting position of the associated data. If the "Streamflow Estimate (Regression)" option is used, then the flow is calculated by using the specified regression equation, and the plotting position is calculated from the flow estimate.

The second tab titled "II. Select Pumping Plans" (fig. 33C) is an interface for selecting two pumping plans. The first combobox on the tab (labeled "1. Select Last Year's Pumping Plan") is used to select a pumping plan that is representative of pumping volumes in the months leading up to the drought-projection month. The second combobox on the tab (labeled "2. Select Pumping Plan For Coming Months") is used to select a pumping plan that is representative of expected pumping volumes during the current month and the subsequent months in the projection analysis. This two-plan approach lets you estimate the risk for streamflow being below a target in the coming months under different pumping-management plans. To do this type of sensitivity analysis, you need to pick a plan and run the analysis, then repeat the process for each additional pumping-management plan under consideration. This tab also has a textbox with a brief description for each plan and a command button to view the details for each plan. Each "View Selected Plan Details" button opens a form similar to figure 15 with detailed plan information. The detailed plan information includes the withdrawal-plan name, type of plan, type description, and user-defined plan information. The detailed plan information also describes all the withdrawal points in the plan with the name, comments, and water-use-database identification numbers. Detailed plan information also includes monthly response coefficients and monthly mean pumping rates for each withdrawal point.

The third tab titled "III. Run Analysis and View Output" (fig. 33D) is an interface for selecting a master random-seed key, selecting the drought-forecast variables, running the analysis, and creating the analysis output values. The random key is reset each time the form is loaded, but it may be reselected manually by using the four comboboxes in the "Master Random Seed Key" group. The "90-day Precipitation Forecast" option box includes "Below Normal," "Normal," or "Above Normal" forecasts and the associated "Drought Censoring Percentile." The "Run Analysis" command button runs the drought-projection analysis with the preselected inputs and enables the "View Output" command button.

The random-seed key defines the first random seed in the sequence of random numbers that are generated. Computers cannot produce true random numbers without special equipment, so programs are written to produce numbers that appear to be random (called pseudorandom numbers). Most of these random-number generators create a long series of values that are eventually repeated. The random seed defines the point of entry into this series of pseudorandom numbers. One problem with many Monte Carlo models is that you cannot select the random seed and therefore cannot replicate the same series of calculations in subsequent runs. This HyDroDSS automatically generates a random-seed value when the form is loaded, but it lets you select the master seed so that you can replicate the same series of pseudorandom numbers. The values in the comboboxes on the form are not equal to the actual random seed. Each of these numbers is the index number for one of the 9,999 random-seed pairs in the index table.

The "90-day Precipitation Forecast" selection and the "Drought Censoring Percentile" control the range of plotting position values generated in the first three months of a drought-projection analysis. The "90-day Precipitation Forecast" selection indicates an estimate for the coming months, which may be based on the National Weather Service Climate Prediction Center's 90-day drought outlook. The categories 
(below normal, normal, and above normal) are used by the National Weather Service to describe forecast results from their climate models. The "Drought Censoring Percentile" determines the limits on the plotting positions (and therefore estimated streamflows) generated by the model during the first three months of the analysis. For example, if a below-normal condition is selected with a 25-percent censoring limit, then flows will be generated by using the lower 75 percent of plotting position values. Conversely, if an above-normal condition is selected with a 25 -percent censoring limit, then flows will be generated by using the upper 75 percent of plotting position values. If a normal condition is selected, the DCP is not used in the projection analysis.

The "View Output" command button takes the userselected options for the streamflow units, the format of probabilities, and sorting order and launches the information form with the selected output (fig. 34). Three output options for these estimated flows are provided. Flows may be exported in units of cubic feet per second ("CFS" on the form) or cubic feet per second per square mile ("CFSM" on the form).The probabilities may be exported as fractions $(0-1)$ or percentiles $(0-100)$. The three sorting-order selections are flow durations (flows sorted from high to low), flow quantiles (flows sorted from low to high), and position analysis traces (flows sorted in the order that they are generated).

Information about the analysis and output selections is provided as the header to the numerical output (fig. 34A). The header lines are denoted by pound symbols (\#). Information about the analysis includes the date and time of the analysis, the site of interest, the initial month, the first projection month, the last projection month, the master random-seed key, the 90-day precipitation forecast, the DCP, the pumping plans, and the initial streamflow estimate. The information about the analysis includes all the information that is necessary to redo a given analysis from the user interface by using the same version of the HyDroDSS. Information about the output selections includes the streamflow units (cubic feet per second or cubic feet per second per square mile), the type of probabilities (fractions or percentiles), the type of output selected (flow durations, quantiles, or position analysis traces). The header information also includes explanations for the headings of the flow-duration and flow-quantile output tables.

The flow-duration and flow-quantile options are provided to present the output in a format that is easy to use with spreadsheets or graphing software to communicate the risk of the flow being below a user-specified threshold. One tabdelimited table with 21 tab-delimited columns (fig. 34B) is created to provide the results of analysis if the flow-duration or flow-quantile option is selected. The first column of this table is an index number $(\mathrm{N})$, which is simply a line number for the flow-duration and flow-quantile output. The index number is followed by 2 columns labeled "PP0" and "QEst 0 ," which are the plotting position and flow value for the initial position analysis. The next 18 columns are the plotting position, the estimated unaltered streamflow, and the estimated streamflow with depletion for each of the 6 months included in the position analysis. The abbreviations for each month are printed in the plotting-position column in the row before the variable names. In the outputs for the flow durations or flow quantiles, each row contains the plotting position and flow estimate that corresponds to the adjacent plotting-position value. Each of the estimated streamflows with depletion is calculated from the associated estimated unaltered-streamflow value with a consistent depletion estimate for each month. Therefore, the streamflow values for a given month in each pair of share the same plotting position. The monthly values in each row are sorted by plotting position rather than by the Monte Carlo index number. Therefore, the monthly values within a row represent the results of different position analysis trials.

The "Position Analysis Traces" option (fig. 33D, lower right quadrant) is provided to present the values in the order in which they were generated by using the Monte Carlo algorithms. This output format also is designed to be easy to use with spreadsheets or graphing software. Four tab-delimited tables with eight tab-delimited columns (fig. 34C) are created to provide the results of analysis if the "Position Analysis Traces" option is selected. This option is designed to directly display the Monte Carlo analysis results and to demonstrate how monthly minimum streamflow records may evolve from an initial position given the serial correlation of unaltered monthly minimum streamflow values in the estimated historical record. The first table shows the population plotting positions, which are the values generated by the uniform random-number generator. The population plotting positions will include any number between 0 and 1 (between 0 and 100 if percentiles are used). For this reason, these plotting-position values may represent flows that are within or outside the range of available data. If drought-forecast censoring is used, then population plotting positions beyond the censoring threshold are rejected and therefore do not appear in the Monte Carlo results. The second table shows the sample plotting positions, which are calculated by ranking flow values and calculating plotting-position values using the Cunnane formula (Helsel and Hirsch, 2002) as if the generated values represent the available sample of historical flows. For example, if a DCP of 25 percent were selected, then the population plotting positions would range from greater than or equal to 25 percent to less than 100 percent, whereas the sample percentiles for the 251 position analysis trials could range from 0.24 to 99.76 percent based on the Cunnane formula (Helsel and Hirsch, 2002). The third table shows the estimated monthly minimum unaltered flows; these values are estimated from available data. If the population plotting-position values are within the plotting-position range of the historical dataset, then estimated unaltered flow values are calculated by interpolating the flows and plotting positions of the dataset. If the population plotting-position value is above or below the range, then the maximum or minimum estimated unaltered-flow value is assigned, respectively. The fourth output table shows the estimated monthly minimum flows with depletions; these values are calculated by subtracting the calculated net depletion for each month from the estimated unaltered-flow value. The 
A

\begin{tabular}{|c|c|c|c|c|c|c|c|}
\hline \multicolumn{7}{|l|}{ L Output Information } & $x$ \\
\hline Output Information: & Font Size: & (C) Regular & $C$ Large & ? & Save Output & Close & \\
\hline \multicolumn{6}{|c|}{ 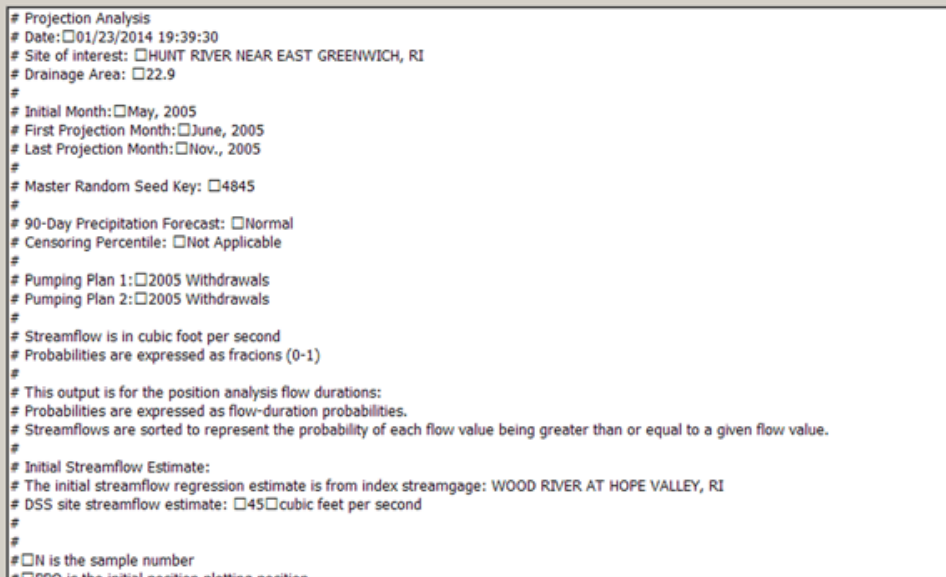 } & $\Delta$ & \\
\hline
\end{tabular}

\section{B}

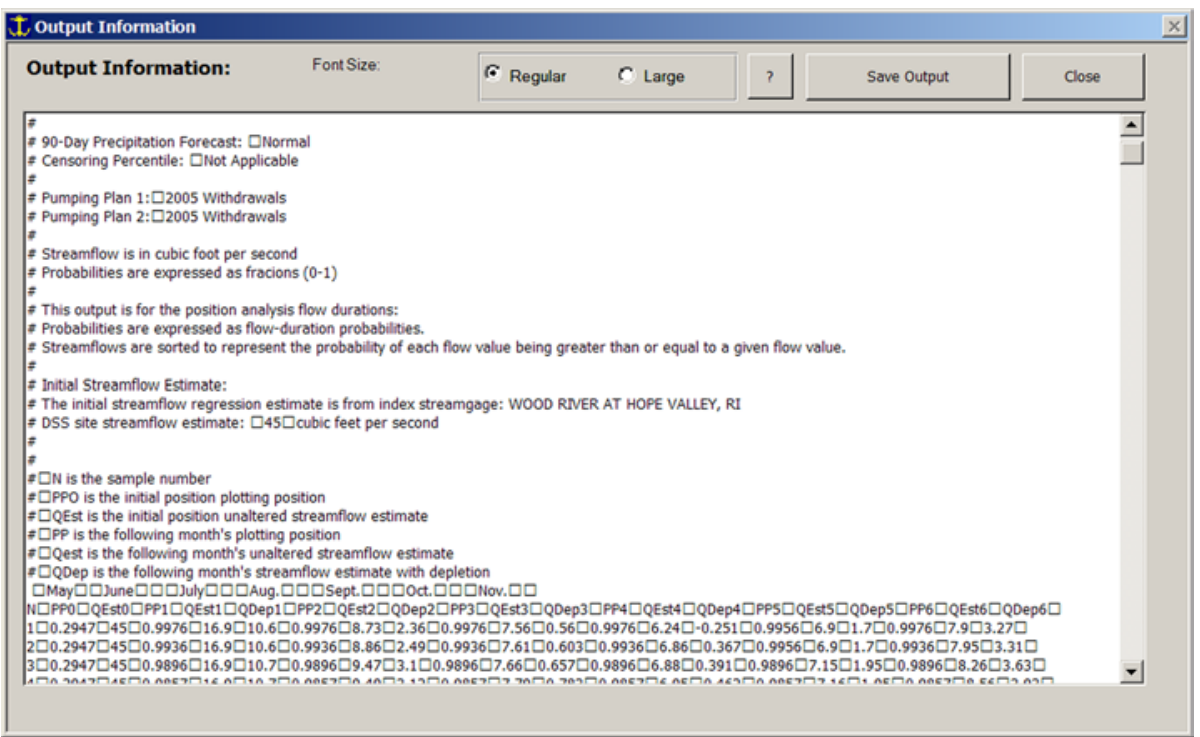

C

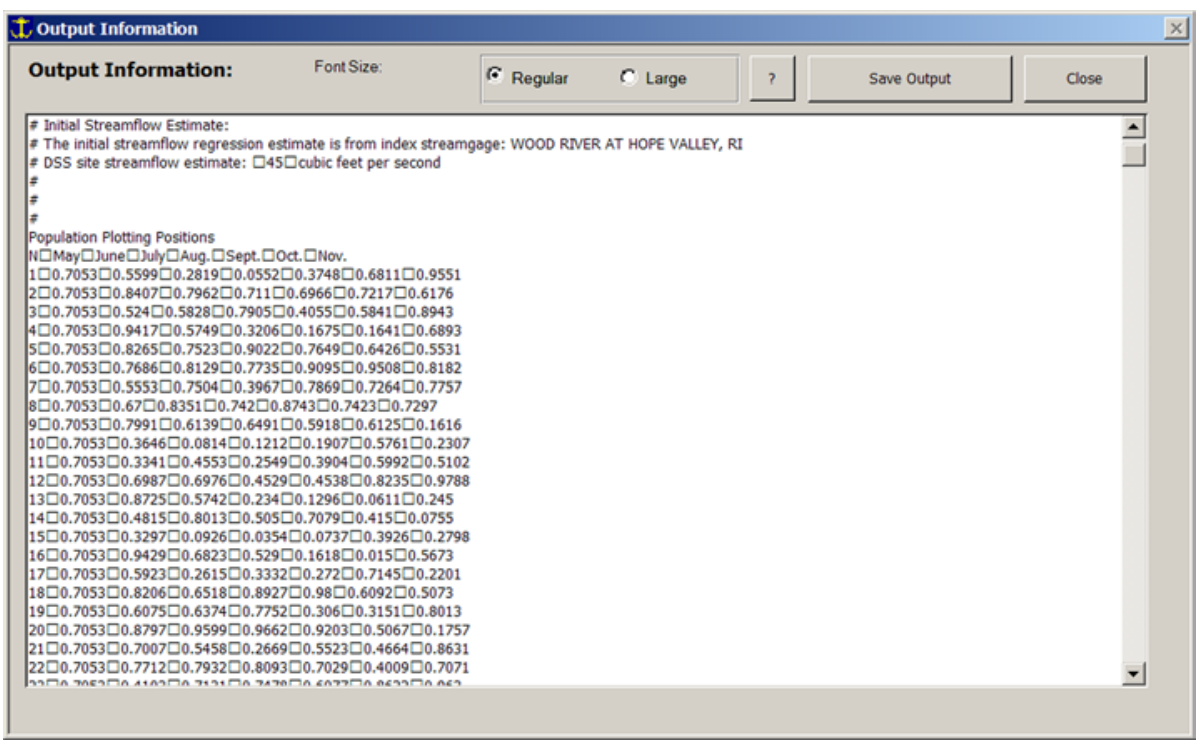

Figure 34. "Output Information" form showing hydrologic drought-projection results for $A$, the analysis header information, $B$, the flow-duration or flowquantile output table, and $C$, a position analysis trace table. 
calculated net depletion for each month is a constant for all the Monte Carlo traces for that month. Therefore, the variation in streamflows with depletions within a given month is entirely due to variations in estimated unaltered streamflows generated by the Monte Carlo algorithms.

The first of the eight columns of this table contains an index number $(\mathrm{N})$, which is the index number of each Monte Carlo trace in the order that it was generated. The second column of the table, labeled with the abbreviation for the initial month of the analysis, holds the constant input value of the variable (the population plotting positions, sample plotting positions, estimated monthly minimum unaltered flows, or estimated monthly minimum flows with depletions) in each of the tables. The third through eighth columns hold the results of the Monte Carlo analysis for the variables in the tables for the months in the projection analysis. The headings for these six columns are the abbreviations for the months included in the projection analysis.

Once the "View Output" button is clicked, the results are sent to the information form. When the information form is opened, the focus is set on the output textbox and the text is highlighted in black. While the text is highlighted, the output information can be copied from the information form by right-clicking the text and selecting "Copy" on the pop-up menu or by clicking the Ctrl-C keyboard combination. This information can then be pasted into another application. To read the information within the form, click the large-font-size option and view the output information in the textbox by using the scroll bar on the right. The results can be saved to an output file by clicking the "Save Output" button, which will launch a common-dialog form (fig. 16) for saving the results in a user-specified text file. The spreadsheets ExampleOutput01BootstrapTraces. xls, ExampleOutputMonthlyGraphs.xls, and ExampleOutputMonthlyGraphs2.xls are provided as part of the digital media accompanying this report as tools to facilitate production of graphs of projection-analysis results in different formats. Once you are done reviewing the information, click the "Close" button to return to the main menu.

\section{Case Study-Streamgage 01117000 Hunt River near East Greenwich, Rhode Island}

Streamflow and water-withdrawal data from the basin upstream of USGS streamgage 01117000 on the Hunt River near East Greenwich, R.I., (fig. 35) were used as the case study for developing the HyDroDSS because of long-standing concerns about the sustainability of historical withdrawal rates for water supply in this basin. The example provided in the HyDroDSS is based on the long-term streamflow, water-withdrawal, and hydrogeologic data for this study area and the well-vetted groundwater model derived from the data (Barlow, 1997; Dickerman and Barlow, 1997; Barlow and Dickerman, 2001; Barlow and others 2003; Barlow and Ostiguy, 2007). Concerns about the long-term sustainability of water supplies in relation to ecological protection goals for the Hunt River Basin and the adjoining Annaquatucket and Pettaquamscutt stream-aquifer systems (collectively known as the HAP stream-aquifer system) prompted the studies to develop groundwater and conjunctive-management models to provide a way for local water managers to balance watersupply needs with ecological protection goals in the basin. After these studies were finished, record pumping volumes (more than 5.1 Mgal/d) from wells in the Hunt River Basin that were concurrent with a period of low streamflows during August 2005 prompted further concerns from water suppliers (Kathleen Crawley, RIWRB, written commun., 2005), the Rhode Island Department of Environmental Management (RIDEM) (Alisa Richardson, RIDEM, written commun., 2005), and environmental groups (Harold Ward, Rhode Island Coalition for Water Security, written commun., 2005). These groups concurred that better water-management tools were needed to help mitigate the potential effects of hydrologic drought conditions caused by withdrawals and precipitation deficits. These groups also concurred that the Hunt River should be the first basin to be evaluated with such management tools.

Application of the HyDroDSS for the case study was limited to the Hunt River portion of the HAP for several reasons. Continuous streamflow records are available for the Hunt River, but are not available for the Annaquatucket and Pettaquamscutt Rivers. Ratios of withdrawals to available streamflow have, historically, been higher in the Hunt River Basin than in the other two basins (Barlow and Dickerman, 2001). Extreme low flows in the Hunt River during August 2005 provided the impetus for development of the HyDroDSS and many other water-management initiatives in Rhode Island (Kathleen Crawley, RIWRB, written commun., 2010).

Pumping data indicate that increases in withdrawals over time may be a substantial driver in the frequency and severity of hydrologic drought because of low flows caused by depletions. Data from all North Kingstown wells were selected for trend analysis because complete pumping records are available for the 1978-2008 period (Susan Licardi, North Kingstown Water Department, written commun., 2008), and selection of only the wells in the Hunt River Basin may reflect the effects of well field operations as well as overall trends with time. Total monthly water withdrawals in million gallons per month (Mgal/mo) during the 1978-2008 period are shown in figure 36 with three regression lines. The data show considerable annual variations with substantially higher withdrawal rates in June, July, and August. Peak withdrawal rates for these months were about $167 \mathrm{Mgal} / \mathrm{mo}$ in June 1999, about $205 \mathrm{Mgal} / \mathrm{mo}$ in July 2002, and about 205.5 Mgal/mo in August 2005. A seasonal Kendall trend test (Hirsch and others, 1982; Helsel and Hirsch, 2002; Helsel and others, 2006) indicates that the general trend for all months of the year is about $1 \mathrm{Mgal} / \mathrm{mo}$ each year during the 1978-2008 


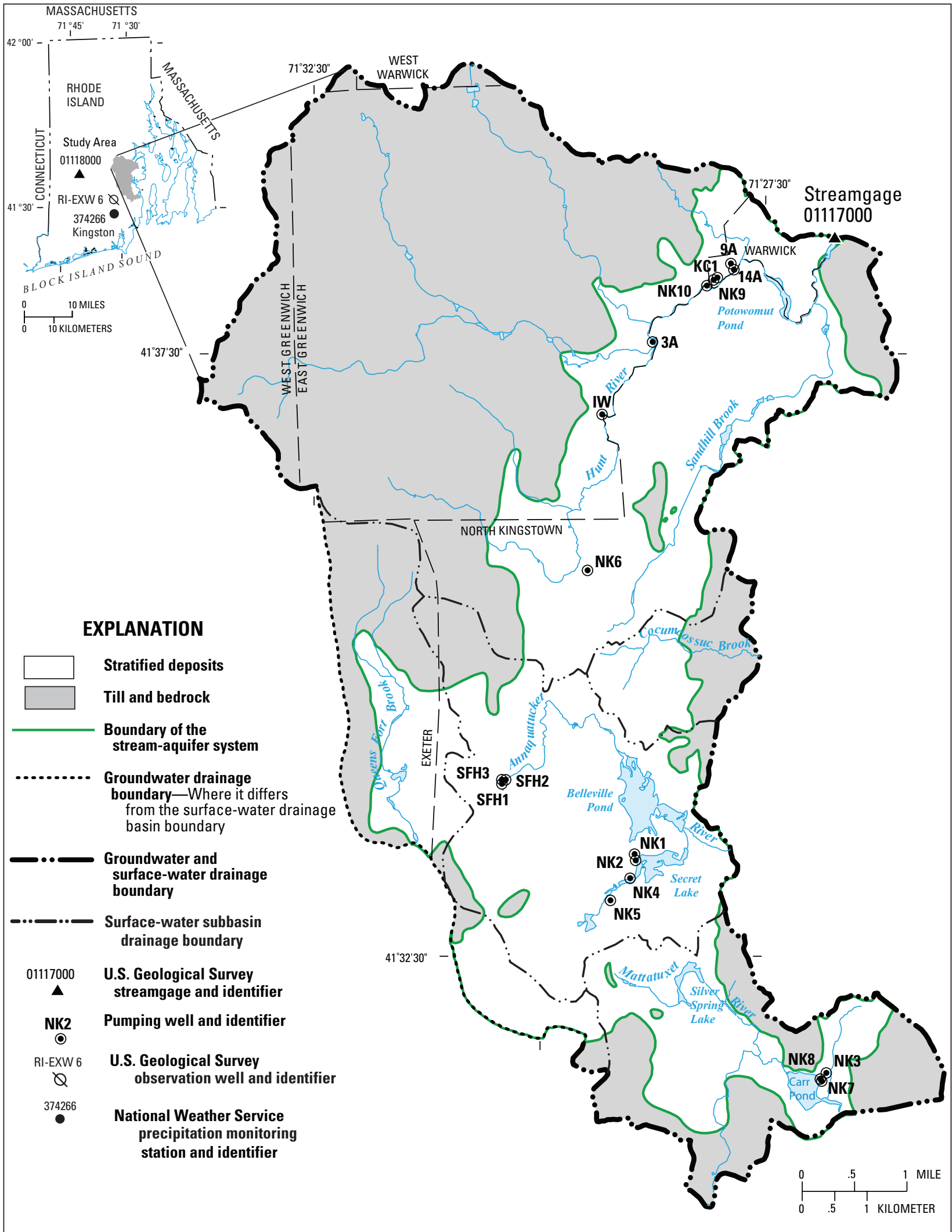

Base map from Rhode Island Geographic Information System

East Greenwich, Slocum, Wickford,

Crompton, 1:24,000, 1988-94

Rhode Island state plane projection

Figure 35. Location of the Hunt River Basin and pumping wells in the Hunt-Annaquatucket-Pettaquamscutt stream-aquifer system and the locations of hydrologic monitoring stations in Rhode Island (modified from fig. 1, Barlow and Dickerman, 2001). 


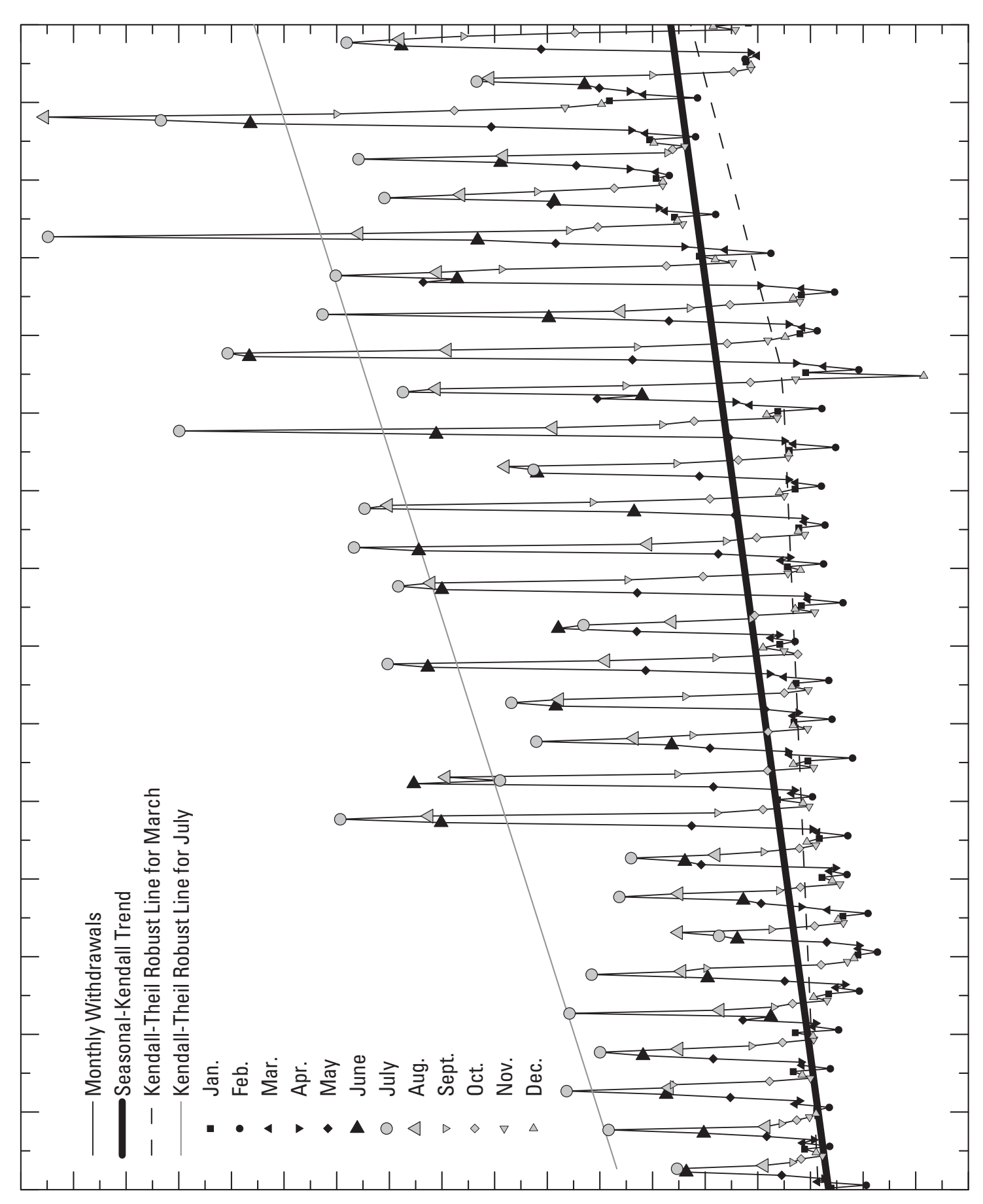

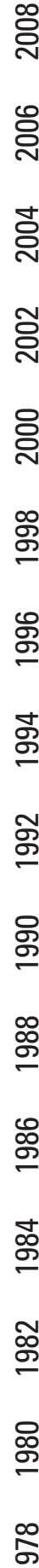

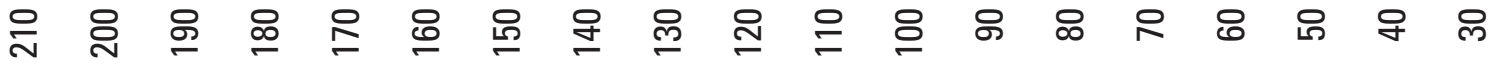

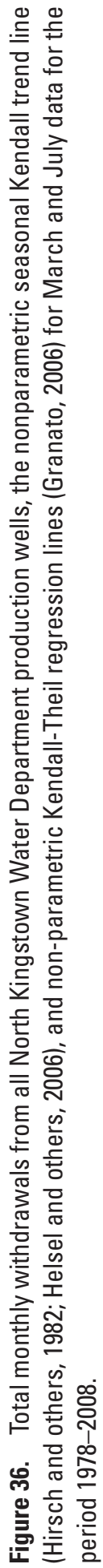


period. Regression analysis by using the Kendall-Theil robust line method (Helsel and Hirsch, 2002; Granato, 2006) for the summer months indicate much larger trends with time for these months than for the entire year-about 1.8, 2.3, and 2.1 Mgal/mo each year for June, July, and August, respectively. The trend line for July withdrawals is shown as an example in figure 36. Regression analysis for May, September, and October indicate that trends with time for these months are about 1.5, 1.4 and $1.0 \mathrm{Mgal} / \mathrm{mo}$ each year. Pumping data for the months May-August indicate that, in general, withdrawal values for dry months tend to plot above the local value of the long-term trend line and values for wet months tend to plot below the trend line for each month. Trends for the months November through April are smaller than the seasonal Kendall value (less than $0.5 \mathrm{Mgal} / \mathrm{mo}$ each year) before the late 1990s but much larger in the last decade (about 2.3 Mgal $/ \mathrm{mo}$ each year). These increased trends have been attributed to winterization of summer residences in the late 1990s (Emily Wild, U.S. Geological Survey, written commun., 2008). Although large increases in pumping during the months of November through April occur in relatively wet months, some portion of the increased depletions may be carried over into later months because of the long response times for some wells in the basin.

\section{Retrospective Streamflow-Depletion Analysis}

Retrospective streamflow-depletion analysis can be used to demonstrate relations between pumping volumes and extreme low-flow risks. Historical pumping plans can be used to demonstrate relations between recent water-use volumes and streamflows. Hypothetical plans, including conjunctivemanagement models, can be used to demonstrate the potential effectiveness of different drought-mitigation strategies.

\section{Response Coefficients}

Response coefficients are used with pumping volumes to calculate depletions for the retrospective streamflow-depletion analysis and are used to formulate conjunctive-management models. The response coefficients for the seven production wells and one industrial well in the Hunt River Basin (fig. 35) were developed by Barlow and Dickerman (2001) from the groundwater model developed for the HAP area. The dynamic equilibrium method with a 5 -year cycle was used to reach equilibrium. Barlow and Dickerman (2001) set up the model to calculate streamflow depletions by simulating different pumping rates and pumping in different months of the year.

The response coefficients for these wells are shown in figure 37. Well QDC03A has the quickest response to pumping because of proximity to the stream and local aquifer conditions. Well NK06 has the slowest response to pumping because the well is farthest from the stream; the sum of the response coefficients is less than one $(0.841)$ because well NK06 captures water that would otherwise flow through the aquifer to the Annaquatucket River. The sums of the response coefficients for all the other wells are slightly less than 1 (an average of about 0.985 ) because the withdrawals cause drawdowns that reduce riparian evapotranspiration in the model. The remaining wells have similar response coefficients because they are all near the stream in areas with similar hydrogeologic properties. These response coefficients were used to calculate depletions for the retrospective depletion and drought-projection analyses in this case study to demonstrate use of the HyDroDSS.

\section{Streamflow Depletions and Estimated Unaltered Streamflow}

Estimates of unaltered streamflow in the Hunt River at USGS streamgage 01117000 were developed for use in the retrospective streamflow-depletion analysis, the rank correlation analysis, and the drought-projection analysis. Figure 38 shows the flow-duration curves for daily mean flows at USGS streamgages 01117000 Hunt River near East Greenwich, R.I., and 01118000 Wood River at Hope Valley, R.I., and for estimated unaltered daily-mean flows at the site of interest on the Hunt River (USGS streamgage 01117000) during the 19422009 period. The flows are graphed in units of feet per second per square mile to facilitate comparison among stations. The effects of withdrawals on streamflow in the Hunt River are readily apparent in figure 38 , because the flow-duration curve for measured flows in the Hunt River begins to substantially diverge (by more than 20 percent) from measured flows in the Wood River at a flow duration of about 65 percent, indicating that depletions have a substantial effect on flows 35 percent of the time (below a threshold of about $1 \mathrm{ft}^{3} / \mathrm{s} / \mathrm{mi}^{2}$ ). This graph also demonstrates the concept of hydrologic drought defined by using a low-flow threshold. If, for example, a hypothetical value of $0.5 \mathrm{ft}^{3} / \mathrm{s} / \mathrm{mi}^{2}$ is used as a criterion to indicate hydrologic drought, then measured streamflows in the Wood River at USGS streamgage 01118000 would be in this drought condition less than 11.5 percent of the time, but measured streamflows in the Hunt River at USGS streamgage 01117000 would be in this drought condition almost 22.3 percent of the time (fig. 38).

A three-step process was used to calculate the estimated unaltered daily mean streamflows in the Hunt River at USGS streamgage 01117000 that are shown in figure 38 . The first step was to compile pumping data, which are available for the period January 1992 through December 2008, and calculate the depletions by using the response coefficients for each well with the program RespDep.exe, which is provided as part of the digital media accompanying this report. The second step was to develop regression equations to extend this record of estimated unaltered streamflows. The first year of calculated values for the period January through December 1992 was discarded because these values do not include residual depletions caused by withdrawals prior to January 1992. A one-segment MOVE.1 line (Granato, 2009) and a two-segment KTRLine 


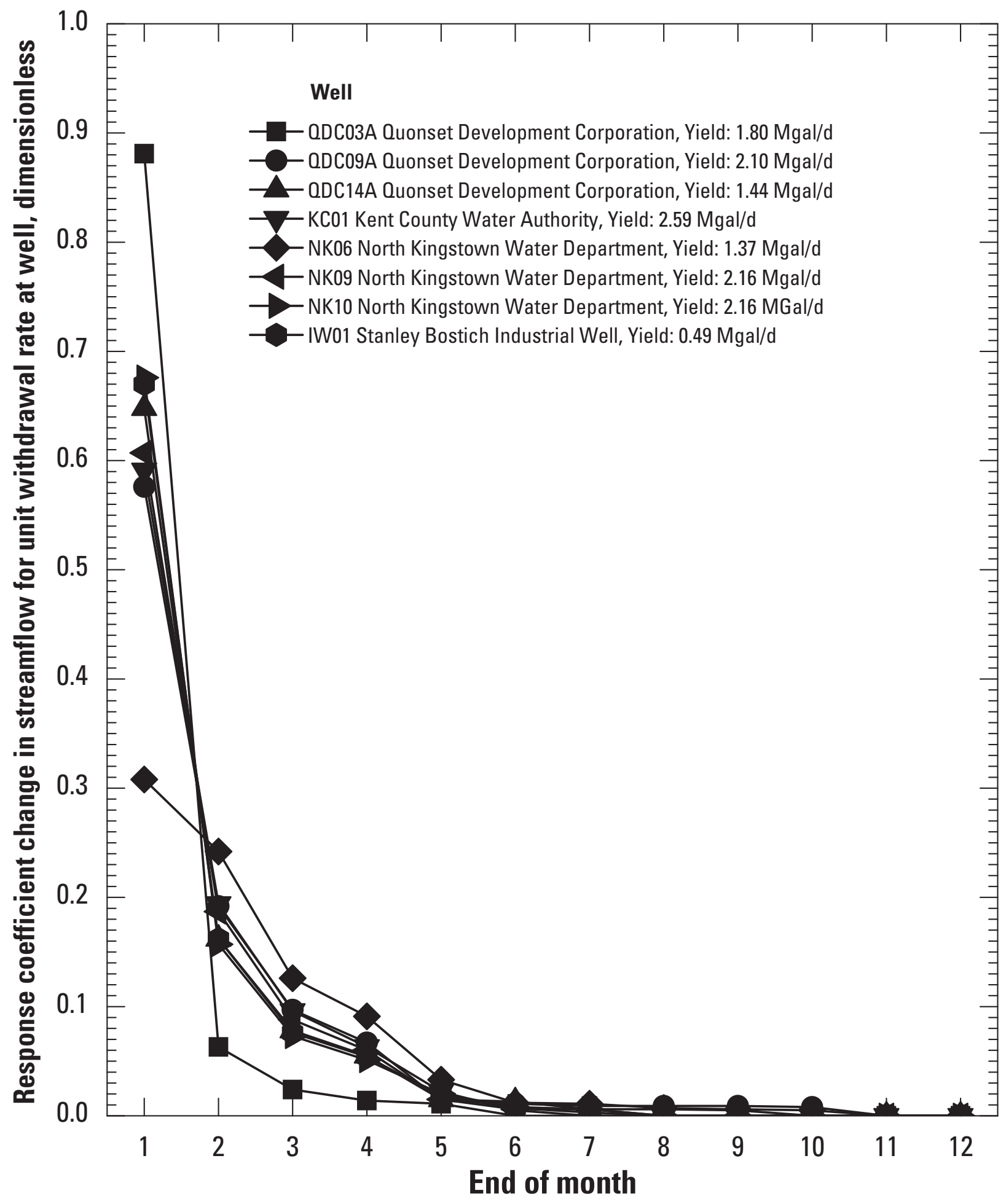

Figure 37. Simulated response coefficients and well yields for the pumping wells in the Hunt River Basin. Response coefficients were developed for the U.S. Geological Survey streamgage 01117000 near East Greenwich, Rhode Island, by Barlow and Dickerman (2001) from the groundwater-flow model developed for the HAP stream-aquifer system. 

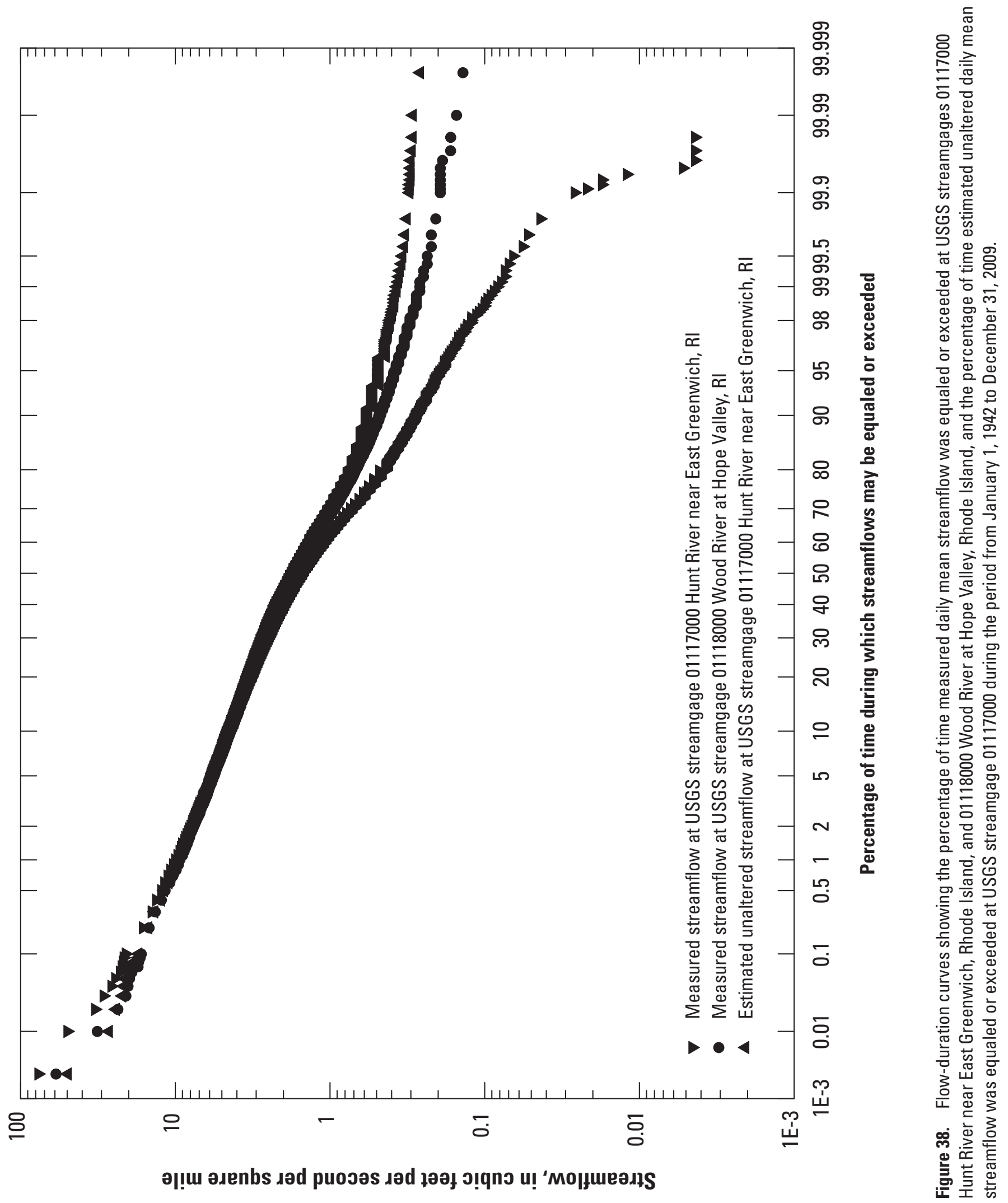
(Granato, 2006) were developed to extend the record of estimated unaltered daily mean streamflows (fig. 39). The two-segment KTRLine equation was selected because it better represents the critical low flows than the MOVE.1 equation. The third step was to use the KTRLine equation in the SREF program (Granato, 2009) with measurements from streamgage 01118000 to generate a long-term record of estimated unaltered streamflows in the Hunt River at streamgage 01117000 during the 1942-1993 and 2008-2009 periods to supplement the estimates made for 1993-2008 with actual streamflow and withdrawal data.

The flow-duration curve for the estimated unaltered streamflows is shown in figure 38. The flow-duration curve for estimated unaltered flows in the Hunt River begins to substantially diverge (by more than 20 percent) from measured flows in the Wood River at a flow duration of about 92 percent, indicating that the small proportion of depletions in the Wood River Basin have a substantial effect on flows less than about 8 percent of the time (a threshold of about $0.43 \mathrm{ft}^{3} / \mathrm{s} / \mathrm{mi}^{2}$ ). The flow-duration curves for unaltered flows in the Hunt River estimated by using methods described herein are similar to unaltered-streamflow estimates made for sites in the Pawcatuck River Basin by using a watershed model (Zarriello, 2011), indicating that the two-segment KTRLine estimate is a good model for unaltered streamflows in the Hunt River.

\section{Conjunctive-Management Models}

Knowledge of relations between streamflow criteria and maximum potential water withdrawals is crucial for waterresource-planning efforts (Barlow and Dickerman, 2001a,b; Barlow and others, 2003; Granato and Barlow, 2005; Granato and Walter, 2011). Groundwater-supply-system operators cannot control the total volume of streamflow if they do not also operate a surface-water reservoir that can be used to intercept and store high flows for later release during dry periods to maintain streamflows. Most groundwater-supply systems in Rhode Island do not have surface-water reservoirs with adequate capacities for public supply and streamflow maintenance. Groundwater-supply-system operators, however, can affect the magnitude and timing of streamflow depletions caused by groundwater withdrawals within operational constraints. Managing groundwater withdrawals in response to short-term (days or weeks) streamflow variation is not possible because one or more months might be needed for changes in groundwater withdrawals to have a substantial effect on streamflow depletions. With this in mind, Granato and Barlow (2005) formulated and tested potential allowable-depletion criteria based on one-day monthly minimum streamflows for each month at a streamgage for the period 1960-2000. In that study, postoptimization analysis indicated that the selected potential allowable-depletion criteria were adequate to provide water for public supply while maintaining nonzero streamflows during the simulation period. This approach also resulted in a high degree of natural variability at higher streamflow rates because withdrawals were a small fraction of these flows. Granato and Walter (2011) applied similar techniques to develop conjunctive-management models for municipal and agricultural demands at several sites in the Pawcatuck River Basin and found that pumping plans could be modified to help mitigate the potential effects of drought while maintaining a high degree of natural variability at higher streamflow rates.

Granato and Walter (2011) developed the groundwateryield curve to visually demonstrate the total annual withdrawals that could be achieved by using optimization methods under different potential allowable depletions. The yield graph can be used by water managers to balance watersupply needs with environmental-protection goals. The x-axis represents the allowable depletion, which may be less than, equal to, or greater than the minimum daily mean streamflow. An increase in allowable depletion represents an equal reduction in streamflows. The streamflow-depletion criteria are established on the basis of historical minimum daily mean streamflows in each month of the year, but the yield graphs that are presented are for annual total withdrawals. Granato and Walter (2011) found that although the conjunctivemanagement-model optimization criteria were designed to meet low-flow constraints in every month, the yield curve could be plotted against allowable depletions during the month with minimum flows; the allowable-depletion criteria for the low-flow month tend to constrain pumping throughout the year, especially if coupled with a seasonal or monthly demandpattern constraint. Granato and Walter (2011) noted that, in the Pawcatuck Basin, the minimum daily mean streamflows for the period of record for each constraint site were lowest in the month of September.

The shape of the curve or curves on the yield graph indicates the change in total annual withdrawals with a change in allowable depletion (Granato and Walter, 2011). A steep slope in the curve indicates a large change in allowable withdrawals with a small change in allowable depletion. If the slope is steep, selection of an allowable-depletion criterion (and therefore, the minimum daily mean streamflow with allowable withdrawals) is critical for determining available water supplies. A low slope in the curve indicates that a small change in allowable depletions will result in a small change in allowable withdrawals; in this case, a compromise in the allowable-depletion criterion may not have a large effect on available water supplies. A zero slope indicates that selection of an allowable-depletion criterion will not affect the available water supply. In this case, another factor (for example, the number and capacity of available water-withdrawal sites) controls the available water supply.

Sixty conjunctive-management models were developed by using optimization techniques to maximize water withdrawals from seven production wells in the Hunt River Basin to demonstrate used of the HyDroDSS. The methods used to develop these models are described by Barlow and Dickerman (2001), Granato and Barlow (2005), and Granato and Walter (2011). These conjunctive-management models were formulated by using well information and response coefficients 


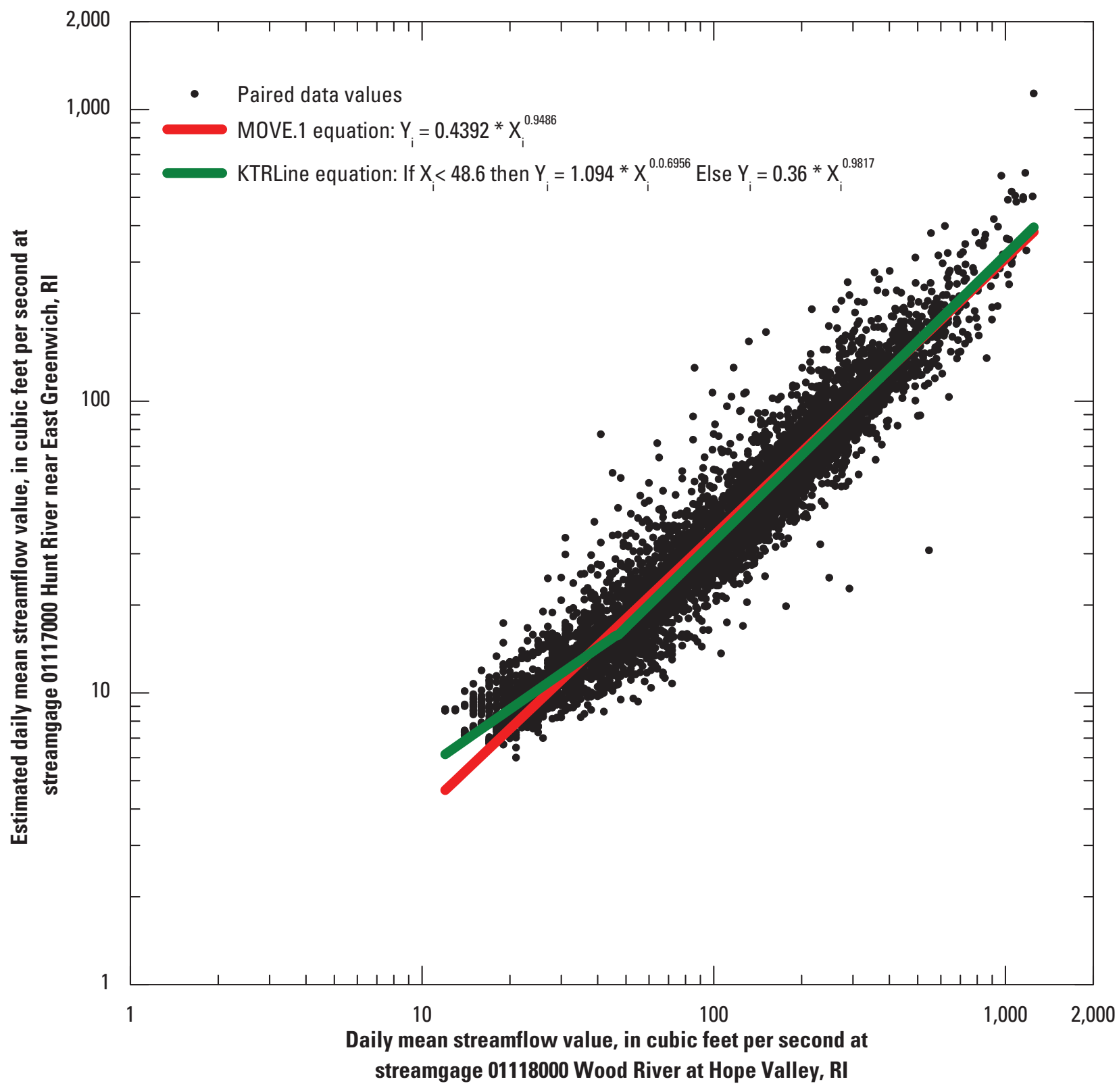

Figure 39. Maintenance of Variance type 1 (MOVE.1) and Kendall-Theil Robust Line (KTRLine) regression equations between measured streamflows at USGS streamgage 01118000 , the Wood River at Hope Valley, Rhode Island, and estimated unaltered streamflows at USGS streamgage 01117000, the Hunt River near East Greenwich, Rhode Island. 
developed by Barlow and Dickerman (2001). The conjunctivemanagement models developed to demonstrate the use of the HyDroDSS are based on the assumption that the production wells can be integrated into a cooperative regional watermanagement system with supplemental supplies outside the Hunt River Basin. This assumption allows withdrawals to be maximized within allowable-depletion criteria and seasonaldemand constraints while providing an equitable proportion of total withdrawals to each supply system with existing wells in the Hunt River Basin. These scenarios, however, do not include the industrial well (well IW in fig. 35) because of concerns about the potential quality of water from this well, the facility's access to public supplies, decreased use of the well in recent years, and the unfeasibility of integrating the well into a cooperative regional water-management system.

Four management patterns - the Hunt River Basin municipal-withdrawal pattern, the Pawcatuck River Basin municipal-withdrawal pattern (Granato and Walter, 2011), equal withdrawals in each month, and unconstrained withdrawals - were selected for the determination of relations between withdrawal patterns and maximum allowable withdrawals. The Hunt River Basin municipal-withdrawal pattern is represented by the average of total monthly pumping rates for the 1992-2008 period, for which a complete record for all withdrawal wells is available (fig. 40A). This pattern was selected to represent actual utilization of wells in the Hunt River Basin during the period of available data. The Pawcatuck River Basin municipal-withdrawal pattern documented by Granato and Walter (2011) was selected because this pattern is more representative of the municipal demands in Rhode Island (fig. 40B). This withdrawal pattern was based on data for the period October 1995 through September 2004 from 4 water-supply systems (Kingston, Richmond, United Water, and Westerly) in the Pawcatuck River Basin that were largely dependent on groundwater supplies. Also, it is similar to the monthly-demand pattern that Granato and Barlow (2005) documented by using data from 6 water-supply systems in Rhode Island and the pattern that Archfield and others (2010) documented by using data from 25 groundwater-supply systems in Massachusetts. The unconstrained withdrawal-management strategy will yield the most water, but use of this strategy requires the availability of other supply sources to meet seasonal demands.

Fifteen potential allowable-depletion criteria were selected for the determination of relations between these criteria and maximum allowable withdrawals by using the four withdrawal pattern management strategies (fig. 41). Seven potential allowable-depletion criteria were based on the flow durations of monthly minimum streamflows for each month of the year, which is the minimum one day flow that occurs in a given month and year. The 50th, 75th, 80th, 95th, and 98th flow durations were selected to represent the amount of pumping that could be achieved with decreasing risk of zero flow. An allowable-depletion criterion equal to the minimum of monthly minimum flows during the period of record was selected to maximize withdrawals while minimizing the risk for zero flows. This statistic also is known as the minimum monthly flow. Seven potential allowable-depletion criteria were based on decreasing fractions of the minimum of monthly minimum flows during the period of record. These criteria were selected to maximize withdrawals while theoretically precluding zero flows. These scenarios included allowable depletions that were $95,85,75,65,50,25$, and 10 percent of the minimum of monthly minimum flows in each month during the period of record.

Results of the conjunctive management model calculations are shown in figure 41. Annual production volumes range from $159 \mathrm{Mgal} / \mathrm{yr}$ with the most restrictive criteria to 4,219 Mgal/yr for the least restrictive criteria tested. In comparison, annual production volumes for 2005; 2006; 2007; and 2008 were about 1,518; 1,120; 1,205; and $1,059 \mathrm{Mgal} / \mathrm{yr}$, respectively. Each of these management models generally shows a relatively constant slope. None of these management models plateau at a fixed value within the range of potential allowable depletions tested. These two factors indicate that the capacity of the well network exceeds the depletion criteria tested. The unconstrained withdrawal strategy produces the most water for each given allowabledepletion criterion because pumping volumes in high-flow months are not controlled by the ratio to peak withdrawals in other months. Similarly, the withdrawal strategy with equal withdrawals in each month produces more water than the municipal-demand withdrawal strategy because pumping volumes during wetter months are not controlled by the ratio to peak withdrawals in July. The Pawcatuck River Basin municipal-withdrawal pattern produces slightly more water than the Hunt River Basin withdrawal pattern because the former has a smaller summer peak than the latter (fig. 41). Pumping rates for all the conjunctive management models are provided in tab-delimited text files that are part of the digital media accompanying this report.

Water-resource decisionmakers also may use such groundwater-yield curves to set different allowabledepletion criteria for wet and dry years. For example, if the allowable-depletion criterion is equal to the minimum daily mean streamflow value in wet and normal years, the sevenwell network could produce 1,430 Mgal/yr with the Hunt River Basin withdrawal pattern and 1,546 Mgal/yr with the Pawcatuck River Basin withdrawal pattern. Although the allowable-depletion criterion equals the historical minimum daily mean streamflow, use of this criterion would not result in a zero-flow event in wet or normal years. If waterconservation measures could be expected to reduce annual withdrawals by 10 percent in dry years, an annual production rate of about 1,000 Mgal/yr might be achievable with a dry-year allowable-depletion value that is about 50 percent of the minimum streamflow. In this example, the probability is about 2 percent in any given year that this dry-year allowable-depletion criterion would produce a minimum daily mean streamflow value that is 50 percent of the minimum streamflow without withdrawals. 


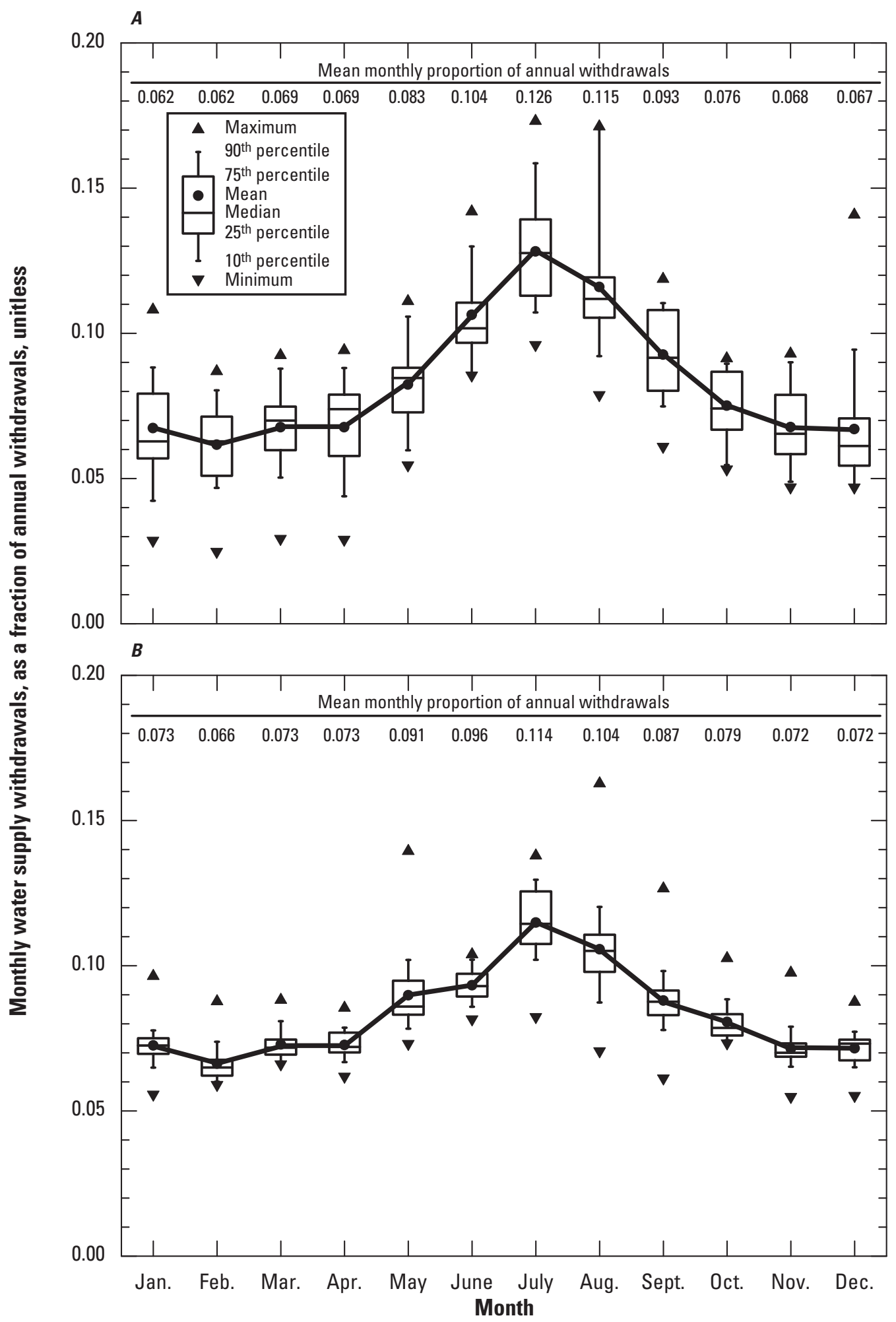

Figure 40. The distributions of monthly withdrawals as fractions of total annual withdrawals $A$, from seven wells in the Hunt River Basin, central Rhode Island, during the period 1992-2008, and $B$, from four water-supply systems that withdrew primarily from groundwater sources in the Pawcatuck River Basin, southwestern Rhode Island, during the period 1995-2004. 


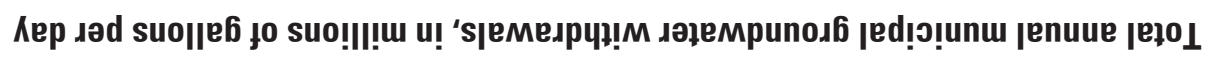

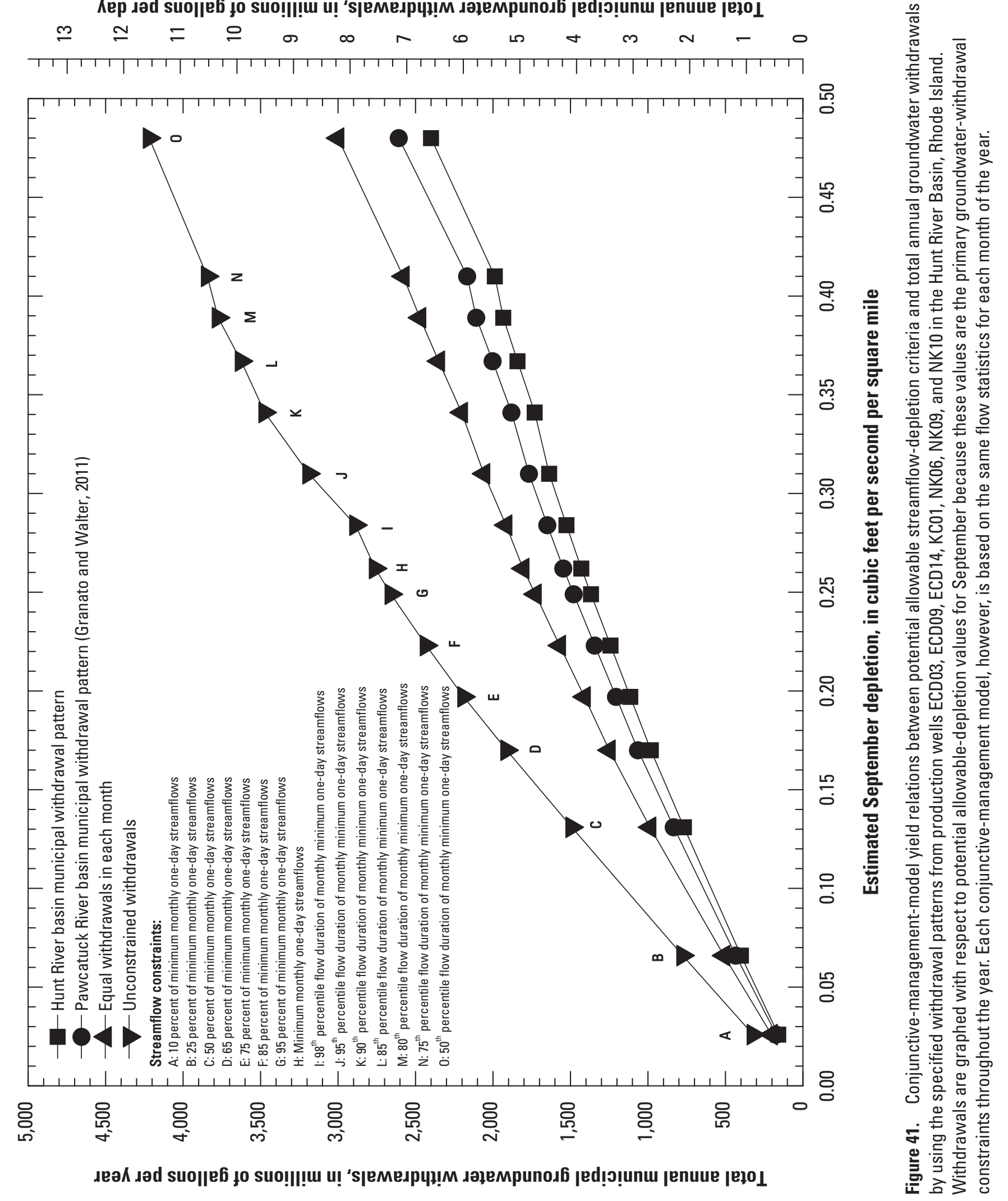


Currently (2012) the RIDEM is considering an allowabledepletion criterion equal to one-half of the estimated unaltered 7Q10 to limit the effects of water-supply development on aquatic ecosystems (Kathleen Crawley, RIWRB, written commun., 2011). The estimated unaltered 7Q10 for the Hunt River streamgage is $0.36 \mathrm{ft}^{3} / \mathrm{s} / \mathrm{mi}^{2}$ (Gardner Bent, U.S. Geological Survey, written commun., 2011), so the allowable depletion would be $0.18 \mathrm{ft}^{3} / \mathrm{s} / \mathrm{mi}^{2}$. The groundwater withdrawal-rate curves from the conjunctive-management models shown in figure 41 indicate that a unified network of wells could produce about 1,050 Mgal/yr by using the Hunt River municipal-withdrawal pattern and almost $1,140 \mathrm{Mgal} / \mathrm{yr}$ if an unconstrained withdrawal pattern could be used. Management model D (fig. 41) with an allowable-depletion criterion of $0.17 \mathrm{ft}^{3} / \mathrm{s} / \mathrm{mi}^{2}$ would produce about $981 \mathrm{Mgal} / \mathrm{yr}$ for the Hunt River municipal-withdrawal pattern and 1,064 Mgal/y for the unconstrained pumping plan.

\section{Interpreting Results of the Retrospective Streamflow-Depletion Analysis}

The retrospective streamflow-depletion analysis module in the HyDroDSS facilitates analysis and examination of the potential effects of different pumping plans on streamflows. This module has two primary types of output - the flow-duration-curve output and the time-series output. The flow-duration-curve output indicates the risk of flow being below a userspecified criterion during the selected period of record. The flow-duration-curve output quantifies risk, but it does not provide the historical perspective about the frequency and duration of different low-flow excursions. The time-series output shows how a pumping plan would have affected streamflows over different seasons and in different years. Four pumping plans were selected for examination of the different scenarios in this case study. The first two, labeled "Wells pumping at the median monthly rates from 2004-2008" and "Wells pumping at monthly rates from 2005," are based on actual water-use data for the production wells in the Hunt River Basin (fig. 35). Average annual production volumes from these pumping plans would be about 1,135 and 1,300 Mgal/yr, respectively. The second two pumping plans are conjunctive-management models D and $\mathrm{N}$ for wells in the Hunt River Basin (fig. 41) that are based on the Pawcatuck River Basin municipal-withdrawal pattern. Plan D has a minimum allowable depletion of $0.17 \mathrm{ft}^{3} / \mathrm{s} / \mathrm{mi}^{2}$ and produces about 1,064 Mgal $/ \mathrm{yr}$. Plan N has a minimum allowable depletion of $0.41 \mathrm{ft}^{3} / \mathrm{s} / \mathrm{mi}^{2}$ and produces about 2,167 Mgal/yr.

The flow-duration curves in figure 42 show the percentage of time estimated unaltered daily mean streamflow and streamflow with hypothetical depletions were equaled or exceeded at USGS streamgage 01117000 the Hunt River in central Rhode Island (1942-2009). If these flows are compared to a hypothetical target equal to one-half of the estimated unaltered $7 \mathrm{Q} 10$, then the flow-duration curve indicates the percentage of time the flows with depletion will be greater than this flow value. As expected, the estimated unaltered flows do not fall below this value. About 2.5 percent of flow values fall below this target for the pumping plan based on the median monthly rates from 2004-2008. Theoretically, on average, this would be about 9 days per year. About 4.1 percent of flow values (about 15 days per year) fall below this target for the pumping plan based on the median monthly rates from 2005. About 1.2 percent of flow values (about 4 days per year) fall below this target for the pumping plan based on conjunctive-management model D. About 13 percent of flow values (about 49 days per year) fall below this target for the pumping plan based on conjunctive-management model N. Although the percentiles do correspond to an average number of days per year, low flows tend to extend over long time intervals in some years. Therefore, low-flow excursions are not distributed evenly during the historical period, and a time-series analysis is needed to gain this perspective.

The time series output from the HyDroDSS for the 1990-1999 period is shown in figure 43 in relation to a value of $0.18 \mathrm{ft}^{3} / \mathrm{s} / \mathrm{mi}^{2}$, which is one half of the estimated 7Q10 for unaltered flows in the Hunt River Basin (Gardner Bent, U.S. Geological Survey, written commun., 2010). The graph shows that, in comparison to this hypothetical standard, withdrawal rates which are equal to the medians of monthly pumping rates of production wells in the Hunt River Basin (during 2004-2008) would have caused minor flow excursions in 2 of the 10 years and substantial flow excursions in 4 of the 10 years (fig. 43A). Withdrawal rates which are equal to monthly pumping rates of production wells in the Hunt River Basin during 2005 would have caused minor flow excursions in 1 of the 10 years and substantial flow excursions in 5 of the 10 years. Furthermore, pumping at the 2005 rates could have caused zero-flow events during 1993 and 1994. Two conjunctive-management models that use the Pawcatuck River Basin municipal-withdrawal pattern also were tested. Withdrawals following conjunctive-management model D (with a minimum allowable depletion of $0.17 \mathrm{ft}^{3} / \mathrm{s} / \mathrm{mi}^{2}$ ) would have caused minor flow excursions in 2 of the 10 years and substantial flow excursions in 3 of the 10 years. Withdrawals following conjunctive-management model $\mathrm{N}$ (with a minimum allowable depletion equal to the 75th-percentile flow duration of minimum monthly one-day streamflows - about $0.41 \mathrm{ft}^{3} / \mathrm{s} / \mathrm{mi}^{2}$ for September) would have caused minor flow excursions in 1 of the 10 years and substantial flow excursions in 9 of the 10 years during the 1990-1999 period. Use of this withdrawal plan during the 1990s could have caused zero-flow events during 1991, 1993, 1994, 1995, 1997 and 1999. 

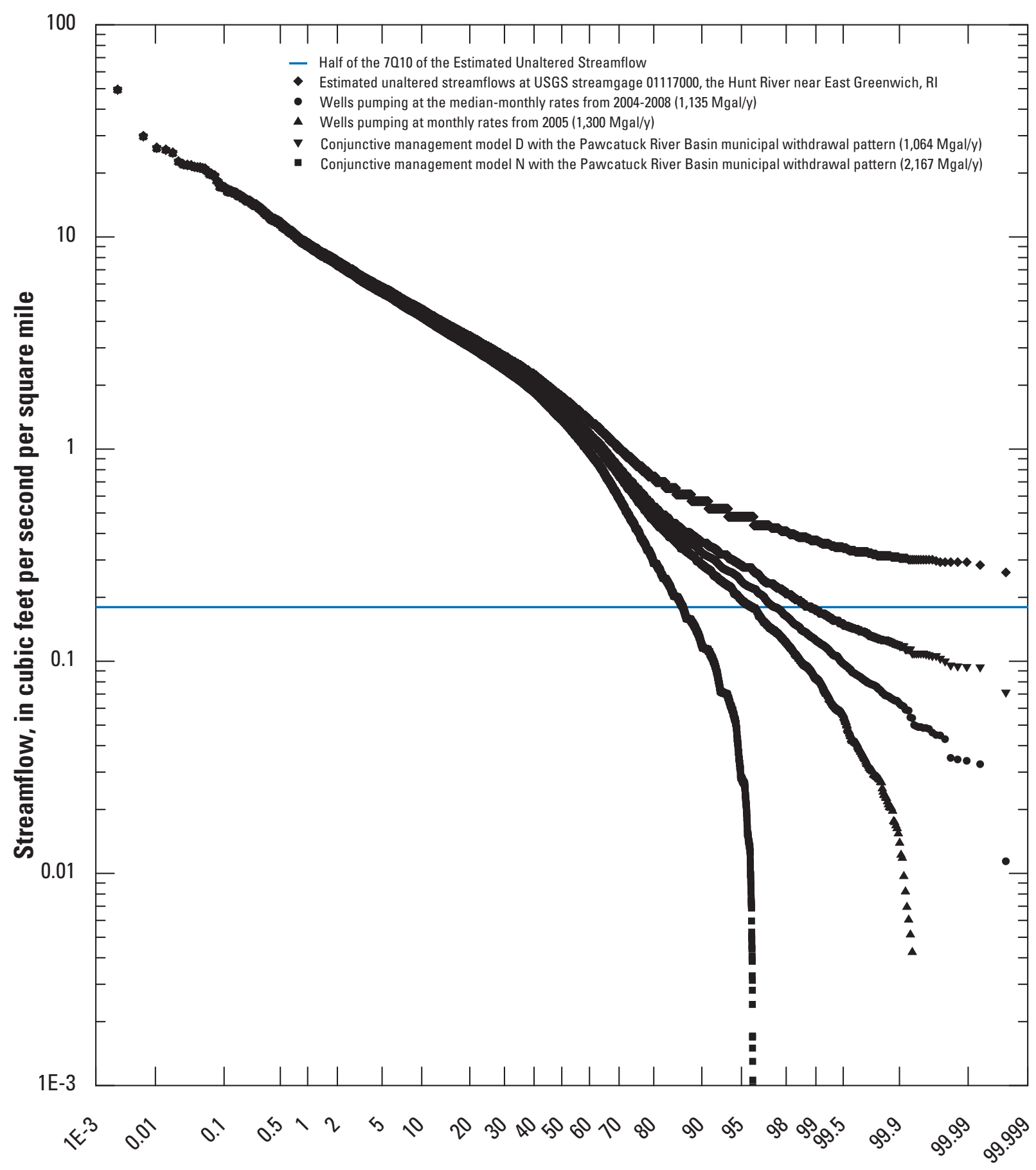

Percentage of time estimated streamflow was equaled or exceeded

Figure 42. Flow-duration curves showing the percentage of time estimated unaltered daily mean streamflow and streamflow with hypothetical depletions was equaled or exceeded at USGS streamgage 01117000 the Hunt River in central Rhode Island (1942-2009). Streamflows with depletions are calculated by using various pumping plans in the HyDroDSS. Pumping volumes for conjunctive-management models are shown in figure 41 . Streamflows are compared to a value of 0.18 $\mathrm{ft}^{3} / \mathrm{s} / \mathrm{mi}^{2}$, which is one half of the estimated 7010 for unaltered flows in the Hunt River Basin (Gardner Bent, U.S. Geological Survey, written commun., 2011). 
A. Wells pumping at the median-monthly rates from 2004-2008

100

10

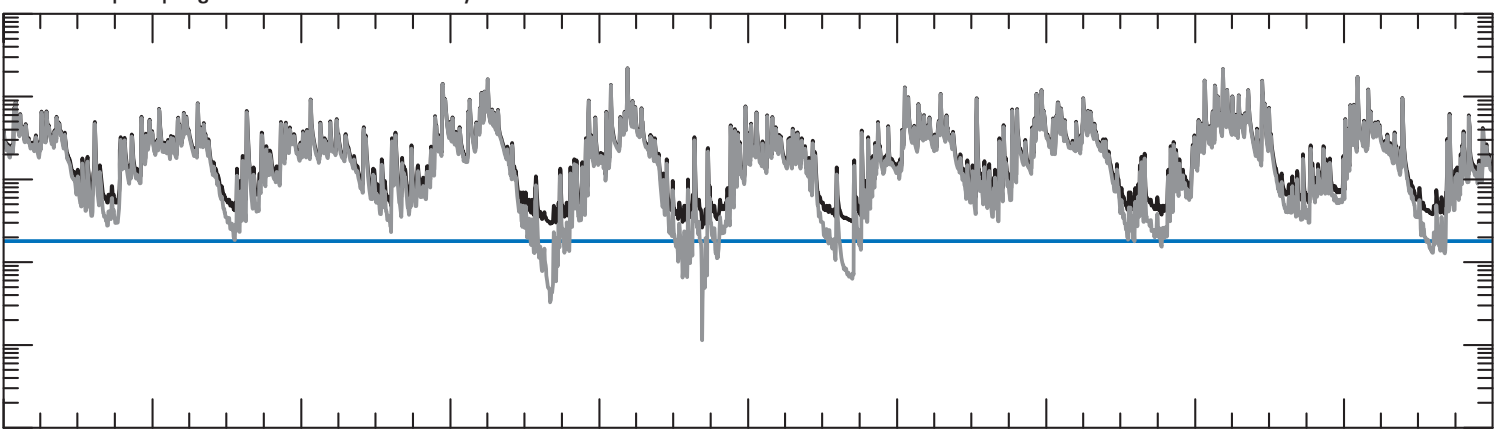

$1 \mathrm{E}-3$

100

B. Wells pumping at monthly rates from 2005

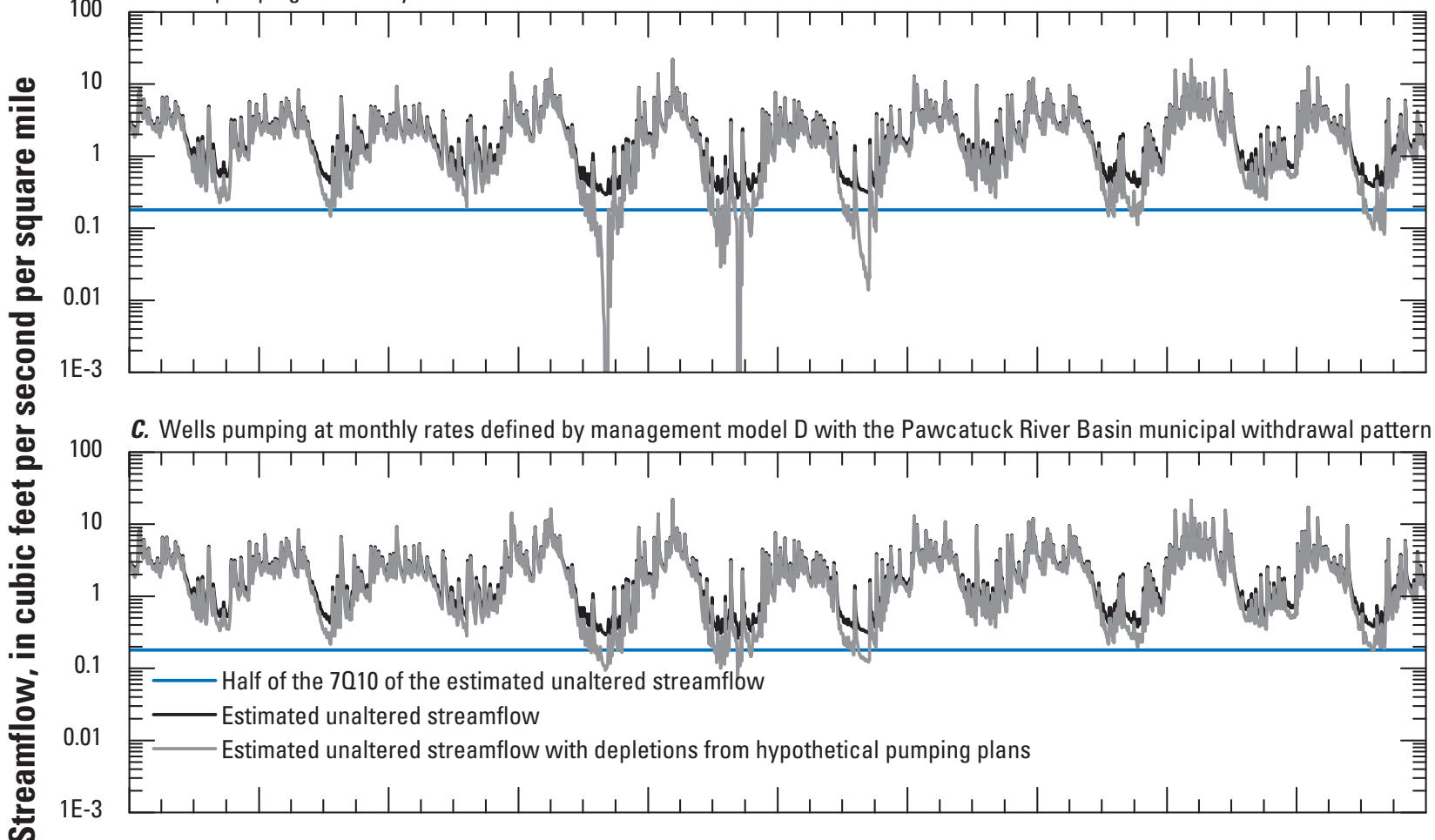

D. Wells pumping at monthly rates defined by management model N with the Pawcatuck River Basin municipal withdrawal pattern 10

(1)

0.

0.01

1E-3

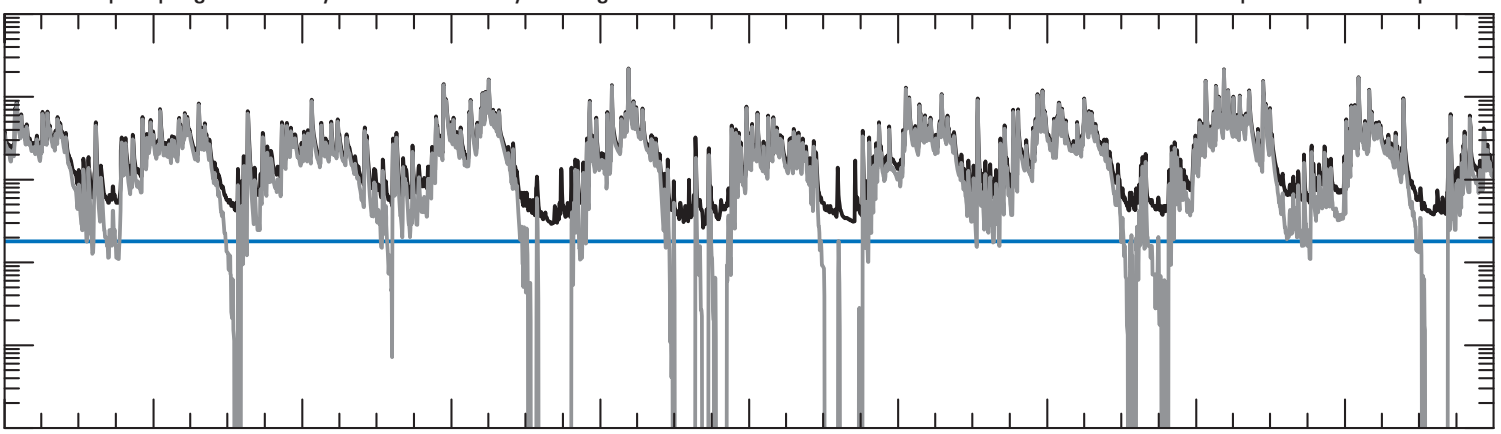

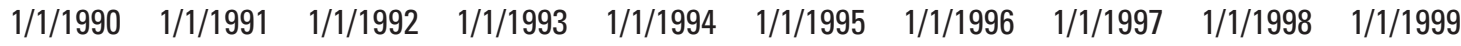

Date

Figure 43. Time-series graph showing estimated unaltered streamflow and streamflow with hypothetical depletions at USGS streamgage 01117000 on the Hunt River in central Rhode Island (1990-2000). Pumping volumes for conjunctive-management models are shown in figure 41. Streamflows are compared to a value of $0.18 \mathrm{ft} 3 / \mathrm{s} / \mathrm{mi}^{2}$, which is one half of the estimated $7010 \mathrm{for}$ unaltered flows in the Hunt River Basin (Gardner Bent, U.S. Geological Survey, written commun., 2011). 


\section{Rank Correlation Analysis}

Rank correlation analysis between estimated monthly minimum unaltered streamflows in the Hunt River at streamgage 01117000 and other hydrologic variables indicate that none of the local hydrologic variables are suitable for providing highly accurate quantitative predictions of hydrologic drought caused by precipitation deficits more than one month in advance. Rank correlations between estimated monthly minimum unaltered streamflow at the Hunt River streamgage (01117000) and total monthly precipitation measured at the National Oceanic and Atmospheric Administration (NOAA) precipitation monitoring station at T.F. Green Airport near Providence, R.I. (NOAA station 376698), for the period 1942 2009 are weak (fig. 44A). The largest correlations between these values are the lag- 1 correlations, which are correlations from one month to the next; these correlations range from about 0.44 to 0.65 , and all values are statistically significant ( $p$ less than 0.05). Rank correlations between estimated unaltered streamflow at the Hunt River streamgage (01117000) and groundwater levels measured at well RI-SNW 6 for the period 1955-2009 also are weak (fig. 44B). Rank correlations between monthly groundwater levels and estimated monthly minimum unaltered streamflow are negative because dry conditions cause the depth to groundwater to increase and streamflows to decline. The largest correlations between these values are the lag- 0 correlations, which are correlations between one variable and another within the same month; these correlations range from about -0.61 to -0.81 , and all values are statistically significant ( $\mathrm{p}$ less than 0.05 ). The lag- 1 correlations range from about -0.31 to -0.72 , and all values are statistically significant ( $p$ less than 0.05). Rank correlations between estimated monthly minimum unaltered streamflows at the Hunt River streamgage (01117000) and streamflows measured at the Wood River streamgage (01118000) for the period 1942-2009 are much stronger than correlations for the other hydrologic variables (fig. 44C). The largest correlations between these values are the lag- 0 correlations; these correlations range from about 0.94 to 0.99 , and all values are statistically significant ( $\mathrm{p}$ less than 0.05 ). The highest lag-0 correlations are for April, May, and June. The lag- 1 correlations range from about 0.34 to 0.78 , and all values are statistically significant ( $\mathrm{p}$ less than 0.05). The highest lag-1 correlations are for June, July, and August (to July, August, and September, respectively). Comparison of the rank correlation values in the graphs in figure 44 and the example scatterplots in figure 6 , however, indicate that, with the exception of lag- 0 correlations between streamflows, the rho values for any of these hydrologic variables are not strong predictors.

Hydrologic drought (low streamflows) also may be caused or exacerbated by streamflow depletions caused by pumping. Correlations between hydrologic variables and total withdrawals seem logical if the demand patterns (fig. 40) are based on summer-season peak water use. Analysis of rank correlations between total monthly pumping volumes from production wells in the Hunt River Basin (fig. 35) and total monthly precipitation measured at NOAA monitoring station 376698 (T.F. Green Airport near Providence, R.I.), monthly groundwater levels measured at USGS monitoring well RI-SNW 6 (in South Kingstown, R.I.), and monthly minimum streamflows measured at USGS streamgage 01118000 (Wood River near Hope Valley, R.I.) for the 1992-2008 period indicate that relations generally are weak and statistically insignificant ( $\mathrm{p}$ greater than 0.05 ). The only exceptions are rank correlation coefficients between precipitation and withdrawals in the same month for July and September, which are -0.73 and -0.58 , respectively (the negative numbers indicate increases in withdrawals with decreases in total monthly precipitation). These relations do not persist into the following months, but depletions from increased withdrawals will persist. The Kent County and North Kingstown water departments have other water supplies outside the Hunt River Basin that can be used to help meet water demands; use of these alternate supplies may explain the unexpected weak correlations between hydrologic variables and total withdrawals in the basin.

\section{Drought-Projection Analysis}

An example drought-projection analysis was done by using available data from the months leading up to August 2005. This period was selected because extreme low flows measured in the Hunt River and high pumping in 2005 helped establish the need for a decision support system to facilitate drought mitigation planning. Furthermore, neither the drought forecast predictions (National Weather Service Climate Data Center, 2011) nor the metrics used in the Rhode Island drought-management plans (Rhode Island Department of Administration, 2002; RIWRB, 2003) identified August 2005 as a drought month in Rhode Island. The extreme low flows (with a flow-duration value of about 96.3 percent) in the Wood River (table 1) during August were caused primarily by precipitation deficits during June, July, and early August of that year. The extreme low flows (with a flow-duration value of about 91 percent) in the Hunt River (table 1) during August were caused by precipitation deficits and high pumping volumes during July and early August of that year. Despite the 2005 water withdrawals, the flow-duration value for August 2005 for the Hunt River is less extreme than that for the same month for the Wood River; the latter value probably reflects the effects of heavy water use at the Quonset Point Navy base during dry periods in the 1940s and 1960s. The large precipitation totals in August 2005 reflect the effect of two large storms during the last 2 weeks of the month. The total precipitation measured at precipitation-monitoring station 376698 during these two storms was 0.77 in. on August 21, 2005, and 3.45 in. on August 29, 2005. These storms resulted in the low duration percentiles in table 1, which were 29.9 percent in Providence, R.I., and 20.7 percent in Kingston, R.I., despite the small amount of precipitation during the first three weeks. 


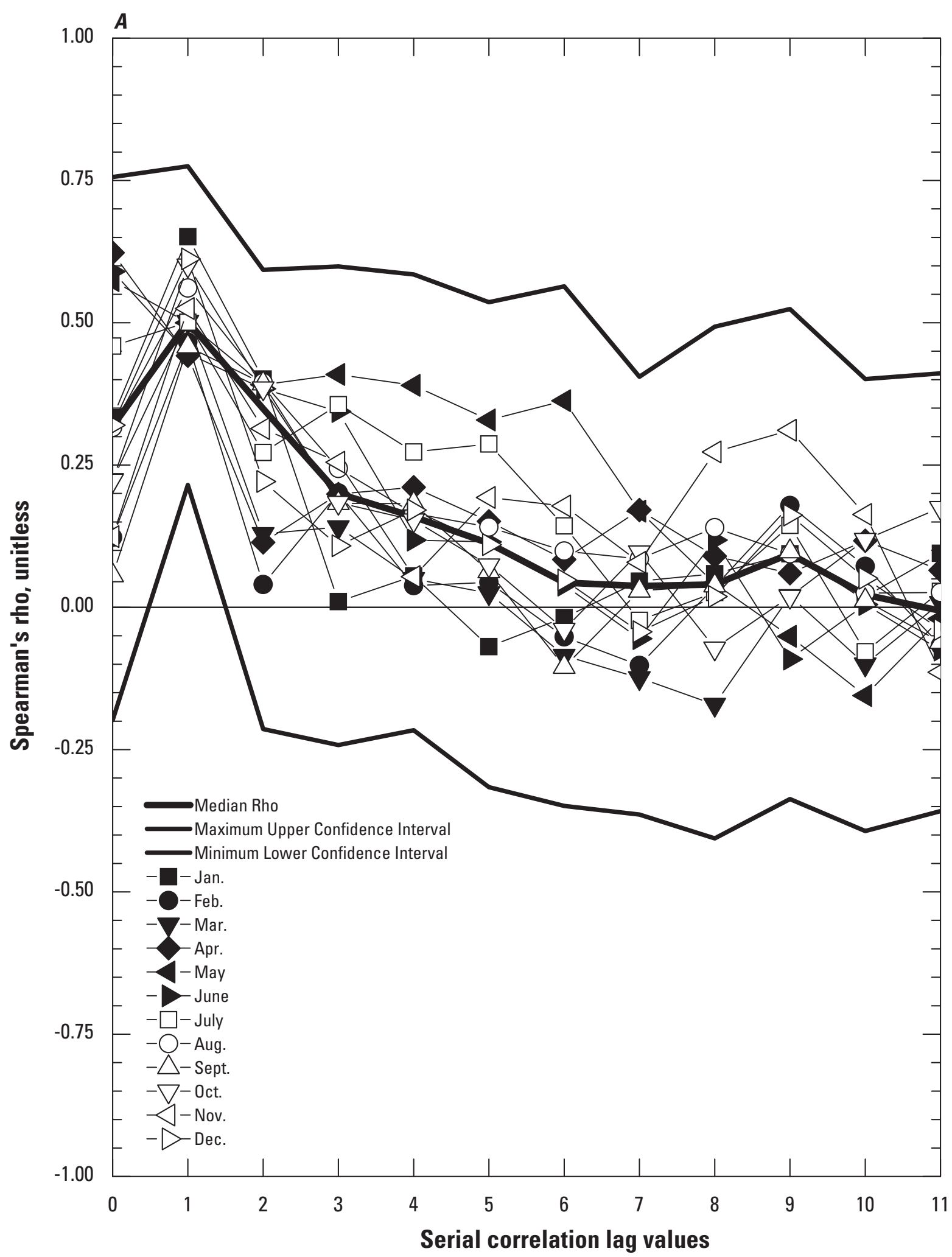

Figure 44. Monthly serial rank correlation coefficient values, the median rank correlation for each time lag, and the maximum and minimum confidence intervals for each time lag between estimated monthly minimum unaltered streamflows in the Hunt River at streamgage 01117000 and $A$, monthly precipitation at monitoring station 376698 at T.F. Green Airport near Providence, Rhode Island, $B$, monthly groundwater levels at USGS monitoring well RI-SNW 6 in South Kingstown, Rhode Island, and $C$, monthly minimum streamflows at USGS streamgage 01118000 near Hope Valley, Rhode Island. Data from the stations selected for presentation are best correlated to the estimated unaltered streamflows in the Hunt River; values for other hydrologic-monitoring stations can be generated by using the HyDroDSS. 


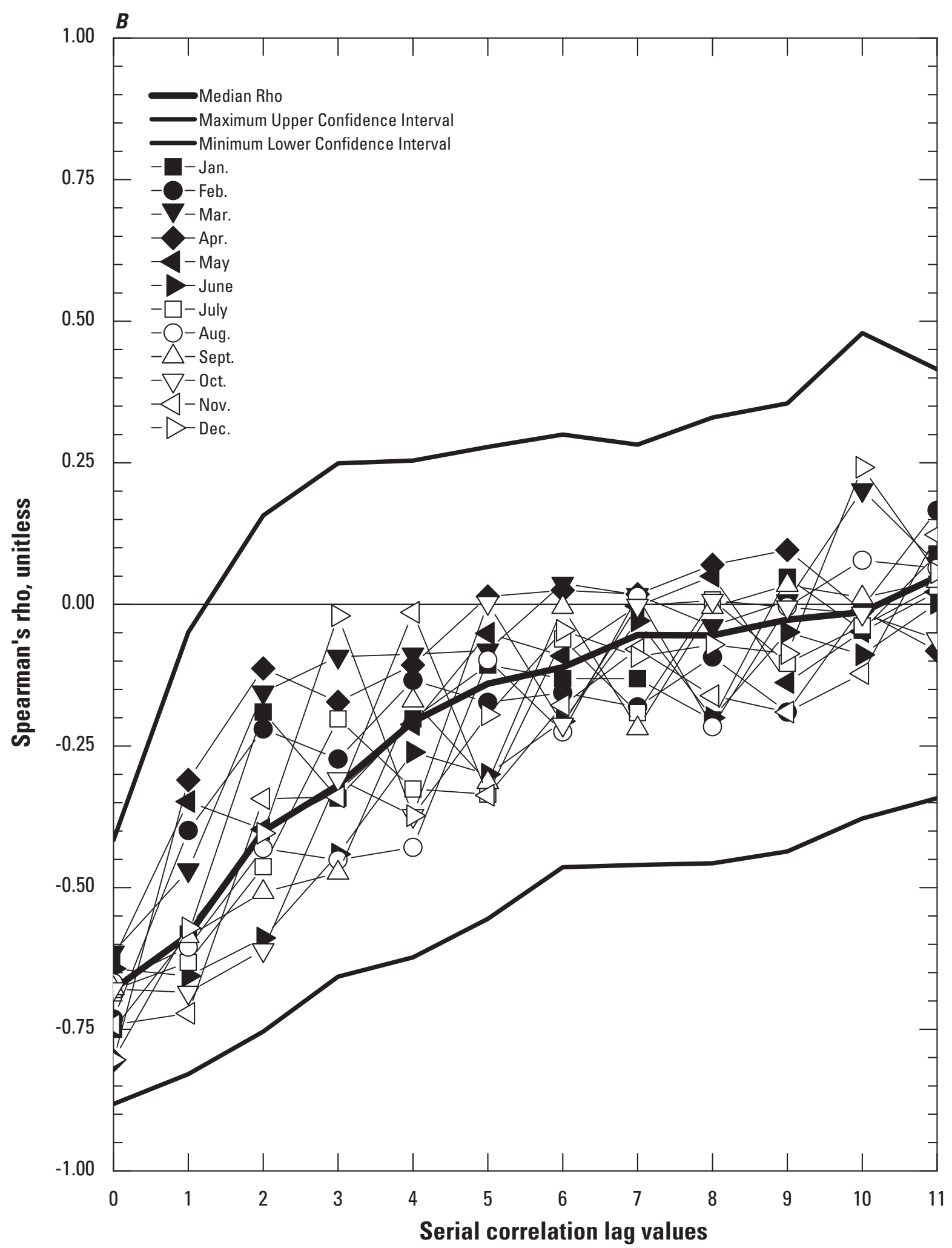

Figure 44. Monthly serial rank correlation coefficient values, the median rank correlation for each time lag, and the maximum and minimum confidence intervals for each time lag between estimated monthly minimum unaltered streamflows in the Hunt River at streamgage 01117000 and $A$, monthly precipitation at monitoring station 376698 at T.F. Green Airport near Providence, Rhode Island, $B$, monthly groundwater levels at USGS monitoring well RI-SNW 6 in South Kingstown, Rhode Island, and $C$, monthly minimum streamflows at USGS streamgage 01118000 near Hope Valley, Rhode Island. Data from the stations selected for presentation are best correlated to the estimated unaltered streamflows in the Hunt River; values for other hydrologic-monitoring stations can be generated by using the HyDroDSS.-Continued 


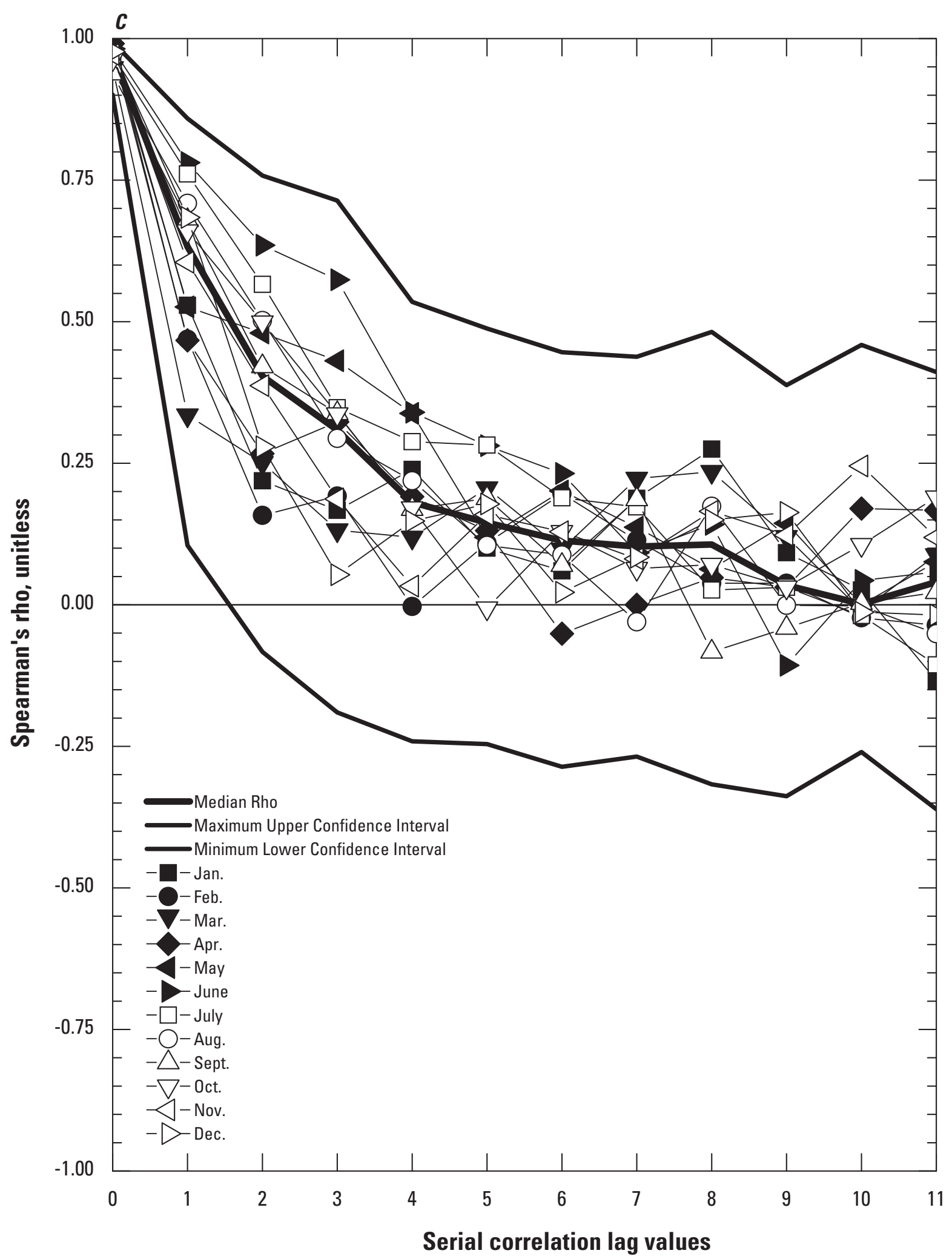

Figure 44. Monthly serial rank correlation coefficient values, the median rank correlation for each time lag, and the maximum and minimum confidence intervals for each time lag between estimated monthly minimum unaltered streamflows in the Hunt River at streamgage 01117000 and $A$, monthly precipitation at monitoring station 376698 at T.F. Green Airport near Providence, Rhode Island, $B$, monthly groundwater levels at USGS monitoring well RI-SNW 6 in South Kingstown, Rhode Island, and $C$, monthly minimum streamflows at USGS streamgage 01118000 near Hope Valley, Rhode Island. Data from the stations selected for presentation are best correlated to the estimated unaltered streamflows in the Hunt River; values for other hydrologic-monitoring stations can be generated by using the HyDroDSS.-Continued 
Table 1. Duration percentiles for data collected at two precipitation and two streamflow stations, March-August 2005.

[RI, Rhode Island. Duration percentiles are the percentage of months with data values that are greater than or equal to a given value. The percentage less than the given value is 100 minus the duration percentile.]

\begin{tabular}{|c|c|c|c|c|}
\hline \multirow[b]{2}{*}{ Month } & \multicolumn{2}{|c|}{ Total monthly precipitation } & \multirow{2}{*}{$\begin{array}{c}\text { Minimum monthly streamflow } \\
\text { Streamgage } 01118000 \\
\text { Wood River at Hope Valley, RI }\end{array}$} & \multirow{2}{*}{$\begin{array}{c}\text { Minimum monthly streamflow } \\
\text { Streamgage } 01117000 \\
\text { Hunt River near East Greenwich, RI }\end{array}$} \\
\hline & $\begin{array}{l}\text { Precipitation station } 376698 \\
\text { Providence TF Green Airport RI }\end{array}$ & $\begin{array}{c}\text { Precipitation station } 374266 \\
\text { Kingston RI }\end{array}$ & & \\
\hline March & 24.4 & 28.3 & 46.4 & 40.7 \\
\hline April & 36.9 & 26.7 & 32.2 & 25.8 \\
\hline May & 23.2 & 41.2 & 25.1 & 27.9 \\
\hline June & 81.2 & 92.6 & 67.8 & 66.4 \\
\hline July & 95.5 & 89.4 & 85.6 & 97.7 \\
\hline August & 29.9 & 20.7 & 96.3 & 91.3 \\
\hline
\end{tabular}

Figure 45 shows the monthly minimum flow-duration curves developed by using the drought-projection analysis module in the HyDroDSS on the basis of data that was available at the beginning of April, May, June, and July of 2005. The graph shows the estimated monthly minimum streamflow projections for August 2005. The filled symbols show the projections for the monthly minimum unaltered flow, the flow with depletions from 2005 withdrawals, the flow with depletions from the median of 2004-2008 withdrawals, and a waterconservation scenario in which the medians of 2004-2008 withdrawals are reduced by 10 percent. The black horizontal line and the open square show the calculated monthly minimum unaltered streamflow and the associated flow-duration percentile for August 2005. The grey line and open circle show the measured monthly minimum streamflow (which includes actual depletions from pumping) and the associated flow-duration percentile for August 2005. The dashed line shows the streamflow value equal to one-half of the estimated unaltered 7Q10 as a reference for a hypothetical allowable depletion standard (Kathleen Crawley, RIWRB, oral commun., April 2011). Thus, figure 45 demonstrates the information that would be provided by the drought-projection analysis as the season progresses within the context of actual data and a hypothetical flow target.

The projection made by using information that was available at the beginning of April 2005 accurately predicts the flow duration of the actual measured streamflow and the estimated unaltered streamflow values in the Hunt River by happenstance (fig. 45A); the HyDroDSS should not be expected to provide such precise results in any given year. The projection made by using information that was available at the beginning of May 2005 (fig. 45B) indicates a lower risk for being below these flow values (as indicated by a larger flow-duration percentile); the May projection was based on the monthly minimum flow in the Wood River in April, which was a relatively high flow with a duration of about 32 percent (table 1). Similarly, the projection made by using information that was available at the beginning of June 2005 (fig. 45C) indicates a substantially lower risk for being below the measured streamflow and estimated unaltered streamflow values for August 2005 because this projection was based on a monthly minimum flow with a duration of about 25 percent (table 1). The projection made by using information that was available at the beginning of July 2005 (fig. 45D) indicates that the estimated unaltered streamflow is close to the flowduration value for August. The projection for the flows with depletions from production wells pumping at the actual 2005 rates indicates a greater risk for flows being below the measured value. The risk may have been greater because of random variation in the Monte Carlo bootstrap process or because the 2005 pumping plan used in the projection analysis did not include the industrial withdrawals and discharges in the Hunt River Basin in 2005.

If a streamflow of $0.18 \mathrm{ft} 3 / \mathrm{s} / \mathrm{mi}^{2}$, which is equal to one-half the estimated 7Q10 low-flow value of $0.36 \mathrm{ft}^{3} / \mathrm{s} / \mathrm{mi}^{2}$ (Gardner Bent, U.S. Geological Survey, written commun., 2011), is used as a hypothetical minimum-flow target, then the unaltered monthly minimum flows will be above this value, but all three pumping plans present some risk for producing monthly minimum flows below this target (fig. 45). The projection analyses done with information available at the beginning of April, May, June, and July, and the 2005 pumping plan indicate that the risks for being below this hypothetical target flow, based on the monthly projection, are about $26,17,14$, and 38 percent, respectively. The same projection analyses done with the median pumping values for the years 2004-2008 have risks for being below this hypothetical target flow that are about $25,16,13$, and 36 percent, respectively. If these estimated risks were considered unacceptable by decisionmakers, and a 10-percent reduction in withdrawals was made starting in April, May, June, or July, then the estimated risks for flow being below this hypothetical target, based on the monthly projection, would be about $16,11,7$, and 25 percent, respectively. 

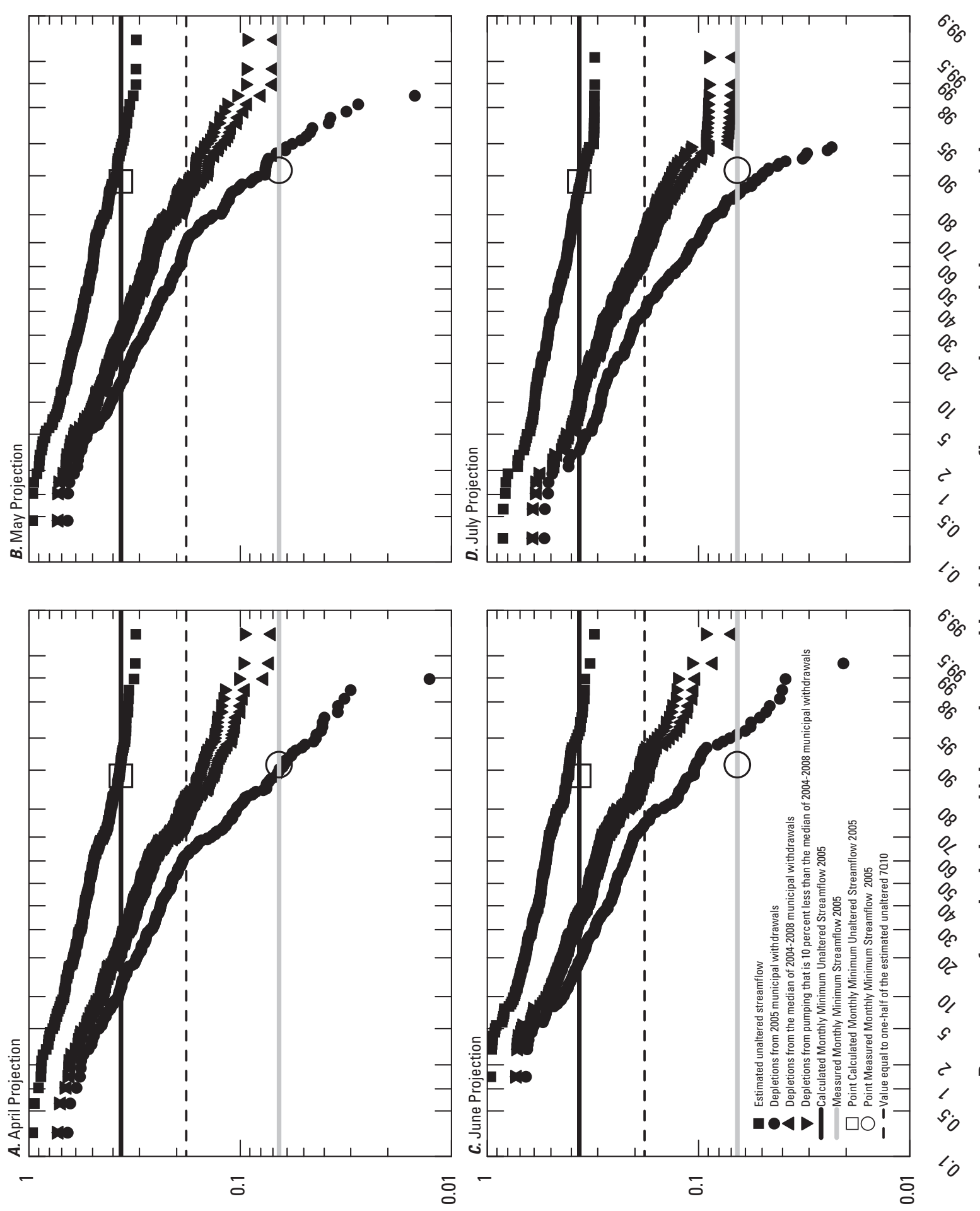

蒙 등 은

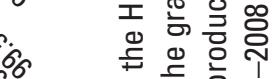

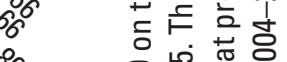

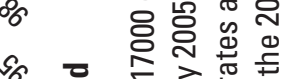

。

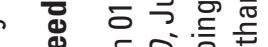

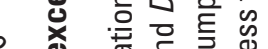

Q

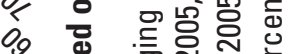

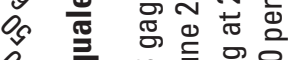

os

O

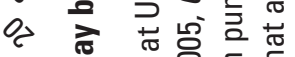

E

0, \&

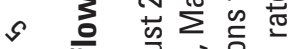

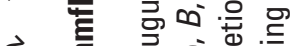

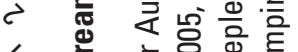

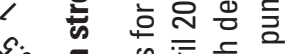

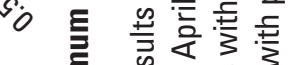

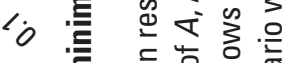

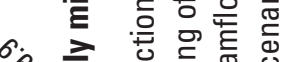

$\sigma_{\sigma}$ 글

s.

6f

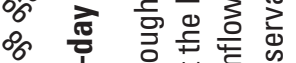

ఏ 흥 离

O

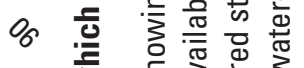

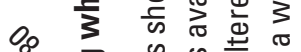

官

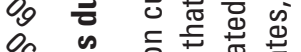

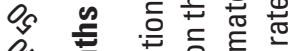

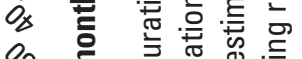

O

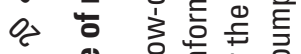

$0, \quad \stackrel{0}{\circ}$ 흔

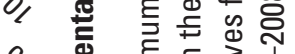

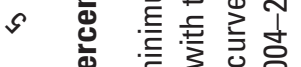

$\checkmark$ ब

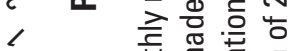

s.

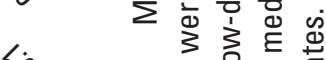

เค

o 원

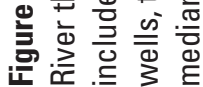


Although risks for being below this hypothetical minimum flow target are similar for the 2005 pumping plan and the pumping plan representing the median rates for the years 2004-2008, differences in the estimated minimum streamflows are substantial (fig. 45). The minimum estimated flow value with depletions from the 2005 pumping plan is $0.005 \mathrm{ft}^{3} / \mathrm{s} / \mathrm{mi}^{2}$, and the percentages of streamflows below the minimum value of $0.01 \mathrm{ft}^{3} / \mathrm{s} / \mathrm{mi}^{2}$ on the graph are about 19, 12, 8, and 6 percent for the April, May, June, and July estimates, respectively. However, none of the estimated streamflows with depletions from the median-rates pumping plan for the years 2004-2008 or for this plan with 10-percent reductions fall below the minimum graphed value of $0.01 \mathrm{ft}^{3} / \mathrm{s} / \mathrm{mi}^{2}$ (fig. 45).

The minimum estimated unaltered streamflows are $0.312,0.31,0.311$, and $0.31 \mathrm{ft} / \mathrm{s} / \mathrm{mi}^{2}$ for April, May, June, and July, respectively. The minimum of estimated unaltered August streamflows is 0.31 . This value demonstrates that the bootstrapping method is limited to values in the flow record. This limitation is most evident in the July projection, in which about 5 percent of projected streamflows are at or near the minimum limit estimated from the historical record.

\section{Summary}

This report describes the theory, implementation, use, and interpretation of results from the hydrologic drought decision support system (HyDroDSS). Decision support systems are commonly described as interactive computer programs that integrate models and complex data to help managers make planning-level decisions for complex situations that may be rapidly changing and not well defined in advance. The HyDroDSS was developed by the U.S. Geological Survey (USGS) in cooperation with the Rhode Island Water Resources Board (RIWRB) for use in the analysis of hydrologic variables that may indicate the risk for streamflows to be below userdefined flow targets at a designated site of interest. A site of interest is defined herein as a data-collection site on a stream that may be adversely affected by pumping. The HyDroDSS is designed to provide water managers with risk-based information necessary to mitigate potential effects of hydrologic drought. This information is needed by decisionmakers to balance water-supply needs and aquatic-habitat protection goals. Hydrologic drought is defined herein as a period of lowerthan-normal streamflows caused by precipitation deficits and (or) water withdrawals. The HyDroDSS includes methods for retrospective streamflow-depletion analysis, rank correlation analysis, and drought-projection analysis. All three methods are designed to inform decisions made by drought steering committees and decisionmakers on the basis of quantitative risk assessment. All three methods use estimates of unaltered streamflow, which is the measured or modeled flow without major withdrawals or discharges, to approximate a natural low-flow regime.
Retrospective streamflow-depletion analysis can be used by water-resource managers to evaluate relations between withdrawal plans and the potential effects of withdrawal plans on streams at one or more sites of interest in an area. Retrospective streamflow-depletion analysis indicates the historical risk of flows being below user-defined targets if different pumping plans were implemented for the period of record. Retrospective streamflow-depletion analysis also indicates the risk for creating hydrologic drought conditions caused by use of a pumping plan. Retrospective streamflow-depletion analysis is done by calculating the net streamflow depletions from withdrawals and discharges and applying these depletions to a simulated record of unaltered streamflow.

Rank correlation analysis in the HyDroDSS indicates the persistence of hydrologic measurements from month to month for the prediction of developing hydrologic drought conditions and quantitatively indicates which hydrologic variables may be used to indicate the onset of hydrologic drought conditions. Rank correlation analysis also indicates the potential for each variable used to estimate monthly minimum unaltered flow at a site of interest to be used in the drought-projection analysis. Rank correlation analysis in the HyDroDSS is done by calculating Spearman's rho for paired samples and the 95-percent confidence limits of this rho value. Rank correlation analysis can be done by using precipitation, groundwater levels, measured streamflows, and estimated unaltered streamflows. Serial correlation analysis, which indicates relations between current and future values, can be done for one site. Cross correlation analysis, which indicates relations among current values at one site and current and future values at a second site, also can be done.

Drought-projection analysis in the HyDroDSS indicates the risk for being in a hydrologic drought condition during the current month and the five following months with and without pumping. Drought-projection analysis also indicates the potential effectiveness of water-conservation methods for mitigating the effect of withdrawals in the coming months on the basis of the risk of unaltered flows being below streamflow targets and the amount of depletion caused by different pumping plans. Drought-projection analysis in the HyDroDSS is done with Monte Carlo methods by using the position analysis method. In this method, the initial value of estimated unaltered streamflows is estimated by correlation to a measured hydrologic variable (monthly precipitation, groundwater levels, or streamflows at an index gage). Then a pseudorandom-number generator is used to create 251 6-month-long flow traces by using a bootstrap method. Serial correlation of the estimated unaltered monthly minimum streamflows, which are calculated by using the rank correlation analysis, is preserved within each flow trace. The sample of unaltered streamflows indicates the risk of flows being below targets in the coming months under simulated natural conditions (without historic withdrawals). The streamflow-depletion algorithms are then used to estimate risks of flows being below targets for different pumping plans. 
The HyDroDSS was developed as a Microsoft Access ${ }^{\circledR}$ database application to facilitate storage, handling, and use of hydrologic datasets with a simple graphical user interface. The program is implemented in the database by using the Visual Basic for Applications ${ }^{\circledR}$ (VBA) programming language. Program source code for the analytical techniques is provided in the HyDroDSS and in electronic text files accompanying this report. Program source code for the graphical user interface and for data handling, which is specific to Microsoft Access $^{\circledR}$ and the HyDroDSS, is provided in the database. An installation package with a run-time version of the software is available with this report for potential users who do not have a compatible copy of Microsoft Access ${ }^{\circledR}$. Administrative rights are needed to install this version of the HyDroDSS.

The USGS streamgage on the Hunt River (station 01117000) near East Greenwich in central Rhode Island is used as the site of interest in a case study for demonstrating use of the HyDroDSS. The Hunt River streamgage was used because it has a long record of streamflow and it is in a well-studied basin where hydrologic and water-use data are available and water use is characterized by a substantial rate of groundwater pumping for municipal supply. Site-specific examples of the retrospective streamflow-depletion analysis, the rank correlation analysis, and the drought-projection analysis are provided to demonstrate the use of and interpretation of results from the HyDroDSS.

\section{References Cited}

Ahlfeld, D.P., and Mulligan, A.E., 2000, Optimal management of flow in groundwater systems: San Diego, Calif., Academic Press, 185 p.

Alley, W.M., and Leake, S.A., 2004, The journey from safe yield to sustainability: Ground Water, v. 42, no. 1, p. 12-16.

Alley, W.M., Reilly, T.E., and Franke, O.L., 1999, Sustainability of ground-water resources: U.S. Geological Survey Circular 1186, 79 p.

Archfield, S.A., Vogel, R.M., Steeves, P.A., Brandt, S.L., Weiskel, P.K., and Garabedian, S.P., 2010, The Massachusetts Sustainable-Yield Estimator: A decision-support tool to assess water availability at ungaged stream locations in Massachusetts: U.S. Geological Survey Scientific Investigations Report 2009-5227, 41 p., plus CD-ROM.

Barlow, P.M., 1997, Dynamic models for conjunctive management of stream-aquifer systems of the glaciated Northeast: Storrs, Conn., University of Connecticut, Ph.D. dissertation, $256 \mathrm{p}$.
Barlow, P.M., 2000, Documentation of computer program STRMDEPL-A program to calculate streamflow depletion by wells using analytical solutions, in Zarriello, P.J., and Ries, K.G., III, A precipitation-runoff model for analysis of the effects of water withdrawals on streamflow, Ipswich River Basin, Massachusetts: U.S. Geological Survey WaterResources Investigations Report 00-4029, p. 77-99.

Barlow, P.M., Ahlfeld, D.P., and Dickerman, D.C., 2003, Conjunctive-management models for sustained yield of stream-aquifer systems: Journal of Water Resources Planning and Management, v. 129, no. 1, p. 35-48.

Barlow, P.M., and Dickerman, D.C., 2001, Numericalsimulation and conjunctive-management models of the Hunt-Annaquatucket-Pettaquamscutt stream-aquifer system, Rhode Island: U.S. Geological Survey Professional Paper $1636,88 \mathrm{p}$.

Barlow, P.M., and Ostiguy, L.J., 2007, Simulation of hydrologic-system responses to ground-water withdrawals in the Hunt-Annaquatucket-Pettaquamscutt stream-aquifer system, Rhode Island: U.S. Geological Survey Open-File Report 2006-1226, $51 \mathrm{p}$.

Benson, M.A., and Carter, R.W., 1973, A national study of the streamflow data collection program: U.S. Geological Survey Water-Supply Paper 2028, 44 p.

Bent, G.C., Waite, A.M., and Church, P.E., 2011, Water resources in the Pawcatuck River Basin-Part 2 in Bent, G.C., Zarriello, P.J., Granato, G.E., Masterson, J.P., Walter, D.A., Waite, A.M., and Church, P.E., Simulated effects of water withdrawals and land-use changes on streamflows and groundwater levels in the Pawcatuck River Basin, southwestern Rhode Island and southeastern Connecticut: U.S. Geological Survey Scientific Investigations Report 2009-5127, $254 \mathrm{p}$.

Brekke, L.D., Kiang, J.E., Olsen, J.R., Pulwarty, R.S., Raff, D.A., Turnipseed, D.P., Webb, R.S., and White, K.D., 2009, Climate change and water resources management-A federal perspective: U.S. Geological Survey Circular 1331, $65 \mathrm{p}$.

Caruso, J.C., and Cliff, Norman, 1997, Empirical size, coverage, and power of the confidence intervals for Spearman's rho: Educational and Psychological Measurement, v. 57, no. 4 , p. 637-653.

Chow, V.T., Maidment, D.R., and Mays, L.W., 1988: Applied hydrology: New York, McGraw-Hill Inc., 572 p.

Connecticut Interagency Drought Work Group, 2003, Connecticut drought preparedness and response plan: Hartford, Conn., Connecticut Water Planning Council, 35 p.

Cunnane, C., 1978, Unbiased plotting positions - a review: Journal of Hydrology, v. 37, p. 205-222. 
DeSimone, L.A., 2004, Simulation of ground-water flow and evaluation of water-management alternatives in the Assabet River Basin, eastern Massachusetts: U.S. Geological Survey Scientific Investigations Report 2004-5119, 133 p.

DeSimone, L.A., Walter, D.A., Eggleston, J.R., and Nimiroski, M.T., 2002, Simulation of ground-water flow and evaluation of water-management alternatives in the Upper Charles River Basin, eastern Massachusetts: U.S. Geological Survey Water-Resources Investigations Report 02-4234, 94 p.

Devroye, Luc, 1986, Non-uniform random variate generation: New York, Springer-Verlag, 843 p.

Dickerman, D.C., and Barlow, P.M., 1997, Water-table conditions and stream-aquifer interaction in the HuntAnnaquatucket-Pettaquamscutt aquifer, central Rhode Island, October 7-9, 1996: U.S. Geological Survey WaterResources Investigations Report 97-4167, 1 sheet.

Dunne, Paul, and Tasker, G.D., 1996, Computer model of Raritan River Basin water-supply system in central New Jersey: U.S. Geological Survey Open-File Report 96-360, $62 \mathrm{p}$.

Efron, Bradley, 1979, Bootstrap methods-Another look at the jackknife: The Annals of Statistics, v. 7, no. 1, p. 1-26.

Eggleston, J.R., 2004, Evaluation of strategies for balancing water use and streamflow reductions in the Upper Charles River Basin, Eastern Massachusetts: U.S. Geological WaterResources Investigations Report 03-4330, 94 p.

Eng, Ken, Kiang, J.E., Chen, Y.-Y., Carlisle, D.M., and Granato, G.E., 2011, Causes of systematic over- or underestimation of low streamflows by use of index-streamgage approaches in the United States: Hydrological Processes, v. 25, p. 2211-2220, doi:10.1002/hyp. 7976.

Eng, Ken, Tasker, G.D., and Milly, P.C.D., 2005, An analysis of region-of-influence methods: Journal of the American Water Resources Association, v. 41, no. 1, p. 135-143.

Fennessey, N.M., 1994, A hydro-climatological model of daily streamflow for the northeast United States: Medford, Mass., Tufts University, Ph.D. dissertation, variously paged.

Fisher, R.A., 1924, On a distribution yielding the error functions of several well known statistics: Toronto, Proceedings of the International Congress of Mathematics, v. 2, p. $805-813$.

Galloway, G.E., 2011, If stationarity is dead, what do we do now?: Journal of the American Water Resources Association, v. 47, no. 3, p. 563-570.

Gentle, J.E., 2003, Random number generation and Monte Carlo methods ( $2 \mathrm{~d}$ ed.): New York, Springer Science + Business Media, Inc., 381 p.
Gorelick, S.M., Freeze, R.A., Donohue, David, and Keely, J.F., 1993, Groundwater contamination-Optimal capture and containment: Boca Raton, Fla., Lewis Publishers, $385 \mathrm{p}$.

Granato, G.E., 2004, Rhode Island Water-Supply System Management Plan Database (WSSMP — Version 1.0): U.S. Geological Survey Open-File Report 04-1231, 77 p., at http://pubs.water.usgs.gov/ofr20041231/.

Granato, G.E., 2006, Kendall-Theil Robust Line (KTRLineversion 1.0)-A Visual Basic program for calculating and graphing robust nonparametric estimates of linearregression coefficients between two continuous variables: Techniques and Methods of the U.S. Geological Survey, book 4, chap. A7, 31 p.

Granato, G.E., 2009, Computer programs for obtaining and analyzing daily mean streamflow data from the U.S. Geological Survey National Water Information System Web Site: U.S. Geological Survey Open-File Report 2008-1362, 123 p., on CD-ROM, appendix 3 of 5.

Granato, G.E., 2010, Statistical characterization of streamflow data-Appendix 2 in Granato, G.E., 2010, Methods for development of planning-level estimates of stormflow at unmonitored sites in the conterminous United States: Washington, D.C., U.S. Department of Transportation, Federal Highway Administration, FHWA-HEP-09-005, 90 p., with CD-ROM.

Granato, G.E., 2013, Stochastic empirical loading and dilution model (SELDM) version 1.0.0: U.S. Geological Survey Techniques and Methods, book 4, chap. C3, 99 p.

Granato, G.E., and Barlow, P.M., 2005, Effects of alternative instream-flow criteria and water-supply demands on ground-water development options in the Big River Area, Rhode Island: U.S. Geological Survey Scientific Investigations Report 2004-5301, 110 p., at http://water.usgs.gov/ pubs/sir/2004/5301/.

Granato, G.E., Barlow, P.M., and Dickerman, D.C., 2003, Hydrogeology and simulated effects of ground-water withdrawals in the Big River Area, Rhode Island: U.S. Geological Survey Water-Resources Investigations Report 03-4222, 76 p., at http://water.usgs.gov/pubs/wri/wri034222/.

Granato, G.E., and Walter, D.A., 2011, Conjunctivemanagement models as tools for water-resources planning-Part 4 in Bent, G.C., Zarriello, P.J., Granato, G.E., Masterson, J.P., Walter, D.A., Waite, A.M., and Church, P.E., Simulated effects of water withdrawals and land-use changes on streamflows and groundwater levels in the Pawcatuck River Basin, southwestern Rhode Island and southeastern Connecticut: U.S. Geological Survey Scientific Investigations Report 2009-5127, 254 p. 
Haan, C.T., 1977, Statistical methods in hydrology: Ames, Iowa, Iowa State University Press, 378 p.

Hayes, M.J., 2006, What is drought?, University of Nebraska-Lincoln, National Drought Mitigation Center, accessed November 16, 2013, at http://drought.unl.edu/ DroughtBasics.aspx.

Hayhoe, Katharine, Wake, C.P., Huntington, T.G., Luo, Lifeng, Schwartz, M.D., Sheffield, Justin, Wood, Eric, Anderson, Bruce, Bradbury, James, DeGaetano, Art, Troy, T.J., and Wolfe, David, 2007, Past and future changes in climate and hydrological indicators in the U.S. Northeast: Climate Dynamics, v. 28, p. 381-407.

Heath, R.C., 2004, Basic ground-water hydrology: U.S. Geological Survey Water-Supply Paper 2220, 86 p.

Helsel, D.R., and Hirsch, R.M., 2002, Statistical methods in water resources-Hydrologic analysis and interpretation: U.S. Geological Survey Techniques of Water-Resources Investigations, book 4, chap. A3, 510 p.

Helsel, D.R., Mueller, D.K., and Slack, J.R., 2006, Computer program for the Kendall family of trend tests: U.S. Geological Survey Scientific Investigations Report 2005-5275, 4 p.

Hirsch, R.M., 1978, Risk analysis for a water-supply systemOccoquan Reservoir, Fairfax and Prince William Counties, Virginia: Hydrological Sciences Bulletin, v. 23, no. 4, p. $476-505$.

Hirsch, R.M., 1979, Synthetic hydrology and water supply reliability: Water Resources Research, v. 15, no. 6, p. 16031615.

Hirsch, R.M., 1981a, Estimating probabilities of reservoir storage for the upper Delaware River basin: U.S. Geological Survey Open-File Report 81-478, 20 p.

Hirsch, R.M., 1981b, Stochastic hydrological model for drought management: Journal of Water Resources Planning and Management, v. 107, no. 2, p. 303-313.

Hirsch, R.M., 1982, A comparison of four streamflow record extension techniques: Water Resources Research, v. 18, no. 4 , p. $1081-1088$.

Hirsch, R.M., Slack, J.R., and Smith, R.A., 1982, Techniques of trend analysis for monthly water quality data: Water Resources Research, v. 18, p. 107-121.

Hodgkins, G.A., and Dudley, R.W., 2011, Historical summer base flow and stormflow trends for New England rivers: Water Resources Research, v. 47, 16 p., W07528, doi:10.1029/2010WR009109.
Hughes, D.A., and Smakhtin, V.U., 1996, Daily flow time series patching or extension-A spatial interpolation approach based on flow duration curves: Journal of Hydrological Sciences, v. 41, no. 6, p. 851-871.

Ito, K., Xu, Z.X., Jinno, K., Kojiri T., and Kawamura, A., 2001, Decision support system for surface water planning in river basins: Journal of Water Resources Planning and Management, v. 127, no. 4, p. 272-276.

L'Ecuyer, Pierre, 1999, Good parameters and implementations for combined multiple recursive random number generators: Operations Research, v. 47, no. 1, p. 159-164.

L'Ecuyer, Pierre, and Simard, Richard, 2007, TestU01—A C library for empirical testing of random number generators: Association for Computing Machinery, Transactions on Mathematical Software, v. 33, no. 4, article 22, 40 p.

Lins, H.F., Hirsch, R.M., and Kiang, Julie, 2010, Water-the Nation's fundamental climate issue-A white paper on the U.S. Geological Survey role and capabilities: U.S. Geological Survey Circular 1347, 9 p.

Lins, H.F., and Slack, J.R., 1999, Streamflow trends in the United States: Geophysical Research Letters, v. 26, p. $227-$ 230 .

Lins, H.F., and Slack, J.R., 2005, Seasonal and regional characteristics of U.S. streamflow trends in the United States from 1940-1999: Physical Geography, v. 26, p. 489-501.

Linsley, R.K., Kohler, M.A., and Paulhus, J.L.H., 1975, Hydrology for engineers ( $2 \mathrm{~d}$ ed.): New York, N.Y., McGraw-Hill, 482 p.

Maimone, M., 2004, Defining and managing sustainable yield: Ground Water, v. 42, no. 6, November-December, p. 809-814.

Male, J.W., and Mueller, F.A., 1992, Model for prescribing ground-water use permits: Journal of Water Resources Planning and Management, v. 118, no. 5, p. 543-561.

Massachusetts Drought Management Task Force, 2001, Massachusetts drought management plan: Boston, Mass., Executive Office of Environmental Affairs, $34 \mathrm{p}$.

Masterson, J.P., 2011, Simulated effects of withdrawals on groundwater flow (MODFLOW models) - Part 3 in Bent, G.C., Zarriello, P.J., Granato, G.E., Masterson, J.P., Walter, D.A., Waite, A.M., and Church, P.E., Simulated effects of water withdrawals and land-use changes on streamflows and groundwater levels in the Pawcatuck River Basin, southwestern Rhode Island and southeastern Connecticut: U.S. Geological Survey Scientific Investigations Report 2009-5127, 254 p. 
McCabe, G.J., and Wolock, D.M., 2002, A step increase in streamflow in the conterminous United States: Geophysical Research Letters, v. 29, p. 2185-2188.

McCullough, B.D., 2008, Microsoft Excel's "Not the Wichmann-Hill" random number generators: Computational Statistics \& Data Analysis, v. 52, p. 4587-4593.

Milly, P.C.D., Betancourt, J., Falkenmark, M., Hirsch, R.M., Kundzewicz, Z.W., Lettenmaier, D.P., and Stouffer, R.J., 2008, Stationarity is dead: Whither water management?: Science, v. 319, no. 5863, p. 573-574.

Mohamoud, Y.M., 2008, Prediction of daily flow duration curves and streamflow for ungauged catchments using regional flow duration curves: Journal of Hydrological Sciences, v. 53, no. 4, p. 706-724.

Mueller, F.A., and Male, J.W., 1993, A management model for specification of groundwater withdrawal permits: Water Resources Research, v. 29, no. 5, p. 1359-1368.

Mykytka, E.F., and Cheng, C.Y., 1994, Generating correlated random variates based on an analogy between correlation and force in Tew, J.D., Manivannan, M.S., Sadowski, D.A., and Seila, A.F., eds., 1994 Winter Simulation Conference, Lake Buena Vista, Fla., December 11-14, 1994, Proceedings: New York, N.Y., Association for Computing Machinery, p. 1413-1416.

National Drought Policy Commission, 2011, Drought Portal: National Drought Policy Commission, accessed November 16, 2013, at http://www.drought.gov

New Jersey Department of Environmental Protection, 1991, State of New Jersey drought emergency plan: Trenton, N.J., New Jersey Department of Environmental Protection, $40 \mathrm{p}$.

New York State Drought Management Task Force, 1987, New York State drought preparedness plan: Albany N.Y., New York State Department of Environmental Conservation, $126 \mathrm{p}$.

Pennsylvania Department of Environmental Protection, 2010a, Drought management in Pennsylvania: Commonwealth of Pennsylvania, Department of Environmental Protection Report 3920-BK-DEP4284 7/2010, 6 p.

Pennsylvania Department of Environmental Protection, 2010b, Pennsylvania drought management guidelines for public water suppliers: Commonwealth of Pennsylvania, Department of Environmental Protection Report 3920-BKDEP4285 6/2010, $30 \mathrm{p}$.

Poff, N.L., Allen, J.D., Bain, M.B., Karr, J.R., Prestagaard, K.L., Richter, B.D., Sparks, R.E., and Stromberg, J.C., 1997, The natural flow regime-A paradigm for river conservation and restoration: Bioscience, v. 47, p. 769-784.
Press, W.H., Flannery, B.P., Teukolsky, S.A., and Vetterling, W.T., 1992, Numerical recipes in FORTRAN 77-The art of scientific computing ( $2 \mathrm{~d}$ ed.): New York, Cambridge University Press, 992 p.

Reeves, H.W., 2008, STRMDEPL08-An extended version of STRMDEPL with additional analytical solutions to calculate streamflow depletion by nearby pumping wells: U.S. Geological Survey Open-File Report 2008-1166, 22 p.

Rhode Island Department of Administration, 2002, Rhode Island Drought Management Plan State Guide-Plan Element 724: Providence, R.I., Department of Administration, Statewide Planning Program, Report No. 104, 85 p.

Rhode Island Water Resources Board, 2003, Post drought evaluation report-Rhode Island Water Resources Board for the Rhode Island Drought Steering Committee, Rhode Island Water Resources Board, $12 \mathrm{p}$.

Ries, K.G., III, and Friesz, P.J., 2000, Methods for estimating low-flow statistics for Massachusetts streams: U.S. Geological Survey Water-Resources Investigations Report 2000-4135, $81 \mathrm{p}$.

Ries, K.G., III, Steeves, P.A., Coles, J.D., Rea, A.H., and Stewart, D.W., 2004, StreamStats-A U.S. Geological Survey Web application for stream information: U.S. Geological Survey Fact Sheet 2004-3115, 4 p., available at http://md.water.usgs.gov/publications/fs-2004-3115/html/ index.html.

Saucier, Richard, 2000, Computer generation of statistical distributions: U.S. Army Research Laboratory Report ARLTR-2168, $105 \mathrm{p}$.

Searcy, J.K., 1959, Flow-duration curves, in Low-Flow Techniques, part 2, Manual of Hydrology: U.S. Geological Survey Water-Supply Paper 1542-A, 33 p.

Smakhtin, V.U., 1999, Generation of natural daily flow time series in regulated rivers using a non-linear spatial interpolation technique - Regulated Rivers: Research and Management, v. 15, p. 311-323.

Smakhtin, V.U., and Masse, B., 2000, Continuous daily hydrograph simulation using duration curves of a precipitation index: Hydrological Processes, v. 14, p. 1083-1100.

Sophocleous, M., 2000, From safe yield to sustainable development of water resources - the Kansas experience: Journal of Hydrology, v. 23, no. 5, issues 1-2, p. 27-43.

Srinivas, V.V., and Srinivasan, K., 2005, Hybrid moving block bootstrap for stochastic simulation of multi-site multiseason streamflows: Journal of Hydrology, v. 302, no. 1-4, p. 307-330. 
Stedinger, J.R., Vogel, R.M., and Foufoula-Georgiou, Efi, 1993, Frequency analysis of extreme events, chap. 18 in Maidment, D.R., ed., Handbook of Hydrology: New York, McGraw-Hill, Inc., p. 18.1-18.66.

Stern, Ken, 1990, New Hampshire drought management plan: Concord, N.H., New Hampshire Department of Environmental Services, Water Resources Division Report NHDES-WRB-90-1, 45 p.

Tasker, G.D., 1999, Bootstrapping periodic ARMA model to forecast streamflow at multiple sites: Computer Science and Statistics, v. 31, p. 296-299.

Tasker, G.D., and Dunne, Paul, 1997, Forecasting drought risks for a water-supply storage system using bootstrap position analysis: in Managing Water-Coping with Scarcity and Abundance, in 27th Congress of the International Association for Hydraulic Research, San Francisco, Calif., August 10-15, 1997, Proceedings: Dronten, the Netherlands, International Association for Hydraulic Research, p. 645-650.

Tasker, G.D., and Stedinger, J.R., 1989, An operational GLS model for hydrologic regression: Journal of Hydrology, v. 111 , no. $1-4$, p. $361-375$.

Thomas, D.M., and Benson, M.A., 1970, Generalization of streamflow characteristics from drainage-basin characteristics: U.S. Geological Survey Water-Supply Paper 1975, $55 \mathrm{p}$.

U.S. Geological Survey, 2002, Computing low-flow statistics for ungaged locations on Pennsylvania streams by use of drainage-area ratios: U.S. Geological Survey, accessed July 1, 2011, at http://paapps.er.usgs.gov/flowstats/revised deplowflow.pdf.
Vogel, R.M., and Shallcross, A.L., 1996, The moving blocks bootstrap: Water Resources Research, v. 32, no. 6, p. 18751882.

Waldron, M.C., and Archfield, S.A., 2006, Factors affecting firm yield and the estimation of firm yield for selected streamflow-dominated drinking-water-supply reservoirs in Massachusetts: U.S. Geological Survey Scientific Investigations Report 2006-5044, 39 p.

Winter, T.C., Harvey, J.W., Franke, O.L., and Alley, W.M., 1998, Ground water and surface water - a single resource: U.S. Geological Survey Circular 1139, 77 p.

Zarriello, P.J., 2011, Simulation of water-use and land-use changes on streamflow with a precipitation-runoff model (HSPF), Part 2 in Bent, G.C., Zarriello, P.J., Granato, G.E., Masterson, J.P., Walter, D.A., Waite, A.M., and Church, P.E., Simulated effects of water withdrawals and land-use changes on streamflows and groundwater levels in the Pawcatuck River Basin, southwestern Rhode Island and southeastern Connecticut: U.S. Geological Survey Scientific Investigations Report 2009-5127, 254 p.

Zarriello, P.J., and Ries, K.G., III, 2000, A precipitation-runoff model for analysis of the effects of water withdrawals on streamflow, Ipswich River Basin, Massachusetts: U.S. Geological Survey Water-Resources Investigations Report 00-4029, 99 p. 



\section{Hydrologic Drought Decision Support System (HyDroDSS)-Appendix 1. Monte Carlo Methods}

By Gregory E. Granato

Prepared in cooperation with the Rhode Island Water Resources Board

Open-File Report 2014-1003 


\title{
U.S. Department of the Interior SALLY JEWELL, Secretary
}

\section{U.S. Geological Survey Suzette M. Kimball, Acting Director}

\author{
U.S. Geological Survey, Reston, Virginia: 2014
}

For more information on the USGS - the Federal source for science about the Earth, its natural and living resources, natural hazards, and the environment, visit http://www.usgs.gov or call 1-888-ASK-USGS.

For an overview of USGS information products, including maps, imagery, and publications, visit http://www.usgs.gov/pubprod

To order this and other USGS information products, visit http://store.usgs.gov

Any use of trade, firm, or product names is for descriptive purposes only and does not imply endorsement by the U.S. Government.

Although this information product, for the most part, is in the public domain, it also may contain copyrighted materials as noted in the text. Permission to reproduce copyrighted items must be secured from the copyright owner.

Suggested citation:

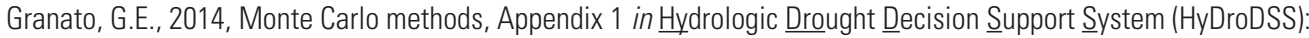
U.S. Geological Survey Open-File Report 2014-1003, 8 p., with CD-ROM, http://dx.doi.org/10.3133/ofr20141003. 


\section{Contents}

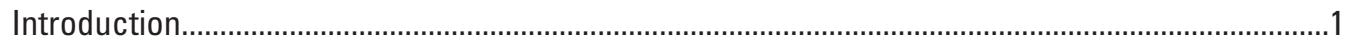

Generating Random Numbers from a Uniform Distribution...............................................................1

The MRG32K3A Multiple Recursive Pseudorandom-Number Generator ..................................2

Random-Seed Management in HyDroDSS ..............................................................................

Generating Random Numbers with an Input Rank Correlation Coefficient .......................................4

Generating Streamflow Values with the Hybrid Bootstrap Method...................................................6

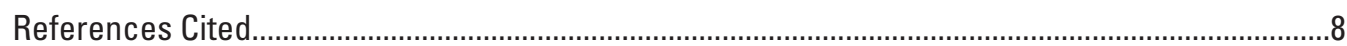

\section{Figure}

1-1. Graph showing examples of the theoretical 95-percent confidence intervals for selected values of Spearman's rank correlation coefficients generated by using the large-sample approximation

\section{Table}

1-1. Parameters for the MRG32k3a combined multiple recursive random-number generator by L'Ecuyer (1999).

\section{Abbreviations}

CMRRNG combined multiple recursive random-number generator

HyDroDSS Hydrologic Drought Decision Support System

INT integer function

LCG linear congruential generator

MRRNG multiple recursive random-number generator

PPCC probability plot correlation coefficient

PRNG pseudorandom-number generator

$U_{01} \quad$ uniform random variate, a pseudorandom decimal value that is generated to represent a random variable with a uniform distribution between 0 and 1

VB Microsoft Visual Basic ${ }^{\circledR}$

VBA Microsoft Visual Basic for Applications ${ }^{\circledR}$ 



\title{
Hydrologic Drought Decision Support System (HyDroDSS)-Appendix 1. Monte Carlo Methods
}

\author{
By Gregory E. Granato
}

\section{Introduction}

The hydrologic drought decision support system (HyDroDSS) uses Monte Carlo methods to generate projected estimates of unaltered monthly minimum streamflows. The results of the stochastic analysis, when coupled with estimated monthly streamflow depletions from withdrawals, indicate the risk for being at or below targeted monthly minimum flows and therefore the potential need for measures to reduce withdrawals. Monte Carlo methods are used to generate unaltered monthly minimum streamflow values from a starting position based on calculated rank correlation coefficients and a drought-censoring percentile defined for a 90-day precipitation forecast. HyDroDSS uses a hybrid bootstrap method. Bootstrap methods simulate data by numerically sampling from available data values. Sample percentiles are generated, and an associated flow is determined from the available data. With the hybrid bootstrap method interpolation is used to calculate a streamflow value from adjacent values if the generated percentile falls between two sample percentiles. As with regular bootstrapping, however, a value outside the range of input values cannot be selected.

The purpose of this appendix is to document the numerical methods that are implemented in the HyDroDSS with references to literature that describes the theory and development of such methods. This appendix provides the information and equations needed to generate stochastic data used in the HyDroDSS and documents methods for adjusting these data to represent correlations between variables by using rank correlation coefficients. Uses for different methods are described as examples in this appendix, but the application of each method for individual hydrologic variables is described in the main body of this report.

\section{Generating Random Numbers from a Uniform Distribution}

HyDroDSS uses a pseudorandom-number generator (PRNG) to generate seemingly random numbers that simulate a uniform distribution. Computer-based random-number generators are identified as PRNGs because computers are, by design, precise and deterministic calculators that cannot produce a set of truly random numbers without an external random signal (Press and others, 1992; L'Ecuyer, 1999; Saucier, 2000; Gentle, 2003). A variate is commonly defined as a single pseudorandom number that is generated to represent a random variable (Devroye, 1986). A series of variates generated by a PRNG represents a sample of values from a specified probability distribution. All values within the specified range of a uniform distribution are equally probable. Hydrologic processes do not commonly produce values that fit a uniform distribution (Haan, 1977; Chow and others, 1988; Stedinger and others, 1993), but the other distributions of interest for modeling hydrologic data are generated by using one or more variates from a uniform distribution (Devroye, 1986; Press and others, 1992; Salas, 1993; Saucier, 2000; Gentle, 2003; L'Ecuyer and Simard, 2007; Granato, 2013).

A high-quality PRNG is needed for defensible stochastic simulation models; however, concerns persist about the quality of many available PRNGs (Press and others, 1992; Hellekalek, 1998; Saucier, 2000; Gentle, 2003; McCullough and Wilson, 2005, L'Ecuyer and Simard, 2007, 2009; McCullough, 2008). HyDroDSS was developed as a Microsoft Access ${ }^{\circledR}$ database software application using Visual Basic for Applications ${ }^{\circledR}$ (VBA). Research shows that the PRNGs native to Microsoft Visual Basic $^{\circledR}$ (VB) and VBA may not meet criteria for highquality PRNGs (McCullough and Wilson, 2005, L'Ecuyer and Simard, 2007; McCullough, 2008). Thus, a high-quality PRNG known as MRG32k3a (L'Ecuyer, 1999) was implemented in VBA to generate variates from a uniform distribution for use with HyDroDSS.

A high-quality PRNG is commonly defined as a generator that passes a number of numerical tests and is found suitable for intended uses (L'Ecuyer, 1988; Press and others, 1992; Hellekalek, 1998; L'Ecuyer, 1998, 1999; Gentle, 2003; L'Ecuyer and Simard, 2007). Statistical theory dictates that random numbers are independent and identically distributed, but PRNGs have several characteristics that are at odds with statistical theory. PRNGs are deterministic; given a starting position, they will produce the same string of output values with each value being a function of the previous value(s). For this reason, subsequent values are not independent. Paradoxically, however, this characteristic of PRNGs also is 
advantageous for stochastic simulation models because the implementation of the generator can be verified, and stochastic simulations can be repeated, by using the same starting values. A true uniform random-number set will, in theory, completely fill the interval from 0 to 1 . A PRNG cannot produce values for every possible value in the interval. The mathematical structure of a PRNG causes the series of numbers to fall on lattice planes (L'Ecuyer, 1988, 1998; Gentle, 2003). Highquality PRNGs, however, are designed so that the lattice planes are of such a high order that serial correlations within the series are not readily detected. The distances between lattice planes also are small enough so that they are effectively 0 . Output values from a high-quality PRNG should be almost indistinguishable from the theoretical distribution. As such, the output from a high-quality PRNG will pass goodnessof-fit tests such as the Anderson-Darling, chi-square, and Kolmogorov-Smirnov tests (L'Ecuyer and Simard, 2007). PRNGs have a set period equal to the length of the sequence of output values that are generated before the PRNG returns to the initial value. Once a PRNG progresses through its period, it repeats the same string of output values. Thus the period of a high-quality PRNG should be several orders of magnitude greater than the longest series needed for an analysis. The length of the period is especially important if a Monte Carlo analysis includes more than one variable, so that the string of pseudorandom numbers for one variable does not substantially overlap the string for another variable.

\section{The MRG32K3A Multiple Recursive Pseudorandom-Number Generator}

Many PRNGs are based on one or more linear congruential generators (Press and others, 1992; L'Ecuyer, 1999; Saucier, 2000; Gentle, 2003). These PRNGs produce seemingly random numbers by using the integer remainder from the division of two numbers. A linear congruential generator (LCG) is implemented using the equation

$$
X_{(i+1)}=\left(a \times X_{(i)}+c\right) \bmod m
$$

where

$$
\begin{gathered}
X_{(i+1)} \quad \text { is an integer value produced by the current } \\
\text { iteration } i \text { of the LCG; } \\
X_{(i)} \quad \text { is an integer value input to the current } \\
\text { iteration } i \text { of the LCG-the first value of } \\
X_{(i)} \text { that is used to start a random sequence } \\
\text { is commonly referred to as the random } \\
\text { seed; } \\
\text { is the constant multiplier, which should be a } \\
\text { large prime-integer value; } \\
\text { is the constant increment, which must be an } \\
\text { integer; and } \\
\text { is the constant modulus, which should be a } \\
\text { large prime-integer value. }
\end{gathered}
$$

A multiple recursive random-number generator (MRRNG) uses more than one previous value of $X_{(i)}$ to generate each subsequent seed value of $X_{(i+1)}$. L'Ecuyer (1999) selected a second-order generator of the form

$$
X_{(j)}=\left(a_{1} \times X_{(j-1)}+a_{2} \times X_{(j-2)}+c\right) \bmod m
$$

with the $X, a, c$, and $m$ values having the same definitions as in equation $1-1$, and $j$ the same definition as $i$ in equation $1-1$. The integer values of $X$ produced by equation $1-1$ or equation $1-2$ are converted to uniform random variates between 0 and 1 (U01) by using equation $1-3$, which is

$$
U_{01}=\frac{X}{m}
$$

Good values of $a, c$, and $m$ are critical because they define the spacing of values, the apparent randomness of the series, and the correlations between successive values of $U_{01}$ generated in the series (Press and others, 1992; Hellekalek, 1998; L'Ecuyer, 1999; Gentle, 2003). Selecting a good value of $m$ is critical because this value controls the period of the generator and the extent to which the generator fills the interval from 0 to 1 .

MRG32k3a (L'Ecuyer, 1999) was selected for use in HyDroDSS because it passed several batteries of tests commonly used to identify high-quality PRNGs (Marsaglia and Tsang, 2002; L'Ecuyer and Simard, 2007; 2009). MRG32k3a is a combined multiple recursive random-number generator (CMRRNG), which uses two instances of equation 1-2 with different values of $a, c$ and $m$. If $X_{j}$ and $Y_{j}$ are the numbers produced by the CMRRNG with two instances of equation 1-2, then the combined generator would have the form

$$
U_{01}=\frac{\left(X_{j}-Y_{j}\right)}{\left(m_{x}+1\right)}
$$

if $X_{j}$ is greater than $Y_{j}$ and

$$
U_{01}=\frac{\left(X_{j}-Y_{j}+m_{x}\right)}{\left(m_{x}+1\right)}
$$

if $X_{j}$ is less than or equal to $Y_{j}$ (L'Ecuyer, 1999). Using equations 1-4 and 1-5 with $m_{x}+1$ as the modulus of the combined generator ensures that the uniform numbers produced fall in the range between 0 and 1 . The parameters, $a, c$, and $m$ for this generator are listed in table 1-1.

L'Ecuyer (1999) developed several criteria for selecting parameters that would result in a high-quality PRNG that could be implemented on a 32-bit computer, and conducted a 20-40-hr random search for each set of constraints. The MRG32k3a CMRRNG had the best properties from among the 32-bit PRNGs that were tested. The period of this generator is $2^{191}$ (about $3.14 \times 10^{57}$ ); as a result, randomly selected 
Table 1-1. Parameters for the MRG32k3a combined multiple recursive random-number generator by L'Ecuyer (1999).

[Variables $a, c$, and $m$ shown in equation 1-2]

\begin{tabular}{lccccc}
\hline \multirow{2}{*}{ Generator } & Multiplier $a_{1}$ & Multiplier $a_{2}$ & Increment $c$ & \multicolumn{2}{c}{ Modulus $(m)$} \\
\cline { 5 - 6 } & & & & Real number & Base 2 expression \\
\hline LCG1 & $1,403,580$ & 810,728 & 0 & $4,294,967,087$ & $2^{32}-209$ \\
LCG2 & 527,612 & $1,370,589$ & 0 & $4,294,944,443$ & $2^{32}-22,853$ \\
\hline
\end{tabular}

seed values have a small chance of producing an overlapping series of output values. The large divisor also means that the minimum distance between two uniform random numbers is about $2.3 \times 10^{-11}$, which is a good approximation for a continuous random variable. L'Ecuyer (1999) also checked the lattice structure for this generator and described it as a "well behaved" lattice structure of 45 dimensions.

Although PRNGs are theoretically built on integer operations, MRG32k3a is implemented on the basis of double-precision floating-point (real) numbers. The largest (long) integer that can be represented on a 32-bit processor is $2,147,483,647$, which is $2^{31}-1$. The double-precision floatingpoint data type, however, can represent numbers on the order of $1.79 \times 10^{308}$, which is almost $2^{1,024}$. The parameters, $a, c$, and $m$ also are selected so that values for $X_{j}$ and $Y_{j}$ in equation 1-2 maintain integer values, even though floating-point variables and operators are used to generate uniform random numbers with the MRG32k3a algorithm (L'Ecuyer, 1999).

\section{Random-Seed Management in HyDroDSS}

A random-seed management algorithm was developed for HyDroDSS. This algorithm was designed to generate reproducible results and to facilitate sensitivity analysis and manual seed selections that allow the user to repeat a specific analysis. Repeatability is necessary for the evaluation of the potential effects of different withdrawal plans that use the same set of projected unaltered monthly minimum streamflow values. The initial random-seed values determine the series of random numbers for each drought-projection analysis. The randomseed management algorithm uses a master seed that is generated for an analysis, and the random-number generator selects seed values for each simulated parameter from a random-seed lookup table. The management algorithm also was designed so that the relatively small stochastic datasets generated for HyDroDSS runs would not have uniform random variates $\left(U_{01}\right)$ that substantially depart from theoretical values (an average of 0.5 , a standard deviation equal to the square root of $1 / 12$ (about 0.288675 ), and a coefficient of skew equal to 0 ). In many Monte Carlo applications, a single parameter is run hundreds or thousands of times to generate many realizations to simulate multiple samplings of an underlying population. In such cases, random-seed management is undesirable because it is the variation in sample statistics or outcomes for one variable that is of interest. In the HyDroDSS, however, Monte Carlo methods are used to simulate a small sample of 251 realizations, which are each 6 months in duration. HyDroDSS is designed to evaluate the effects of different combinations of environmental variables based on serial correlation statistics from the historical record. The 251 realizations represent a record that is about three times the record length of available data from long-term monitoring sites in Rhode Island. The $U_{01}$ statistics are controlled within tight tolerances so that the output values will represent hydrologic variability rather than statistical sampling variability. If input statistics are assumed to be representative, each simulation should represent the permutations and combinations of the variables being simulated.

HyDroDSS can be run multiple times while hydrologic inputs and the different master random-seed keys are varied for different sensitivity analyses. Resetting the master randomseed key while keeping the same input hydrologic specifications will produce a stochastic sensitivity analysis. Varying input hydrologic specifications while keeping the same master random-seed key will produce a hydrologic sensitivity analysis.

HyDroDSS calculates a series of seeds from the masterseed value and uses the series to generate each stochastic sample. The seed values are randomly selected from a series of $U_{01}$ values, are rescaled to the range of index values (from 1 to $10,001)$ in table tblURNSeeds, and are converted to the integer values equal to the index numbers identifying the random-seed pairs. The following equation (Saucier, 2000)

$$
U_{\text {min }-\max }=i_{\text {min }}+\left(\left[i_{\text {max }}-i_{\text {min }}\right] \times U_{01}\right)
$$

is used to rescale a $U_{01}$ value to any range, where

$$
\begin{aligned}
& U_{01} \quad \text { is the uniform random variate, which is a } \\
& \text { decimal value between } 0 \text { and } 1 \text {; } \\
& i_{\min } \quad \text { is the lower bound of the generated variates, } \\
& i_{\max } \text { is the upper bound of the generated variates, } \\
& \text { which was set equal to } 10,001 \text { in } \\
& \text { HyDroDSS; and } \\
& U_{\text {min-max }} \text { is the uniform random variate in the specified }
\end{aligned}
$$

The double-precision real number $U_{\text {min-max }}$ is truncated to an integer by the VBA integer function (INT). 
Each time the drought-projection analysis is loaded, a new random index number is generated. First, the native Microsoft VBA random-number generator $\mathrm{RND}()$ is randomized, and four $\mathrm{U}_{01}$ variates are generated. Second, each variate is scaled to the range from 0 to 9 by using equation $1-6$. Third, the four variates are loaded into the comboboxes for the thousands', hundreds', tens', and ones' place of the index number. The user has the opportunity to reselect each number. For example, the user can rerun a previous example with a different starting value, a different drought projection, and a different pumping plan. If a value of 0000 is selected by the random initialization process or by the user, then a value of 0001 is substituted because the index-number convention for the standard Microsoft Access table does not include zero. When the analysis is initiated by clicking the "Run Analysis" button, the DSS obtains the initial seed values from the random-seed table (tblURNSeeds), which contains 10,001 random-seed pairs, and proceeds with the same random sequence for all numbers generated for each droughtprojection analysis. These random-seed pairs were generated to produce small samples of uniform random numbers that are well behaved (Granato, 2013).

\section{Generating Random Numbers with an Input Rank Correlation Coefficient}

HyDroDSS simulates relations between selected variables by generating random numbers with a defined rank correlation coefficient. The nonparametric rank correlation (based on Spearman's rho, $\rho$ ) was selected for implementation in HyDroDSS rather than the parametric correlation coefficient (Pearson's $r$ ) for several reasons. Pearson's $r$, the linear correlation coefficient, is not resistant to outliers and is not effective for quantifying nonlinear monotonic correlation (Haan, 1977; Helsel and Hirsch, 2002). Spearman's rho, however, characterizes monotonic correlation between the ranks of data and is not influenced by the distribution of data (Haan, 1977; Helsel and Hirsch, 2002). Rho can be used to generate two sets of $U_{01}$ variates with a specified degree of (rank) correlation because the ranks are a function of the uniform variates. The resulting variates can be used to generate random numbers as two correlated samples from the same distribution or from different distributions.

An algorithm by Mykytka and Cheng (1994) was selected for generating correlated uniform random numbers in HyDroDSS because the commonly used algorithms have three critical limitations: most critically, these algorithms produce samples with a substantial reduction in variance in comparison to the theoretical distribution; the random variates produced by these algorithms may not fit tight tolerances for a uniform random distribution; and these algorithms are designed to produce pairs of values rather than one or more correlated random values from a master input variable (Granato, 2013). The algorithm by Mykytka and Cheng (1994) was adapted for use with HyDroDSS because it is designed to minimize the reduction in variance, match the properties of a theoretical uniform random distribution, and facilitate use of a master uniform random variable.

The algorithm by Mykytka and Cheng (1994) uses the correlation coefficient and two independent $U_{01}$ values to generate a third intermediate value, and then adjusts the intermediate value to produce the final correlated $U_{01}$ value. The mean, standard deviation, and test statistics for the probability plot correlation coefficient (PPCC) (Vogel and Kroll, 1989) for the population of adjusted $U_{01}$ values generated by using this algorithm will be within expected statistical limits for large sample sizes. The mean reduction in the standard deviation of the final correlated $U_{01}$ values produced by this algorithm was less than one-tenth of a percent over the full range of rho values (Granato, 2013). However, the algorithm by Mykytka and Cheng (1994) does produce a small amount of bias in the rank correlations that are produced. Granato (2013) generated more than 154,000 stochastic samples to define this bias and developed four polynomial equations to correct this bias. If the absolute value of the desired correlation coefficient $(|\rho|)$ is less than or equal to 0.2 , an adjusted value $\left(\rho^{*}\right)$ is calculated as

$$
\rho^{*}=|\rho|+(0.0578 \times|\rho|)-0.0012
$$

If the absolute value of the desired correlation coefficient $(|\rho|)$ is less than or equal to 0.7 , an adjusted value $\left(\rho^{*}\right)$ is calculated as

$$
\rho^{*}=|\rho|-\left(0.3245 \times|\rho|^{2}\right)+(0.3155 \times|\rho|)-0.0527 .
$$

If the absolute value of the desired correlation coefficient $(|\rho|)$ is less than or equal to 0.77 , an adjusted value $\left(\rho^{*}\right)$ is calculated as

$$
\rho^{*}=|\rho|-(0.126 \times|\rho|)+0.0974
$$

If the absolute value of the desired correlation coefficient $(|\rho|)$ is less than or equal to 0.97 , an adjusted value $\left(\rho^{*}\right)$ is calculated as

$$
\dot{\rho}=|\rho|-\left(0.6814 \times|\rho|^{3}\right)+\left(2.2569 \times|\rho|^{2}\right)-(2.3823 \times|\rho|)+0.8078,(1-10)
$$

and if $|\rho|$ is greater than 0.97 , then

$$
\rho^{*}=|\rho| .
$$

With $\rho^{*}$, the algorithm by Mykytka and Cheng (1994) uses three coefficients $A, B$, and $C$ with the input $U_{01}$ value $\left(X_{i}\right)$ and the independent $U_{01}$ value $\left(Y 01_{i}\right)$ to calculate the third intermediate value $\left(Y 02_{i}\right)$. The three coefficients are

$$
A=\rho^{*},
$$




$$
B=\sqrt{1-\left(\rho^{*}\right)^{2}}
$$

and

$$
C=\frac{1-A-B}{2} .
$$

The equation for calculating the third intermediate value is

$$
Y 02_{i}=A \times X_{i}+B \times Y 01_{i}+C
$$

The value of the correlated $U_{01}$ value $\left(Y_{i}\right)$ is calculated by using an equation that depends on the value of $\rho^{*}$ and $Y 02_{i}$ :

if $\rho^{*} \leq \frac{1}{\sqrt{2}}$ and $C \leq Y 02_{i} \leq A+C$, then

$$
Y_{i}=\frac{\left(Y 02_{i}-C\right)^{2}}{2 A B}
$$

if $\rho^{*} \leq \frac{1}{\sqrt{2}}$ and $A+C<Y 02_{i} \leq B+C$, then

$$
Y_{i}=\frac{Y 02_{i}-(A / 2)-C}{B}
$$

if $\rho^{*} \leq \frac{1}{\sqrt{2}}$ and $B+C<Y 02_{i} \leq A+B+C$, then

$$
Y_{i}=1-\frac{\left(A+B+C-Y 02_{i}\right)^{2}}{2 A B}
$$

if $\rho^{*}>\frac{1}{\sqrt{2}}$ and $C \leq Y 02_{i} \leq B+C$, then

$$
Y_{i}=\frac{\left(Y 02_{i}-C\right)^{2}}{2 A B}
$$

if $\rho^{*}>\frac{1}{\sqrt{2}}$ and $B+C<Y 02_{i} \leq A+C$, then

$$
\text { if } \rho^{*}>\frac{1}{\sqrt{2}} \text { and } A+C<Y 02_{i} \leq A+B+C \text {, then }
$$

$$
Y_{i}=1-\frac{\left(A+B+C-Y 02_{i}\right)^{2}}{2 A B}
$$

If the original correlation coefficient $(\rho)$ is negative, then the negatively correlated $U_{01}$ value $\left(Y_{i}\right)$ is

$$
Y_{i}=1-Y_{i}
$$

The HyDroDSS user can specify a rank correlation coefficient (rho) between several variables in the input dataset, but, as with other stochastic variables, the rho value in the output dataset may vary substantially from the input value. The four polynomial bias-correction equations eliminate bias in the average of resultant correlation coefficients, but they do not eliminate the inevitable variations in the stochastically generated values. The reason for this variation is that HyDroDSS generates a random sample rather than the complete population of stochastic variables, and the rate of convergence of the rank correlation coefficient is slow. These variations are more pronounced for low values of rho than for high values of rho (Haan, 1977, Caruso and Cliff, 1997). Confidence intervals for rho can be estimated by methods developed for Pearson's $r$ because Spearman's rho is analogous to Pearson's $r$ between the ranks of the samples (Haan, 1977; Caruso and Cliff, 1997; Helsel and Hirsch, 2002). Examples of the theoretical 95-percent confidence intervals for selected values of Spearman's rho generated by using the large-sample approximation (Haan, 1977; Caruso and Cliff, 1997) are shown in figure 1-1. These examples demonstrate that the confidence intervals of rho are a function of the value of rho and the sample size. For example, if the user selects a value of rho of 0.25 and a stochastic sample size of 1,000 points, then 95 percent of the samples generated would be expected to have rho values between 0.19 and 0.31 (fig. 1-1). If a sample size of 2,000 points is selected, then 95 percent of the samples generated would be expected to have rho values between 0.21 and 0.29 . In comparison, 95 percent of 1,000-point samples with a specified rho value of 0.9 would be expected to have sample rho values between 0.89 and 0.91 (fig. 1-1). Rho values input by the user are 
probably more uncertain than numerical variations in the HyDroDSS model because many environmental-monitoring datasets comprise measurements from relatively few samples (Helsel and Hirsch, 2002). For example, Granato (2010) calculated rho values between prestorm streamflows and the corresponding runoff coefficients from available stormflowmonitoring datasets for 42 sites to see if prestorm streamflows were a good explanatory variable for variability in runoff coefficients. About 67 percent of these datasets comprised measurements from fewer than 50 samples; only one dataset comprised measurements from more than 100 samples. The 95-percent confidence limit for a dataset with 50 samples and a rho value of 0.75 would be expected to include values in the range from 0.60 to 0.85 (fig. $1-1$ ). This is not to say that the output sample is more accurate than the actual input data, but instead that numerical variations in large stochastic samples are expected to be within the uncertainty of input values.

\section{Generating Streamflow Values with the Hybrid Bootstrap Method}

The HyDroDSS uses a hybrid bootstrap method to sample from all possible minimum monthly flows within the range of the available sample of estimated unaltered streamflows. Bootstrap methods simulate data by numerically sampling from available data values. Sample percentiles are generated by using the random-number generator, and an associated flow is selected from available data. If the generated percentile equals a sample percentile, then the associated streamflow is selected. If the generated percentile falls between two sample percentiles, interpolation by percentiles is used to calculate a streamflow value from adjacent streamflow values. As is true for regular bootstrapping, a value outside the range of input values cannot be selected because percentiles outside the range of sample percentiles are set equal to the minimum or maximum value. The hybrid bootstrap method used by the HyDroDSS samples with replacement, but it samples from the population defined by the available sample. Also known as stochastic interpolation, this method is more sophisticated than regular bootstrapping because it will generate new data points within the range defined by the sample (Saucier, 2000).
Variables generated by a pure bootstrap method are discrete because they are limited to the exact values of the sample (Saucier, 2000; Gentle, 2003). Streamflow, however, is a continuous random variable, and the hybrid bootstrap method will maintain this property without the uncertainty of applying any selected probability distribution. The streamflow with depletion is calculated by subtracting the monthly depletion from the sum of all estimated unaltered flows for each month in the depletion analysis.

The bootstrap method is implemented by generating a correlated uniform random number, scaling that number to a plotting position, and then calculating the associated streamflow value. If the uniform random number equals the plotting position of a streamflow value in the available sample, then that streamflow value is used in the projection analysis. If the uniform random number is between values, then the HyDroDSS uses linear interpolation to calculate a flow value between two streamflows in the sample:

$$
Q_{a}=Q_{1} \times \frac{\left(U 01_{a}-P P_{2}\right)}{\left(P P_{1}-P P_{2}\right)}+Q_{2} \times \frac{\left(U 01_{a}-P P_{1}\right)}{\left(P P_{2}-P P_{1}\right)}
$$

where

$$
\begin{gathered}
U 01_{\text {a }} \text { is the plotting position calculated from the } \\
\text { uniform random number, } \\
P P_{1} \text { is the plotting position below } U 01_{a^{\prime}} \\
P P_{2} \text { is the plotting position above } U 0 a_{a}, \\
Q_{1} \text { is the streamflow value associated with } P P_{1}, \\
Q_{2} \text { is the streamflow value associated with } P P_{2}, \\
\text { and } \\
Q_{\text {a }} \quad \text { is the output streamflow value associated with } \\
U 01_{a} \text {. }
\end{gathered}
$$

This stochastic interpolation is especially useful for short periods of record, which may have large gaps between data values. If the plotting position generated by using the uniform random number is greater than or equal to the maximum plotting position in the sample or is less than or equal to the minimum plotting position in the sample, then the maximum or minimum flow values are used, respectively. 


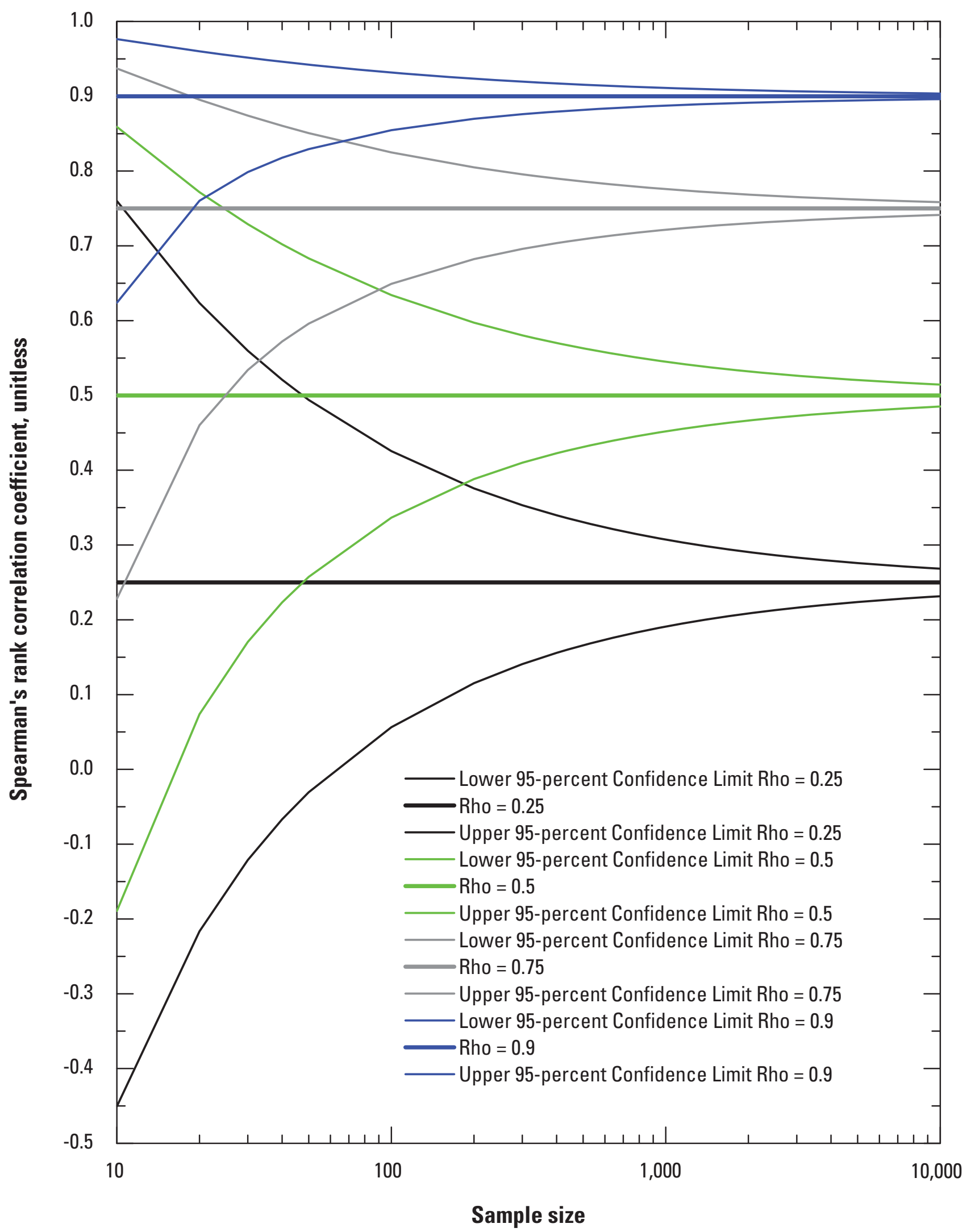

Figure 1-1. Examples of the theoretical 95-percent confidence intervals for selected values of Spearman's rank correlation coefficients generated by using the large-sample approximation (Haan, 1977; Caruso and Cliff, 1997). 


\section{References Cited}

Caruso, J.C., and Cliff, Norman, 1997, Empirical size, coverage, and power of the confidence intervals for Spearman's rho: Educational and Psychological Measurement, v. 57, no. 4, p. 637-654.

Chow, V.T., Maidment, D.R., and Mays, L.W., 1988, Applied hydrology: New York, McGraw-Hill, Inc., 572 p.

Devroye, Luc, 1986, Non-uniform random variate generation: New York, Springer-Verlag, 843 p.

Gentle, J.E., 2003, Random number generation and Monte Carlo methods (2d ed.): New York, Springer Science+Business Media, Inc., 381 p.

Granato, G.E., 2010, Methods for development of planninglevel estimates of stormflow at unmonitored sites in the conterminous United States: Federal Highway Administration Report FHWA-HEP-09-005, 90 p., on CD-ROM.

Granato, G.E., 2013, Stochastic empirical loading and dilution model (SELDM) version 1.0.0-Appendix 1, Monte Carlo methods: U.S. Geological Survey Techniques and Methods, book 4, chap. C3, 26 p., on CD-ROM.

Haan, C.T., 1977, Statistical methods in hydrology: Ames, Iowa, Iowa State University Press, 378 p.

Hellekalek, Peter, 1998, Good random number generators are (not so) easy to find: Mathematics and Computers in Simulation, v. 46, p. 485-505.

Helsel, D.R., and Hirsch, R.M., 2002, Statistical methods in water resources-Hydrologic analysis and interpretation: U.S. Geological Survey Techniques of Water-Resources Investigations, book 4, chap. A3, $510 \mathrm{p}$.

L'Ecuyer, Pierre, 1988, Efficient and portable combined random number generators: Communications of the Association for Computing Machinery, v. 31, no. 6, p. 742-751.

L'Ecuyer, Pierre, 1998, Random number generation, chap. 4 in Banks, Jerry, ed., The Handbook on Simulation: New York, John Wiley, Inc., 66 p.

L'Ecuyer, Pierre, 1999, Good parameters and implementations for combined multiple recursive random number generators: Operations Research, v. 47, no. 1, p. 159-164.
L'Ecuyer, Pierre, and Simard, Richard, 2007, TestU01-A C library for empirical testing of random number generators: Association for Computing Machinery, Transactions on Mathematical Software, v. 33, no. 4, article 22, 40 p.

L'Ecuyer, Pierre, and Simard, Richard, 2009, TestU01-A C library for empirical testing of random number generators, user's guide, compact version: Montreal, Canada, University of Montreal, 214 p. (Also available at http://www.iro. umontreal.ca/ lecuyer/.)

Marsaglia, George, and Tsang, W.W., 2002, Some difficult-topass tests of randomness: Journal of Statistical Software, v. 7, no. 3, p. 1-9.

McCullough, B.D., 2008, Microsoft Excel's "Not the Wichmann-Hill" random number generators: Computational Statistics \& Data Analysis, v. 52, p. 4587-4593.

McCullough, B.D., and Wilson, Berry, 2005, On the accuracy of statistical procedures in Microsoft Excel 2003: Computational Statistics \& Data Analysis, v. 49, p. 1244-1252.

Mykytka, E.F., and Cheng, C.Y., 1994, Generating correlated random variates based on an analogy between correlation and force in Tew, J.D., Manivannan, M.S., Sadowski, D.A., and Seila, A.F., eds., 1994 Winter Simulation Conference, Lake Buena Vista, Fla., December 11-14, 1994, Proceedings: New York, N.Y., Association for Computing Machinery, p. 1413-1416.

Press, W.H., Flannery, B.P., Teukolsky, S.A., and Vetterling, W.T., 1992, Numerical recipes in FORTRAN 77-The art of scientific computing ( $2 \mathrm{~d}$ ed.): New York, Cambridge University Press, 992 p.

Salas, J.D., 1993, Analysis and modeling of hydrologic time series, chap. 19-in Maidment, D.R., ed., Handbook of Hydrology: New York, McGraw Hill, p. 19.1-19.72.

Saucier, Richard, 2000, Computer generation of statistical distributions: U.S. Army Research Laboratory Report ARLTR-2168, $105 \mathrm{p}$.

Stedinger, J.R., Vogel, R.M., and Foufoula-Georgiou, Efi, 1993, Frequency analysis of extreme events, chap. 18 in Maidment, D.R., ed., Handbook of Hydrology: New York, McGraw-Hill, Inc., p. 18.1-18.66.

Vogel, R.M., and Kroll, C.N., 1989, Low-flow frequency analysis using probability-plot correlation coefficients: Journal of Water Resources Planning and Management, v. 115 , no. 3 , p. 338-357. 
Prepared by the Pembroke Publishing Service Center.

For more information concerning this report, contact:

Office Chief

U.S. Geological Survey

New England Water Science Center

Massachusetts-Rhode Island Office

10 Bearfoot Road

Northborough, MA 01532

dc_ma@usgs.gov

or visit our Web site at:

http://ma.water.usgs.gov 


\section{$\frac{\mathbb{2}}{30}$}

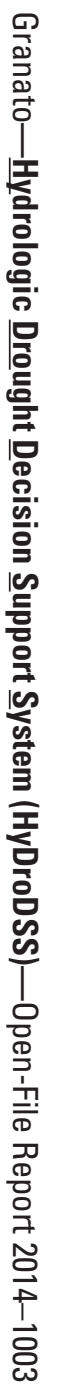

